\title{
Studies on the role of vitamin K1 and K2 in bone metabolism and cardiovascular disease : structural differences determine different metabolic pathways
}

Citation for published version (APA):

Schurgers, L. J. (2002). Studies on the role of vitamin K1 and K2 in bone metabolism and cardiovascular disease : structural differences determine different metabolic pathways. [Doctoral Thesis, Maastricht University]. Universiteit Maastricht. https://doi.org/10.26481/dis.20020621ls

Document status and date:

Published: 01/01/2002

DOI:

10.26481/dis.20020621/s

Document Version:

Publisher's PDF, also known as Version of record

Please check the document version of this publication:

- A submitted manuscript is the version of the article upon submission and before peer-review. There can be important differences between the submitted version and the official published version of record.

People interested in the research are advised to contact the author for the final version of the publication, or visit the DOI to the publisher's website.

- The final author version and the galley proof are versions of the publication after peer review.

- The final published version features the final layout of the paper including the volume, issue and page numbers.

Link to publication

\footnotetext{
General rights rights.

- You may freely distribute the URL identifying the publication in the public portal. please follow below link for the End User Agreement:

www.umlib.nl/taverne-license

Take down policy

If you believe that this document breaches copyright please contact us at:

repository@maastrichtuniversity.nl

providing details and we will investigate your claim.
}

Copyright and moral rights for the publications made accessible in the public portal are retained by the authors and/or other copyright owners and it is a condition of accessing publications that users recognise and abide by the legal requirements associated with these

- Users may download and print one copy of any publication from the public portal for the purpose of private study or research.

- You may not further distribute the material or use it for any profit-making activity or commercial gain

If the publication is distributed under the terms of Article $25 \mathrm{fa}$ of the Dutch Copyright Act, indicated by the "Taverne" license above, 
STUDIES ON THE ROLE OF VITAMIN $\mathrm{K}_{1}$ AND $\mathrm{K}_{2}$ IN BONE METABOLISM AND CARDIOVASCULAR DISEASE

STRUCTURAL DIFFERENCES DETERMINE DIFFERENT METABOLIC PATHWAYS 
Cover: $\quad$ Ralph hendrikx / Leon Schurgers

Printed by: Unigraphic, Universiteit Maastricht

ISBN: $\quad$ 90-5681-138-X

๑ Leon J. Schurgers, Sittard 2002

Thesis University Maastricht - with a summary in Dutch

No part of this book may be reproduced, stored in a retrieval system or transmitted in any form or by any means, without permission of the author, or, when appropriate, of the publishers of the publications.

Financial support by the Dutch Heart Foundation for the publication of this thesis is gratefully acknowledged.

Additional financial support for this thesis by Roche Vitamins Ltd., Unilever Bestfoods Europe, and Greiner Bio-One is gratefully acknowledged. 


\section{STUDIES ON THE ROLE OF VITAMIN $K_{1}$ AND $K_{2}$ IN BONE METABOLISM AND CARDIOVASCULAR DISEASE}

STRUCTURAL DIFFERENCES DETERMINE DIFFERENT METABOLIC PATHWAYS

\section{PROEFSCHRIFT}

ter verkrijging van de graad van doctor aan de Universiteit Maastricht, op gezag van de Rector Magnificus, Prof. Dr. A.C. Nieuwenhuijzen Kruseman volgens het besluit van het College van Decanen, in het openbaar te verdedigen

op vrijdag 21 juni 2002 om 12.00 uur

door

\section{Leon Johannes Schürgers}

Geboren 17 februari 1970 te Geilenkirchen 
Promotor:

Co-promotor:

Beoordelingscommisie: Prof. Dr. J.G.R De Mey (voorzitter)

Prof. Dr. M.A.J.P. Daemen

Prof. Dr. H.F.P. Hillen

Prof. Dr. W. Jahnen-Dechent (University Hospital Aachen)

Prof. Dr. Ir. W.H.M. Saris 
En este mundo traidor

Nada es verdad ni mentira

Sino que todo es del color

Del cristal con que se mira

(Luis de Góngora 1561-1627)

Op deze verraderlijke wereld

is er niets waar of onwaar,

alles heeft slechts de kleur

van de bril waardoor men er naar kijkt

Aan mijn ouders

voor Romy

Juul en Sam 



\section{CONTENTS}

1 Introduction

1.1 General introduction 3

1.2 Function of vitamin K 9

1.3 Physiological roles of vitamin K-dependent proteins 11

$\begin{array}{lll}1.4 & \text { Vitamin K requirement } & 14\end{array}$

1.5 Introduction to this thesis 19

2 Measurement of phylloquinone and menaquinones: absorption, bioavailibility and transport of dietary vitamin $K$

2.1 Determination of phylloquinone and menaquinones in food.

2.2 Intestinal, hepatic, and circulating vitamin $\mathrm{K}$ at low and high intake of vitamin $\mathrm{K}$ in rats.

2.3 Differential lipoprotein transport pathways of K-vitamins in healthy subjects.

3 Dietary factors that influence vitamin $\mathrm{K}$ absorption

3.1 Corn oil-induced decrease of arterial thrombosis tendency may be related to altered plasma vitamin $\mathrm{K}$ transport.

3.2 Novel effects of diets enriched with corn oil or an olive oil/ sunflower oil mixture on vitamin $\mathrm{K}$ metabolism and vitamin $\mathrm{K}$-dependent proteins in young men.

$4 \quad$ Vitamin $\mathrm{K}$ metabolism in subjects with low vitamin K-status

4.1 Patients with congenital vitamin K deficiency and patients with malabsorption of fat-soluble vitamins have low vitamin $\mathrm{K}$ status

4.2 Effect of dietary vitamin $\mathrm{K}$ on stability of oral anticoagulant therapy: dose response relationships in healthy subjects

5 Role of K-vitamins and vitamin K-dependent proteins in ectopic calcification

5 Role of vitamin $\mathrm{K}$ and vitamin $\mathrm{K}$-dependent proteins in vascular calcification

6 General discussion / Samenvatting

6.1 General discussion

6.2 Samenvatting 


\section{Papers and manuscripts based on the studies described in this thesis}

\section{Chapter 1}

Vermeer, C., Knapen, M.H.J., Schurgers, L.J. (1998). Vitamin K and metabolic bone disease. J.Clin. Pathol. 51, 424-426.

Vermeer, C., Gijsbers, B.L.M.G., Schurgers, L.J., Soute, B.A.M. (1998). Role of vitamin K in vascular mineralization and in reduction of arterial thrombosis. In: Vitamin $\mathrm{K}$ and aging. (Ed.: H. Orimo) Intermed Inc., Tokyo, pp 33-45.

Vermeer, C., Schurgers, L.J. (2000). A comprehensive review on vitamin K and vitamin K antagonists. Hematol. Oncol. Clin. North Am. 14, 339-353.

\section{Chapter 2}

Schurgers, L.J., Geleijnse, J.M., Grobbee, D.E., Pols, H.A.P., Hofman, A., Witteman, J.C.M., Vermeer, C. (1999). Nutritional intake of vitamins K-1 (phylloquinone) and K-2 (menaquinone) in The Netherlands. J. Nutr. Environm. Med. 9, 115-122.

Schurgers, L.J., and Vermeer, C. (2000). Determination of phylloquinone and menaquinones in food. Effect of food matrix on circulating vitamin K concentrations. Haemostasis 30, 298307.

Koivu-Tikkanen, T.J., Schurgers, L.J., Thijssen, H.H.W., Vermeer, C. (2000). Intestinal, hepatic, and circulating vitamin $\mathrm{K}$ at low and high intake of vitamin $\mathrm{K}$ in rats. Brit. J. Nutr. $83,185-190$.

Schurgers, L.J., Vermeer, C. Lipoprotein distribution of K-vitamins. (2002). Biochim Biophys Acta, 1570, 27-32

\section{Chapter 3}

Schurgers L.J., Vermeer, C. (2001). Corn oil-induced decrease of arterial thrombosis tendency may be related to altered plasma vitamin K transport. J Lipid Res. 42, 1120-1124.

Schurgers, L.J., Shearer, M.J., Soute, B.A.M., Elmadfa, I., Harvey, J., Wagner, K-H., Tomasch, R., Vermeer, C. Novel Effects of Diets enriched with corn oil or an olive oil/sunflower oil mixture on vitamin K metabolism and vitamin K-dependent proteins in young men. J Lipid Res, In press 


\section{Chapter 4}

Oldenburg, J., Brederlow, B. von, Fregin, A., Rost, S., Wolz, W., Eberl, W., Eber, S., Lenz, E., Schwaab, R., Brackmann, H.H., Effenberger, W., Harbrecht, U., Schurgers, L.J., Vermeer, C., Müller, C.R. (2000). Congenital deficiency of vitamin K dependent coagulation factors in two families is caused likely by a defect of the vitamin K-epoxide-reductase complex. Thromb. Haemostas. 84, 937-941.

Schoon, E.J., Müller, M.A.C., Vermeer, C., Schurgers, L.J., Stockbrügger, R.W., Brummer, R.-J. (2001). Low serum and bone vitamin K status in patients with longstanding Crohn's disease: another pathogenic factor of osteoporosis in Crohn's disease? Gut. 48, 473-477.

Schurgers, L.J., Shearer, M.J., Hamulyak, K., Stoecklin, E., Vermeer, C. Effect of dietary vitamin $\mathrm{K}$ on stability of oral anticoagulant therapy: dose response relationships in healthy subjects. Submitted.

\section{Chapter 5}

Schurgers, L.J., Dissel, P.E.P., Spronk, H.M.H., Soute, B.A.M., Cleutjens, J.A.P., Dhore, C., Vermeer, C. (2001). Role of vitamin K and vitamin K-dependent proteins in vascular calcification. Z Kardiologie. Suppl 3, III/57 -III/63. 

1

INTRODUCTION 



\section{REVIEW ON VITAMIN K}

\subsection{GENERAL INTRODUCTION}

\section{Historical background}

Vitamin $\mathrm{K}$ was discovered more than 50 years ago as an anti-hemorrhagic factor capable of correcting diet-induced bleeding disorders in chickens ${ }^{1}$, as well as clotting defects caused by obstructive jaundice and other biliary diseases in humans ${ }^{2}$. Its name stems from the German word 'Koagulationsvitamin' which means clotting vitamin. Until HPLC-based detection techniques were developed in the $1980{ }^{\prime}{ }^{3}{ }^{3}$, the chick-bioassay in which the extent to which nutritional vitamin K-deficiency could be compensated was the main technique for vitamin $\mathrm{K}$ quantitation in nutrients. Because circulating vitamin $\mathrm{K}$ concentrations are extremely low (200-800 pg/mL), sensitive detection methods had to be developed for its quantification in human serum or plasma ${ }^{4}$.

The bleeding symptoms, provoked by a vitamin K-deficient diet, were similar to those described in the 1920s when a hemorrhagic disease was noticed among cattle in Canada and the USA. The underlying cause of the disease was found to be improperly cured sweet clover hay ${ }^{5}$. It appeared that in the hay a compound had been liberated which acted as an antagonist of vitamin $\mathrm{K}^{6}$. This active compound, 3,3'-methylene-bis-(4-hydroxycoumarin), is now synthesized in a number of derivatives, all exhibiting anticoagulant activity. Vitamin $\mathrm{K}$-antagonists are used in the production of rodenticides (warfarin, brodifacoum, flocoumafen $)^{7}$ as well as for the treatment and prophylaxis of thrombotic disease (acenocoumarol, phenprocoumon, warfarin) ${ }^{8}$.

\section{Various forms of vitamin $\mathrm{K}$}

Vitamin $\mathrm{K}$ is a group name for a number of related compounds, which have a methylated naphthoquinone ring structure in common, and which vary in the aliphatic side chain attached at the 3-position (Figure 1). Two natural occurring forms can be distinguished, namely phylloquinone (also known as vitamin K1) and the menaquinones (vitamin K2). Phylloquinone (2-methyl-3-phytyl-1,4-naphtaquinone) is found in plants and has the same phytyl side chain as chlorophyll ${ }^{9}$. The menaquinones (2-methyl-3-multi-prenyl-1, 4naphtoquinone) are generally denoted as MK-n, where $n$ stands for the number of unsaturated isoprenyl residues which may vary between 1 and 14 . The forms most common in food are 
menaquinone-4 (MK-4, containing 4 isoprenoid residues) and the long-chain menaquinones MK7, MK-8 and MK-9. Vitamin K3 also called menadione, is another form of vitamin K, however it does not occur naturally and has no vitamin $\mathrm{K}$ activity by itself. This form is a synthetic homologue which does not contain a side chain. Menadione is called a provitamin and is converted in the body to $\mathrm{MK}-4^{10,11}$. Menadione is often used as a supplement in animal food. In humans, it is not used anymore because of its toxic side effects ${ }^{12,13}$.

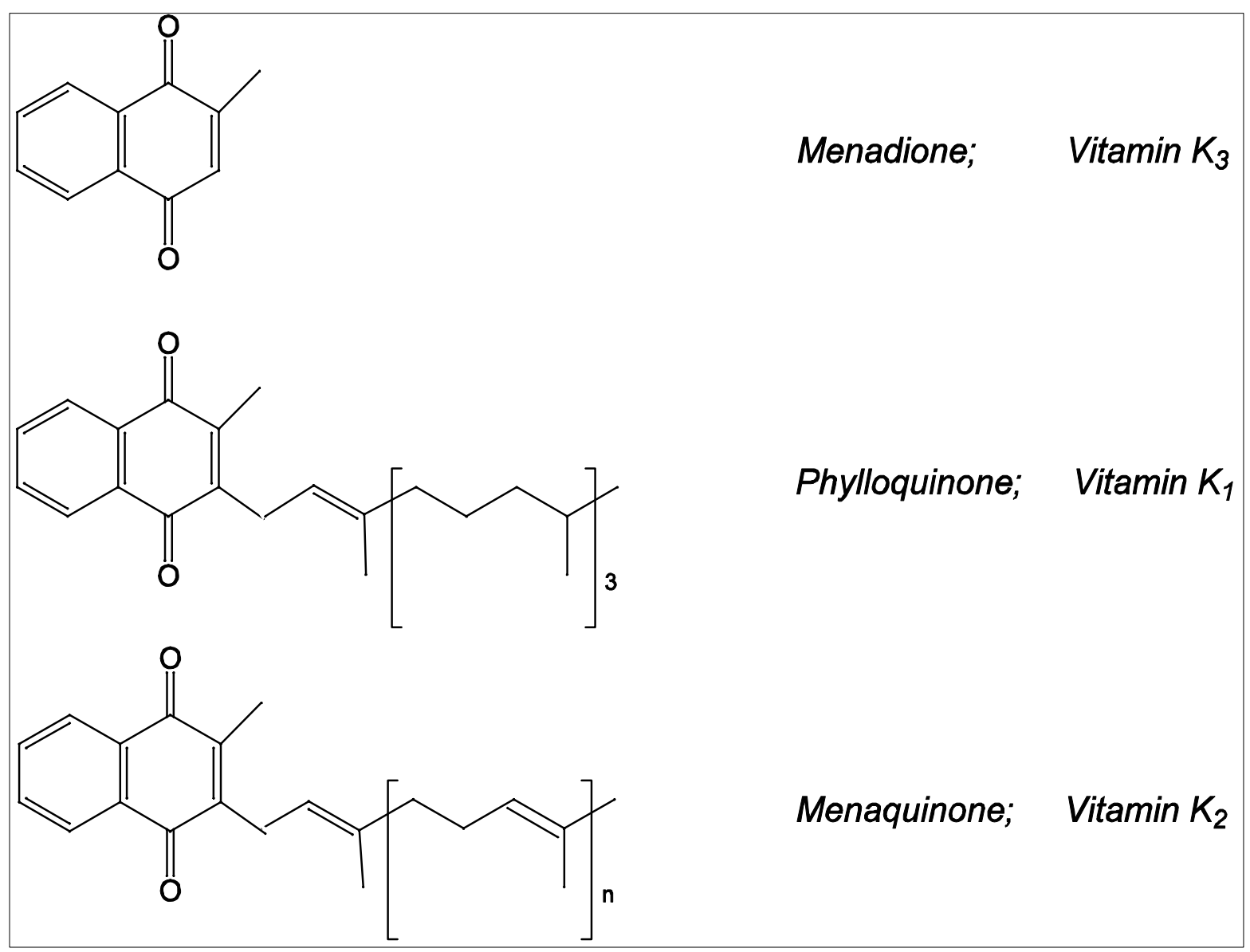

Figure 1.

Chemical structures of menadione (vitamin $\mathrm{K}_{3}$ ), phylloquinone (vitamin $\mathrm{K}_{1}$ ), and menaquinone (vitamin $\mathrm{K}_{2}$ ). The $(\mathrm{n})$ stands for number of isoprene residues.

It is generally accepted that in all K-vitamins the naphthoquinone is the functional group, so that the mechanism of action is similar for all K-vitamins. Substantial differences may be expected, however, with respect to intestinal absorption, transport, tissue distribution, and bioavailability. These differences which are caused by the different lipophilicity of the various side chains will be discussed below. 


\section{Sources}

By far the most abundant form of dietary vitamin $\mathrm{K}$ is phylloquinone, which occurs in green vegetables such as kale, spinach, broccoli, and Brussels sprouts ${ }^{14,15}$. Except for some plant oils ${ }^{16}$, other foods have much lower phylloquinone contents (Table 1). Menaquinones have an even more restricted distribution in the diet than phylloquinone, with nutritionally significant amounts of MK-4 only occurring in animal meat and liver, and higher menaquinones (MK-7 through MK-9) in fermented products, cheese and curd cheese (Table 1) ${ }^{17}$. In Japan the MK-7 intake may be high because of the abundance of this vitamer in the typical Japanese food product natto, which consists of fermented soy beans ${ }^{18}$.

Table 1. Vitamin K content of various foods $(\mu \mathrm{g} / 100 \mathrm{~g})$

\begin{tabular}{lcc}
\hline Nutrient & $\mathrm{K} 1$ & $\mathrm{~K} 2$ \\
\hline Meat & $0.5-3$ & $1-8$ \\
Fish & $0.1-1$ & $0.1-1.6$ \\
Milk & $0.5-1$ & $0.2-2$ \\
Yoghurt & $0.2-0.5$ & $0.1-1$ \\
Cheese (all types) & $2.5-15$ & $0.5-80$ \\
Butter & $9-20$ & $10-20$ \\
Margarines (from plant oil) & $80-110$ & 0 \\
Green vegetables & $100-750$ & 0 \\
Natto (fermented soybeans) & $20-30$ & $800-1,000$ \\
Fruit & $0.1-3$ & 0 \\
Bread & $0.5-1$ & 0 \\
\hline
\end{tabular}

Also the intestinal flora in the colon produces considerable amounts of menaquinones, notably MK-7, MK-8, MK-10, and MK-11 ${ }^{19}$. The human colonic menaquinone content, mainly consisting of MK-10 amounts to about $20 \mu \mathrm{g} / \mathrm{g}$ dry weight ${ }^{20}$. These highly lipophilic compounds are tightly bound to the bacterial membranes, and require bile salts for solubilization and absorption ${ }^{17}$. Since virtually all cholate is absorbed in the small intestine, it is difficult to envisage how the colonic pool of menaquinones can be made available for absorption and contribute to the human vitamin $\mathrm{K}$ status ${ }^{21,22}$. This view is supported by experimental animal data showing that in rats, originally thought to be resistant to dietary deprivation, deficiency of vitamin $\mathrm{K}$ can be readily induced by preventing coprophagy ${ }^{23}$. Apparently rats can only utilize enterically synthesized menaquinones by a second passage through the bowel and concomitant absorption in the upper region of the small bowel ${ }^{24}$. Furthermore, reports studying the effect on hypoprothrombinaemia after administration of either vitamin K1, MK-4, or MK-9 in the colon showed no effect, suggesting no absorption in the colon of K-vitamins ${ }^{25}$. There are some findings, however, that also the terminal ileum and caecum contains amounts of menaquinones produced by the intestinal bacteria ${ }^{17,20}$, 
although the inter-individual variation was large. In rats, a positive correlation was found between the menaquinone content in the caecum and the liver after various dietary interventions ${ }^{26}$. The menaquinones present in this part of the gastro-intestinal tract could explain the presence of the long-chain menaquinones in the liver, and may therefore contribute to the vitamin K-status.

Synthetic forms of both phylloquinone and MK-4 are commercially available and used in humans a) for the prevention of the haemorrhagic disease of the newborn (HDN), b) to correct an overshoot of coumarin drugs during oral anticoagulant treatment, and c) to maintain normal haemostasis during poisoning with vitamin $\mathrm{K}$-antagonists ${ }^{27,28}$. Moreover, an increasing number of vitamin supplements containing synthetic vitamin $\mathrm{K}$ (generally phylloquinone) in dosages between 100 and $500 \mu \mathrm{g}$ per tablet are presently sold as over the counter products. In Japan MK-4 (menatetrenone) is registered as a therapeutic agent for postmenopausal osteoporosis, in which form it is widely prescribed in a dosage of $45 \mathrm{mg}$ /day for continuous treatment periods of many years.

\section{Plasma levels of vitamin $K$}

The extent to which plasma vitamin $\mathrm{K}$ reflects tissue vitamin $\mathrm{K}$ status is still a matter of debate. The very low levels of menaquinones in fasting plasma are beyond the limit of detection of current methodologies. Most of the data on plasma vitamin $\mathrm{K}$ are therefore limited to phylloquinone. The use of plasma phylloquinone to estimate tissue phylloquinone status is limited by the marked influence of various lipids. High plasma values vitamin $\mathrm{K}$ were found in hyperlipidaemia and hyperlipoproteinaemia ${ }^{29-31}$. Low vitamin $\mathrm{K}$ plasma values were found in osteoporosis, coeliac disease, parenteral feeding, and severe pancreatic insufficiency or biliary obstruction ${ }^{4,31,32}$. Fasting plasma concentrations of vitamin $\mathrm{K}$ were positively correlated with dietary K-intake ${ }^{29,33}$. Because the ratio plasma phylloquinone / triglycerides lead to a decrease in intra- and inter individual variations, some authors use this ratio rather than plasma phylloquinone alone ${ }^{22,34}$. Furthermore, fasting plasma concentrations of phylloquinone are strongly influenced by the common genetic polymorphism of apoE, being higher in patients with the apoE2 variant, intermediate in apoE3, and lower in apoE4. This is in line with the known link between apoE phenotype and the rate of hepatic clearance of chylomicron remnants. The length of time that phylloquinone remains in the circulation may have implications for the transport of phylloquinone to extra hepatic tissues such as bone 35

\section{Absorption, bioavailability and tissue distribution}

Like other fat-soluble vitamins, $\mathrm{K}$ vitamins taken in the diet are absorbed in the intestine by the bile salt-mediated pathway. After solubilization into lipid droplets, vitamin $\mathrm{K}$ 
is incorporated in micelles consisting of triacylglycerol, phospholipids, and chlolesterol esters. After passing the enterocytes, vitamin $\mathrm{K}$ is released into the blood stream, via the lymph, in so-called chylomicrons. These lipoproteins are catabolized in the circulation by the action of lipoprotein lipase (LPL) resulting in chylomicron remnants ${ }^{36}$. These chylomicron remnants are then cleared mainly by the liver via an apoE receptor-specific uptake ${ }^{37,38}$ (Figure 2).

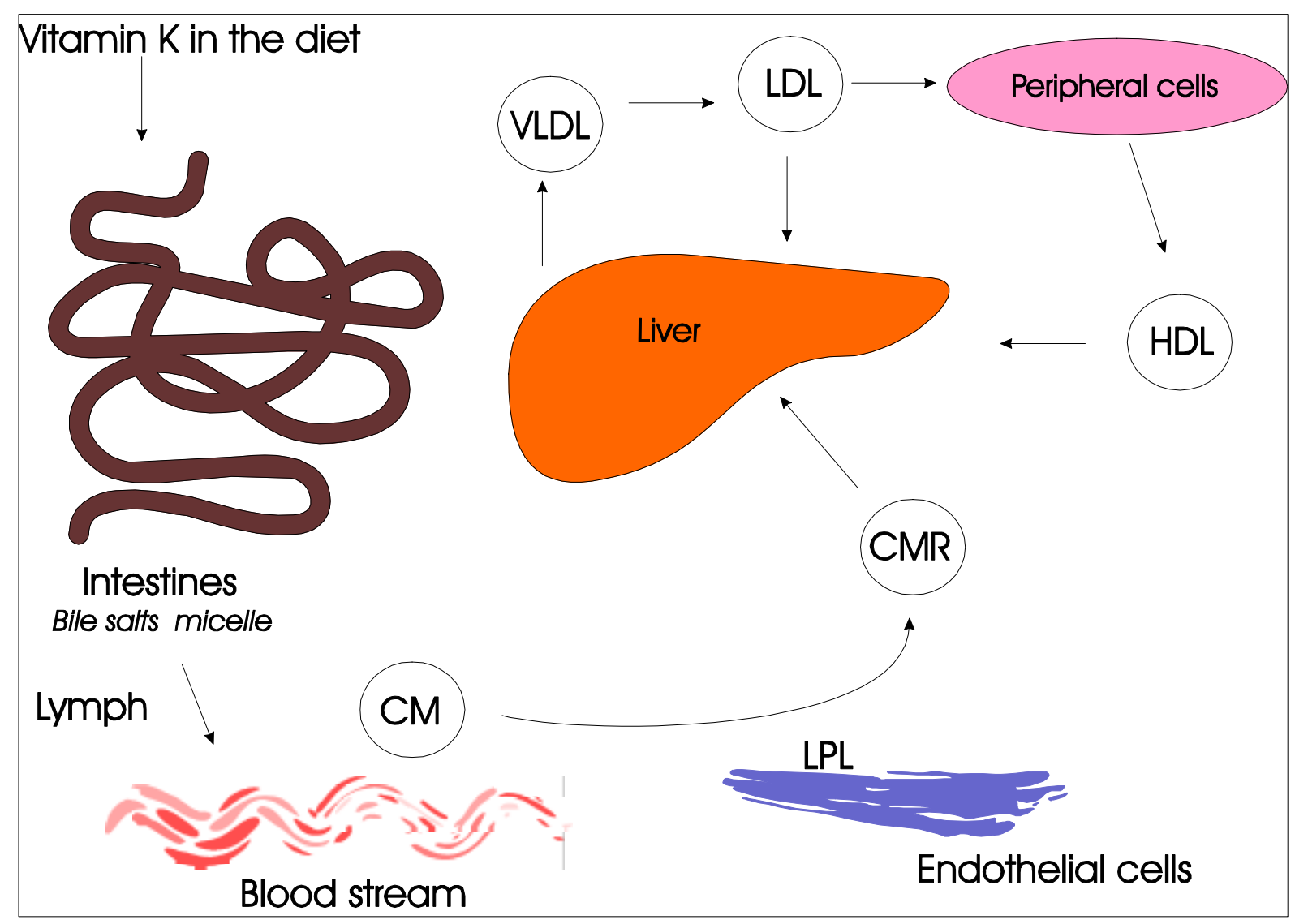

Figure 2.

Schematic overview of vitamin absorption and distribution in humans. Vitamin $\mathrm{K}$ is absorbed in the intestines with the aid of bile salts. The so-called mixed micelles enter the bloodstream via the lymphatic system. In the blood stream vitamin $\mathrm{K}$ is transported in lipoprotein particles. These lipoproteins deliver the vitamin $\mathrm{K}$ to their target cells.

Consistent with this model is the striking impairment of absorption of vitamin $\mathrm{K}$ in patients with extra-hepatic cholestasis and severe pancreatic insufficiency ${ }^{31}$. It has been estimated that healthy adults absorb $\sim 80 \%$ of an oral dose of phylloquinone given in a detergent-solubilized form ${ }^{31}$. The efficacy with which vitamin $\mathrm{K}$ is liberated from the food matrix is still a matter of debate and the reported bioavailablility ranges from $<10-70 \%{ }^{39-41}$. 
Factors affecting uptake from the diet include the amount and type of fat in the diet, and matrix in which the vitamin is dissolved. Therefore, considerable differences may be expected between phylloquinone and the menaquinones. Extraction of phylloquinone from vegetables, where it is tightly bound to the chloroplast membrane, is thought to be less efficient than from dairy produce ${ }^{22}$.

In plasma, phylloquinone is mainly associated with the triacylglycerol rich lipoprotein (TGRLP) fraction ${ }^{22,34,42}$ and only a small part of vitamin $\mathrm{K}$ is associated with the LDL and HDL fraction. Although the liver clears most of the postprandial phylloquinone, only $10 \%$ of the total liver store comprises of phylloquinone whereas the other $90 \%$ are menaquinones ${ }^{4,43}$. That the liver stores of phylloquinone are subject to rapid changes was shown by Usui et al. ${ }^{43}$, who demonstrated that after only 3 days of severe dietary depletion hepatic phylloquinone had decreased to $\sim 25 \%$ of original concentration. Although the liver contains large amounts of menaquinones, plasma menaquinones are difficult to measure and thus far only MK-7 and MK- 8 could be detected ${ }^{4,43,44}$. Extra-hepatic tissues hardly contain menaquinones except MK-4, which accumulates in testis, aorta, pancreas, brain, and salivary glands ${ }^{45,46}$. Thijssen et al. showed that after feeding rats a vitamin $\mathrm{K}$ deficient diet for 9 days, hepatic stores were almost depleted whereas other tissues like pancreas, brain and sternum still contained considerable amounts of vitamin $\mathrm{K}$, mainly in the form of MK-4 ${ }^{47}$. This suggests differences in tissue uptake and metabolism. The fact that there is a tissue-specific vitamin $\mathrm{K}$ accumulation had been already demonstrated in 1960 by Billeter and Martius. The authors found that after an oral dose of phylloquinone to rats, MK-4 was found in skeletal muscle, heart, and kidney but hardly in the liver ${ }^{48}$. Later, this observation was confirmed by Thijssen et al. and Yamamoto et al. who found that many rat tissues, including pancreas, sternum, brain and heart, accumulated MK-4 after oral phylloquinone intake ${ }^{47,49}$. The question remained whether the conversion of phylloquinone into MK-4 is exerted by the bacteria in the gut or in the tissues. In 1996, Ronden et al. found that in germ free rats fed exclusively a phylloquinone rich diet, many tissues accumulated MK-4 ${ }^{50}$. Since germ-free rats lack an intestinal flora, these experiments were the first direct proof that the conversion of phylloquinone into MK-4 takes place in some well-defined tissues. This observation was confirmed by Davidson et al. ${ }^{51}$.

\section{Biological activity of K-vitamins}

The functional group in vitamin $\mathrm{K}$ is the methylated naphtoquinone ring found in both phylloquinone and menaquinones. In vitro, the cofactor activity of vitamin $\mathrm{K}$ can be measured directly in specific assays for $\gamma$-glutamyl carboxylase and KO-reductase ${ }^{52,53}$. The cofacor activity was found to be dependent on the side chain of the vitamin. Based on the $\mathrm{V}_{\text {sat }} / \mathrm{K}_{\mathrm{m}}$ ratios, the long chain menaquinones $(\mathrm{n}>5)$ were most active ${ }^{52}$. In vivo, the 
biological acitivity can be assessed by measuring the potency in counteracting hypoprothrombinaemia. Matschiner and Taggart used rats to investigate the biological activity of various K-vitamins by injecting them intracardially (to exclude absorption effects), and found that 18 hours after injection the activity of phylloquinone in reversing hypoprothrombinaemia was 8 times higher than that of $\mathrm{MK}-4$, but that long chain menaquinones (MK-7 to MK-10) were up to 25 times more active than phylloquinone ${ }^{54}$. Also Groenen et al. found a 2-5 times better efficacy for phylloquinone than for MK-4 in reversing hypoprothombinaemia ${ }^{55}$. In another study Will and Suttie fed rats 1-3 weeks with either phylloquinone or MK-9 and found that MK-9 was less active than phylloquinone ${ }^{56}$. This result is inconsistent with that of Matschiner and Taggart ${ }^{54}$, but the protocols are difficult to compare. First, the administration routes were different and second, the time point measured after injection was different. Reedstrom and Suttie measured the sub-cellular distribution and the utilization of K-vitamins after blocking the K-cycle with warfarin ${ }^{57}$. It was found that both MK-9 and MK-9 epoxide were localized in the mitochondria rather than in the microsomes whereas phylloquinone was equally distributed over the two sub-cellular fractions. Since virtually all enzymes of the K-cycle are present in the microsomes rather then in the mitochondria, the K-vitamins present in the microsomes are readily available for $\gamma$ glutamyl carboxylase. In the same report the utilization of K-vitamins was also deduced from the $\mathrm{KO} / \mathrm{K}$ ratio, which was found to be much higher for phylloquinone than for MK-9.

\subsection{FUNCTION OF VITAMIN K}

\section{Protein carboxylation}

In mammals the only known function of vitamin $\mathrm{K}$ is that it serves as a cofactor for $\gamma$-glutamylcarboxylase, an endoplasmic enzyme involved in the posttranslational carboxylation of glutamate residues into $\gamma$-carboxyglutamate (Gla). Hence, the vitamin $\mathrm{K}$ dependent step is a carboxylation reaction taking place during the later stages of protein biosynthesis (Figure 3). Vitamin $\mathrm{K}$ hydroquinone $\left(\mathrm{KH}_{2}\right)$ is the active coenzyme, the oxidation of which to vitamin $\mathrm{K} 2,3$ epoxide (KO) provides the energy to drive the carboxylation reaction. The resulting Gla-residues are found in a limited number of proteins, and in these proteins only at certain well-defined positions ${ }^{58,59}$. Using specific staining ${ }^{60}$ (western blot) or HPLC detection techniques ${ }^{15}$ (after hydrolysis) these so-called Gla-proteins can be identified as unique products of vitamin $\mathrm{K}$ action. In vitamin K-deficiency the carboxylation reaction cannot proceed, hence the Gla-proteins are released in an undercarboxylated form. These socalled descarboxy proteins (formerly designated as PIVKA's, proteins induced by vitamin $\underline{\mathrm{K}}$ absence) were shown to be inactive in all cases in which the function of the corresponding 
Gla-protein is known ${ }^{59}$. Gla-residues form calcium-binding groups in proteins, so the main physico-chemical difference between normal and descarboxy proteins is their large difference in both binding of calcium from solution and the adsorption of these proteins to insoluble calcium salts.

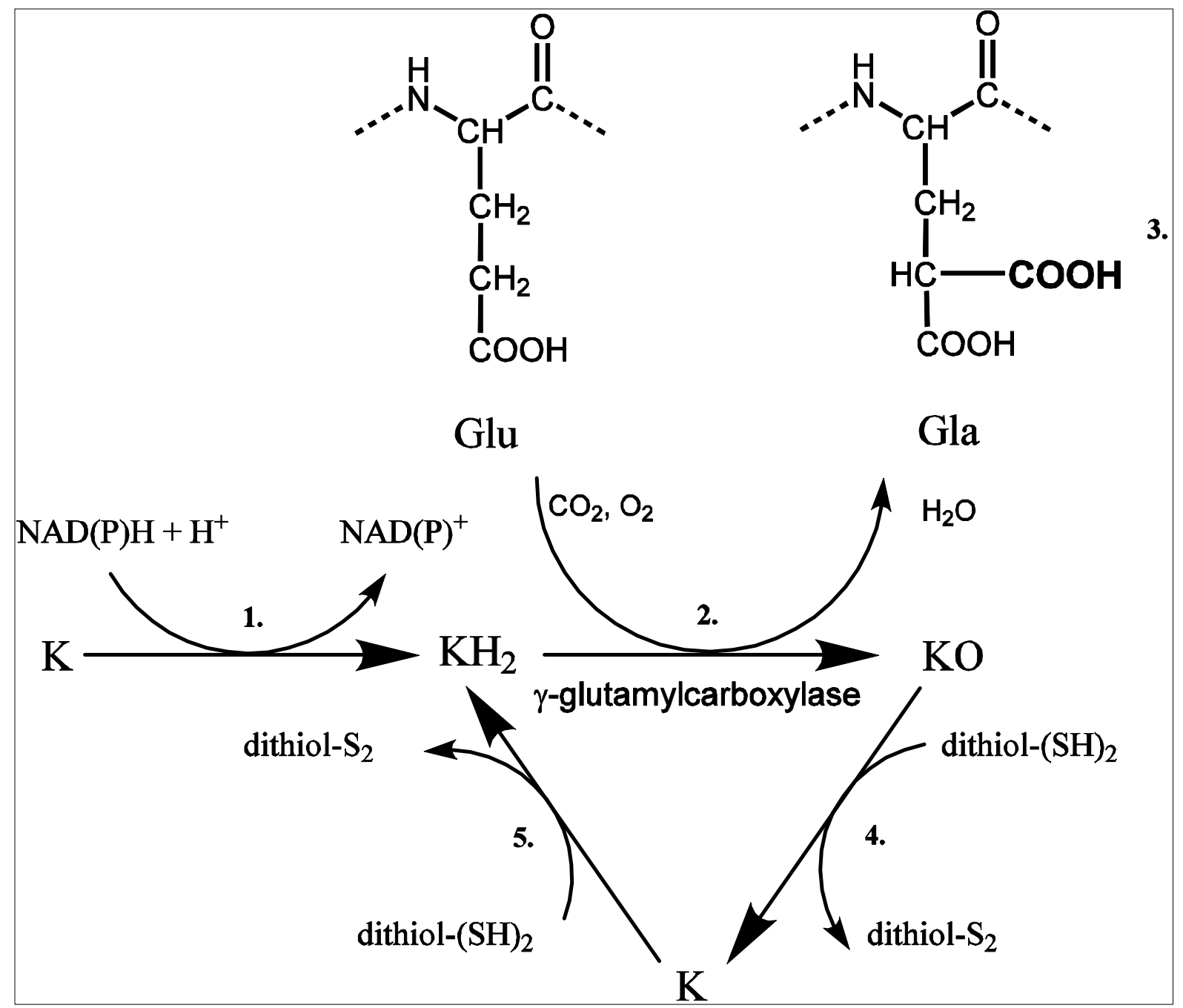

Figure 3.

The vitamin K-cycle. Vitamin K-quinone $(\mathrm{K})$ is first reduced to vitamin $\mathrm{K}$-hydroquinone $\left(\mathrm{KH}_{2}\right)$, and then oxidized to vitamin K-epoxide (KO). During the oxidation step glutamic acid (Glu) is reduced to $\boldsymbol{\gamma}$-carboxyglutamic acid (Gla). Finally KO is reduced to K. $\underline{\mathbf{1}}=$ NAD $(\mathrm{H})$-dependent reductase, $\underline{\mathbf{2}} \mathbf{.}=$ $\gamma$-glutamylcarboxylase enzyme, $\underline{3_{.}}=$extra introduced carboxy group, $\underline{4} .=$ dithiol-dependent $\mathrm{KO}$ reductase, $\underline{\mathbf{5}} \mathbf{=}$ dithiol-dependent $\mathrm{K}$-reductase

\section{Vitamin K-recycling}

After being formed as part of a polypeptide chain, free Gla will enter the circulation after protein degradation. Unlike the usual amino acids, Gla cannot be re-used and will be 10 
excreted via the urine. So there is a 1:1 stoichiometric relation between the conversion of $\mathrm{KH}_{2}$ into $\mathrm{KO}$ and the number of protein-bound Gla-residues formed. On the basis of nutritional vitamin $\mathrm{K}$ intake and urinary Gla excretion it may be calculated that in mammals the number of carboxylation events exceeds the number of available vitamin $\mathrm{K}$ molecules several thousand fold. Therefore, the KO formed must be recycled, which is accomplished by an enzyme known as KO-reductase (Figure 3). Two reduction steps are required to recycle one molecule of $\mathrm{KO}$ into $\mathrm{KH}_{2}$ and many independent observations favour the assumption that both steps are exerted by the same enzyme ${ }^{61}$. When KO-reductase is blocked (see below), a second enzyme (NADPH-dependent K-reductase, also known as DT-diaphorase) may take over the generation of $\mathrm{KH}_{2}$. This pathway can convert only vitamin $\mathrm{K}$ quinone, and not the epoxide into the hydroquinone. When the KO-reductase is blocked vitamin $\mathrm{K}$ cannot be recycled, which increases its nutritional requirement to values well above the normal dietary intake.

\section{Substrate recognition by carboxylase}

All Gla-containing proteins are synthesized in the endoplasmic reticulum as precursor proteins containing a signal sequence for translocation over/thru the endoplasmic membrane, and a carboxylase recognition site, which is usually found within the leader-sequence of the precursor protein ${ }^{14,59}$. An exception in this respect is matrix Gla-protein (MGP) in which the carboxylase recognition site forms part of the mature protein. Among all Gla-proteins presently known the amino acid residues $\mathrm{Phe}^{-16}$ and $\mathrm{Ala}^{-10}$ in their respective carboxylase recognition sites have been remarkably conserved ${ }^{14}$, and in vitro studies in which synthetic peptides were used as substrates for carboxylase have shown that mutations at these positions lead to a dramatic loss of enzyme-substrate affinity ${ }^{62}$. In vivo such mutations are expected to lead to the cellular secretion of undercarboxylated and thus inactive proteins.

\subsection{PhysiologicAl ROLES OF VITAMIN K-DEPENDENT PROTEINS}

Gla-containing proteins have been detected in many different species including snake ${ }^{63,64}$, snails ${ }^{65}$, and birds ${ }^{66}$. This thesis will focus, however, on mammalian Glaproteins and mammalian vitamin K-metabolism. Vitamin K-dependent carboxylase has been found in nearly all mammalian tissues investigated, but it seems that - besides those mentioned below - the corresponding Gla-proteins are produced in relatively low quantities. Incompletely characterized Gla-proteins have been reported to occur in spermatozoa ${ }^{67}$, urine ${ }^{68}$, and extracts of calcified atherosclerotic plaques ${ }^{69}$. Those characterized to the level of aminoacid sequence play regulating roles in either of three important physiological processes: blood coagulation, bone metabolism, and vascular biology (Table 2). 
Table 2. Tissue distribution and roles of vitamin K-dependent (Gla) proteins

\begin{tabular}{lll}
\hline Gla Protein & Tissue & Role \\
\hline & & \\
Prothrombin (FII), Factors VII, IX, and X & Liver (then plasma) & Procoagulants \\
Protein C, Z & Liver (then plasma) & Anticoagulants \\
Protein S & Liver (then plasma), endothelium, bone & Anticoagulant role as cofactor for protein C \\
Osteocalcin (bone Gla-protein) & Bone, dentin & Regulator of orderly crystallization \\
Matrix Gla-protein (MGP) & Bone, cartilage, and most soft tissues & Inhibitor of ectopic mineralization \\
Gas-6 (growth arrest specific gene-6 protein) & Most soft tissues & Regulator of cell growth \\
Proline rich Gla-proteins (PRGP) & Most soft tissues & Unknown \\
Transmembrane Gla-proteins (TMG) & Most soft tissues & Unknown \\
\hline
\end{tabular}

\section{Blood coagulation}

Involvement in blood coagulation is the classical role of vitamin $\mathrm{K}$, and the major function of Gla-residues in the coagulation factors is that they facilitate the binding of these proteins to the negatively charged phospholipids on the surface of activated blood platelets ${ }^{70}$. In this way the reaction rate of thrombin formation is accelerated by several orders of magnitude. Gla-containing proteins involved in blood coagulation are prothrombin, the factors VII, IX, and X, as well as the anticoagulant protein $\mathrm{C}$ and $\mathrm{S}$. Protein $\mathrm{Z}$ is also involved in coagulation; one of its functions was reported to be the fixation of thrombin to the site of injury ${ }^{71}$. In 1998 Han et al. ${ }^{72}$ showed that protein $\mathrm{Z}$ inhibited factor X activity dosedependently in the presence of phospholipids and calcium by forming a complex via a protein called protein Z-inhibitor (pZI). Recently, this was confirmed in protein Z-deficient mice ${ }^{73}$.

With the exception of protein $\mathrm{S}$ (which is produced in a variety of tissues) all the vitamin K-dependent coagulation factors are synthesized in the liver. Their Gla-content ranges between 10 (prothrombin) to 12 (factor IX) residues per molecule and the respective Gla-domains are essential for these proteins in their binding to negatively charged phospholipids such as those found in the outer membranes of activated blood platelets. The negatively charged Gla-residues have a high affinity for calcium ions. It has been shown by X-ray crystal structure analysis and 2D NMR spectroscopy that when bound to calcium ions the coagulation factors undergo structural changes leading to internalization of the Gla-Ca ${ }^{++}$ complex in the core of the protein, and to exposure of the phospholipid-binding domain $14,74,75$.

\section{Bone metabolism}

All three bone Gla-proteins presently known are synthesized by the osteoblasts (the bone forming cells), but only osteocalcin is a unique product of bone tissue. Protein $\mathrm{S}$ and MGP are also synthesized in a number of soft tissues including the vessel wall (see below). 
Osteocalcin represents about $20 \%$ of the non-collagenous proteins in bone and is one of the most abundant proteins in humans ${ }^{76}$. The precise function of the bone Gla-proteins is not yet clear. Osteocalcin-deficient mice turned out to grow more rapidly than the wild types, showing that osteocalcin is a negative regulator of bone formation. Furthermore, histomorphometric studies revealed that the absence of osteocalcin leads to an increased bone formation and improved quality without impairing bone resporption. ${ }^{77}$.

Knock-out mice have also been generated for MGP. These animals showed substantial growth retardation, with excessive calcifications of their growth plates, osteopenia and bone fractures ${ }^{78}$. Since all animals died from cardiovascular disease within 2 months after birth (see below) long term effects of MGP-deficiency on bone are still unknown. Recently, it was reported that in three independent cases the human Keutel syndrome is associated with a DNA mutation leading to the expression of non-functional MGP ${ }^{79}$. Keutel syndrome is an autosomal recessive disorder characterized by abnormal cartilage calcification, peripheral pulmonary stenosis, short terminal phalanges, abnormal cartilage calcification of the auricles, nose, larynx, trachea and ribs, and by mid-facial hypoplasia with a depressed nasal bridge. Recently, it was reported that upon post mortem examination of KS patients also revealed concentric calcification of pulmonary, coronary, hepatic, renal, meningeal, and cerebral arteries ${ }^{80}$. Hence the phenotypes of the MGP-deficient mouse and KS patients are similar, although the human defect does not lead to early cardiovascular mortality. Further research to elucidate this apparent contradiction remains to be carried out.

\section{Vascular biology}

In the arterial vessel wall the functions of Gla-proteins are probably associated with: local inhibition of thrombosis (protein $\mathrm{S}$ ) ${ }^{81}$, inhibition of mineralization (MGP) ${ }^{82}$, and stimulation of normal cell growth and prevention of apoptosis in growth arrested cells (Gas6) ${ }^{83}$. In the circulation protein $\mathrm{S}$ is known to inhibit blood coagulation and thrombus formation by acting as a cofactor for activated protein $C$; there are no arguments suggesting that the function of the vascular synthesised protein $\mathrm{S}$ would be different. As was discussed above, MGP-deficient mice were born to term but died before the 8th week of life due to massive arterial calcification and rupture of the thoracic or abdominal aorta ${ }^{78}$. These experiments established that MGP is a strong inhibitor of soft tissue calcification including cartilage and vessel wall ${ }^{84}$. Excessive aorta mineralization was also observed in rats after 4-6 weeks of treatment with vitamin K-antagonists ${ }^{85}$, showing that the Gla-residues in MGP are essential for its function. Gla-proteins have been extracted from human atheromatous plaques and although they were only partially characterized, the poor solubility of the human vascular Gla-proteins suggests that the major fraction may be similar to MGP ${ }^{69}$. The function of Gas6 (which stands for: growth arrest specific gene 6 protein) has been investigated only in cell 
culture systems thus far. In response to conditions leading to cell death, for instance during serum starvation, cells are induced to produce growth arrest specific proteins. Most of these proteins promote cell death (apoptosis), but Gas6 is an exception in this respect: it was shown to prevent serum starvation-induced death of fibroblasts and smooth muscle cells, and also may act as a growth-potentiating factor which acts synergistically with other known growth factors in these cells ${ }^{83,86,87}$. Gla-residues were shown to be essential for its functions in cell culture ${ }^{86}$. These data suggest that in humans Gas6 may play a key role in preventing the degeneration of atherosclerotic vessels. The recent observation that Gas6 is produced in both spinal motor neurons and large neurons of the dorsal root ganglia, and that Gas6 is a potent stimulator of human Schwann-cell growth suggests that this protein is involved in growth regulation in other tissues as well, but this needs further confirmation ${ }^{88}$.

\subsection{VITAMIN K REQUIREMENT}

After an overnight fasting period, circulating vitamin $\mathrm{K}$ levels in healthy adults range between $200-800 \mathrm{pg} / \mathrm{mL}$, however, they decrease rapidly after prolonged low vitamin $\mathrm{K}$ intake. In non-fasting individuals serum vitamin $\mathrm{K}$ concentrations may fluctuate as a result of the consumption of various foods ${ }^{4,29,33}$. Serum vitamin $\mathrm{K}$ and triglyceride levels seem to be firmly correlated and presently it is not clear whether plasma concentrations (either as absolute values or as the vitamin $\mathrm{K} /$ triglyceride ratio) are an accurate indicator of tissue reserves. Experimental animal studies have demonstrated that the distribution of vitamin $\mathrm{K}$ throughout the various tissues depends on the daily dose of vitamin $\mathrm{K}$, and on the type of vitamin $\mathrm{K}^{45}$. It is believed, therefore, that a subject's vitamin $\mathrm{K}$ status cannot be assessed from overall variables like serum vitamin $\mathrm{K}$ or urinary Gla-excretion. A more reliable method to determine tissue vitamin K-status seems to be measurement of the Gla-content of Gla-containing proteins. The occurrence of undercarboxylated proteins in the circulation has enabled us to develop biochemical tests with which vitamin K deficiency can be assessed by measuring the quality (= active proteins) of the products formed in specific tissues.

\section{Vitamin K deficiency}

A: Blood coagulation: Although in the absence of precipitating causes vitamin $\mathrm{K}$ deficiency is rarely seen in adults (measured by the overall coagulation tests), deficiency in the newborn or haemorrhagic disease of the newborn (HDN) remains a significant worldwide cause of infant morbidity and mortality ${ }^{89}$. The disease can be subdivided into three clinical patterns: early HDN (within 24 hours after birth), classical HDN (days 2 - 7 after birth), and late onset HDN (week 2 - 6 months after birth). There are several hypotheses for the poor vitamin $\mathrm{K}$ status of the newborn. First, the placental barrier for maternal vitamin $\mathrm{K}$ leads to a 
calculated ratio of vitamin $\mathrm{K}$ in cord blood and maternal blood of 1:30 ${ }^{90}$ and second, the vitamin $\mathrm{K}$ content of human milk is low ${ }^{91}$. Therefore, breast fed babies have a higher incidence of classical or late $\mathrm{HDN}^{89,92}$. The use of medication during pregnancy is another reason for inducing a poor fetal vitamin $\mathrm{K}$ status. It is known that anticonvulsants and tuberculostatics interfere with vitamin $\mathrm{K}$ metabolism and increase the incidence of early HDN ${ }^{93,94}$. As prophylaxis for HDN, vitamin $\mathrm{K}$ is given routinely to newborns in all developed countries ${ }^{95}$. The route of administration is either orally or intramuscularly. The latter administration was reported to have an association with childhood cancer in two British hospitals in a retrospective study ${ }^{96,97}$. A number of prospective epidemiological studies did not confirm this association ${ }^{98-100}$. However, the finding of Golding et al. resulted in the change of recommendation in many countries in favor of oral administration.

B: bone metabolism. In 1991 it had been already found in population-based studies that circulating osteocalcin is far more sensitive to poor vitamin $\mathrm{K}$ status than other Glaproteins ${ }^{101}$. There are two mechanisms underlying this observation. First, the affinity of the endoplasmic osteocalcin precursor proteins (pro-osteocalcin) for $\gamma$-glutamylcarboxylase is distinctly lower than that of other Gla-proteins. It was demonstrated that this poor affinity is due to an $\mathrm{Ala}^{-10} \rightarrow$ Gly mutation in the leader sequence: during periods of low vitamin $\mathrm{K}$ supply, precursors of a variety of vitamin K-dependent proteins will accumulate, and the competition for the carboxylase binding site will inevitably be lost by pro-osteocalcin ${ }^{102}$. Later, it was demonstrated by Houben et al. that osteocalcin has a $\gamma$-carboxylase binding site distinct form that of other vitamin K-dependent proteins ${ }^{103}$. Second, after its synthesis by the osteoblasts, osteocalcin is set free amidst the hydroxyapatite matrix of bone, which will preferentially adsorb the normally carboxylated osteocalcin, so that undercarboxylated osteocalcin will be selectively set free in the circulation. Optimal carboxylation of the bone Gla-proteins requires a higher vitamin $\mathrm{K}$ intake, and in recent years it has been demonstrated that undercarboxylation of osteocalcin is quite common, notably in the elderly ${ }^{104,105}$. It is important, therefore, to realize that vitamin K-deficiency is a state which should be defined per tissue, not for a whole organism. As early as 1985 it had been reported that low circulating phylloquinone levels were associated with an increased risk for osteoporotic hip fractures ${ }^{32,106}$. More recently these data were confirmed ${ }^{107}$, and it was found that plasma menaquinone concentrations were also substantially reduced in osteoporotic women ${ }^{108}$. The question remained whether the observed low circulating vitamin $\mathrm{K}$ levels were associated with a detectable vitamin $\mathrm{K}$ deficiency of bone tissue. Knapen et al. developed an assay for the assessment of the ratio between normal and undercarboxylated osteocalcin, and it was found that the fraction of undercarboxylated osteocalcin is increased in postmenopausal women ${ }^{104,105}$. Szulc et al. reported that undercarboxylated osteocalcin is inversely correlated with bone mass ${ }^{109}$, and that undercarboxylated osteocalcin is an independent predictive 
marker for hip fracture risk ${ }^{110,111}$. These data where confirmed in a group of women who were between 1 and 10 years postmenopausal, and it was found that age, body weight and undercarboxylated osteocalcin are three independent variables from which the bone mineral density may be calculated with an accuracy of over $70 \%{ }^{112}$.

C: Vascular biology. Atherosclerosis is the major cause of mortality in the Western world ${ }^{113}$. It is characterized by the presence of atherosclerotic lesions in the arterial intima. Atherosclerosis is thought to progress from fatty streak to fibrous plaques, and finally to calcified atheromata ${ }^{114}$. Vascular calcification does not remain restricted to the intima, but also occurs in the media were it is known as Mönckeberg sclerosis ${ }^{115}$. In contrast to intimal calcification, medial calcification occurs in the absence of inflammatory cell infiltration and lipid deposition ${ }^{116,117}$. Although both processes are different in many ways, it is generally accepted that vascular calcification is an active process rather than a passive process resulting from the accumulation of calcium released from dying cells. With the generation of the MGP knock-out mouse ${ }^{78}$, which exhibits extensive and lethal calcification and cartilaginous metaplasia of the media of all elastic arteries, the role of vitamin $\mathrm{K}$ and vitamin $\mathrm{K}$-dependent proteins in vascular calcification has gained substantial attention. Several Gla-proteins have been isolated from the calcified atherosclerotic plaques ${ }^{69,118-120}$. The finding of different proteins containing Gla in bone and ectopic calcification including hardened plaque suggests that certain calcium-binding proteins containing this amino acid may be of importance in the mineralization process. Indeed, on a level of gene expression, MGP was found to be upregulated in vivo and in vitro in association with calcification ${ }^{82,117,120}$. The role of vitamin $\mathrm{K}$ in atherosclerosis was recently investigated. In these studies the authors ${ }^{121,122}$ screened for the occurrence of calcifications in the abdominal aorta in more then hundred of apparently healthy volunteers between 60 and 80 years of age. They also recorded the nutritional habits and preferences with the aid of food frequency questionnaires. The subjects were classified into four categories according to the degree of aortic calcification, ranging from no visible calcification to severe calcifications. It turned out that subjects with severe atherosclerotic calcifications had a significantly lower long-term vitamin $\mathrm{K}$ intake, a higher amount of undercarboxylated bone Gla-protein (osteocalcin), and lower bone mass. These data suggest that a biochemical vitamin K-deficiency is common in atherosclerotic subjects.

On the basis of these data we propose to re-define vitamin K-deficiency as follows. Mild vitamin $\mathrm{K}$ deficiency is a condition in which the circulating osteocalcin is significantly undercarboxylated, whereas the blood coagulation factor prothrombin still contains a functional Gla domain ${ }^{123,124}$. Severe vitamin K deficiency may than be regarded as a condition in which descarboxyprothrombin is detectable in the circulation. 


\section{Vitamin $K$ and coumarins}

Nearly all known inhibitors of the vitamin K cycle interfere with KO-reductase, and to a far lesser extend with carboxylase and DT-diaphorase ${ }^{61,125}$ (Figure3). Well known inhibitors are those derived from 4-hydroxycoumarin. Because these coumarin derivatives effectively block the recycling of vitamin-KO, their action results in an exhaustion of the $\mathrm{KH}_{2}$ stores and thus in an apparent vitamin K-deficiency. During the last 50 years vitamin Kantagonists (coumarin derivatives) have been used on a large scale for the treatment of patients at risk of thrombo-embolic events ${ }^{8}$. The drugs are generally administered for periods of several years or longer, a major area of clinical application is the prevention of myocardial re-infarction. Most of these patients are well over 50 years of age, although during recent years oral anticoagulant therapy at younger ages has become more common.

In the early 1970's it became usual to treat relatively young patients with coumarin derivatives, for instance those how had received an artificial heart valve. Because of compelling medical indications the treatment of women was continued even after they had become pregnant. It appeared, however, that in about $30 \%$ of the cases the newborns had developed serious bone defects ${ }^{126}$. Subsequent experiments in animals (rats, lambs) have shown that notably in rapidly growing (young) bone tissue coumarin derivatives interfere with the regulation of calcium deposition resulting in excessive and irregular precipitation of calcium salts in areas which are normally not calcified (e.g. the growth plates). This leads to bone deformations and growth reduction ${ }^{127-129}$, phenomena which must be attributed to strongly impaired activities of the bone Gla-proteins. Remarkably, coumarin derivatives appear to have less effect on adult bone ${ }^{130-133}$.

\section{Congenital vitamin $\mathrm{K}$ deficiencies}

Carboxylase and reductase deficiency. Combined deficiencies of all clotting factors are rare and obviously one has first to exclude unequivocally the occurrence of vitamin Kdeficiency or unsuspected intake of coumarins. Since the first suggestion of a defect in the carboxylase/reductase system ${ }^{134}$, several other cases have been reported some of which also mentioned the occurrence of bone abnormalities comparable with those seen in warfarininduced embryopathy ${ }^{135}$. Such combined defects of bone development before birth and of the blood clotting system during childhood strongly suggest a decreased carboxylation of all Glaproteins, and may be due to mutations in either the carboxylase or KO-reductase. After the carboxylase cDNA had been sequenced and cloned ${ }^{136}$, some of these cases could indeed be associated with a mutation in the carboxylase gene ${ }^{137,138}$.

Mutations in the clotting factor Pro-domain. These mutations may lead either to poor recognition of the precursor protein by carboxylase ${ }^{102,139}$, or to impaired cleavage of the propeptide during protein maturation ${ }^{140}$. Reported cases of impaired carboxylase recognition 
refer to factor IX and were discovered by the clinical symptoms (acquired haemophilia B) after mild coumarin treatment. Impaired pro-peptide cleavage leads to fully carboxylated clotting factors which lack procoagulant activity because the extension at their amino terminus strongly interferes with their binding to negatively charged phospholipid vesicles 140

Mutations in the clotting factor Gla-domain. Besides frame-shift mutations and the introduction of stop codons, direct mutations in the Gla-domain may result in replacement of regular amino acids and of Gla-residues. Whereas all mutations may give rise to altered conformations, mutations leading to a decreased number of Gla-residues will inevitably decrease the protein's charge and calcium binding capacity. In the case of the four vitamin Kdependent clotting factors this will result in a decreased haemostatic capacity and a risk of bleeding, whereas in the case of the coagulation inhibiting protein $\mathrm{C}$ and protein $\mathrm{S}$ the expected result is an increased thrombosis risk. Indeed several of such mutations have been reported during recent years, and the clinical symptoms matched the expectations ${ }^{141,142}$. Whereas in the case of protein $\mathrm{C}$ and protein $\mathrm{S}$ mutations the thrombosis risk could be successfully normalized by oral anticoagulant therapy, the symptoms of mutations in the clotting factors cannot be relieved by vitamin $\mathrm{K}$. 


\subsection{INTRODUCTION TO THIS THESIS}

Vitamin $\mathrm{K}$ is a fat-soluble vitamin which has a well-defined role in the process of blood coagulation. For over half a century, this has been its only known function. During the last two decades, however, the discovery of extra-hepatic Gla-proteins and their functions, has renewed the interest in vitamin $\mathrm{K}$. These so-called extra-hepatic Gla-proteins are now known to occur in a wide variety of tissues including bone, arterial vessel wall, testis, lung, pancreas and spleen. All recommendations for dietary vitamin $\mathrm{K}$ intake are based on the requirements for the synthesis of blood coagulation factors. Extra-hepatic vitamin $\mathrm{K}$ requirement has remained unknown thus far. Moreover, thus far the $\mathrm{K}_{2}$ vitamins have received little attention, and their contribution to the human vitamin $\mathrm{K}$ status was unknown before we started the work reported here.

In this thesis we have investigated the metabolic pathways of $\mathrm{K}$ vitamins following ingestion either in the form of a standardized diet or as supplements. First, we have established an up-to-date food composition table for vitamins $K_{1}$ and $K_{2}$ in a wide range of foods purchased in the Netherlands. With the aid of this data base we have investigated in experimental animals and human volunteers the absorption of K-vitamins, their plasma transport by lipoproteins, and the effect of other dietary factors on vitamin $\mathrm{K}$ absorption and metabolism. Next, we have demonstrated the occurrence of vitamin K-deficiency in cases of increased expenditure or impaired intestinal uptake, and we have addressed the question of whether vitamin K-containing food supplements may be safely marketed as OTC products. Finally, we have studied the accumulation of the vitamin K-dependent protein MGP in calcifying human arteries. The results from the latter study form the basis for our hypothesis that vitamin $\mathrm{K}$ intake at levels above the present $\mathrm{RDA}$ are required for optimal protection against arterial calcification. 


\section{REFERENCES}

1. Dam H. The antihemorrhagic vitamin of the chick: occurrence and chemical nature. Nature. 1935;135:652-653.

2. Almquist HJ. Vitamin K. Physiol Rev. 1941;21:194-216.

3. Haroon Y, Shearer MJ, Rahim S, Gunn WG, McEnery G, Barkhan P. The content of phylloquinone (vitamin K1) in human milk, cows' milk and infant formula foods determined by high-performance liquid chromatography. J Nutr. 1982;112:1105-1117.

4. Shearer MJ, McCarthy PT, Crampton OE, Mattock MB. The assessment of human vitamin K status from tissue measurement. Current advances in vitamin $K$ research (ed. JW Suttie). 1988;Elsevier:437-452.

5. Shofield FW. A brief account of a disease in cattle simulating hemorrhagic septicemia due to feeding sweet clover. Can Vet Rec. 1922;3:74-79.

6. Campbell MA. Haemorrhagic disease in cattle. J Biol Chem. 1941;18:21-33.

7. Hadler MR, Shadbolt RS. Novel 4-hydroxycoumarin anticoagulants active against resistant rats. Nature. 1975;253:275-277.

8. Hirsh J, Fuster V. Guide to anticoagulant therapy. Part 2: Oral anticoagulants. American Heart Association. Circulation. 1994;89:1469-1480.

9. Lichtenthaler HK. The plant prenyllipids, including cartenoids, chlorophylls and prenylquinones. Plant Lipids (ed. Moore, T.). 1993;CRC Press, Boca Raton:421-464.

10. Dialameh GH, Taggart WV, Matschiner JT, Olson RE. Isolation and characterization of menaquinone-4 as a product of menadione metabolism in chicks and rats. Int J Vitam Nutr Res. 1971;41:391-400.

11. Ritzl VF. Biosynthetische veranderungen von tritium-markiertem vitamin $\mathrm{K}_{3}$ in menschen. Atomkernenergie. 1970;15:162-166.

12. Allison AC. Danger of vitamin K to newborn. Lancet. 1955;I:669.

13. Meyer TC, Angus J. The effect of large doses of 'synkavit' in the newborn. Arch Dis Child. 1956;31:213-215.

14. Furie B, Bouchard BA, Furie BC. Vitamin K-dependent biosynthesis of gammacarboxyglutamic acid. Blood. 1999;93:1798-808.

15. Kuwada M, Katayama K. An improved method for the determination of gammacarboxyglutamic acid in proteins, bone, and urine. Anal Biochem. 1983;131:173-9.

16. Ferland G, Sadowski JA. Vitamin $\mathrm{K}_{1}$ (phylloquinone) content of edible oils: effects of heating and light exposure. J Agricult Food Chem. 1992;40:1869-1873.

17. Shearer MJ, Kries RV, Saupe J. Comparative aspects of human vitamin K metabolism and nutriture. J Nutr Sci Vitaminol Tokyo. 1992:413-6.

18. Sakano T, Nagaoka T, Morimoto A, Hirauchi K. Measurement of K vitamins in human and animal feces by high-performance liquid chromatography with fluorometric detection. Chem Pharm Bull (Tokyo). 1986;34:4322-4326.

19. Shearer MJ. Vitamin K. Lancet. 1995;345:229-34.

20. Conly JM, Stein K. Quantitative and qualitative measurements of K vitamins in human intestinal contents. Am J Gastroenterol. 1992;87:311-6.

21. Conly JM, Stein K. The production of menaquinones (vitamin K2) by intestinal bacteria and their role in maintaining coagulation homeostasis. Prog Food Nutr Sci. 1992;16:307-43.

22. Shearer MJ. Vitamin K metabolism and nutriture. Blood-Rev. 1992;6:92-104.

23. Barnes RH, Fiala G. Effects of the prevention of coprophagey in the rat. $J$ Nutr. 1959;68:603-614.

24. Ichihashi T, Takagishi Y, Uchida K, Yamada H. Colonic absorption of menaquinone-4 and 
menaquinone-9 in rats. $J$ Nutr. 1992;122:506-512.

25. Groenen van Dooren MM, Ronden JE, Soute BA, Vermeer C. Bioavailability of phylloquinone and menaquinones after oral and colorectal administration in vitamin K-deficient rats. Biochem Pharmacol. 1995;50:797-801.

26. Ramotar K, Krulicki W, Gray G, Louie TJ. Studies on intestinal and hepatic concentrations of menaquinone and hypoprothrombinaemia in vitamin $\mathrm{K}_{1}$ deficiency in rats. Elsevier, New York. 1988;Current advances in vitamin K research (ed. Suttie, J.W.):493-498.

27. Chong LL, Chau WK, Ho CH. A case of 'superwarfarin' poisoning. Scand J Haematol. 1986;36:314-315.

28. Lipton RA, Klass EM. Human ingestion of a 'superwarfarin' rodenticide resulting in a prolonged anticoagulant effect. Jama. 1984;252:3004-3005.

29. Booth SL, Tucker KL, McKeown NM, Davidson KW, Dallal GE, Sadowski JA. Relationships between dietary intakes and fasting plasma concentrations of fat-soluble vitamins in humans. $J$ Nutr. 1997; 127:587-592.

30. Mattock MB, Shearer MJ, Rahim S, Redmond S, El-Gohari R, Barkhan P. The plasma transport of vitamin $\mathrm{K}_{1}$ (phylloquinone) in hyperlipoprotaemia. Clin Sci. 1983;64:63p.

31. Shearer MJ, McBurney A, Barkhan P. Studies on the absorption and metabolism of phylloquinone (vitamin K1) in man. Vitam Horm. 1974;32:513-42.

32. Hart JP, Shearer MJ, Klenerman L, Catterall A, Reeve J, Sambrook PN, Dodds RA, Bitensky L, Chayen J. Electrochemical detection of depressed circulating levels of vitamin K1 in osteoporosis. J Clin Endocrinol Metab. 1985;60:1268-9.

33. Booth SL, Sokoll LJ, O'Brien ME, Tucker K, Dawson-Hughes B, Sadowski JA. Assessment of dietary phylloquinone intake and vitamin $\mathrm{K}$ status in postmenopausal women. Eur J Clin Nutr. 1995;49:832-841.

34. Sadowski JA, Hood SJ, Dallal GE, Garry PJ. Phylloquinone in plasma from elderly and young adults: factors influencing its concentration. Am-J-Clin-Nutr. 1989;50:100-8.

35. Kohlmeier M, Salomon A, Saupe J, Shearer MJ. Transport of vitamin K to bone in humans. J Nutr. 1996;126:1192s-6s.

36. Havel RJ, Kane JP. Introduction: structure and metabolism of plasma lipoproteins. The metabolic and molecular basis of inherited disease (ed. Scriver, C.R.). 1995;7th ed. New York: McGraw-Hill:1841-1851.

37. Sherrill BC, Innerarity TL, Mahley RW. Rapid hepatic clearance of the canine lipoproteins containing only the $\mathrm{E}$ apoprotein by a high affinity receptor. Identity with the chylomicron remnant transport process. J Biol Chem. 1980;255:1804-7.

38. Brown MS, Herz J, Kowal RC, Goldstein JL. The low-density lipoprotein receptor-related protein: double agent or decoy? Curr Opin Lipodol. 1991;2:65-72.

39. Gijsbers BL, Jie KS, Vermeer C. Effect of food composition on vitamin K absorption in human volunteers. Br J Nutr. 1996;76:223-9.

40. Garber AK, Binkley NC, Krueger DC, Suttie JW. Comparison of phylloquinone bioavailability from food sources or a supplement in human subjects. $J$ Nutr. 1999;129:1201-3.

41. Olson RE. The function and metabolism of vitamin K. Annu Rev Nutr. 1984;4:281-337.

42. Lamon-Fava S, Sadowski JA, Davidson KW, O'Brien ME, McNamara JR, Schaefer EJ. Plasma lipoproteins as carriers of phylloquinone (vitamin $\mathrm{K}_{1}$ ) in humans. Am $J$ Clin Nutr. 1998;67:1226-1231.

43. Usui Y, Tanimura H, Nishimura N, Kobayashi N, Okanoue T, Ozawa K. Vitamin K concentrations in the plasma and liver of surgical patients. Am J Clin Nutr. 1990;51:846-52.

44. Hodges SJ, Pilkington MJ, Shearer MJ, Bitensky L, Chayen J. Age-related changes in the circulating levels of congeners of vitamin $\mathrm{K} 2$, menaquinone-7 and menaquinone-8. 
Clin Sci Colch. 1990;78:63-6.

45. Ronden JE, Thijssen HH, Vermeer C. Tissue distribution of K-vitamers under different nutritional regimens in the rat. Biochim Biophys Acta. 1998;1379:16-22.

46. Thijssen HHW, Drittij-Reijnders MJ, Fischer MA. Phylloquinone and menaquinone-4 distribution in rats: synthesis rather than uptake determines menaquinone-4 organ concentrations. J Nutr. 1996;126:537-543.

47. Thijssen HH, Drittij Reijnders MJ. Vitamin K distribution in rat tissues: dietary phylloquinone is a source of tissue menaquinone-4. Br J Nutr. 1994;72:415-25.

48. Billeter M, Martius C. Über die umwandlung von phyllochinon (vitamin $\mathrm{K}_{1}$ ) in vitamin $\mathrm{K}_{2(20)} \mathrm{im}$ tierkörper. Biochem Z. 1960;333:430-439.

49. Thijssen HH, Drittij Reijnders MJ, Fischer MA. Phylloquinone and menaquinone-4 distribution in rats: synthesis rather than uptake determines menaquinone-4 organ concentrations. $J$ Nutr. 1996;126:537-43.

50. Ronden JE, Drittij-Reijnders MJ, Vermeer C, Thijssen HH. Intestinal flora is not an intermediate in the phylloquinone- menaquinone-4 conversion in the rat. Biochim Biophys Acta. 1998;1379:69-75.

51. Davidson RT, Foley AL, Engelke JA, Suttie JW. Conversion of dietary phylloquinone to tissue menaquinone-4 in rats is not dependent on gut bacteria. $J$ Nutr. 1998;128:220-223.

52. Buitenhuis HC, Soute BA, Vermeer C. Comparison of the vitamins K1, K2 and K3 as cofactors for the hepatic vitamin K-dependent carboxylase. Biochim Biophys Acta. 1990;1034:170-5.

53. Yen CS, Mack DO. Solubilized rat liver vitamin K carboxylase demonstrates little selectivity between vitamin K1 and the menaquinones. Proc Soc Exp Biol Med. 1980;165:306-308.

54. Matschiner JT, Taggart WV. Bioassay of vitamin K by intracardial injection in deficient adult male rats. J Nutr. 1968;94:57-9.

55. Groenen-van Dooren MM, Soute BA, Jie KS, Thijssen HH, Vermeer C. The relative effects of phylloquinone and menaquinone-4 on the blood coagulation factor synthesis in vitamin $\mathrm{K}$ deficient rats. Biochem Pharmacol. 1993;46:433-437.

56. Will BH, Suttie JW. Comparative metabolism of phylloquinone and menaquinone-9 in rat liver. J Nutr. 1992;122:953-8.

57. Reedstrom CK, Suttie JW. Comparative distribution, metabolism, and utilization of phylloquinone and menaquinone-9 in rat liver. Proc-Soc-Exp-Biol-Med. 1995;209:403-9.

58. Furie B, Furie BC. Molecular and cellular biology of blood coagulation. $N$ Engl J Med. 1992;326:800-6.

59. Vermeer C. Gamma-carboxyglutamate-containing proteins and the vitamin K-dependent carboxylase. Biochem J. 1990;266:625-36.

60. Jie KS, Gijsbers BL, Vermeer C. A specific colorimetric staining method for gammacarboxyglutamic acid-containing proteins in polyacrylamide gels. Anal Bioch. 1995;224:163-5.

61. Fasco MJ, Hildebrandt EF, Suttie JW. Evidence that warfarin anticoagulant action involves two distinct reductase activities. $J$ Biol Chem. 1982;257:11210-2.

62. Stanley TB, Wu SM, Houben RJ, Mutucumarana VP, Stafford DW. Role of the propeptide and gamma-glutamic acid domain of factor IX for in vitro carboxylation by the vitamin K-dependent carboxylase. Biochemistry. 1998;37:13262-8.

63. Tans G, Govers Riemslag JW, van Rijn JL, Rosing J. Purification and properties of a prothrombin activator from the venom of Notechis scutatus scutatus. $J$ Biol Chem. 1985;260:9366-72.

64. Speijer H, Govers-Riemslag JW, Zwaal RF, Rosing J. Prothrombin activation by an activator from the venom of Oxyuranus scutellatus (Taipan snake). J Biol Chem. 1986;261:13258-13267.

65. McIntosh JM, Olivera BM, Cruz LJ, Gray WR. Gamma-carboxyglutamate in a neuroactive 
toxin. J Biol Chem. 1984;259:14343-6.

66. Lian JB, Hauschka PV, Gallop PM. Properties and biosynthesis of a vitamin K-dependent calcium binding protein in bone. Fed Proc. 1978;37:2615-2620.

67. Soute BA, Muller Esterl W, de Boer van den Berg MA, Ulrich M, Vermeer C. Discovery of a gamma-carboxyglutamic acid-containing protein in human spermatozoa. FEBS-Lett. 1985;190:137-41.

68. Nakagawa Y, Abram V, Coe FL. Isolation of calcium oxalate crystal growth inhibitor from rat kidney and urine. Am J Physiol. 1984;247:F765-F772.

69. Gijsbers BL, van Haarlem LJ, Soute BA, Ebberink RH, Vermeer C. Characterization of a Glacontaining protein from calcified human atherosclerotic plaques. Arteriosclerosis. 1990;10:991-5.

70. Davie EW. Biochemical and molecular aspects of the coagulation cascade. Thromb Haemost. 1995;74:1-6.

71. Hogg PJ, Stenflo J. Interaction of vitamin K-dependent protein $Z$ with thrombin. Consequences for the amidolytic activity of thrombin and the interaction of thrombin with phospholipid vesicles. J Biol Chem. 1991;266:10953-8.

72. Han X, Fiehler R, Broze GJ, Jr. Isolation of a protein Z-dependent plasma protease inhibitor. Proc Natl Acad Sci U S A. 1998;95:9250-5.

73. Yin ZF, Huang ZF, Cui J, Fiehler R, Lasky N, Ginsburg D, Broze GJ, Jr. Prothrombotic phenotype of protein Z deficiency. Proc Natl Acad Sci U S A. 2000;97:6734-8.

74. Li L, Darden TA, Freedman SJ, Furie BC, Furie B, Baleja JD, Smith H, Hiskey RG, Pedersen LG. Refinement of the NMR solution structure of the gamma-carboxyglutamic acid domain of coagulation factor IX using molecular dynamics simulation with initial $\mathrm{Ca} 2+$ positions determined by a genetic algorithm. Biochemistry. 1997;36:2132-8.

75. Soriano-Garcia M, Padmanabhan K, de Vos AM, Tulinsky A. The Ca2+ ion and membrane binding structure of the Gla domain of Ca- prothrombin fragment 1. Biochemistry. 1992;31:2554-66.

76. Hauschka PV, Lian JB, Cole DE, Gundberg CM. Osteocalcin and matrix Gla protein: vitamin Kdependent proteins in bone. Physiol rev. 1989;69:990-1047.

77. Ducy P, Desbois C, Boyce B, Pinero G, Story B, Dunstan C, Smith E, Bonadio J, Goldstein S, Gundberg C, Bradley A, Karsenty G. Increased bone formation in osteocalcin-deficient mice. Nature. 1996;382:448-52.

78. Luo G, Ducy P, McKee MD, Pinero GJ, Loyer E, Behringer RR, Karsenty G. Spontaneous calcification of arteries and cartilage in mice lacking matrix GLA protein. Nature. 1997;385:78-81.

79. Munroe PB, Olgunturk RO, Fryns JP, Van Maldergem L, Ziereisen F, Yuksel B, Gardiner RM, Chung E. Mutations in the gene encoding the human matrix Gla protein cause Keutel syndrome. Nat Genet. 1999;21:142-4.

80. Meier M, Weng LP, Alexandrakis E, Ruschoff J, Goeckenjan G. Tracheobronchial stenosis in Keutel syndrome. Eur Respir J. 2001;17:566-9.

81. Fair DS, Marlar RA, Levin EG. Human endothelial cells synthesize protein S. Blood. 1986;67:1168-71.

82. Proudfoot D, Shanahan CM, Weissberg PL. Vascular calcification: new insights into an old problem [editorial; comment]. J Pathol. 1998;185:1-3.

83. Goruppi S, Ruaro E, Schneider C. Gas6, the ligand of Axl tyrosine kinase receptor, has mitogenic and survival activities for serum starved NIH3T3 fibroblasts. Oncogene. 1996;12:47180 .

84. Schinke T, McKee MD, Karsenty G. Extracellular matrix calcification: where is the action? [news; comment]. Nat Genet. 1999;21:150-1.

85. Price PA, Faus SA, Williamson MK. Warfarin causes rapid calcification of the elastic lamellae 
in rat arteries and heart valves. Arterioscler Thromb Vasc Biol. 1998;18:1400-7.

86. Nakano T, Kawamoto K, Kishino J, Nomura K, Higashino K, Arita H. Requirement of gammacarboxyglutamic acid residues for the biological activity of Gas6: contribution of endogenous Gas6 to the proliferation of vascular smooth muscle cells. Biochem J. 1997;323:387-92.

87. Varnum BC, Young C, Elliott G, Garcia A, Bartley TD, Fridell YW, Hunt RW, Trail G, Clogston C, Toso RJ, et al. Axl receptor tyrosine kinase stimulated by the vitamin K-dependent protein encoded by growth-arrest-specific gene 6. Nature. 1995;373:623-6.

88. Li R, Chen J, Hammonds G, Phillips H, Armanini M, Wood P, Bunge R, Godowski PJ, Sliwkowski MX, Mather JP. Identification of Gas6 as a growth factor for human Schwann cells. J Neurosci. 1996;16:2012-9.

89. Lane PA, Hathaway WE. Vitamin K in infancy. J Pediatr. 1985;106:351-9.

90. Shearer MJ, Crampton OE, McCarthy PT, Mattock MB. Vitamin K1 in plasma: relationship to vitamin K status, age, pregnancy, diet, and disease. Haemostasis. 1986;16:83.

91. Greer FR, Marshall S, Cherry J, Suttie JW. Vitamin K status of lactating mothers, human milk, and breast-feeding infants. Pediatrics. 1991;88:751-6.

92. von Kries R, Shearer MJ, Gobel U. Vitamin K in infancy. Eur J Pediatr. 1988;147:106-12.

93. Moslet U, Hansen ES. A review of vitamin K, epilepsy and pregnancy. Acta Neurol Scand. 1992;85:39-43.

94. Cornelissen M, Steegers-Theunissen R, Kollee L, Eskes T, Vogels-Mentink G, Motohara K, De Abreu R, Monnens L. Increased incidence of neonatal vitamin $\mathrm{K}$ deficiency resulting from maternal anticonvulsant therapy. Am J Obstet Gynecol. 1993;168:923-8.

95. Brousson MA, Klein MC. Controversies surrounding the administration of vitamin $\mathrm{K}$ to newborns: a review [see comments]. Can Med Assoc J. 1996;154:307-15.

96. Golding J, Paterson M, Kinlen LJ. Factors associated with childhood cancer in a national cohort study. Br J Cancer. 1990;62:304-8.

97. Golding J, Greenwood R, Birmingham K, Mott M. Childhood cancer, intramuscular vitamin K, and pethidine given during labour [see comments]. BMJ. 1992;305:341-6.

98. Ekelund H, Finnstrom O, Gunnarskog J, Kallen B, Larsson Y. Administration of vitamin K to newborn infants and childhood cancer. BMJ. 1993;307:89-91.

99. Olsen JH, Hertz H, Blinkenberg K, Verder H. Vitamin K regimens and incidence of childhood cancer in Denmark [see comments]. BMJ. 1994;308:895-6.

100. Klebanoff MA, Read JS, Mills JL, Shiono PH. The risk of childhood cancer after neonatal exposure to vitamin K [see comments]. N Engl J Med. 1993;329:905-8.

101. Knapen MH, Eisenwiener HG, Vermeer C. Osteocalcin detection in aging serum and whole blood: stability of different osteocalcin fractions. Clin Chim Acta. 1996;256:151-64.

102. Chu K, Wu SM, Stanley T, Stafford DW, High KA. A mutation in the propeptide of Factor IX leads to warfarin sensitivity by a novel mechanism [see comments]. J Clin Invest. 1996;98:161925.

103. Houben RJ, Jin D, Stafford DW, Proost P, Ebberink RH, Vermeer C, Soute BA. Osteocalcin binds tightly to the gamma-glutamylcarboxylase at a site distinct from that of the other known vitamin K-dependent proteins. Biochem J. 1999;341:265-269.

104. Knapen MH, Jie KS, Hamulyak K, Vermeer C. Vitamin K-induced changes in markers for osteoblast activity and urinary calcium loss. Calcif Tissue Int. 1993;53:81-5.

105. Knapen MH, Hamulyak K, Vermeer C. The effect of vitamin K supplementation on circulating osteocalcin (bone Gla protein) and urinary calcium excretion. Ann Intern Med. 1989;111:1001-5.

106. Hart JP, Catterall A, Dodds RA, Klenerman L, Shearer MJ, Bitensky L, Chayen J. Circulating vitamin K1 levels in fractured neck of femur [letter]. Lancet. 1984;2:283.

107. Roberts NB, Holding JD, Walsh HP, Klenerman L, Helliwell T, King D, Shearer M. Serial 
changes in serum vitamin K1, triglyceride, cholesterol, osteocalcin and 25-hydroxyvitamin D3 in patients after hip replacement for fractured neck of femur or osteoarthritis. Eur J Clin Invest. 1996;26:24-9.

108. Hodges SJ, Bejui J, Leclercq M, Delmas PD. Detection and measurement of vitamins K1 and K2 in human cortical and trabecular bone. J Bone Miner Res. 1993;8:1005-8.

109. Szulc P, Arlot M, Chapuy MC, Duboeuf F, Meunier PJ, Delmas PD. Serum undercarboxylated osteocalcin correlates with hip bone mineral density in elderly women. $J$ Bone Miner Res. 1994;9:1591-5.

110. Szulc P, Chapuy MC, Meunier PJ, Delmas PD. Serum undercarboxylated osteocalcin is a marker of the risk of hip fracture in elderly women [see comments]. $J$ Clin Invest. 1993;91:1769-74.

111. Szulc P, Chapuy MC, Meunier PJ, Delmas PD. Serum undercarboxylated osteocalcin is a marker of the risk of hip fracture: a three year follow-up study [see comments]. Bone. 1996;18:487-8.

112. Knapen MH, Nieuwenhuijzen Kruseman AC, Wouters RS, Vermeer C. Correlation of serum osteocalcin fractions with bone mineral density in women during the first 10 years after menopause. Calcif Tissue Int. 1998;63:375-9.

113. Ross R. The pathogenesis of atherosclerosis: a perspective for the 1990s. Nature. 1993;362: 801-9.

114. Wexler L, Brundage B, Crouse J, Detrano R, Fuster V, Maddahi J, Rumberger J, Stanford W, White R, Taubert K. Coronary artery calcification: pathophysiology, epidemiology, imaging methods, and clinical implications. A statement for health professionals from the American Heart Association. Writing Group. Circulation. 1996;94:1175-92.

115. Mönckeberg JG. Uber die reine mediaverkalkung der extremitätenarterien und ihr verhalten zur arteriosklerose. Virchows Arch Pathol Anat. 1902;171:141-167.

116. Jeziorska M, McCollum C, Woolley DE. Mast cell distribution, activation, and phenotype in atherosclerotic lesions of human carotid arteries [published erratum appears in J Pathol 1997 Oct;183(2):248]. J Pathol. 1997;182:115-22.

117. Shanahan CM, Cary NR, Salisbury JR, Proudfoot D, Weissberg PL, Edmonds ME. Medial Localization of Mineralization-Regulating Proteins in Association With Monckeberg's Sclerosis: Evidence for Smooth Muscle Cell-Mediated Vascular Calcification. Circulation. 1999;100:2168-2176.

118. Levy RJ, Lian JB, Gallop P. Atherocalcin, a gamma-carboxyglutamic acid containing protein from atherosclerotic plaque. Biochem Biophys Res Commun. 1979;91:41-9.

119. Levy RJ, Gundberg C, Scheinman R. The identification of the vitamin K-dependent bone protein osteocalcin as one of the gamma-carboxyglutamic acid containing proteins present in calcified atherosclerotic plaque and mineralized heart valves. Atherosclerosis. 1983;46:49-56.

120. Shanahan CM, Cary NR, Metcalfe JC, Weissberg PL. High expression of genes for calcification-regulating proteins in human atherosclerotic plaques. J Clin Invest. 1994;93:23932402.

121. Jie KS, Bots ML, Vermeer C, Witteman JC, Grobbee DE. Vitamin K intake and osteocalcin levels in women with and without aortic atherosclerosis: a population-based study. Atherosclerosis. 1995;116:117-23.

122. Jie KG, Bots ML, Vermeer C, Witteman JC, Grobbee DE. Vitamin K status and bone mass in women with and without aortic atherosclerosis: a population-based study. Calcif Tissue Int. 1996;59:352-6.

123. Booth SL, Suttie JW. Dietary intake and adequacy of vitamin K. J Nutr. 1998;128:785-8.

124. Knapen MHJ, Jie K-G, Hamulyak K, Vermeer C. Vitamin K-deficiency redefined. Thromb 
haemostas. 1991;65:671.

125. Vermeer C, Hamulyak K. Pathophysiology of vitamin K-deficiency and oral anticoagulants. Thromb Haemost. 1991;66:153-9.

126. Pettifor JM, Benson R. Congenital malformations associated with the administration of oral anticoagulants during pregnancy. J Pediatr. 1975;86:459-62.

127. Howe AM, Webster WS. The warfarin embryopathy: a rat model showing maxillonasal hypoplasia and other skeletal disturbances. Teratology. 1992;46:379-90.

128. Pastoureau P, Vergnaud P, Meunier PJ, Delmas PD. Osteopenia and bone-remodeling abnormalities in warfarin-treated lambs. J Bone Miner Res. 1993;8:1417-26.

129. Price PA, Williamson MK, Haba T, Dell RB, Jee WS. Excessive mineralization with growth plate closure in rats on chronic warfarin treatment. Proc Natl Acad Sci U S A. 1982;79:7734-8.

130. Fiore CE, Tamburino C, Foti R, Grimaldi D. Reduced axial bone mineral content in patients taking an oral anticoagulant. South Med J. 1990;83:538-42.

131. Resch H, Pietschmann P, Krexner E, Willvonseder R. Decreased peripheral bone mineral content in patients under anticoagulant therapy with phenprocoumon. Eur Heart J. 1991;12:439-41.

132. Rosen HN, Maitland LA, Suttie JW, Manning WJ, Glynn RJ, Greenspan SL. Vitamin K and maintenance of skeletal integrity in adults. Am J Med. 1993;94:62-8.

133. Sato Y, Honda Y, Kunoh H, Oizumi K. Long-term oral anticoagulation reduces bone mass in patients with previous hemispheric infarction and nonrheumatic atrial fibrillation. Stroke. 1997;28:2390-4.

134. Chung KS, Bezeaud A, Goldsmith JC, McMillan CW, Menache D, Roberts HR. Congenital deficiency of blood clotting factors II, VII, IX, and X. Blood. 1979;53:776-87.

135. Pauli RM, Lian JB, Mosher DF, Suttie JW. Association of congenital deficiency of multiple vitamin K-dependent coagulation factors and the phenotype of the warfarin embryopathy: clues to the mechanism of teratogenicity of coumarin derivatives. Am J Hum Genet. 1987;41:566-83.

136. Wu SM, Cheung WF, Frazier D, Stafford DW. Cloning and expression of the cDNA for human gamma-glutamyl carboxylase. Science. 1991;254:1634-6.

137. Brenner B. Hereditary deficiency of vitamin K-dependent coagulation factors. Thromb Haemost. 2000;84:935-6.

138. Spronk HM, Farah RA, Buchanan GR, Vermeer C, Soute BA. Novel mutation in the gammaglutamyl carboxylase gene resulting in congenital combined deficiency of all vitamin $\mathrm{K}$ dependent blood coagulation factors. Blood. 2000;96:3650-3652.

139. Oldenburg J, Quenzel EM, Harbrecht U, Fregin A, Kress W, Muller CR, Hertfelder HJ, Schwaab R, Brackmann HH, Hanfland P. Missense mutations at ALA-10 in the factor IX propeptide: an insignificant variant in normal life but a decisive cause of bleeding during oral anticoagulant therapy [see comments]. Br J Haematol. 1997;98:240-4.

140. Bristol JA, Freedman SJ, Furie BC, Furie B. Profactor IX: the propeptide inhibits binding to membrane surfaces and activation by factor XIa. Biochemistry. 1994;33:14136-43.

141. Gaussem P, Gandrille S, Duchemin J, Emmerich J, Alhenc-Gelas M, Aillaud MF, Aiach M. Influence of six mutations of the protein $\mathrm{C}$ gene on the Gla domain conformation and calcium affinity. Thromb Haemost. 1994;71:748-54.

142. Millar DS, Grundy CB, Bignell P, Moffat EH, Martin R, Kakkar VV, Cooper DN. A Gla domain mutation (Arg 15-->Trp) in the protein C (PROC) gene causing type 2 protein $\mathrm{C}$ deficiency and recurrent venous thrombosis. Blood Coagul Fibrinolysis. 1993;4:345-7. 


2

MEASUREMENT OF PHYLLOQUINONE AND MENAQUINONES IN FOOD AND SERUM 



\title{
2.1
}

\section{DETERMINATION OF PHYLLOQUINONE AND MENAQUINONES IN FOOD. EFFECT OF FOOD MATRIX ON CIRCULATING VITAMIN K CONCENTRATIONS}

\begin{abstract}
Fluctuations in INR-values are often ascribed to dietary changes in vitamin $K$ intake. Here we present a database with vitamin $K_{1}$ and $K_{2}$ contents of a wide variety of food items. $K_{1}$ was mainly present in green vegetables and plant margarines, $K_{2}$ in meat, liver, butter, egg yolk, natto, cheese and curd cheese. To investigate the effect of the food matrix on vitamin K bioavailability, six healthy male volunteers consumed either a detergent solubilized $K_{1}(3.5 \mu$ moles $)$ or a meal consisting 400 grams of spinach $\left(3.5 \mu\right.$ moles $\left.K_{l}\right)$ and 200 grams of natto (3.1 $\mu$ moles $\left.K_{2}\right)$. The absorption of pure $K_{1}$ was faster than that of food-bound $K$ vitamins (serum peak values at 4 hours vs 6 hours after ingestion). Moreover, circulating $K_{2}$ concentrations after the consumption of natto were about 10 times higher than than those of $K_{1}$ after eating spinach. It is concluded that the contribution of $K_{2}$ vitamins (menaquinones) to the human vitamin $K$ status is presently underestimated, and that their potential interference with oral anticoagulant treatment needs to be investigated.
\end{abstract}

\section{Introduction}

Vitamin $\mathrm{K}$ is an essential dietary micro-nutrient that facilitates the synthesis of specific blood coagulation factors and of proteins involved in bone metabolism and vascular biology ${ }^{1,2}$. It serves as a cofactor for the membrane-bound microsomal enzyme $\gamma$ glutamylcarboxylase ${ }^{3}$. Dietary vitamin $\mathrm{K}$ is absorbed and transported in blood in its most stable form, i.e. as a quinone. Vitamin $\mathrm{K}$ occurs in two biologically active forms namely phylloquinone (also known as vitamin $\mathrm{K}_{1}$ ) and the menaquinones (known by their group name vitamin $\left.\mathrm{K}_{2}\right)^{2-4}$. All $\mathrm{K}$-vitamins have 2-methyl-1,4-naphthoquinone (also known as menadione) as a common ring structure, but differ from each other in the length and saturation degree of the polyisoprenoid side chain attached to the 3-position. Phylloquinone is produced by green plants, where it is tightly associated with the thylakoid membranes of the chloroplasts. It is a single compound containing 4 isoprenoid residues (one of which is unsaturated) in its aliphatic side chain. Menaquinones contain side chains of varying length; they are designated as MK-n where $\mathrm{n}$ denotes the number of isoprenoid residues, all of which are unsaturated. Long chain menaquinones (MK-7 through MK-10) are exclusively 
synthesized by bacteria ${ }^{5,6}$. Menadione is often added to fortified animal food and must be converted in the liver into MK-4 before being active as a cofactor for $\gamma$-glutamylcarboxylase ${ }^{7,8}$. In addition, a number of other tissues (notably pancreas, testis and vessel wall) are capable of converting phylloquinone into MK-4 ${ }^{9,10}$. For these reasons animal products (meat, dairy, and eggs) may contain relatively high concentrations of MK-4. It is well known that the bacterial flora in the colon produces large amounts of higher menaquinones (notably MK-10) ${ }^{11}$, but since absorption seems to be unlikely at the site of synthesis, the question of whether and to what extent the intestinal flora contributes to the human vitamin $\mathrm{K}$ status is still unclear.

Warfarin and other 4-hydroxycoumarin-derivatives are antagonists of vitamin Kaction and are effective antithrombotic agents (the so-called oral anticoagulants). They block the conversion of $\mathrm{KO}$ into $\mathrm{K}$ by inhibiting the enzyme KO-reductase, thus hampering the recycling of vitamin $\mathrm{K}^{12}$. Under these conditions there is a $1: 1$ stoichiometric relation between KO formation and the number of Gla-residues synthesized. The INR of some $25 \%$ of patients on oral anticoagulant treatment may be outside their therapeutic range. ${ }^{13}$. Besides interfering drugs, age, poor compliance, and concurrent diseases ${ }^{14-18}$, unstable levels of anticoagulation are often ascribed to dietary influences, mainly fluctuating vitamin $\mathrm{K}$-intake $19-23$

In absolute amounts $\mathrm{K}_{1}$ forms well over $80 \%$ of the total amount of vitamin $\mathrm{K}$ in the human diet, and most of our present knowledge on vitamin $\mathrm{K}$ concerns $\mathrm{K}_{1}$. It is known, however, that the absorption form green vegetables is poor and that only $10-15 \%$ of the vitamin is bioavailable, whereas for $\mathrm{K}_{2}$ vitamins this may be higher ${ }^{24,25}$. Here we present a data base on both dietary forms of vitamin $\mathrm{K}$, phylloquinone and the menaquinones in a wide range of foods available on the Dutch market. Since the specimens selected formed a representative sample from the common Dutch foods the data presented here can be used in nutritional studies in The Netherlands. Furthermore, we have compared the efficacy of absorption of phylloquinone and menaquinones as deduced from their serum profiles following oral ingestion.

\section{Materials and Methods}

\section{Materials}

Phylloquinone was obtained form Sigma (St. Louis, MO). The menaquinones (MK-4 through MK-10) and 2,3,-dihydrophylloquinone were kind gifts from Hoffmann La Roche (Basel, Switzerland). All common foods were obtained at local supermarkets. Konakion ${ }^{\circledR}$ (detergent-solubilized vitamin $\mathrm{K}_{1}$ pharmaceutical product) was obtained from Hoffmann La Roche. For the nutrition experiment we used creamed cooked spinach from Iglo Ola (Utrecht, 
Netherlands), and natto, which was bought as a ready-to-use product at a local oriental store. Silica Sep-pak cartridges were purchased from Millipore (Milford, MA, USA). All other chemicals used were of the highest analytical grade.

\section{Extraction of food}

The procedure for extraction and purification of vitamin $\mathrm{K}$ from beverages and dairy produce (except butter and cheese) was performed as described earlier ${ }^{25}$ using 2,3,dihydrophylloquinone as an internal standard. Vegetables were bought as pre-cooked deepfrozen products. Cooked vegetables and raw fruits were homogenized in a blender (Ultra Turrax; Janke \& Kunkel, Staufen, Germany), and processed as described for cooked spinach ${ }^{25}$. Aliquots of $1 \mathrm{~g}$ of cheese, butter, or margarine were extracted with $4 \mathrm{~mL}$ of 2-propanol, $20 \mathrm{ng}$ internal standard (MK-6 for margarine, 2,3-dihydrophylloquinone for other products) and 2 $\mathrm{mL}$ of distilled water. The mixture was homogenized with a blender, warmed to a temperature of $60{ }^{\circ} \mathrm{C}$ and extracted with $8 \mathrm{~mL}$ of hexane. Raw meat and fish were cut into pieces, $1 \mathrm{~g}$ of which was supplemented with $2 \mathrm{~mL}$ of distilled water, $5 \mathrm{ng}$ of internal standard (2,3,-dihydrophylloquinone), and $4 \mathrm{~mL}$ of ethanol. Homogenization took place with a blender at room temperature, and $8 \mathrm{~mL}$ of hexane were used for extraction. Bread was dried and ground to powder in a mortar, 1 gram aliquots were supplemented with $5 \mathrm{ng}$ internal standard (2,3,-dihydrophylloquinone) and $4 \mathrm{~mL}$ of ethanol. After homogenization in a blender extraction took place with $8 \mathrm{~mL}$ of hexane. In all cases, the hexane phase was evaporated and re-dissolved in two $\mathrm{mL}$ of hexane. After pre-purification over silica Sep-Pak cartridges the samples were ready measure on reversed-phase HPLC. All samples were measured in duplicate.

\section{Vitamin K detection}

Vitamin K was analysed by HPLC using a C-18 reversed phase column and fluorometric detection after post-column electro-chemical reduction as described previously ${ }^{25}$. Phylloquinone and the menaquinones were recorded in the same run. Because of the long retention times for the long-chain menaquinones the flow was increased from 0.5 to 1.0 $\mathrm{ml} / \mathrm{min}$ at 11 minutes after injection. The inter-day variation was $6-8 \%$.

\section{Human volunteer study}

A panel of 6 male volunteers took part in this protocol. Their mean age was 33.5 years, and their body mass index was $24.3 \mathrm{~kg} / \mathrm{m}^{2}$ (Table 1). All participants were apparently healthy, and their serum lipid profiles were in the normal range. Neither medications nor vitamin supplements (other than the experimental supplements) were taken. The experimental 
Table 1. Characteristics of the subjects

\begin{tabular}{lcc}
\hline & Mean & \\
\hline & & \\
Age (years) & 33.5 & 2.57 \\
Body mass index $(\mathrm{kg} / \mathrm{m} 2)$ & 24.3 & 0.82 \\
Triacylglycerol (mmol/L) & 0.87 & 0.14 \\
Cholesterol (mmol/L) & 3.96 & 0.28 \\
Phylloquinone (nmol/L) & 1.48 & 0.19 \\
Menaquinones (nmol/L) & n.d. \\
\hline
\end{tabular}

Mean values \pm SEM of six healthy male volunteers. n.d. stands for not detectable

protocol started at 8 am after an overnight fast. At that time the participants received a breakfast containing a diet low in vitamin $\mathrm{K}$, a similar diet with additional detergentsolubilized phylloquinone, or a diet containing $400 \mathrm{~g}$ of spinach and $200 \mathrm{~g}$ of natto. All diets contained $30 \mathrm{~g}$ of fat. During the rest of the day participants were only allowed to have a lunch low in vitamin $\mathrm{K}$ (toast, marmalade, bananas, apples), and to drink orange juice and water ad libitum. After $6 \mathrm{pm}$ and during the rest of the experiment only consumption of vitamin K-rich foods (spinach, broccoli, Brussels sprouts, kale, natto, and cheese) was prohibited. Blood samples were drawn by venipunctures at $0,1,2,3,4,5,6,7,8,10,11,24$, 48 , and $72 \mathrm{~h}$ after start. Serum was prepared and $1 \mathrm{~mL}$ aliquots were kept frozen at $-80{ }^{\circ} \mathrm{C}$ until vitamin $\mathrm{K}$ determination. The study design was approved by the local Medical Ethics Committee, and informed consent was obtained from all subjects according to the institutional guidelines.

\section{Data analysis}

Serum vitamin $\mathrm{K}$ concentrations during $72 \mathrm{~h}$ after oral ingestion were recorded at indicated intervals. At each time point mean values $\pm \mathrm{SE}$ for the six participants were calculated and plotted as a function of time. Blank values (no vitamin $\mathrm{K}$ ingested) were subtracted throughout the study.

\section{Results}

Vitamin K content of various nutrients

For the determination of dietary phylloquinone and menaquinones we have subdivided common foods in six categories: meat, fish, vegetables \& fruits, dairy, oils \& margarines, bread, and beverages. At least three to six different samples or brands were obtained in various local supermarkets, and mean values for each product are given in Table 2, together with their ranges (lowest and highest value between brackets) for each product. High amounts of $\mathrm{K}_{1}$ were found in green leafy vegetables, broccoli, sauerkraut and margarines based on plant oils. Meat, fish, dairy produce and eggs contained both $\mathrm{K}_{1}$ and 34 | 
MK-4 with relatively high MK-4 concentrations in goose meat and liver, butter, and egg yolk. Long-chain menaquinones were mainly found in curd cheese, hard (Dutch) and soft (French) cheeses, probably derived from the bacterial starters fermentation. Very rich in menaquinones was the Japanese food natto, which consists of fermented soy beans. No substantial differences were found between free-range products (eggs, chicken, and meat) and those from factory farms. The fact that fermented beverages like beer and wines did not contain detectable amounts of menaquinones is probably due to the fact that moulds do not synthesise menaquinones ${ }^{26}$.

\section{Bioavailability of $K$-vitamers from food}

To examine the blank values (serum vitamin $\mathrm{K}$ at low vitamin $\mathrm{K}$ intake) 6 male volunteers received a vitamin K-poor breakfast with blood sampling (up to $72 \mathrm{~h}$ ) as indicated. These blank values (data not shown) were subtracted from those obtained after controlled vitamin $\mathrm{K}$ intake. Based on the analyses summarized in Table 2 we have prepared meals consisting of $400 \mathrm{~g}$ cooked spinach (equivalent to $3.5 \mu$ moles of $\left.\mathrm{K}_{1}\right), 200 \mathrm{~g}$ natto $(3.1 \mu$ moles of MK-7), supplemented with corn oil to a total fat content of $30 \mathrm{~g}$. Postprandial serum vitamin $\mathrm{K}$ concentrations are given in Figure 1. One week later the volunteers received a vitamin K-poor breakfast supplemented with $3.5 \mu$ moles of Konakion ${ }^{\circledR}$. Peak values for serum vitamin $\mathrm{K}$ (both $\mathrm{K}_{1}$ and MK-7) were found at $6 \mathrm{~h}$ following the meal and at $4 \mathrm{~h}$ after intake of the pure compound. The very poor absorption from green vegetables becomes clear by comparing the difference between the curves for $\mathrm{K}_{1}$ pure compound and the similar amount of $\mathrm{K}_{1}$ from spinach. Remarkably, MK-7 from natto was absorbed extremely well with peak values even higher than those for detergent-solubilized $\mathrm{K}_{1}$. After having reached their peak levels a rapid disappearance of both $\mathrm{K}_{1}$ and MK-7 was observed, but MK-7 showed complex pharmacokinetics, with slow disappearance during the second part of the curve, while it remained detectable for at least $72 \mathrm{~h}$. The half-life times for both $\mathrm{K}_{1}$ and MK-7 between 6 and $8 \mathrm{~h}$ postprandially were about $1.5 \mathrm{~h}$, whereas during the later phases of MK-7 disappearance the half-life time was about $50 \mathrm{~h}$. To exclude mutual interference of absorption (e.g. by competition for the same binding protein), the above experiment was repeated in a design in which spinach and natto were given in two separate meals with a one-week interval. The serum curves are shown in Figure 2 and are comparable to those obtained after the combined meal. The above absorption curves were repeated for other foods: broccoli as source for $\mathrm{K}_{1}$ and curd cheese and egg yolk as sources for higher menaquinones (MK-8 and MK-9) and MK-4, respectively (L.J. Schurgers, unpublished data). In all cases it was found that $\mathrm{K}_{1}$ absorption from vegetables was very poor $(5-10 \%$ without concomitant fat intake and 10 $15 \%$ if taken together with $30 \mathrm{~g}$ fat), whereas menaquinone absorption from dairy produce and natto was much better, probably almost complete. 


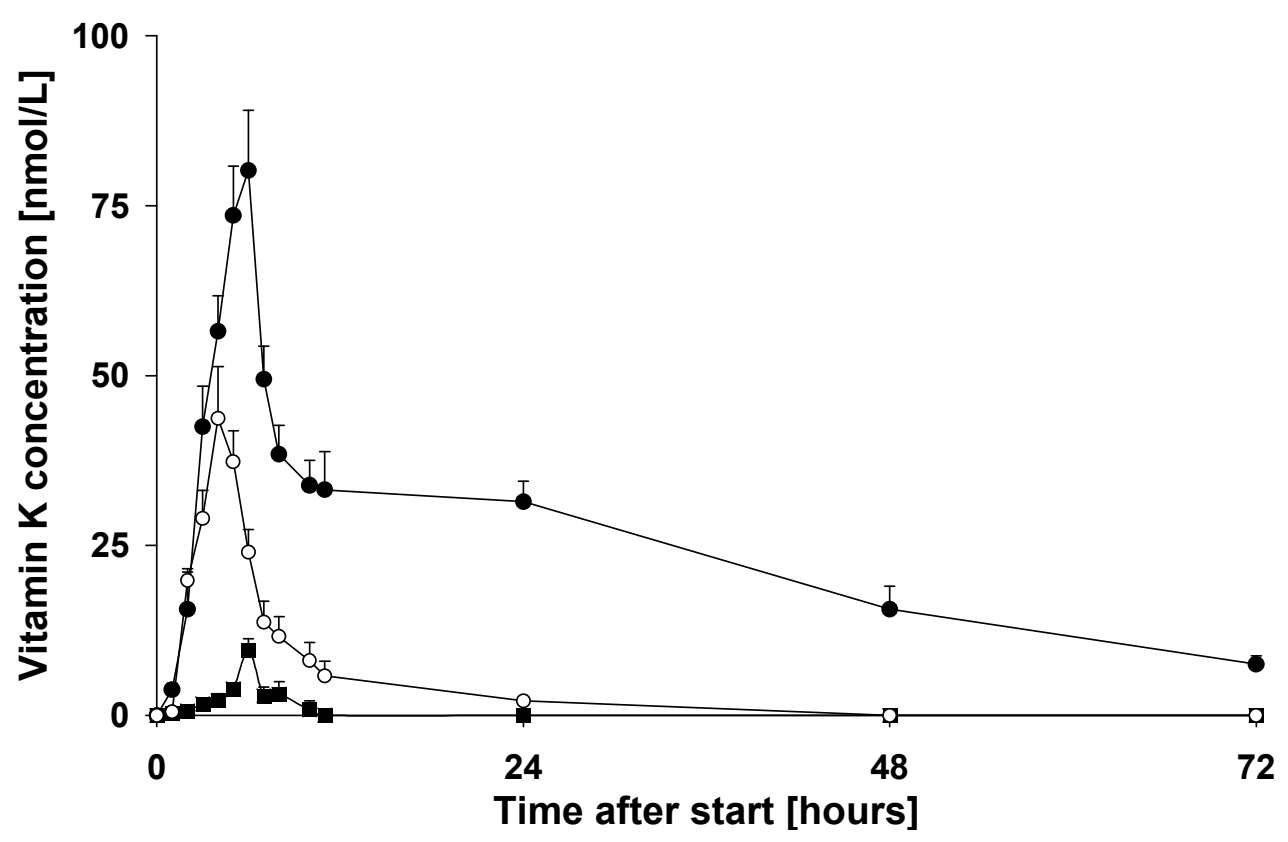

Figure 1.

Serum vitamin $\mathrm{K}$ following the oral intake of either Konakion ${ }^{\circledR}$ or a meal containing spinach and natto. The ingested Konakion contained $3.5 \mu \mathrm{M} \mathrm{K}$, the mixed meal contained $3.5 \mu \mathrm{M}$ of $\mathrm{K}_{1}$ and 3.1 $\mu \mathrm{M}$ of MK-7. Points are mean values from 6 volunteers, error bars represent SEM. Symbols: $\mathrm{O}, \mathrm{K}_{1}$ after Konakion $^{\circledR} ; \mathbf{\square}, \mathrm{K}_{1}$ after mixed meal; $\bullet$, MK-7 after mixed meal.

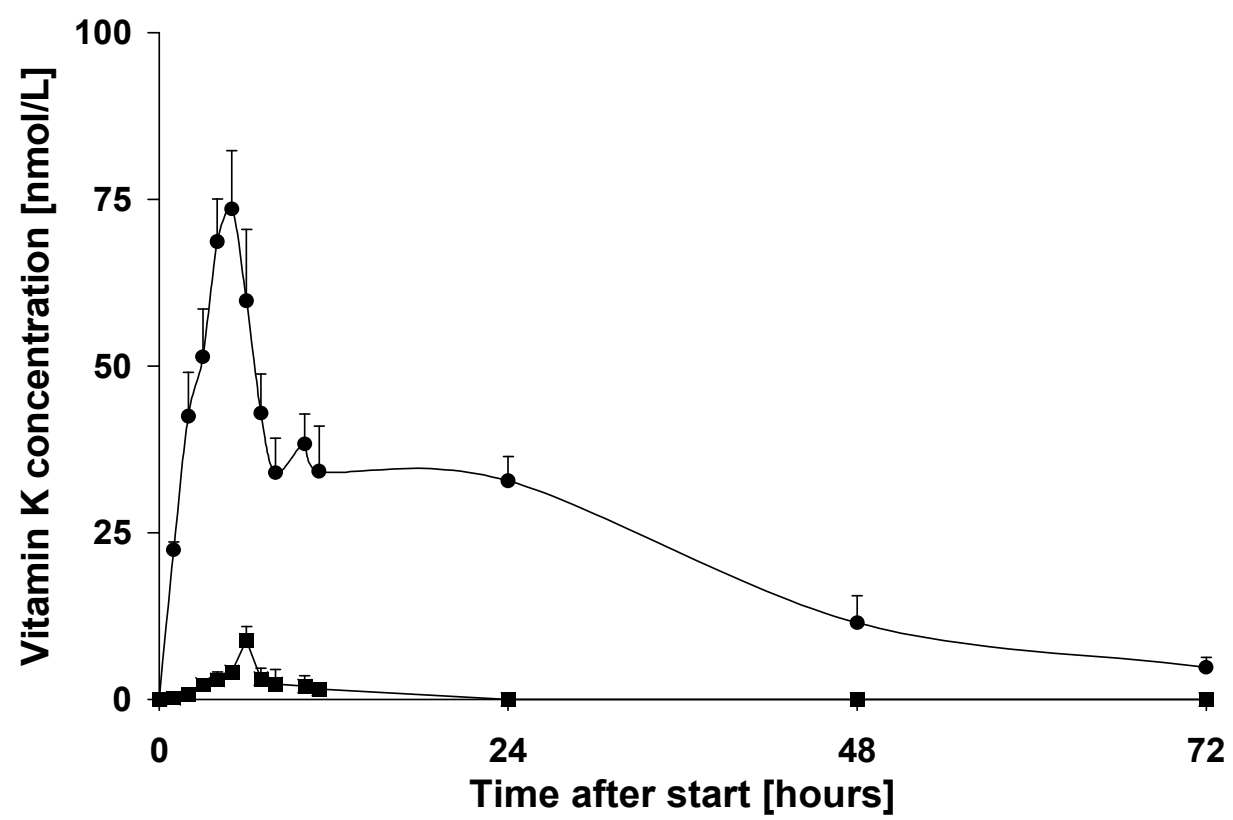

Figure 2.

Serum vitamin $K_{1}$ and MK-7 following the separate intake of either spinach (3.5 $\mu \mathrm{M} \mathrm{K}$ ) or natto (3.1 $\mu \mathrm{M}$ MK-7). Points are mean values from 6 volunteers, error bars represent SEM. Symbols: $\mathbf{\square}, \mathrm{K}_{1}$; $\mathrm{MK}-7$. 
Table 2. Mean of K-vitamins $(\mu \mathrm{g} / 100 \mathrm{~g}$ or $\mu \mathrm{g} / 100 \mathrm{ml})$ in various foods

\begin{tabular}{|c|c|c|c|c|c|c|c|c|}
\hline Type of food & $n$ & K1 & MK-4 & MK-5 & MK-6 & MK-7 & MK-8 & MK-9 \\
\hline \multicolumn{9}{|l|}{ Meat } \\
\hline Beef & 7 & $0.6[0.6-0.7]$ & $1.1[0.7-1.3]$ & - & - & - & - & - \\
\hline Chicken breast & 7 & - & 8.9 [ $6.4-11.3]$ & - & - & - & - & - \\
\hline Chicken leg & 7 & - & $8.5[5.8-10.5]$ & - & - & - & - & - \\
\hline Pork-steak & 7 & $0.3[0.2-0.4]$ & $2.1[1.7-2.4]$ & - & - & - & - & - \\
\hline Pork liver & 7 & $0.2[0.1-0.3]$ & $0.3[0.3-0.4]$ & - & - & $0.5[0.4-0.7]$ & $1.1[0.9-1.2]$ & - \\
\hline Minced meat & 7 & $2.4[2.2-2.5]$ & $6.7[6.5-6.7]$ & - & - & - & - & - \\
\hline Salami & 7 & $2.3[2.1-2.5]$ & $9.0[8.2-10.1]$ & - & - & - & - & - \\
\hline Luncheon meat & 7 & $3.9[3.8-4.2]$ & $7.7[7.4-9.1]$ & - & - & - & - & - \\
\hline Hare leg & 7 & $4.8[4.5-5.3]$ & $0.1[0.0-0.2]$ & - & - & - & - & - \\
\hline Deer back & 7 & $2.0[1.9-2.2]$ & $0.7[0.6-0.7]$ & - & - & - & - & - \\
\hline Goose leg & 5 & $4.1[3.5-4.8]$ & $31.0[28.2-33.1]$ & - & - & - & - & - \\
\hline Goose liver paste & 5 & $10.9[9.3-12.1]$ & $369[317-419]$ & - & - & - & - & - \\
\hline Duck breast & 7 & $1.9[1.7-2.2]$ & $3.6[3.3-3.9]$ & - & - & - & - & - \\
\hline \multicolumn{9}{|l|}{ Fish } \\
\hline Prawn & 7 & $0.1[0.0-0.1]$ & - & - & - & - & - & - \\
\hline Mackerel & 7 & $2.2[1.8-2.6]$ & $0.4[0.3-0.5]$ & - & - & - & - & - \\
\hline Herring & 7 & $0.1[0.0-0.2]$ & - & - & - & - & - & - \\
\hline Plaice & 7 & - & $0.2[0.1-0.3]$ & - & $0.3[0.2-0.3]$ & $0.1[0.0-0.1]$ & $1.6[1.3-1.8]$ & - \\
\hline Eel & 7 & $0.3[0.2-0.5]$ & $1.7[1.4-2.1]$ & - & $0.1[0.0-0.2]$ & $0.4[0.2-0.6]$ & - & - \\
\hline Salmon & 7 & $0.1[0.1-0.2]$ & $0.5\left[\begin{array}{ll}0.4-0.6\end{array}\right]$ & - & - & - & - & - \\
\hline \multicolumn{9}{|l|}{ Fruits \& vegetables } \\
\hline Kale & 4 & $817[752-881]$ & - & - & - & - & - & - \\
\hline Spinach & 6 & $387\left[\begin{array}{ll}299 & -429]\end{array}\right.$ & - & - & - & - & - & - \\
\hline Broccoli & 5 & $156[139-189]$ & - & - & - & - & - & - \\
\hline Green peas & 4 & $36.0[31.2-39.4]$ & - & - & - & - & - & - \\
\hline Sauerkraut & 7 & $25.1[23.8$ - 27.5] & $0.4[0.3-0.5]$ & $0.8[0.6-1.0]$ & $1.5[1.4-1.6]$ & $0.2[0.1-0.3]$ & $0.8[0.6-0.9]$ & $1.1[0.9-1.3]$ \\
\hline Natto & 5 & $34.7[31.2-36.7]$ & - & $7.5[7.1-7.8]$ & $13.8[12.7-14.8]$ & 998 [882-1034] & $84.1[78.3-89.8]$ & - \\
\hline Banana & 4 & $0.3[0.2-0.4]$ & - & - & - & - & - & - \\
\hline Apple & 4 & $3.0[2.7-3.4]$ & - & - & - & - & - & - \\
\hline Orange & 4 & $0.1\left[\begin{array}{lll}0.1 & -0.2\end{array}\right]$ & - & - & - & - & - & - \\
\hline \multicolumn{9}{|l|}{ Dairy produce } \\
\hline Whole milk & 6 & $0.5[0.4-0.6]$ & $0.8[0.7-0.9]$ & $0.1[0.0-0.1]$ & - & - & - & - \\
\hline Skimmed milk & 6 & - & - & - & - & - & - & - \\
\hline Buttermilk & 6 & - & $0.2[0.2-0.3]$ & $0.1[0.1-0.2]$ & $0.1[0.0-0.2]$ & $0.1[0.1-0.3]$ & $0.6[0.5-0.6]$ & $1.4[1.2-1.6]$ \\
\hline Whole yoghurt & 6 & $0.4[0.3-0.5]$ & $0.6[0.5-0.7]$ & $0.1[0.0-0.2]$ & - & - & $0.2[0.2-0.3]$ & - \\
\hline Skimmed yoghurt & 6 & - & - & - & - & - & $0.1[0.0-0.2]$ & - \\
\hline Whipping cream & 6 & $5.1[4.9-5.5]$ & $5.4[5.2-5.6]$ & - & - & - & - & - \\
\hline Chocolate & 6 & $6.6[6.4-6.7]$ & $1.5[1.4-1.6]$ & - & - & - & - & - \\
\hline Hard cheeses & 15 & $10.4[9.4-12.1]$ & $4.7[4.2-6.6]$ & $1.5[1.3-1.7]$ & $0.8[0.6-1.0]$ & $1.3[1.1-1.5]$ & 16.9 [14.9-18.2] & 51.1 [45.3-54.9] \\
\hline Soft cheeses & 15 & $2.6[2.4-2.9]$ & $3.7[3.3-3.9]$ & $0.3[0.2-0.4]$ & $0.5[0.6-0.7]$ & $1.0[0.9-1.1]$ & $11.4[10.7-12.2]$ & $39.6[35.1-42.7]$ \\
\hline Curd cheese & 12 & $0.3[0.2-0.4]$ & $0.4[0.3-0.6]$ & $0.1[0.0-0.2]$ & $0.2[0.1-0.3]$ & $0.3[0.2-0.5]$ & $5.1[4.8-5.4]$ & $18.7\left[\begin{array}{lll}18.1 & 19.2]\end{array}\right]$ \\
\hline Egg yolk & 8 & $2.1[1.9-2.3]$ & 31.4 [29.1 - 33.5] & - & $0.7[0.6-0.8]$ & - & - & - \\
\hline Egg albumen & 8 & - & $0.9[0.8-1.0]$ & - & - & - & - & - \\
\hline \multicolumn{9}{|l|}{ Oils and margarines } \\
\hline Margarine & 6 & 93.2 [85.6 - 98.3] & - & - & - & - & - & \\
\hline Butter & 6 & $14.9[13.2-15.9]$ & $15.0[13.5-15.9]$ & - & - & - & & - \\
\hline Corn oil & 6 & $2.9[2.7-3.1]$ & - & - & - & - & - & \\
\hline Sunflower oil & 6 & $5.7[5.5-5.9]$ & - & - & - & - & - & \\
\hline Olive oil & 6 & $53.7[49.9-57.2]$ & - & - & - & - & - & \\
\hline \multicolumn{9}{|l|}{ Bread } \\
\hline Rue bread & 6 & $0.7[0.5-0.9]$ & - & - & - & - & - & \\
\hline Wheaten bread & 6 & $1.1[1.0-1.2]$ & - & - & - & - & - & \\
\hline Sourdough bread & 6 & $1.0[0.9-1.1]$ & - & - & - & - & & - \\
\hline Buckwheat bread & 6 & $3.0[2.8-3.4]$ & - & - & - & - & & $1.1[1.0-1.2]$ \\
\hline \multicolumn{9}{|l|}{ Beverages } \\
\hline Tea & 4 & $0.3[0.2-0.4]$ & - & - & - & - & - & - \\
\hline Coffee & 4 & - & - & - & - & - & - & - \\
\hline Orange juice & 4 & - & - & - & - & - & - & - \\
\hline
\end{tabular}

All samples were assessed in duplicate, $\mathrm{n}$ stands for the number of different samples tested, a hyphen for not detectable. Values are mean values. Highest and lowest value between brackets. Foods were bought from shops around Maastricht. MK-10 was not detectable in any of the foods. 


\section{Discussion}

In this paper we describe the phylloquinone and menaquinone content of various foods available on the Dutch market. All K-vitamins were quantified in the same run after a slight modification of our previously reported procedure ${ }^{25}$. It was confirmed that phylloquinone is mainly present in green vegetables, margarines, and some plant oils such as olive oil. Since these data are similar to those reported by others ${ }^{27-29}$ we have focussed on the menaquinones in food. MK-4 was present in nearly all animal products (meat, dairy produce, eggs), but the fact that there were no substantial differences between game (hare, deer), freerange animals and those from factory farms suggests that conversion of menadione from fortified animal food (used at factory farms) does not contribute substantially to the total tissue MK-4 stores. Rather, it seems that the major part of MK-4 in animal products originates from conversion of $\mathrm{K}_{1}$ as was also reported to occur in rats ${ }^{30}$. Relatively high concentrations of long-chain menaquinones were found in all cheeses. As was suggested by Shearer, they probably originate from bacteria present in the starter cultures used to induce fermentation ${ }^{26}$. On the basis of food frequency questionnaires and the data in Table 2 it has been calculated that phylloquinone forms almost $90 \%$ of the total dietary vitamin $\mathrm{K}$ intake in the Dutch population, whereas menaquinones account for less than $12 \%{ }^{6}$. Phylloquinone, however, is tightly bound to the thylakoid membranes of plant chloroplasts, and the efficacy of its liberation there from in the digestive tract is poor ${ }^{24,25}$. This was confirmed in an experiment in which we compared the serum concentration vitamin $\mathrm{K}$ profiles after ingestion of similar amounts of $\mathrm{K}_{1}$ from spinach and from a detergent-solubilized pharmaceutical product. To compare the efficacy of absorption of phylloquinone and menaquinone we have chosen a design in which $\mathrm{K}_{1}$ was obtained from spinach and MK-7 from natto. In this way the molar concentrations of both K-vitamers could be kept similar. As is shown in Figure 1, the postprandial serum concentrations of MK-7 were much higher than those of $\mathrm{K}_{1}$, with a peak height difference of more than 10 fold. Both absorption peaks occurred $2 \mathrm{~h}$ later than that for the detergent-solubilized product. From the curves obtained, it may be concluded that the contribution of MK-7 from natto to the total bioavailable pool of vitamin $\mathrm{K}$ is much higher than estimated on the basis of intake. Menaquinones from other sources (cheeses, egg yolk) were absorbed with comparable efficacy as was MK-7 (L.J. Schurgers, unpublished data), suggesting that the contribution of menaquinones to total human vitamin $\mathrm{K}$ status is much higher than generally assumed, and may equal that of $\mathrm{K}_{1}$.

Another remarkable difference between $\mathrm{K}_{1}$ and menaquinones was that the former had a disappearance curve with an apparent half-life time of $1 \frac{1}{2} \mathrm{~h}$, whereas the long chain menaquinones (not MK-4) had more complex disappearance curves, with very long half-life time. Rapid clearance is consistent with the previously reported uptake and transport of Kvitamins in chylomicrons, from where they are cleared by the liver during the first 8 
postprandial hours. The very long half-life times of the higher menaquinones suggests that these vitamers (and not $\mathrm{K}_{1}$ and $\mathrm{MK}-4$ ) are redistributed by the liver and set free in the circulation in low and high density lipoproteins. It is well known that LDL may be present in the circulation for several days. The long residence times of higher menaquinones in the circulation implies that they are available for extra-hepatic tissue uptake for much longer periods than is phylloquinone. Both because of their high postprandial serum concentration and their slow clearance, the importance of higher menaquinones for extra-hepatic tissues such as bone and arterial vessel wall may be underestimated if only dietary intake is regarded. Since vitamin K-dependent proteins have been reported to be involved in the regulation of calcium deposition in bone ${ }^{31}$ and in the prevention of arterial calcification ${ }^{32}$, intake of higher menaquinones may be important for functions of vitamin $\mathrm{K}$ not related with blood coagulation.

The high efficacy of menaquinone absorption may also have consequences for subjects on oral anticoagulant treatment. In attempts to identify potential causes of unstable anticoagulation, menaquinone intake has been ignored thus far. Our data demonstrate that this is not justified. Their efficient absorption combined with long serum and tissue half life times ${ }^{33}$ suggest that menaquinones from curd and cheese may accumulate at repeated intake and are a potential cause of disturbance of anticoagulant therapy. This is even more so for subjects consuming natto. Although in general natto is rarely eaten by Caucasians, dietary habits may survive after migration of subjects from Asiatic countries so that haematologists in Western countries may be confronted with this unsuspected source of highly bio-available vitamin K. 



\title{
INTESTINAL, HEPATIC, AND CIRCULATING VITAMIN K AT LOW AND HIGH INTAKE OF VITAMIN K IN RATS
}

\begin{abstract}
The aim of this study was to assess how high doses of dietary vitamin $K$ influence the intestinal profile of $K$-vitamins in vitamin $K$-deficient rats, and whether the induced changes are reflected in the hepatic vitamin $K$ store. Vitamin $K$-deficient rats were fed for 10 days with diets containing different forms of vitamin $K$, and analyses carried out to see how these diets influenced the vitamin $K$ concentration at various sites of the intestine, serum, and the liver. It was found that the absorption of phylloquinone from standard food is not more than $10 \%$, whereas the absorption of pharmacological doses of oil-solubilized phylloquinone and menaquinone-4 was 18 and 55\%, respectively. High intakes of phylloquinone suppress the colonic production of all higher menaquinones. High menaquinone-4 intake induces very high menaquinone-8 concentrations, both in the colonic contents as well as in the liver. These data suggest that menaquinone-4 may be converted into menaquinone-8 (but not into other menaquinones) via a metabolic pathway which has not been reported previously.
\end{abstract}

\section{Introduction}

Vitamin $\mathrm{K}$ serves as a cofactor during the posttranslational synthesis of $\gamma$ carboxyglutamic acid (Gla) in several proteins. Since its discovery in the early 1930's, vitamin $\mathrm{K}$ was believed to play an exclusive role in the process of blood coagulation; only recently it has become clear that Gla-containing proteins are synthesized in most mammalian tissues, and that the functions of these proteins include regulation of bone growth (osteocalcin ${ }^{34}$ ), prevention of vascular mineralization (matrix Gla-protein ${ }^{32}$ ), and stimulation of cell growth (growth-arrest-specific gene protein 6 , Gas6 ${ }^{35}$ ). Natural forms of vitamin $\mathrm{K}$ are phylloquinone (also known as vitamin $\mathrm{K}_{1}$ ) and the group of the menaquinones $\left(\mathrm{K}_{2}\right.$ vitamins) ${ }^{2}$. Phylloquinone is synthesized by plants and the highest levels are found in plant oils and green vegetables ${ }^{36-38}$. Menaquinones are of microbial origin: they are found mainly in cheese and fermented foods ${ }^{6,39}$. Also the intestinal microflora produces substantial amounts of menaquinones, but the extent to which these products are absorbed has remained a matter of debate $^{40}$. In this paper the various menaquinones will be designated as MK-n, where n stands for the number of isoprenoid residues in the aliphatic side chain. Menadione (vitamin $\mathrm{K}_{3}$ ) is a 
synthetic form of vitamin $\mathrm{K}$ which is generally used in commercial animal food (rodents, poultry, and cows). Its vitamin $\mathrm{K}$ activity results from its in vivo transformation into menaquinone $-4^{8}$.

The vitamin $\mathrm{K}$ status of an organism depends on the phylloquinone and menaquinone contents of its diet, on the extent to which these vitamins are absorbed in the intestines, as well as on the colonic absorption of menaquinones produced by intestinal microflora. It is generally assumed that absorption of vitamin $\mathrm{K}$ mainly takes place in the jejunum and ileum in the form of mixed micelle complexes with bile salts ${ }^{41}$. Since the absorption of bile salts is virtually completed in the distal ileum, uptake of K-vitamins from the colon is less likely ${ }^{40,42,43}$.

In the present study we have fed vitamin K-deficient rats for 10 days with either standard diets or with diets containing pharmacological doses of oil-solubilized, purified vitamin $\mathrm{K}$ and we have investigated how the vitamin $\mathrm{K}$ content of the diet affects the vitamin $\mathrm{K}$ concentration at various sites in the intestine and in the faeces. Moreover, we have investigated the uptake and metabolism of K-vitamers by recording their respective concentrations in plasma and in the liver.

\section{Materials and Methods}

\section{Chemicals and animal food}

MK-4 and phylloquinone were purchased from Sigma (St. Louis, MO, USA), a set of higher menaquinones (MK-5 through MK-10) as well as 2',3'-dihydrophylloquinone were kind gifts from Hoffmann-La Roche (Basel, Switzerland). Powdered vitamin K-deficient, $\gamma$ irradiated $(0.9 \mathrm{Mrad})$ food and standard animal food were purchased from Hope Farms (Woerden, The Netherlands), the detailed food contents have been described previously ${ }^{44}$. Upon analysis, the vitamin K-deficient food did not contain detectable amounts of either phylloquinone or menaquinone $(<20 \mathrm{pg} / \mathrm{g}$ of diet $)$, the standard food contained phylloquinone $(1.95 \mu \mathrm{g} / \mathrm{g}$ of diet) and menadione $(6.23 \mu \mathrm{g} / \mathrm{g}$ of diet). All solvents and chemicals were of analytical quality or HPLC grade purity.

\section{Animals and preparation of diets}

This study was performed in 15 male rats of Lewis strain, which were 12 weeks old and had a body weight of $303 \pm 49.7 \mathrm{~g}$ (mean $\pm \mathrm{SD}$ ) at the start of the experiment. The animals were housed individually in flat bottom cages under conditions of a 12-h light-dark cycle, controlled temperature $\left(20 \pm 2{ }^{\circ} \mathrm{C}\right)$ and humidity $(50 \pm 10 \%)$. One group of three animals was kept on standard food throughout the experiment and served as the normal 
reference group. The remaining 12 animals were divided into 4 groups ( 3 rats/group), all of which received the vitamin K-deficient diet for 7 days before the start of the experiment. After that period three groups of three rats received vitamin K-deficient food supplemented with $20 \mu \mathrm{g} / \mathrm{g}$ of phylloquinone, MK-4, or menadione. The last group served as the zero-intake reference and received vitamin K-deficient food throughout the experiment. The various diets were prepared by dissolving the respective vitamins in $10 \mathrm{ml}$ of corn oil, which was added to $750 \mathrm{~g}$ of vitamin K-deficient food; the same amount of corn oil (without vitamin $\mathrm{K}$ added) was supplemented to the food of animals receiving either the standard food or the vitamin Kdeficient food. Faeces of the rats were collected on each day of the experiment and lyophilized before analysis. After the animals had received these diets for 10 days, they were killed by aortic exsanguinations under light ether anaesthesia. Blood was collected, diluted 9:1 (v/v) with $0.1 \mathrm{M}$ trisodium citrate and centrifuged for $15 \mathrm{~min}(2,000 \mathrm{x} \mathrm{g})$ for the preparation of plasma. The body was perfused with saline via the abdominal aorta, and the liver and intestine was removed for further analysis.

\section{Vitamin K analysis}

The spectra of K-vitamers (phylloquinone and menaquinones 4-10) were analysed in 9 parts of the intestinal tract, faeces, livers and plasma. In all cases the intestines were similarly divided as follows: duodenum in total (segment 1), first $10 \mathrm{~cm}$ of jejunum (segment 2), middle part of jejunum and ileum in three equal parts (segments 3, 4, and 5), last $10 \mathrm{~cm}$ of ileum (segment 6), caecum in total (segment 7), and colon in two equal parts (segments 8 and 9). The content of each part was collected with careful rinsing of the lumen and freeze-dried; dry intestinal contents were weighted and $0.1 \mathrm{~g}$ was used for analysis. Faecal vitamin $\mathrm{K}$ contents were analysed in $0.2 \mathrm{~g}$ (dry weight) of samples collected at days 5, 7, and 9 of the experiment. In plasma, only the data for phylloquinone and MK-4 are provided. Hepatic and circulating vitamin $\mathrm{K}$ were measured in $1 \mathrm{~g}$ of liver (wet weight) and in $0.5 \mathrm{~mL}$ of plasma. Extraction and detection of vitamin $\mathrm{K}$ were performed as described earlier ${ }^{25,45}$, 2', 3'dihydrophylloquinone served as an internal standard. In short, samples were supplemented with $2.0 \mathrm{~mL}$ of distilled water (for plasma $1.5 \mathrm{~mL}$ ), $4 \mathrm{~mL}$ of ethanol and internal standard (1$40 \mathrm{ng}$, as required) and extracted with $8 \mathrm{~mL}$ of hexane. Liver and faeces were homogenized using an Ultra Turrax homogenizer (Janke and Kunkel, Staufen, Germany) prior to extraction. Extracts were centrifuged (2,000 g for 5 minutes), evaporated under a stream of nitrogen gas, and re-dissolved in $2 \mathrm{~mL}$ hexane. Pre-purification of the samples was performed with silica Sep-pack cartridges (Millipore, Milford, MA, USA) as described previously ${ }^{25}$. Quantitative analysis of the samples was performed by reversed-phase HPLC using a C-18 reversed phase column and fluorescence detection ${ }^{45}$. Because of the long retention times for the long-chain menaquinones (MK-7 through MK-10) the flow was increased from 0.5 to 1.0 
$\mathrm{ml} / \mathrm{min}$ at $11 \mathrm{~min}$ after injection. K-vitamers in the eluate were reduced electrochemically using a Coulochem 5010 analytical cell (ESA, Bedford, MA, USA) maintained at potential of $-1.5 \mathrm{~V}$. Phylloquinone and menaquinones were recorded in the same run. Reference curves were prepared from purified phylloquinone and each of the menaquinones, and a linear doseresponse was obtained for the entire range in which the sample concentrations were measured. The vitamin $\mathrm{K}$ content of the samples was quantified with the internal standard method based on the ratio of peak heights. Detection limits were $0.015 \mathrm{ng} / \mathrm{ml}$ for phylloquinone, MK-4 and MK-5, $0.04 \mathrm{ng} / \mathrm{mL}$ for MK-6 and MK-7, $0.10 \mathrm{ng} / \mathrm{mL}$ for MK-8, and $0.12 \mathrm{ng} / \mathrm{mL}$ for MK-9 and MK-10. Intestinal absorption was calculated by expressing the difference between dietary intake and faecal excretion as a percentage of the intake for each animal separately.

\section{Data analysis}

All groups consisted of three animals, and mean values for each group are given throughout this paper. Differences between groups were compared using the Mann-Whitney U-test, and were regarded to be significant at $\mathrm{p}=0.05$.

\section{Results}

\section{Intestinal absorption of nutritional vitamin $\mathrm{K}$}

In the experiments described in this paper the experimental animals had been on a constant diet for 10 days before their intestinal contents were analysed. During the entire experiment the individual daily food intake was recorded, and was found to be $19.0 \pm 1.9 \mathrm{~g}$ (average for all groups). The average faeces production was $3.2 \pm 1.3 \mathrm{~g}$ (wet weight), and the weight gain was comparable in all groups. To demonstrate that the animals were in a steady state condition at the time of sacrifice, we have assessed the amounts of K-vitamins in the faeces at days 5, 7, and 9 (see Table 1). No significant differences between these three days were found. From this Table 1 it can also be seen that the mean absorption (as calculated from the difference between dietary intake and faecal excretion) of phylloquinone from the standard diet was $4 \mu \mathrm{g} / \mathrm{day}$ (about $10 \%$ of the food content), whereas from the enriched diets the absorption of phylloquinone and menaquinone was substantially higher, both in absolute amounts $(75 \mu \mathrm{g} /$ day and $216 \mu \mathrm{g} /$ day) and as a percentage of the daily intake (18\% and 55\%, respectively). 
Table 1. Dietary intake and faecal excretion of $\mathrm{K}_{1}$ and MK-4 on various days

\begin{tabular}{|c|c|c|c|c|c|c|c|c|c|c|c|c|c|c|c|}
\hline \multirow{2}{*}{$\begin{array}{l}\text { Type of diet } \\
\text { Day number: }\end{array}$} & \multicolumn{3}{|c|}{ Vitamin K-deficient } & \multicolumn{3}{|c|}{ Standard diet } & \multicolumn{3}{|c|}{ High vitamin $\mathrm{K} 1$} & \multicolumn{3}{|c|}{ High MK-4 } & \multicolumn{3}{|c|}{ Menadion } \\
\hline & 5 & 7 & 9 & 5 & 7 & 9 & 5 & 7 & 9 & 5 & 7 & 9 & 5 & 7 & 9 \\
\hline \multicolumn{16}{|c|}{ Dietary intake $(\mu \mathrm{g} /$ day $)$ : } \\
\hline vitamin $\mathrm{K}_{1}$ & 0 & 0 & 0 & 38 & 42 & 40 & 392 & 401 & 397 & 0 & 0 & 0 & 0 & 0 & 0 \\
\hline menaquinone-4 & 0 & 0 & 0 & 0 & 0 & 0 & 0 & 0 & 0 & 405 & 389 & 398 & 0 & 0 & 0 \\
\hline menadione & 0 & 0 & 0 & 109 & 120 & 114 & 0 & 0 & 0 & 0 & 0 & 0 & 377 & 393 & 412 \\
\hline \multicolumn{16}{|c|}{ Faecal excretion ( $\mu \mathrm{g} /$ day): } \\
\hline vitamin $\mathrm{K}_{1}$ & 0.5 & 0.7 & 0.5 & $35^{*}$ & $37^{*}$ & $36^{*}$ & $316^{\#}$ & $332^{\#}$ & $317^{\#}$ & 0.2 & 0.7 & 0.8 & 0.4 & 0.6 & 0.5 \\
\hline menaquinone-4 & 0.5 & 0.1 & 0.2 & $2.1^{*}$ & $2.6^{*}$ & $1.9^{*}$ & $6.1^{\#}$ & $5.0^{\#}$ & 3.2 & 178 & 187 & 180 & $4.9 \#$ & 7.2\# & $5.1 \#$ \\
\hline \multicolumn{16}{|l|}{ Absorption (\%) } \\
\hline vitamin $\mathrm{K}_{1}$ & - & - & - & 8 & 12 & 10 & $19^{\#}$ & $17^{\#}$ & $20^{\#}$ & - & - & - & - & - & - \\
\hline menaquinone-4 & - & - & - & - & - & - & - & - & - & 57 & 54 & 55 & - & - & - \\
\hline
\end{tabular}

Each group consisted of three animals, and all data provided in this Table are mean values for three different animals, standard deviations were $<15 \%$. Explanation of symbols: ${ }^{*}$, significantly different from the vitamin K-deficient group; ${ }^{\#}$, significantly different from the group receiving standard diet.

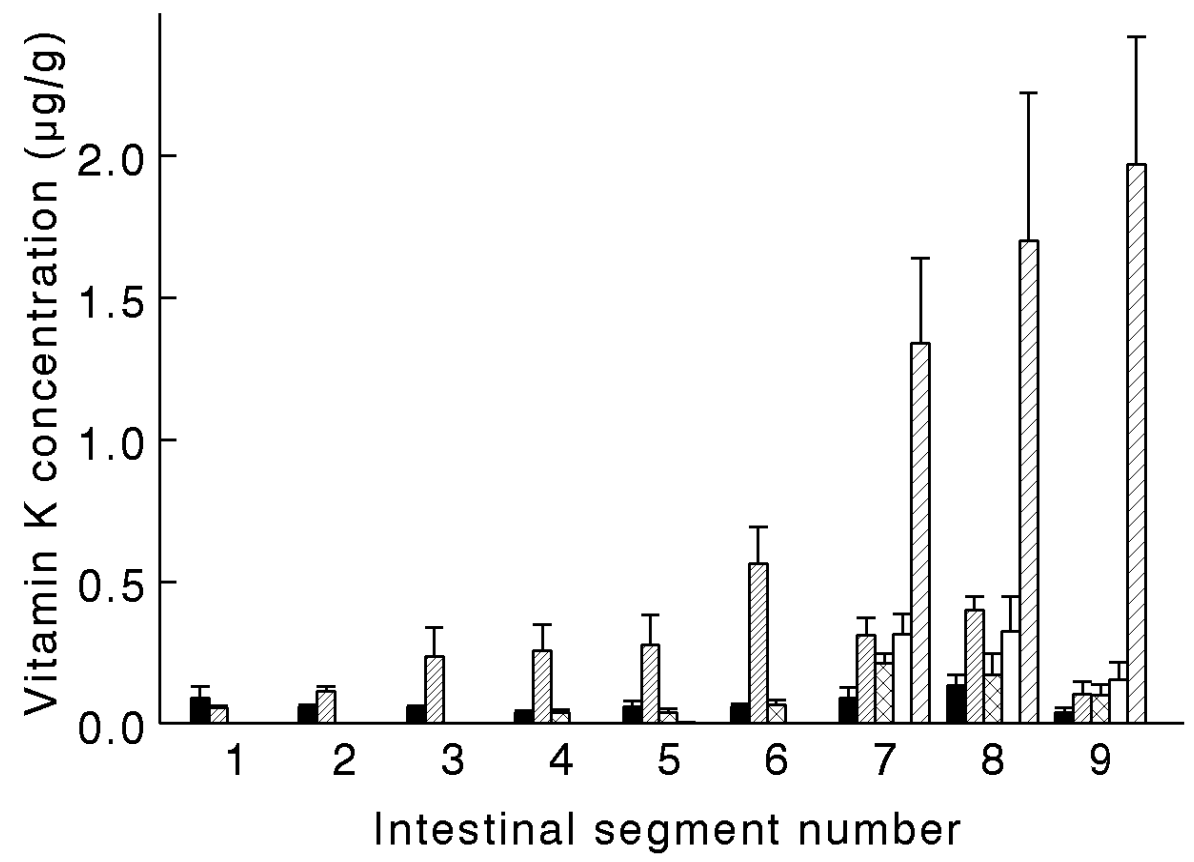

\section{Figure 1.}

Vitamin $\mathrm{K}$ profile in rats on standard diet. The intestinal segments which were analysed were: $1=$ duodenum, 2 proximal jejunum, $3=$ distal jejunum, $4=$ proximal ileum, $5=$ middle ileum, $6=$ distal ileum, 7 = caecum, $8=$ proximal colon, $9=$ distal colon. Bars represent: MK-4 (closed), $\mathrm{K}_{1}$ (narrowly hatched), MK-8 (cross-hatched), MK-9 (open), MK-10 (widely hatched). Error bars represent SD. 


\section{Effect of diet on intestinal vitamin $K$ profile}

The intestinal vitamin $\mathrm{K}$ profile in rats receiving the standard food is shown in Figure 1. $\mathrm{K}$-vitamers recovered were mainly the higher menaquinones (MK-8, MK-9, and MK-10), which were almost exclusively present in the cecum and colon. Other menaquinones were barely detectable or absent in this group, as well as in the other groups described below.

In animals receiving the vitamin $\mathrm{K}$ deficient diet, phylloquinone and MK-4 were low $(<0.05 \mu \mathrm{g} / \mathrm{g})$ in all segments of the intestinal tract (Figure $2 A)$. Long-chain menaquinones were not found in the duodenum, jejunum or ileum, whereas segments 7-9 (caecum and colon) contained considerable amounts of MK-8, MK-9, and MK-10, the concentrations were comparable or even slightly higher than those in rats on standard food (cf. Figures 1 and $2 \mathrm{~A}$ ). Because the rats in the vitamin $\mathrm{K}$-deficient group had not received any vitamin $\mathrm{K}$ during 17 days the menaquinone profile shown in Figure $2 A$ must be the result of menaquinone synthesis by the intestinal flora. Supplementation with menadione did not increase the bacterial menaquinone production (Figure 2B). As compared to the vitamin K-deficient animals, the mean values of MK-4 were about 10-fold elevated in the upper part of the intestinal tract.

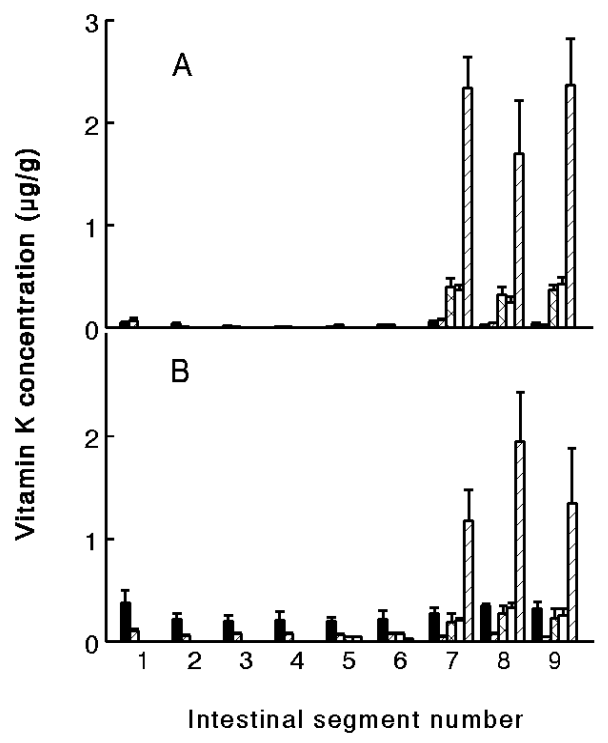

Figure 2.

Effect of vitamin K-deficiency and menadione on intestinal vitamin K content.

A: vitamin K-deficiency.

B: high menadione intake. Further details are as described in the legend to Figure 1. 
In the group receiving a diet rich in phylloquinone (Figure 3A), substantial amounts of this vitamin were found in all parts of the intestinal tract, but the concentration increased from segment 1 to segment 6-9. These result suggested that the absorption of the dietary phylloquinone was far from complete, and that its concentration increased during the passage through the upper part of the intestinal tract because other components of the diet were absorbed more readily. Remarkably, the long chain menaquinones were extremely low in all parts of the intestine (Figure 3B). Also in the group receiving MK-4 the dietary vitamin was recovered from the intestinal contents, but in general the concentrations were lower than in the phylloquinone-group (Figure 3A). So it seems that MK-4 is absorbed somewhat better than phylloquinone. Like in the phylloquinone group, the intestinal production of MK-9 and MK-10 was decreased in animals receiving the menaquinone-rich food. Surprisingly, however, relatively high amounts of MK-8 were found in animals on the MK-4 diet

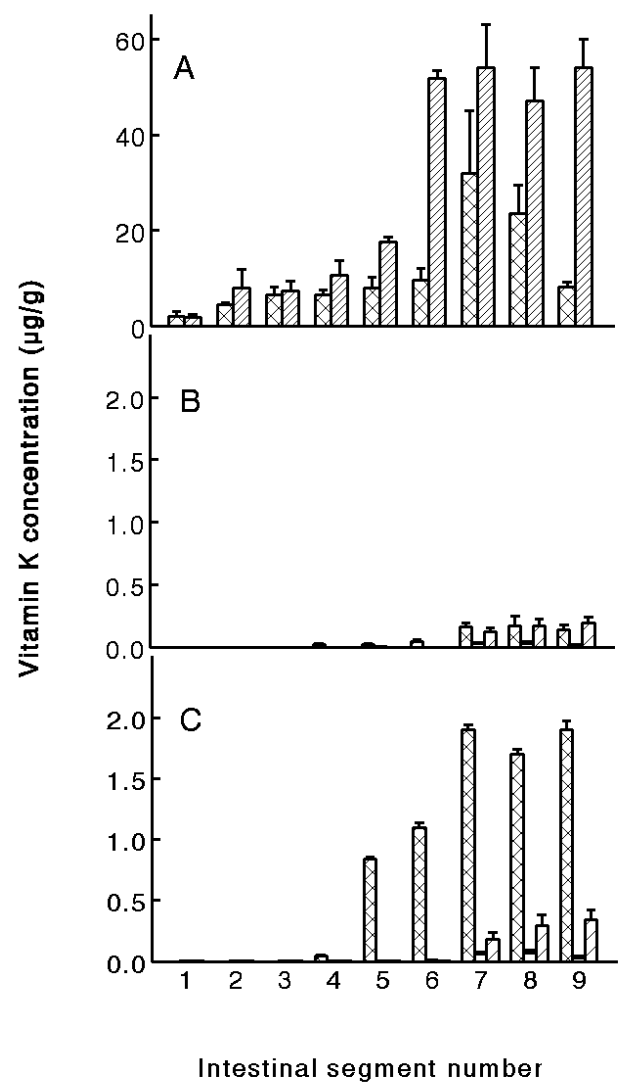

Figure 3.

Effect of dietary phylloquinone and menaquinone-4 on intestinal vitamin $\mathrm{K}$ content.

A: Phylloquinone after phylloquinone-rich diet (hatched) and MK-4 after MK-4 rich diet (cross-hatched).

B: Higher menaquinones after phylloquinone-rich diet: MK-8 (cross-hatched), MK-9 (open), MK-10 (hatched).

C: Higher menaquinones after MK-4-rich diet: MK-8 (cross-hatched), MK-9 (open), and MK-10 (hatched). 
(Figure 3C). The faecal MK-8 level in these animals was even substantially higher than that in vitamin $\mathrm{K}$-deficient rats.

\section{Effect of dietary vitamin $K$ on circulating and hepatic vitamin $K$ concentrations}

In the various plasma samples only phylloquinone and MK-4 were detectable (Table 2). Both vitamins were extremely low in the vitamin K-deficient group; in the menadione group they were found to be only slightly higher. In the groups of controlled phylloquinone and MK-4 diets high concentrations of the respective vitamins were found in plasma. In the livers of both the menadione-supplemented and the phylloquinone-supplemented group MK4 was slightly increased, other K-vitamins were comparable to those in the K-deficient group. In the MK-4 supplemented group the most remarkable observation was the prominent increase of MK-8 from less than $0.05 \mathrm{ng} / \mathrm{g}$ to $71 \mathrm{ng} / \mathrm{g}$ of tissue, which is consistent with the high colonic contents of MK-8.

Table 2. K-vitamers recovered from plasma and liver after controlled vitamin $\mathrm{K}$ intake

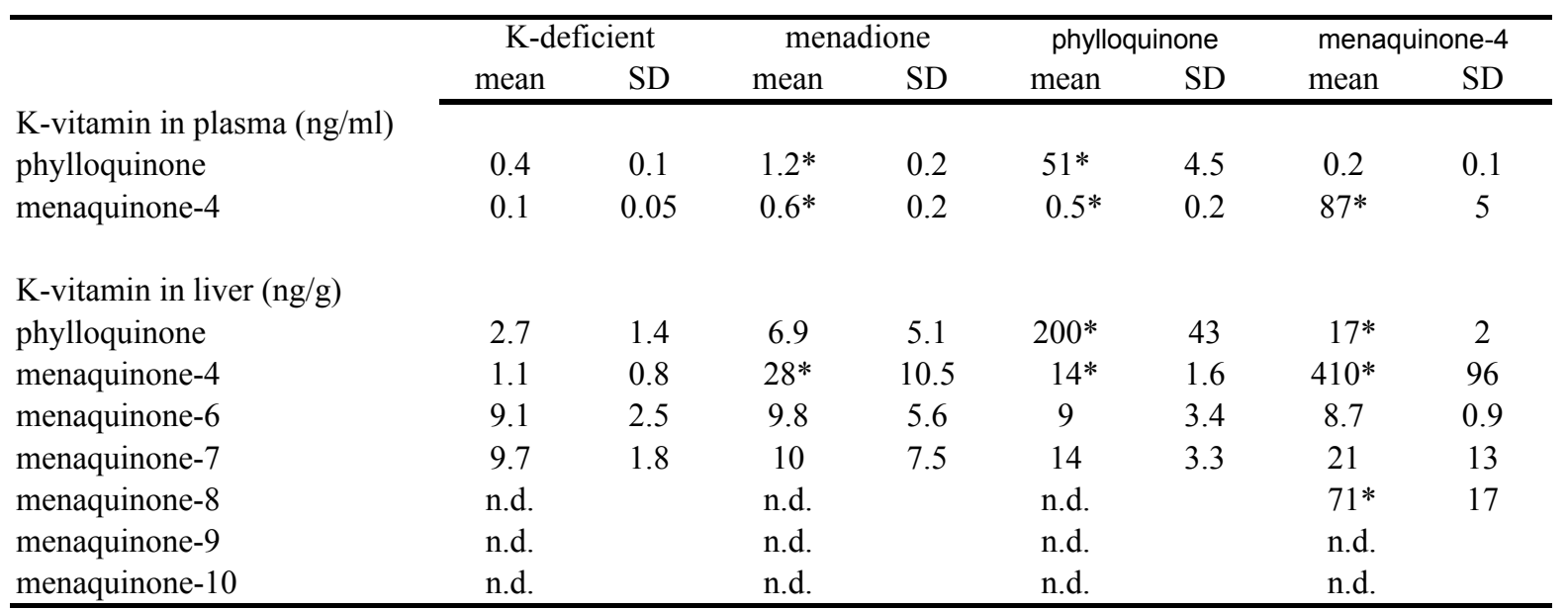

\section{Discussion}

According to the protocol the animals in our study were not treated with a single dose of vitamin $\mathrm{K}$, but they were fed with diets containing well-defined concentrations of menadione, phylloquinone, or menaquinone-4 until they were in a steady state condition. From Table 1 it can be seen that the dietary uptake and faecal excretion of phylloquinone and menaquinone were constant on days 5, 7, and 9 of the experiment. From these data it may also be calculated that the total absorption of phylloquinone from the standard food was not more than $10 \%$. An explanation for this poor uptake may come from the fact that the phylloquinone in this diet originates from grass, which forms the fibre component. Also in humans the uptake of vitamin $\mathrm{K}$ from green vegetables was $5-15 \%$, depending on the fat content of the meal ${ }^{25}$. In the supplemented diets, the K-vitamins had been added dissolved in 48 | 
corn oil, from which they are more readily extracted by the action of bile salts. Here a marked difference was observed between phylloquinone and the slightly more hydrophylic menaquinone- 4 , the latter one being absorbed substantially better than phylloquinone. In this respect it is noteworthy that Ichihashi et al. reported some colonic menaquinone-4 absorption even in the absence of bile salts ${ }^{43}$.

After 17 days of vitamin K-deficiency, long chain menaquinones (notably MK-10) were abundantly present in the cecum and the colon, and definitely not lower than in animals on the standard food (cf. Figures 1 and 2). Apparently, the vitamers are not absorbed from this part of the tract, because two animals in the vitamin K-deficient group were bleeding at the end of the experiment. Also, the higher menaquinones were undetectable in the liver (see Table 2). A menadione-rich diet induced an increase of MK-4 in the liver, but not in the colon. Probably because of the entero-hepatic cycle, MK-4 was slightly increased in the upper part of the digestive tract in this group. These data are consistent with the view that menadione may be converted into MK-4 in the liver ${ }^{8}$, but they also demonstrate clearly that this conversion is absent in the colonic bacteria. Whether menadione may be used as a source for the intestinal production of higher menaquinones remains to be seen, although it is clear that menadione does not increase the menaquinone concentrations in the gut.

A major finding was that high phylloquinone intake suppressed the intestinal menaquinone production. Apparently the flora is capable of using this vitamin, thereby shutting down its own menaquinone production. It is also clear that - despite the high phylloquinone concentration in the food - the phylloquinone concentration was low in the upper part of the digestive tract. A possible explanation may be found from the fact that in all animals (also in the other groups) the ileum was virtually empty, so that mucosal material and not digested food were the main components of what was assembled from its contents. This effect is negligible in the caecum and colon, where a high degree of intestinal filling was observed. The gradual increase of phylloquinone downstream the digestive tract as well as its relatively high concentration in colon and faeces suggests that its absorption is far from complete. In the group receiving a diet rich in MK-4 the recovery of the corresponding vitamer from the intestinal contents was substantially lower than in the phylloquinone group, which is consistent with a better absorption of MK-4 than of phylloquinone (cf. Table 1). This seems to be in contrast to previous data from Groenen-van Dooren, who showed that the utilization for prothrombin synthesis of nutritional phylloquinone is better than that of MK-4 44,46. Differences between the previous protocols and the present experiment are that Groenen-van Dooren used a single-dose of vitamin K, and that the vitamers were dissolved in detergent (HCO-60). When used in a steady state situation and dissolved in a natural compound (corn oil) it seems that MK-4 and phylloquinone accumulate in the liver to comparable levels. 
As it was found in the group receiving the phylloquinone-diet, animals receiving MK4 had low intestinal concentrations of MK-9 and MK-10. Surprisingly, however, the diet containing MK-4 induced a remarkable increase of colonic MK-8. These data suggest that either the intestinal flora or the liver is capable of using MK-4 for the exclusive synthesis of MK-8, which is a hitherto unknown metabolic pathway. A second striking observation was that in this group the high MK-8 levels were reflected in the liver vitamin $\mathrm{K}$ concentrations (Table 2). Since this seems to be in contrast to the poor absorption of higher menaquinones in the vitamin K-deficient animals (see above), we believe that the conversion of MK-4 into MK-8 may take place in the liver, and reach the digestive tract via the entero-hepatic pathway. This hypothesis implies that re-absorption of MK-8 from the intestines is poor, so that it accumulates to the high concentrations in the colon as observed in our study. Investigations in germ-free animals ${ }^{9}$ may help to verify this hypothesis. The data presented here confirm that the absorption of phylloquinone from its natural food matrix in rats is extremely poor, as has also been reported in a limited number of human volunteers ${ }^{25}$. Absorption from oil-solubilized preparations is substantially better but still far from complete. This supports the very high efficacy of hepatic vitamin $\mathrm{K}$ recycling during the blood clotting factor synthesis, and raises the question of whether a similar efficacy is obtained in other tissues, for instance in bone and vessel wall during the production of osteocalcin and matrix Gla-protein. 


\title{
DIFFERENTIAL LIPOPROTEIN TRANSPORT PATHWAYS OF K-VITAMINS IN HEALTHY SUBJECTS
}

\begin{abstract}
Vitamin $K$ is a group name for $K_{1}$ (phylloquinone) and $K_{2}$ (menaquinones). Both forms contribute to the tissue vitamin $K$ status. Following intestinal absorption, the serum transport of these lipophilic compounds to their target tissues takes place via lipoproteins. In previous studies we have found that $K_{1}$ is preferentially accumulated in the liver, whereas menaquinones have a more widespread distribution pattern. Here we have tested whether these differences may be explained by the different liposolubility and or metabolism of the various K-vitamers, resulting in their association with different lipoprotein particles. Six healthy male volunteers received a mixture containing $2 \mu M$ of each of three $K$ vitamers $\left(K_{1}\right.$, $M K-4$, and $M K-9)$ dissolved in corn oil. Blood was obtained at baseline and at different time intervals after intake for the measurement of vitamin $K$ in serum and in the lipoprotein fractions. $K_{I}$ was found to be associated predominantly with the triacylglycerol-rich lipoprotein (TGRLP) fraction, suggesting that it is mainly cleared by the liver. Both menaquinones investigated were found in TGRLP and LDL, MK-4 was also present in HDL. This may explains why menaquinones have a different tissue distribution profile and suggests relatively large impact of menaquinones on extra-hepatic vitamin $K$ status than generally assumed. Moreover, the very long half-life time of MK-9 in the circulation indicates that it may form a more constant source of vitamin $K$ than either $K_{1}$ or $M K-4$.
\end{abstract}

\section{Introduction}

Vitamin $\mathrm{K}$ is a group name for a class of compounds which share a 2-methylnaphthoquinone ring system, substituted at the 3-position with a variable aliphatic side chain ${ }^{2,4}$. Most common forms found in the human diet are phylloquinone (vitamin $\mathrm{K}_{1}$ ) and menaquinones (vitamin $\mathrm{K}_{2}$ ). Whereas phylloquinone is a single compound containing a mono-unsaturated side chain of four isoprenoid residues, menaquinones may be subdivided further on the basis of the number of isoprene residues (all of which are unsaturated) in the aliphatic side chain. According to the general nomenclature menaquinones are denominated as MK- $n$, where $n$ stands for the number of isoprene residues present. Menaquinones most commonly found in food are MK-4, which is regarded as a short chain menaquinone, and the 
long chain menaquinones MK-7, MK-8, and MK-9. Although all K-vitamins are fat-soluble, their lipophylic character increases substantially at increasing chain length; this may have consequences for their uptake, plasma transport, tissue storage, and biological half-life time ${ }^{47}$.

The function of all K-vitamins in mammals is that they serve as a cofactor for the enzyme $\gamma$-glutamylcarboxylase during the biosynthesis of a special class of proteins, the socalled Gla-proteins ${ }^{3}$. Well known examples of Gla-proteins are a number of clotting factors produced by the liver, including prothrombin and factors VII, IX, and $\mathrm{X}^{1}$. During the last two decades, however, $\gamma$-glutamylcarboxylase has been detected in a wide range of non-hepatic tissues, and an increasing number of Gla-proteins of extra-hepatic origin have been characterized ${ }^{1,2}$. Most of these proteins have regulatory functions, for instance in tissue mineralization (osteocalcin and matrix Gla-protein) ${ }^{32,34}$ and cell growth (growth-arrestspecific gene-6 protein, Gas6) ${ }^{48}$.

It is well known that intestinal absorption of $\mathrm{K}_{1}$ takes place via the enterocytes, which facilitate its incorporation into chylomicrons. These chylomicrons enter the circulation via the lymphatic system, and most of the vitamin is delivered to the liver through receptor-mediated uptake of chylomicron remnants by hepatic parenchymal cells ${ }^{4,49}$. It seems probable that the other K-vitamins are taken up via a similar process, but limited data for menaquinone metabolism is available at this time. Moreover, it is not known how the extra-hepatic tissues are provided with vitamin K. Apart from possible uptake from chylomicron remnants another route would be that part of the K-vitamins are re-packed into the low-density lipoproteins (LDL) which form a major transport system from the liver to peripheral tissues. From animal experiments is has become clear that the liver is the main target for uptake and accumulation of vitamin $\mathrm{K}_{1}$, whereas most extra-hepatic tissues (e.g. vessel wall, bone, testis, pancreas, kidney, and lung) preferentially accumulated menaquinone ${ }^{30,50}$.

Recently, it has been shown that postprandially, vitamin $\mathrm{K}_{1}$ is predominantly carried in the triacylglycerol-rich lipoprotein fraction (TGRLP), and little is carried by the LDL or HDL fraction ${ }^{51}$. In the study described in this paper we have hypothesized that the vitamin $\mathrm{K}$ transport in the blood stream to various tissues will take place via circulating lipoproteins, and that the lipophilicity of the various K-vitamers is an important factor in their distribution over the different lipoprotein fractions. To test this hypothesis, human volunteers received a single oral dose of a mixture of $\mathrm{K}_{1}$, MK-4, and MK-9, and we have measured the appearance and disappearance of these vitamins in serum. Subsequently, we have recorded their distribution over the various lipoprotein fractions as a result of changes in postprandial lipoprotein concentration of vitamin $\mathrm{K}$. 


\section{Materials and Methods}

\section{Subjects and study protocol}

This study was carried out in six healthy male volunteers recruited at the University of Maastricht. Their mean age was $33.5 \pm 6.3$ years, and their body mass index was $24.3 \pm 2.0$ $\mathrm{kg} / \mathrm{m}^{2}$. All participants were apparently healthy, and their serum lipid profiles were within the normal range. Neither medications nor vitamin supplements (other than the experimental ones) were taken throughout the study. The experimental protocol started at 8 am after an overnight fast. At that time the participants received a breakfast containing vitamin $\mathrm{K}$ (2 $\mu \mathrm{mol}$ of $\mathrm{K}_{1}$, MK-4 and MK-9) together with $30 \mathrm{~g}$ of fat (corn oil), and toast with marmalade. The blank meal (baseline curve) consisted $30 \mathrm{~g}$ of fat without vitamin $\mathrm{K}$ given at breakfast and values obtained during this control phase were subtracted from those obtained during the experimental design. To exclude influences in vitamin $\mathrm{K}$ metabolism due to additional $\mathrm{K}$ intake by the diet, participants were only allowed to eat food low in vitamin $\mathrm{K}$ (toast, marmalade, bananas, apples) at lunch, and to drink orange juice and water ad libitum. After 6 $\mathrm{pm}$ and during the rest of the week consumption of vitamin K-rich foods (spinach, broccoli, Brussels sprouts and kale) was not allowed. Unless indicated otherwise, blood was drawn by venipunctures at $0,2,4,6,8,24$, and 48 after intake. Serum was prepared and $1 \mathrm{~mL}$ aliquots were kept frozen until serial vitamin $\mathrm{K}$ determination. The study design was approved by the local Medical Ethics Committee, and informed consent was obtained from all subjects according to the institutional guidelines.

\section{Materials}

MK-4 was a kind gift from Eisai (Tokyo, Japan), $\mathrm{K}_{1}$ and MK-9 were obtained from Hoffmann-La Roche (Basel, Switzerland). A set of purified menaquinones (MK-4 through MK-10) was supplied by Roche and served as reference compounds for the identification of menaquinones. Corn oil was from CPC Bestfoods (Heilbronn, Germany) and contained 60 $\mathrm{pmol} / \mathrm{g}$ of vitamin $\mathrm{K}_{1}$ and no detectable amounts of menaquinones.

\section{Analytical techniques}

Triacylglycerol and cholesterol were determined by standard enzymatic techniques (Boehringer Mannheim, Germany) using a Beckmann Synchron CX 7-2 autoanalyser (Beckmann, Fullerton, CA). Vitamin K concentrations were assessed by high performance liquid chromatography, with on-line electrochemical reduction of the effluent and fluorescence detection ${ }^{47}$. The lipoproteins in serum were separated on a $1,006-1,250 \mathrm{~g} / \mathrm{L}$ $\mathrm{KBr}$ density gradient ${ }^{52}$. Serum samples $(3.5 \mathrm{~mL})$ were adjusted to a density of $1,250 \mathrm{~g} / \mathrm{L}$ with solid $\mathrm{KBr}$ in polyallomer tubes and stacked up with three $3 \mathrm{~mL}$ layers of $\mathrm{KBr} / \mathrm{NaCl}$ solutions 
in $1 \mathrm{mM}$ EDTA (pH 7.4) of 1,063, 1,019 and 1,006 g/L, respectively. The gradients were centrifuged for $22 \mathrm{~h}$ at $36,000 \mathrm{rpm}$ in a Beckman SW 40 rotor. In this way the following lipoproteins were obtained in separate fractions: TGRLP (including the chylomicrons, the chylomicron remnants, and the VLDL fraction), the IDL, LDL, HDL, as well as the lipoprotein-free (LPF) fraction.

\section{Data analysis}

Serum vitamin $\mathrm{K}$ concentrations during $48 \mathrm{~h}$ after oral ingestion were recorded at indicated intervals. At each time point mean values $\pm \mathrm{SE}$ for the six participants were calculated and plotted as a function of time. Blank values (no vitamin $\mathrm{K}$ ingested) were subtracted throughout this study.

\section{Results}

Serum profiles for lipid components were prepared after the vitamin K-rich meal only. Cholesterol and triacylglycerol concentrations in total serum at baseline level were within the normal range for all subjects. Lamon Fava et al. showed that vitamin $\mathrm{K}$ did not affect the plasma lipoprotein profile and that serum vitamin $\mathrm{K}$ and cholesterol is not correlated ${ }^{51}$. Therefore, cholesterol in the lipoprotein subfractions was not analysed. Peak values for serum triacylglycerol concentrations were observed around $2 \mathrm{~h}$ postprandially, and were within the normal range. They remained elevated until $8 \mathrm{~h}$ after start and at $24 \mathrm{~h}$ all values had returned to baseline. The profile of serum triacylglycerol in the TGRLP fraction was comparable with that in total serum. The triacylglycerol content of the LDL and HDL fraction remained constant in the experiment.

In the same samples we have measured the concentrations of $\mathrm{K}_{1}, \mathrm{MK}-4$, and MK-9 (Figure 1). Maximal concentrations in serum were reached at 2.5, 4, and $5 \mathrm{~h}$ postprandial for MK-4, $\mathrm{K}_{1}$, and MK-9. All three vitamins showed complex pharmacokinetics with multiphasic disappearance curves, but their clearance rates differed substantially. Whereas $\mathrm{K}_{1}$ and MK-4 had virtually disappeared from the circulation after the overnight period, the clearance of MK-9 was remarkably slower: after $24 \mathrm{~h}$ its serum concentration was still about $25 \%$ of the peak value, and it remained detectable until the last measurement at $48 \mathrm{~h}$ after intake. The estimated half-life time for MK-9 during the latter phase was about $60 \mathrm{~h}$.

In Figure 2 we have plotted the postprandial distribution of $\mathrm{K}_{1}$, MK-4 and MK-9 over the lipoprotein fractions as a function of time. The clearance from the blood stream of $\mathrm{K}_{1}$ in the TGRLP fraction was nearly complete after $8 \mathrm{~h}$, and we have measured whether other lipoprotein fractions contributed to the vitamin $\mathrm{K}$ transport. As is shown in Figure $2 \mathrm{~A}$, the $\mathrm{K}_{1}$ concentration in the LDL and HDL fractions was elevated during the first $24 \mathrm{~h}$ after $\mathrm{K}_{1}$ 
intake, but had returned to baseline at $48 \mathrm{~h}$. If expressed as a percentage of total serum vitamin $\mathrm{K}_{1}$, LDL never contained more than $17 \%$ and HDL less than $18 \%$ of total, whereas the remaining $\mathrm{K}_{1}$ was recovered in the TRLG fraction (Figure 2B). MK-4, on the other hand, was equally distributed over the TGRLP, LDL, and HDL fractions (Figure 2C). The clearance of MK-4 present in the TGRLP fraction followed that of triacylglycerol. Expressed as a percentage, $19 \%$ of total serum MK-4 was present in the LDL fraction at $2 \mathrm{~h}$, and up to $81 \%$ at $8 \mathrm{~h}$ after ingestion (Figure 2D). The pharmacokinetic behaviour of circulating MK-9 was different from that of $\mathrm{K}_{1}$ and MK-4: its appearance in the circulation and incorporation into lipoproteins was slower than for both other vitamins (Figure 2E). MK-9 appeared in the LDL fraction only at $8 \mathrm{~h}$ after intake, and remained detectable therein until at least $48 \mathrm{~h}$. At that time the MK-9 in LDL was 55\% of the total serum concentration (Figure 2F). At no time point MK-9 was found in the HDL fraction.

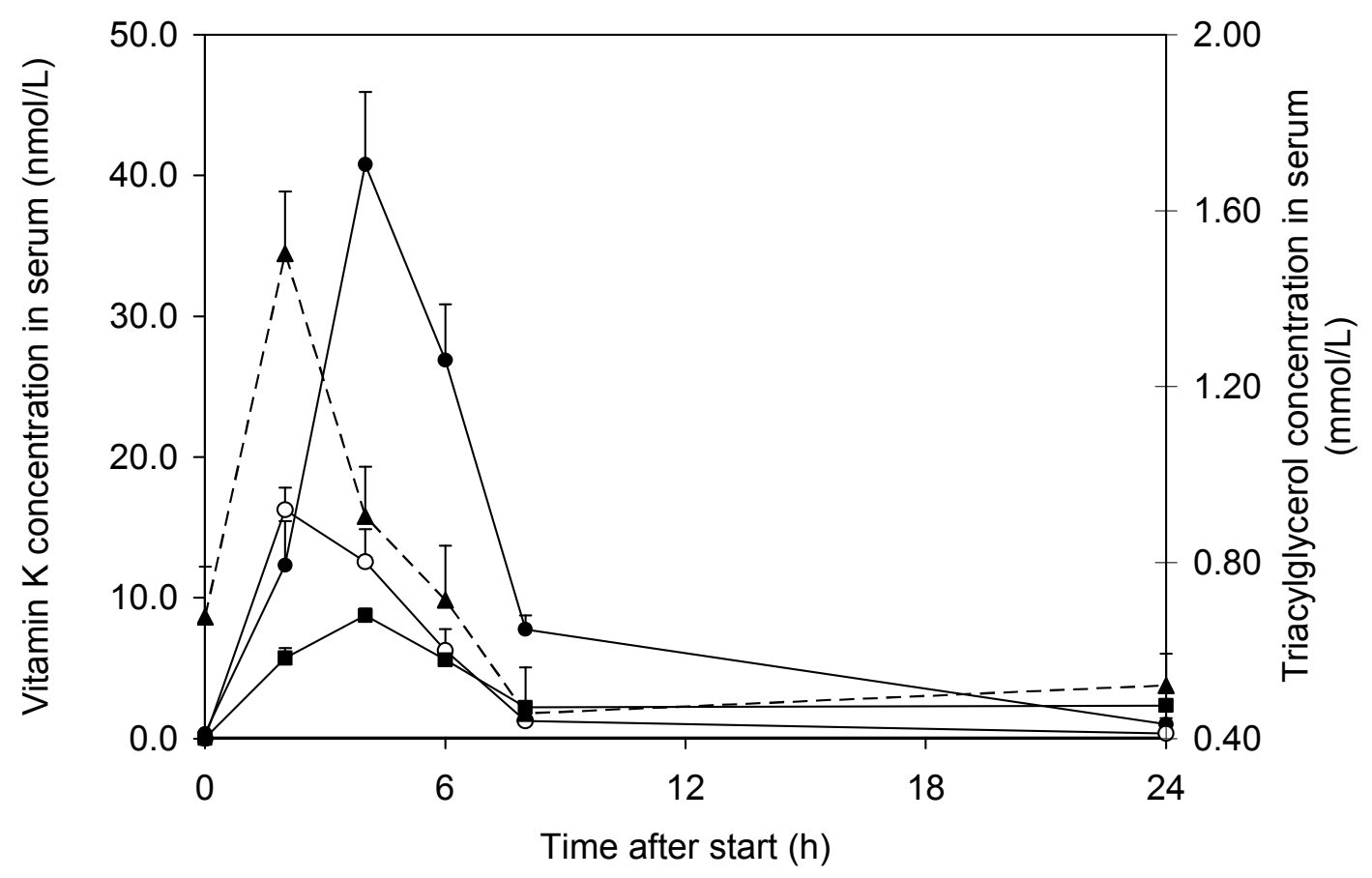

Figure 1.

Serum vitamin $\mathrm{K}$ following the oral intake of $2 \mu \mathrm{mol}$ of oil-solubilized preparations. Also the triacylglycerol concentration of the TGRLP fraction is drawn in the Figure to show the correlation between the K-vitamin and triacylglycerol. Points are mean values from 6 volunteers, error bars represent SEM. Symbols:, $\mathrm{K}_{1}$; O, MK-4; $\mathbf{\square}$, MK-9; $\boldsymbol{\Delta}$, TG-TGRLP. 

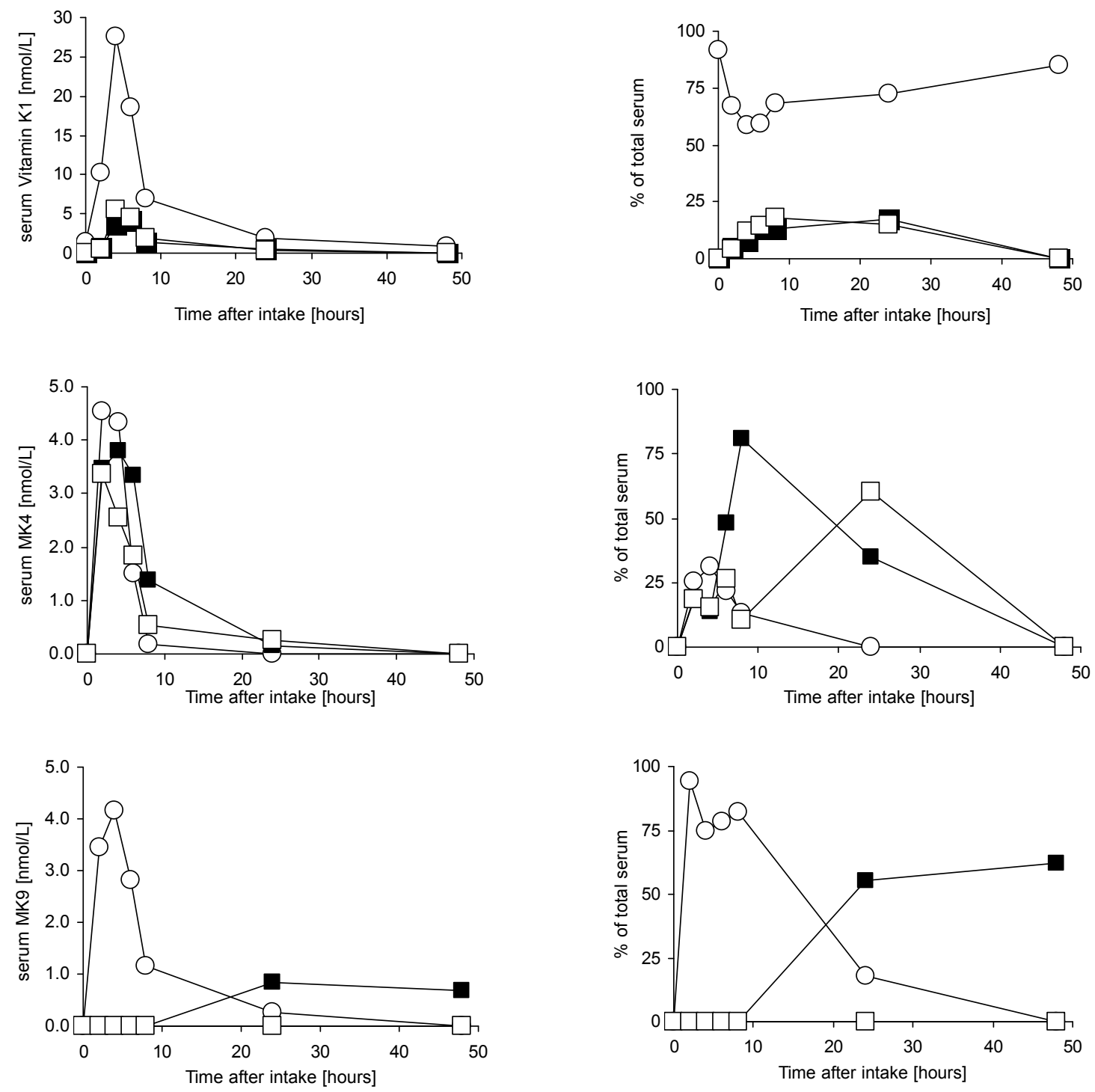

Figure 2.

Serum vitamin $\mathrm{K}$ in lipoprotein fractions $0-48$ hours after intake. Figure $2 \mathrm{~A}, \mathrm{C}$, and $\mathrm{E}$ represent serum vitamin $\mathrm{K}$ in lipoprotein fractions of respectively vitamin $\mathrm{K}_{1}, \mathrm{MK}-4$, and $\mathrm{MK}-9$ in nmol/L. Figure $2 \mathrm{~B}$, $\mathrm{D}$, and $\mathrm{F}$ represent the serum lipoprotein profile of $\mathrm{K} 1, \mathrm{MK}-4$, and $\mathrm{MK}-9$ as a percentage of the sum of all lipoprotein fractions. Symbols: $\mathrm{O}$, TGRLP; $\mathbf{\square}$, LDL; $\square$, HDL. 


\section{Discussion}

Unlike the fat-soluble vitamins $\mathrm{A}$ and $\mathrm{D}$, vitamin $\mathrm{K}$ has no specific plasma carrier protein, but is transported in plasma mainly by lipoproteins ${ }^{49,51}$. Following dietary uptake, vitamin $\mathrm{K}$ is absorbed in the intestine and enters the circulation via the lymphatic system as part of the chylomicrons ${ }^{49}$. In the circulation chylomicrons are catabolized by the action of lipoprotein lipase (LPL) resulting in chylomicron remnants ${ }^{53}$, which are then cleared mainly by the liver via an apoE receptor-specific uptake ${ }^{54,55}$.

In our study it appeared that during the first 8 hours following intake of a mixture of equal amounts of the three K-vitamins, the serum contained much higher concentrations of $\mathrm{K}_{1}$ than MK-4 or MK-9. Several explanations may be given for this observation: they include poor intestinal absorption of menaquinones or rapid uptake of menaquinones from chylomicrons by the tissues. In previous studies in which we compared the absorption of orally ingested $\mathrm{K}_{1}$ and menaquinones, it was found that both in experimental animals and in human volunteers the absorption of menaquinones was far more complete than that of $\mathrm{K}_{1}$ ${ }^{47,56}$. This is not consistent with a low efficacy of intestinal uptake of the menaquinones. The fact that in all experiments the serum concentration of MK-4 reached its maximum well before that of $\mathrm{K}_{1}$ and MK-9 suggests a quicker tissue uptake and clearance of MK-4 from the blood stream, whereas the very long half-life time for MK-9 points to a relatively slow tissue uptake of this vitamer. To explain these observations we hypothesized that the different pharmacokinetic behaviour of the three vitamers is related to their different hydrophobicity: whereas the most water-soluble MK-4 may be packed relatively loosely, the highy liposoluble MK-9 may be present in the core of the lipoprotein particles, with an intermediate position for $K_{1}$. This hypothesis was tested by measuring the vitamin $K$ content of the various lipoprotein fractions.

As early as 1974 Shearer et al. showed that the major transport of vitamin $\mathrm{K}$ in plasma takes place via the TGRLP fraction ${ }^{49}$; recently this was confirmed by Lamon-Fava et $a l$., who hypothesized that during the hydrolysis of triacylglycerol by lipoprotein lipase, $\mathrm{K}_{1}$ remains bound to the $\mathrm{CR}^{51}$. It is well known that after hydrolysis, the resulting fatty acids are readily taken up by endothelial cells, and the fact that the serum profile of MK-4 closely follows that of triacylglycerol in the TGRLP fraction suggests that MK-4 is taken up by the endothelium in parallel with the fatty acids. A similar principle has been reported for tocopherol ${ }^{57}$. During the formation of CR by LPL, excess surface components are transferred to HDL. The fact that - in contrast to the more hydrophobic $\mathrm{K}_{1}$ and MK-9 - at $2 \mathrm{~h}$ after ingestion MK-4 is already present in the HDL fraction further supports the hypothesis that MK-4 is mainly associated with the outer side of the lipoprotein particle, where it is available for substitution. HDL on its turn can transfer such hydrophobic components to all other lipoproteins ${ }^{58,59}$. A second pathway for lipoprotein uptake of MK-4 would be the direct 
exchange from TGRLP to LDL, such as has been demonstrated for retinyl esters ${ }^{60}$.

In fasting serum low amounts of $K_{1}$ were found in the LDL and HDL fractions, with only a slight increase during the postprandial period and peak values between $4-8 \mathrm{~h}$ after ingestion. It is at least plausible that some of the ingested $\mathrm{K}_{1}$ reaches these fractions by hepatic redistribution via the VLDL pathway ${ }^{61}$. These data suggest that the liver is the most important target tissue for vitamin $\mathrm{K}_{1}$, whereas MK-4 is more readily available for other tissues as well. This is consistent with previous data from our group demonstrating that $\mathrm{K}_{1}$ was 2-5 fold more efficient than MK-4 in counteracting vitamin K-deficiency induced hypoprothrombinaemia in rats ${ }^{44}$, and that at equal intakes of $\mathrm{K}_{1}$ and MK-4 the former mainly accumulates in the liver, whereas MK-4 is preferentially absorbed by extra-hepatic tissues such as testis, pancreas, and kidney ${ }^{50}$. Also, the preferential utilization of $\mathrm{K} 1$ in the liver and MK-4 in the vessel wall supports the hypothesis of tissue specific uptake of K-vitamins ${ }^{62}$.

As observed for $K_{1}$, serum MK-9 concentrations reached a maximum at $4 \mathrm{~h}$ after intake. During the first $8 \mathrm{~h}$ MK-9 was exclusively found in the TGRLP fraction, suggesting that the liver is the main target tissue. A major difference with both short chain K-vitamers, however, was that MK-9 remained present in the circulation until the end of the experiment, whereas $\mathrm{K}_{1}$ and MK-4 had returned to baseline levels after $24 \mathrm{~h}$. In a similar experiment (data not shown) MK-9 was even detectable at $72 \mathrm{~h}$ after intake. During this phase MK-9 was mainly found in LDL, which can survive in the circulation for several days. These data are compatible with an initial uptake of MK-9 by the liver, from where it is released slowly via LDL and remains available for all kind of tissues possessing LDL-receptors ${ }^{63}$.

Taken together our results show that the different lipophilicity of the various Kvitamers may result in substantial differences in their plasma transport and delivery to target tissues. The data provide an explanation for the previously observed preferential accumulation and utilization of $\mathrm{K}_{1}$ in liver and MK-4 in extra-hepatic tissues. Also, they provide an explanation for the data from a recent population-based study in which it was shown that long term intake of menaquinones (notably the long-chain ones) is inversely correlated with arterial calcification, whereas for $\mathrm{K}_{1}$ intake the effect was much weaker ${ }^{64}$. 


\section{REFERENCES}

1. Furie B, Furie BC. Molecular and cellular biology of blood coagulation. N Engl J Med. 1992;326:800-6.

2. Shearer MJ. Vitamin K. Lancet. 1995;345:229-34.

3. Vermeer C. Gamma-carboxyglutamate-containing proteins and the vitamin K-dependent carboxylase. Biochem J. 1990;266:625-36.

4. Shearer MJ. Vitamin K metabolism and nutriture. Blood Rev. 1992;6:92-104.

5. Shearer MJ, Bach A, Kohlmeier M. Chemistry, nutritional sources, tissue distribution and metabolism of vitamin K with special reference to bone health. $J$ Nutr. 1996;126:1181s-6s.

6. Schurgers LJ, Geleijnse JM, Grobbee DE, Pols HAP, Hofman A, Witteman JCM, C. Vermeer C. Nutritional intake of vitamins K-1 (phylloquinone) and K-2 (menaquinone) in The Netherlands. $J$ Nutr Environm Med. 1999;9:115-122.

7. Martius C, Esser HO. Über die konstition des im tierkörper aus methylnaphtochinon gebildeten Kvitamines. Biochem Z. 1958;331:S1-S9.

8. Dialameh GH, Taggart WV, Matschiner JT, Olson RE. Isolation and characterization of menaquinone-4 as a product of menadione metabolism in chicks and rats. Int J Vitam Nutr Res. 1971;41:391-400.

9. Ronden JE, Drittij-Reijnders MJ, Vermeer C, Thijssen HH. Intestinal flora is not an intermediate in the phylloquinone- menaquinone-4 conversion in the rat. Biochim Biophys Acta. 1998;1379:69-75.

10. Thijssen HHW, Drittij-Reijnders MJ, Fischer MA. Phylloquinone and menaquinone-4 distribution in rats: synthesis rather than uptake determines menaquinone-4 organ concentrations. J Nutr. 1996;126:537-543.

11. Conly JM, Stein K, Worobetz L, Rutledge-Harding S. The contribution of vitamin K2 (menaquinones) produced by the intestinal microflora to human nutritional requirements for vitamin K. Am $J$ Gastroenterol. 1994;89:915-923.

12. Vermeer C, Hamulyak K. Pathophysiology of vitamin K-deficiency and oral anticoagulants. Thromb Haemost. 1991;66:153-9.

13. Duxbury BM. Therapeutic control of anticoagulant treatment. Br Med J (Clin Res Ed). 1982;284:702704.

14. Kumar S, Haigh JR, Rhodes LE, Peaker S, Davies JA, Roberts BE, Feely MP. Poor compliance is a major factor in unstable outpatient control of anticoagulant therapy. Thromb Haemost. 1989;62:729-732.

15. James AH, Britt RP, Raskino CL, Thompson SG. Factors affecting the maintenance dose of warfarin. $J$ Clin Pathol. 1992;45:704-706.

16. Harris JE. Interaction of dietary factors with oral anticoagulants: review and applications. $J$ Am Diet Assoc. 1995;95:580-584.

17. Beyth RJ, Landefeld CS. Anticoagulants in older patients. A safety perspective [published erratum appears in Drugs Aging 1995 Apr;6(4):343]. Drugs Aging. 1995;6:45-54.

18. Wynne H, Cope L, Kelly P, Whittingham T, Edwards C, Kamali F. The influence of age, liver size and enantiomer concentrations on warfarin requirements. Br J Clin Pharmacol. 1995;40:203-207.

19. Qureshi GD, Reinders TP, Swint JJ, Slate MB. Acquired warfarin resistance and weight-reducing diet. Arch Intern Med. 1981;141:507-509.

20. Kempin SJ. Warfarin resistance caused by broccoli [letter]. N Engl J Med. 1983;308:1229-1230.

21. Karlson B, Leijd B, Hellstrom K. On the influence of vitamin K-rich vegetables and wine on the effectiveness of warfarin treatment. Acta Med Scand. 1986;220:347-350.

22. Kalra PA, Cooklin M, Wood G, O'Shea GM, Holmes AM. Dietary modification as cause of anticoagulation instability [letter]. Lancet. 1988;2:803.

23. Pedersen FM, Hamberg O, Hess K, Ovesen L. The effect of dietary vitamin K on warfarin-induced anticoagulation. J Intern Med. 1991;229:517-520.

24. Garber AK, Binkley NC, Krueger DC, Suttie JW. Comparison of phylloquinone bioavailability from food sources or a supplement in human subjects. J Nutr. 1999;129:1201-3. 
25. Gijsbers BL, Jie KS, Vermeer C. Effect of food composition on vitamin K absorption in human volunteers. Br J Nutr. 1996;76:223-9.

26. Shearer MJ. The roles of vitamins $\mathrm{D}$ and $\mathrm{K}$ in bone health and osteoporosis prevention. Proc Nutr Soc. 1997;56:915-37.

27. Ferland G, Sadowski JA. Vitamin $\mathrm{K}_{1}$ (phylloquinone) content of edible oils: effects of heating and light exposure. J Agricult Food Chem. 1992;40:1869-1873.

28. Booth SL, Sadowski JA, Weihrauch JL, Ferland G. Vitamin $\mathrm{K}_{1}$ (phylloquinone) content of foods: a provisional table. J Food Comp Anal. 1993;6:109-120.

29. Bolton-Smith C, Price RJ, Fenton ST, Harrington DJ, Shearer MJ. Compilation of a provisional UK database for the phylloquinone (vitamin $\mathrm{K}_{1}$ ) content of foods. Br J Nutr. 2000;83:389-399.

30. Thijssen HH, Drittij Reijnders MJ, Fischer MA. Phylloquinone and menaquinone-4 distribution in rats: synthesis rather than uptake determines menaquinone-4 organ concentrations. J Nutr. 1996;126:537-43.

31. Vermeer C, Knapen MH, Schurgers LJ. Vitamin $\mathrm{K}$ and metabolic bone disease [see comments]. J Clin Pathol. 1998;51:424-426.

32. Luo G, Ducy P, McKee MD, Pinero GJ, Loyer E, Behringer RR, Karsenty G. Spontaneous calcification of arteries and cartilage in mice lacking matrix GLA protein. Nature. 1997;385:78-81.

33. Will BH, Suttie JW. Comparative metabolism of phylloquinone and menaquinone-9 in rat liver. $J$ Nutr. 1992;122:953-8.

34. Ducy P, Desbois C, Boyce B, Pinero G, Story B, Dunstan C, Smith E, Bonadio J, Goldstein S, Gundberg C, Bradley A, Karsenty G. Increased bone formation in osteocalcin-deficient mice. Nature. 1996;382:44852.

35. Nakano T, Kawamoto K, Kishino J, Nomura K, Higashino K, Arita H. Requirement of gammacarboxyglutamic acid residues for the biological activity of Gas6: contribution of endogenous Gas 6 to the proliferation of vascular smooth muscle cells. Biochem J. 1997;323:387-92.

36. Booth SL, Sadowski JA, Pennington JAT. Phylloquinone (vitamin $\mathrm{K}_{1}$ ) content of foods in the U.S. Food abd Drug Administration's total diet study. J Agric Food Chem. 1995;43:1574-1579.

37. Koivu TJ, Piironen VI, Henttonen SK, Mattila PH. Determination of phylloquinone in vegetables, fruits and berries by high-performance liquid chromatography with electrochemical detection. $J$ Agric Food Chem. 1997;45:4644-4649.

38. Piironen VI, Koivu TJ, Tammisalo O, Mattila PH. Determination of phylloquinone in oils, margarins and butter by high-performance liquid chromatography with electrochemical detection. Food Chem. 1997;59:473-480.

39. Hirauchi K, Sakano T, Notsumoto S, Nagaoka T, Morimoto A, Fujimoto K, Masuda S, Suzuki Y. Measurement of K-vitamins in food by high-performance liquid chromatography with fluorimetric detection. Vitamins. 1989;63:147-151.

40. Suttie JW. The importance of menaquinones in human nutrition. Annu Rev Nutr. 1995;15:399-417.

41. Hollander D. Intestinal absorption of vitamins A, E, D, and K. J Lab Clin Med. 1981;97:449-62.

42. Uchida K, Okuno I, Takase H, Nomura Y, Kadowaki M, Takeuchi N. Distribution of bile acids in rats. Lipids. 1978;13:42-8.

43. Ichihashi $\mathrm{T}$, Takagishi $\mathrm{Y}$, Uchida $\mathrm{K}$, Yamada H. Colonic absorption of menaquinone-4 and menaquinone-9 in rats. J Nutr. 1992;122:506-512.

44. Groenen-van Dooren MM, Soute BA, Jie KS, Thijssen HH, Vermeer C. The relative effects of phylloquinone and menaquinone 4 on the blood coagulation factor synthesis in vitamin K-deficient rats. Biochem Pharmacol. 1993;46:433-437.

45. Thijssen HH, Drittij-Reijnders MJ. Vitamin $\mathrm{K}$ metabolism and vitamin $\mathrm{K}_{1}$ status in human liver samples: a search for inter-individual differences in warfarin sensitivity. Br J Haematol. 1993;84:681-685.

46. Groenen van Dooren MM, Ronden JE, Soute BA, Vermeer C. Bioavailability of phylloquinone and menaquinones after oral and colorectal administration in vitamin K-deficient rats. Biochem Pharmacol. 
1995;50:797-801.

47. Schurgers LJ, Vermeer C. Determination of Phylloquinone and Menaquinones in Food. effect of food matrix on circulating vitamin K concentrations. Haemostasis. 2000;30:298-307.

48. Nagata K, Ohashi K, Nakano T, Arita H, Zong C, Hanafusa H, Mizuno K. Identification of the product of growth arrest-specific gene 6 as a common ligand for Axl, Sky, and Mer receptor tyrosine kinases. J Biol Chem. 1996;271:30022-7.

49. Shearer MJ, McBurney A, Barkhan P. Studies on the absorption and metabolism of phylloquinone (vitamin K1) in man. Vitam Horm. 1974;32:513-42.

50. Ronden JE, Thijssen HH, Vermeer C. Tissue distribution of K-vitamers under different nutritional regimens in the rat. Biochim Biophys Acta. 1998;1379:16-22.

51. Lamon-Fava S, Sadowski JA, Davidson KW, O'Brien ME, McNamara JR, Schaefer EJ. Plasma lipoproteins as carriers of phylloquinone (vitamin $\mathrm{K}_{1}$ ) in humans. Am J Clin Nutr. 1998;67:1226-1231.

52. Redgrave TG, Roberts DC, West CE. Separation of plasma lipoproteins by density-gradient ultracentrifugation. Anal Biochem. 1975;65:42-49.

53. Havel RJ. Chylomicron remnants: hepatic receptors and metabolism. Curr Opin Lipidol. 1995;6:312-316.

54. Sherrill BC, Innerarity TL, Mahley RW. Rapid hepatic clearance of the canine lipoproteins containing only the $\mathrm{E}$ apoprotein by a high affinity receptor. Identity with the chylomicron remnant transport process. J Biol Chem. 1980;255:1804-7.

55. Brown MS, Herz J, Kowal RC, Goldstein JL. The low-density lipoprotein receptor-related protein: double agent or decoy? Curr Opin Lipodol. 1991;2:65-72.

56. Koivu-Tikkanen TJ, Schurgers LJ, Thijssen HH, Vermeer C. Intestinal, hepatic, and circulating vitamin K levels at low and high intakes of vitamin K in rats. Br J Nutr. 2000;83:185-90.

57. Traber MG, Olivecrona T, Kayden HJ. Bovine milk lipoprotein lipase transfers tocopherol to human fibroblasts during triglyceride hydrolysis in vitro. J Clin Invest. 1985;75:1729-1734.

58. Bjornson LK, Gniewkowski C, Kayden HJ. Comparison of exchange of alpha-tocopherol and free cholesterol between rat plasma lipoproteins and erythrocytes. J Lipid Res. 1975;16:39-53.

59. Traber MG, Lane JC, Lagmay NR, Kayden HJ. Studies on the transfer of tocopherol between lipoproteins. Lipids. 1992;27:657-663.

60. Zilversmit DB, Morton RE, Hughes LB, Thompson KH. Exchange of retinyl and cholesteryl esters between lipoproteins of rabbit plasma. Biochim Biophys Acta. 1982;712:88-93.

61. Havel RJ, Kane JP. Introduction: structure and metabolism of plasma lipoproteins. The metabolic and molecular basis of inherited disease (ed. Scriver, C.R.). 1995;7th ed. New York: McGraw-Hill:18411851.

62. Schurgers LJ, Dissel PEP, Spronk HMH, Soute BAM, Dhore CR, Cleutjens JP, Vermeer C. Role of vitamin K and vitamin K-dependent proteins in vascular calcification. Z Kardiol. 2001;90 Suppl 3:57-63.

63. Brown MS, Goldstein JL. A receptor-mediated pathway for cholesterol homeostasis. Science. 1986;232:34-47.

64. Geleijnse JM, Vermeer C, Schurgers LJ, Grobbee DE, Pols HAP, Witteman JCM. Inverse association of dietary vitamin K-2 intake with cardiac events and aortic atherosclerosis: The Rotterdam study. Thrombosis and Heamostasis. 2001;Supplement ISTH XVIII:P473. 



$$
\frac{3}{\text { DIETARY FACTORS INFLUENCING VITAMIN K ABSORPTION }}
$$





\title{
CORN OIL-INDUCED DECREASE OF ARTERIAL THROMBOSIS TENDENCY MAY BE RELATED TO ALTERED PLASMA VITAMIN K TRANSPORT
}

\begin{abstract}
In this article we report the effects of low and high fat diets on the arterial thrombosis tendency in rats. The animal system used was the aorta loop model, in which we compared the effect of saturated (hardened coconut oil, HCO) and unsaturated (sunflower seed oil, SSO; corn oil, $\mathrm{CO}$ ) on the arterial thrombosis tendency at high fat intake (50 energy\%, 45\% of which was either HCO, SSO, or CO). Under these conditions both SSO and CO had a beneficial effect (relative to HCO) on the arterial thrombosis tendency. In a subsequent study we have compared these high fat diets with a low fat diet (5 energy\%). As compared to the low fat diet only CO significantly decreased the thrombosis risk. Serum vitamin $K$ and triglycerides had decreased substantially after the $C O$ diet, and to a much lesser extent after the SSO diet. It is concluded that corn oil may have a mildly anticoagulant effect, the potential benefit of which is discussed.
\end{abstract}

\section{Introduction}

It is well known that a diet rich in saturated fatty acids (SAFA) forms a risk factor for atherosclerosis in humans ${ }^{1,2}$, and that their inclusion in the diet increases the arterial thrombosis tendency (ATT) in rats ${ }^{3}$. At our institute we have an animal model for arterial thrombosis tendency, known as the aorta loop model ${ }^{4}$. In this model, thrombogenic diets such as those rich in hardened coconut oil (HCO) induce an increase of the ATT. Diets rich in mono- (MUFA) and poly-unsaturated fatty acids (PUFA) such as found in corn oil (CO), sunflower seed oil (SSO), linseed oil, or safflower oil, exhibit this effect to a much lesser extend, but most of these oils will only show a beneficial effect if they are used to replace SAFA in a high fat diet ${ }^{1}$. In humans, several studies have shown that fasting factor VIIc, which is regarded as an independent risk factor for cardiovascular disease, is decreased by low-fat diets. A similar effect has been reported for diets in which the SAFA composition was substituted by MUFA or PUFA ${ }^{5}$. Exceptions in this respect may be fish oil (rich in n-3 PUFA) and corn oil (n-6 PUFA). Several studies have shown that both fish oil and corn oil consumption leads to a reduction of blood cholesterol and triglycerides ${ }^{6-9}$. The mechanism underlying such beneficial effect is still a matter of debate ${ }^{10,11}$, but one hypothesis is that the 
protective effect on cardiovascular disease is due to a decrease of the serum cholesterol and triglyceride levels ${ }^{12}$, and to a mild reduction of the circulating vitamin K-dependent blood coagulation factor concentrations ${ }^{12,13}$. The latter phenomenon may be mediated by a lipidlowering effect which affected the lipoprotein transport and delivery of vitamin $\mathrm{K}$ to the liver, thereby reducing the synthesis of active vitamin K-dependent coagulation proteins. The credence of such a hypothesis is reinforced by findings that plasma concentrations of phylloquinone (vitamin $\mathrm{K}_{1}$ ), the predominant circulating and dietary form of vitamin $\mathrm{K}$, show a strong positive correlation with plasma triglycerides ${ }^{14-16}$ reflecting the fact that triglyceriderich lipoproteins (TGRLP) are the major transporters of vitamin $\mathrm{K}_{1}$ in both the postprandial and fasting states ${ }^{17,18}$. This suggests that factors which influence the metabolism of TGRLP may also affect the transport, tissue distribution and bioavailability of vitamin $\mathrm{K}^{17-19}$. To test this hypothesis we have compared whether lipid-lowering diets based on n-6 PUFA may affect the arterial thrombosis tendency and vitamin $\mathrm{K}$ metabolism in rats. $\mathrm{CO}$ and SSO were the experimental fats selected for this study because - in contrast to many other plant oils their vitamin $\mathrm{K}$ content is low. Moreover, these oils are commonly used for food preparation in The Netherlands. We have compared in experimental animal studies the effects of $\mathrm{CO}$, $\mathrm{SSO}$ and $\mathrm{HCO}$ on the arterial thrombosis tendency, and we have tried to find an explanation for the observed differences from a number of biomarkers in serum.

\section{Materials and Methods}

Materials.

Phylloquinone was purchased from Sigma (St. Louis, MO, USA). The hydrogenated coconut oil (HCO) and sunflower seed oil (SSO) were purchased from Chempri Inc. (Raamsdonksveer, The Netherlands). Corn oil (CO) was a kind gift from CPC-Bestfoods (Heilbronn, Germany). All other chemicals and reagents were of analytical or HPLC grade. Powdered stock rat food was from Hope Farms (Woerden, The Netherlands), and had been made vitamin $\mathrm{K}$ deficient by irradiation $(0.9 \mathrm{mrad})$. Stocks for preparing high $(25 \% \mathrm{w} / \mathrm{w})$ fat contained $23 \%$ of cerelose/glucose, whereas the low $(5 \% \mathrm{w} / \mathrm{w})$ fat stocks contained $54 \%$ of cerelose/glucose. In this way the caloric values for all diets had been made similar. Other dietary components (protein, fibre and trace elements) were present as described previously ${ }^{20}$. Prior to each study the fats (as indicated) were mixed with the stocks by our experimental animal department. The fatty acid composition of the oils is shown in Table 1. 
Table 1. Fatty acid compositions of the different oils

Type of diet

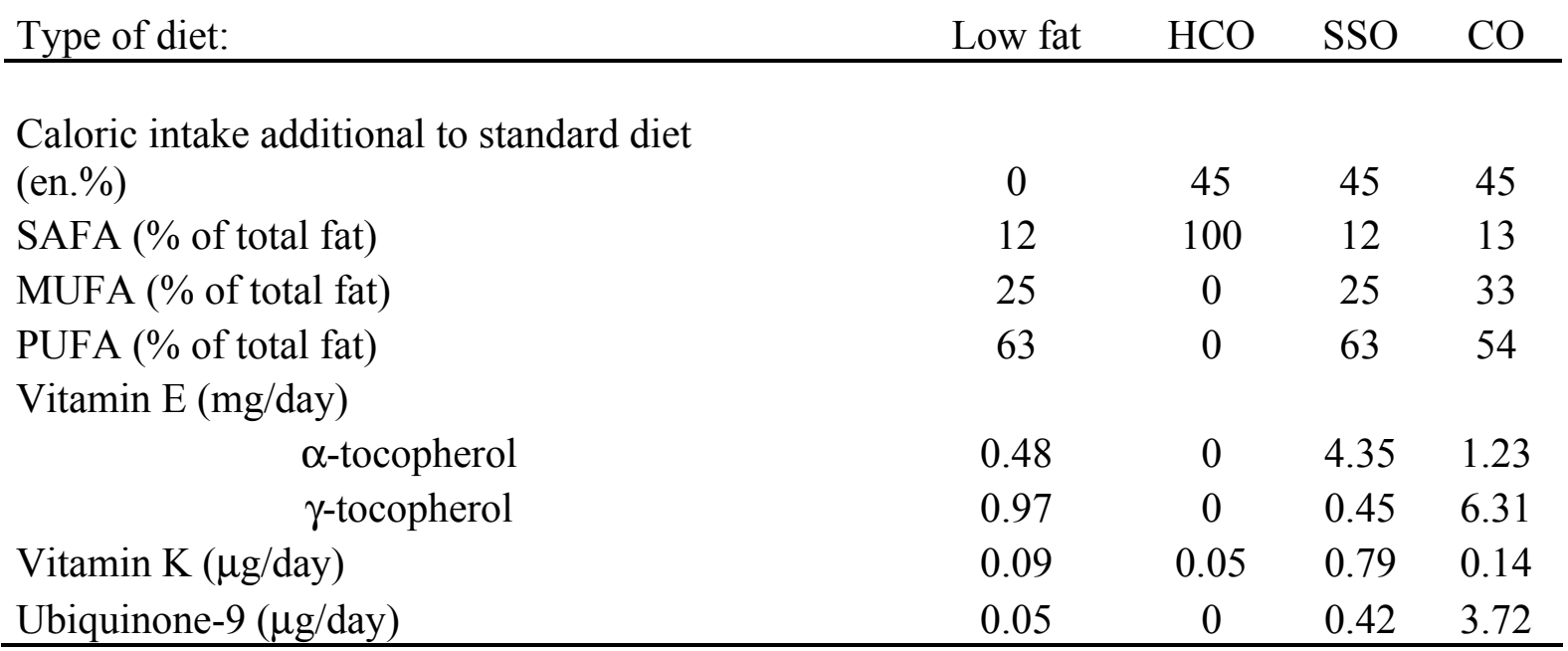

The standard diet (low fat) for rats contained 5 energy\% of SSO. In the high fat diets (HCO, SSO, and $\mathrm{CO}) 45$ energy\% of either $\mathrm{HCO}, \mathrm{SSO}$ or $\mathrm{CO}$ was added to the standard diet to a final 50 energy $\%$.

\section{Animals and diets}

Male Wistar rats were housed individually in wired-bottom cages with a 12-h lightdark cycle and controlled temperature $\left(20 \pm 2{ }^{\circ} \mathrm{C}\right)$ and humidity $(50 \pm 10 \%)$. The vitamin $\mathrm{K}$ deficient food was supplemented with $2 \mu \mathrm{g} / \mathrm{g}$ of vitamin $\mathrm{K}_{1}$ as an oil solution, whereas the added oils provided less than $5 \mathrm{ng}$ of $\mathrm{K}_{1}$ per $\mathrm{g}$ of food. Based on these data the vitamin $\mathrm{K}$ intake was estimated to be $39 \mu \mathrm{g} /$ day. Food for the low fat regimen contained 5 energy $\%$ of $\mathrm{SSO}$ as the only fat compound, food for the high fat regimen contained 5 energy $\%$ of SSO + 45 energy\% of either HCO, SSO or CO (as indicated). To prevent the foods from lipid peroxidation, the diets were prepared freshly each week and stored at $-20{ }^{\circ} \mathrm{C}$ under nitrogen until use. During the experiment the animals were allowed to eat ad libitum. No significant differences between the various groups were found with respect to their mean $( \pm \mathrm{SD}$ ) daily food intake (19 $\pm 5 \mathrm{~g})$ and weight gain (17 $\pm 7 \mathrm{~g} /$ week). The protocol for this experiment was approved by the Maastricht University Committee for Animal Experiments.

\section{Arterial thrombosis tendency in rats}

The ATT was measured using the rat aorta loop model. This model is based on the surgical insertion of a loop-shaped polyethylene cannula in the abdominal aorta of the animals ${ }^{3}$. The wound is closed in such a way that the loop protrudes outside the abdomen and remains available for visual inspection. At places where the cannula is in permanent 
contact with the vessel wall endothelial damage and flow disturbances result in the formation of a thrombus, which is accompanied by a colour change of the loop. Eventually, a thrombus will develop in all cases, and the time required for complete obstruction of the loop is called the obstruction time (OT). It has been well documented that in rats the OT is inversely correlated with the ATT, which may depend on either diet or drugs ${ }^{4,21}$. In the experimental design groups of 24 rats each entered the study at the age of 5 weeks, and received the indicated diets until completion of the experiment. After a feeding period of 8 weeks the loops were implanted, and the obstruction times were recorded. Citrated blood was collected shortly before implantation of the loops

\section{Various analytical techniques}

Prothrombin concentrations were assessed with the one-stage coagulation assay using Thromborel $\mathrm{S}$ and human clotting prothrombin-deficient plasma from Behringwerke (Marburg, Germany). Plasma vitamin K concentrations were assessed by high performance liquid chromatography, with on-line electrochemical detection of the effluent and fluorescence detection ${ }^{22,23}$. Triglycerides and cholesterol were determined by standard enzymatic techniques (Boehringer Mannheim, Germany) on a Beckmann Synchron CX 7-2 autoanalyser (Fullerton, CA).

\section{Statistics}

Because obstruction times show a log-normal distribution pattern, logarithmic transformation of these values was performed before the differences between the groups were tested by the one-way ANOVA using the Bonferroni post-hoc procedure for multiple group analysis. Mean obstruction times were calculated from the mean log-OT values. Effects on blood coagulation were tested non-parametrically for each group using the Mann-Whitney U test. All statistics were performed with the statistical program StatView 4.1, (Abdacus Concepts, Cary. NC).

\section{Results}

Arterial thrombosis tendency in rats at high intake of different oils

The effects of high intake of three different oils were compared in three groups of 24 rats each. The data are shown in Figure 1 and demonstrate that at high fat intake both unsaturated oils ( $\mathrm{SO}$ and $\mathrm{CO}$ ) induced a significantly decreased arterial thrombosis risk as compared to the saturated oil. Remarkably, there was a significant difference between both unsaturated oils as well, with the lowest arterial thrombosis risk for the corn oil group. 


\section{Effects of high and low intake of dietary oils in rats}

In a second, independent study, we compared the effects of high and low fat intake. One group of animals received a low fat diet ( 5 energy $\%$ of SSO), and served as a reference group in this experiment. The other groups received high fat diets as described above. The data of this experiment are summarized in Table 2. It was found that the obstruction times in the HCO-group were significantly shorter than those in the low fat group, indicating an increased arterial thrombosis tendency due to high intake of saturated oil. No such effect was observed at high intake of SSO, which resulted in obstruction times comparable to the low fat group. Consistent with the data in Figure 1, high intake of CO resulted in very long obstruction times, suggesting that high intake of corn oil significantly reduced the arterial thrombosis tendency both as compared to low fat intake as to high SSO intake.

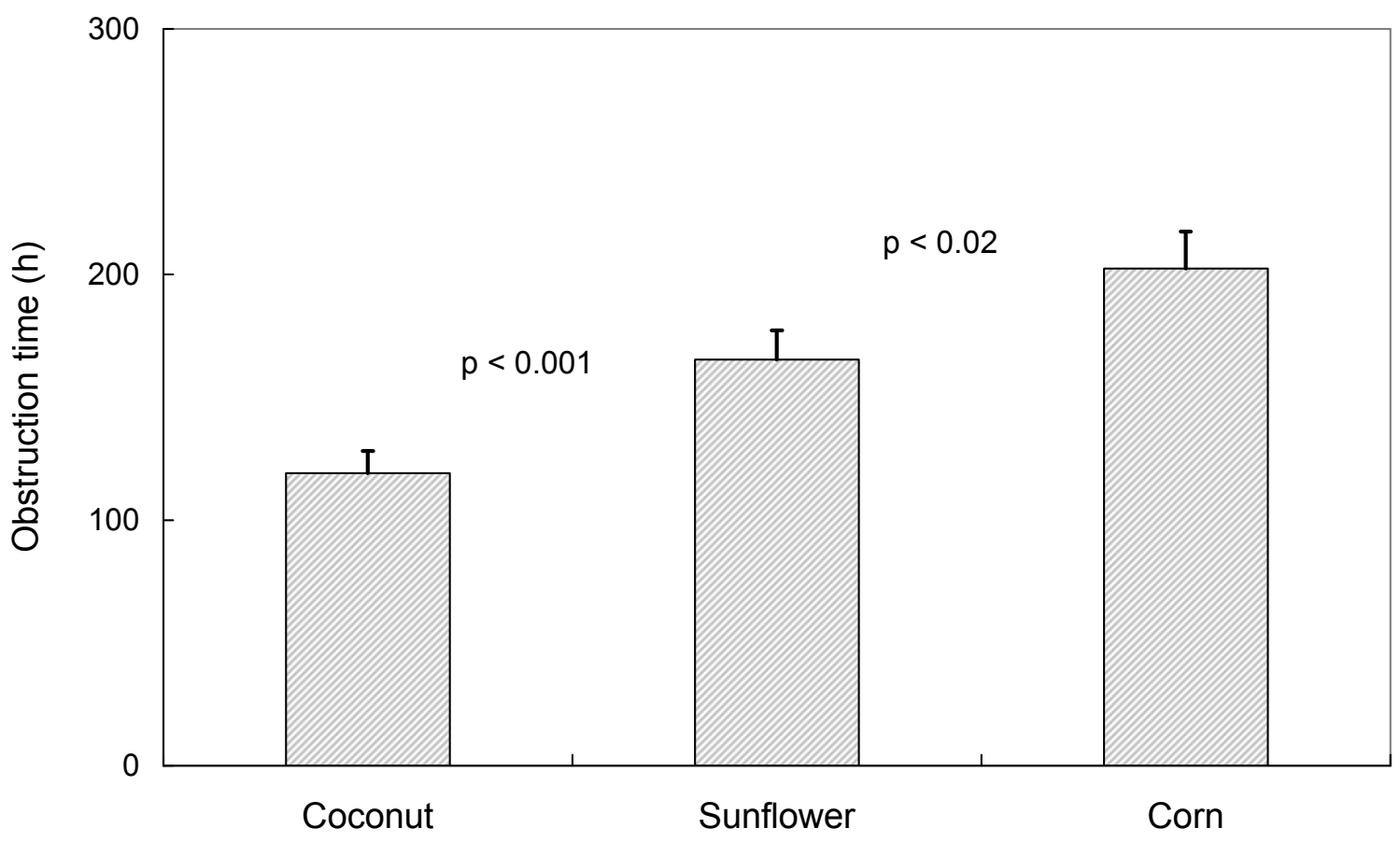

Figure 1.

Arterial thrombosis tendency at high fat intake: comparison of different fat types. The time required for obstruction of the aorta loop (ATT) is inversely correlated to thrombosis tendency, and was expressed in hours \pm SD. Statistical analysis was performed after log-transformation of the data (see Materials and Methods).

In an attempt to explain these data, we have measured a number of variables in the blood taken shortly before the implantation of the loops (Table 2). None of the oils affected the circulating prothrombin concentration. It should mentioned here that the assays were performed with human reagents, which may have affected their sensitivity in a negative way. 
The HCO diet resulted in relatively high circulating levels of triglycerides and vitamin $\mathrm{K}$, whereas in the CO and SSO groups the triglycerides were significantly lower than in the low fat group. This effect was stronger in the CO group than in the SSO group, but whether this difference is sufficient to explain the strongly reduced arterial thrombosis tendency in the $\mathrm{CO}$ group is not clear. Also circulating vitamin $\mathrm{K}$ was reduced during high intake of unsaturated oil, but the effect was only statistically significant in the CO group.

Table 2. Comparison of high and low dietary fat in the rat

\begin{tabular}{lcccc}
\hline & Low fat & HCO & SSO & CO \\
\cline { 2 - 5 } & & & & \\
Number of rats: & 24 & 48 & 48 & 48 \\
Dietary fat (energy\%): & 5 & 50 & 50 & 50 \\
& & & & \\
Obstruction time $(\mathrm{h})$ & $120 \pm 8$ & $91 \pm 11^{*}$ & $123 \pm 10$ & $144 \pm 13^{*}$ \\
Plasma prothrombin $(\%$ of ref) & $96 \pm 7.6$ & $99 \pm 9.2$ & $102 \pm 9.1$ & $101 \pm 5.5$ \\
Serum vitamin $\mathrm{K}_{1}(\mu \mathrm{g} / \mathrm{L})$ & $0.8 \pm 0.2$ & $1.9 \pm 0.3^{*}$ & $0.8 \pm 0.27$ & $0.7 \pm 0.2^{*}$ \\
Serum triglycerides $(\mathrm{mmol} / \mathrm{L})$ & $1.0 \pm 0.1$ & $1.8 \pm 0.1^{*}$ & $0.9 \pm 03^{*}$ & $0.6 \pm 0.05^{*}$ \\
$\mathrm{~K}_{1} /$ triglyceride $(\mu \mathrm{g} / \mathrm{mmol})$ & $0.8 \pm 0.2$ & $1.1 \pm 0.2$ & $0.9 \pm 0.2$ & $1.1 \pm 0.2$ \\
\hline
\end{tabular}

Rats were fed with various diets during 8 weeks before blood was taken and aorta loops were implanted. Determinations in plasma and serum were performed in duplicate, mean values for each individual animal were used to calculate the mean of means $( \pm S D)$ given in this Table. The values obtained in the three high fat groups were compared with the low fat one, differences were regarded to be significant at $\mathrm{p}<0.05(*)$.

\section{Discussion}

This paper is based on the initial discovery that in an animal model system the arterial thrombosis tendency is decreased by replacing $\mathrm{HCO}$ in the diet by either SSO or CO. Whereas these first experiments were performed exclusively in animals on a high-fat regimen (50 energy\%), later studies demonstrated that the beneficial effect of SSO is lost if the highfat diet is compared with low-fat diets ( 5 energy $\%)$. For high intake of $\mathrm{CO}$, however, a substantial and significant protective effect remained even when the diet was compared with a low-fat regimen (Table 2). The difference between $\mathrm{CO}$ and $\mathrm{HCO}$ was comparable to that obtained in rats treated with low doses of vitamin K-antagonist (G. Hornstra, unpublished data) or with high doses of aspirin ${ }^{24}$. The difference between HCO and both plant oils may be explained by the fact that the former is fully saturated, whereas both CO and SSO contain $70 \mid$ 
a large fraction of unsaturated fatty acids. Because the fatty acid composition of CO and SSO is remarkably similar, other explanations have to be found for their different effect on the arterial thrombosis tendency. Substantial differences between CO and SSO were reported with respect to their non-fat fraction. $\mathrm{CO}$, for instance, was reported to contain 10-20 fold more ubiquinone and $\gamma$-tocopherol than did SSO ${ }^{25}$. Since these compounds have a marked structural analogy with vitamin $\mathrm{K}$, our group and others have tested whether either ubiquinone ${ }^{26}$ or tocopherol ${ }^{27}$ may act as competitive inhibitors for the vitamin K-dependent carboxylase, thus inhibiting the biosynthesis of blood coagulation factors. Although in vitro some inhibition was found, the effect was weak and it is unlikely that it can explain the marked in vivo differences between both oils.

We have tested this hypothesis in rats as well as in a human nutritional study. In rats we found no significant effect of any of the oils on the circulating prothrombin concentration. It should be kept in mind, however, that the prothrombin assay is not a very sensitive one to detect small fluctuations. A direct assay for descarboxy-prothrombin would be far more accurate, but this test is not available for rats. As compared to the low fat group, serum vitamin $\mathrm{K}$ had remained constant in rats on $\mathrm{SSO}$, but had significantly decreased in the $\mathrm{CO}$ group. Circulating triglycerides, which play a major role in vitamin $\mathrm{K}$ transport, had decreased in both plant oils, but to a much larger extent in the CO than in the SSO group. Hence it is at least feasible that the type of oil affects the bioavailability and tissue distribution of vitamin $\mathrm{K}$.

When trying to find an explanation for the observed effects of corn oil it is important to realise that after intestinal absorption, vitamin $\mathrm{K}$ is transported in the blood via lipoproteins and that it is liberated therefrom during the hydrolysis of the chylomicron triglycerides in a variety of tissues (including the liver) before the chylomicron remnants are cleared by the liver ${ }^{28}$. Only little vitamin $\mathrm{K}$ is found in the LDL and HDL fractions ${ }^{18}$. Obviously, the postprandial fatty acid content of the chylomicrons will depend on the composition of the diet. Animal and some human studies suggest an increased activity of endothelial lipoprotein lipase towards the hydrolysis of PUFA-rich compared to SAFA-rich chylomicrons ${ }^{8,29}$. In the context of vitamin $\mathrm{K}$ and vitamin $\mathrm{K}$-dependent coagulation proteins, a recent study in rats showed that the PUFA-rich fish oil not only decreased serum cholesterol and triglyceride levels, but also led to decreased levels of the vitamin K-dependent coagulation factors prothrombin and factor VII ${ }^{12}$. These authors postulated that this hypocoagulable effect may be mediated by limited delivery of vitamin $\mathrm{K}$ to the liver and thereby the synthesis of vitamin K-dependent coagulation proteins. Our data support the view that circulating levels of vitamin K-dependent coagulation proteins are linked to lipid metabolism in normal physiology ${ }^{30}$ with the intriguing possibility that part of this interaction with lipids may mediated via an effect on vitamin $\mathrm{K}$ metabolism ${ }^{12}$. An explanation for such an effect could 
be that corn oil induces a different transport for vitamin $\mathrm{K}$ with more extra-hepatic vitamin $\mathrm{K}$ uptake rather than accumulation in the liver, but this is speculative at this time.

We and others have demonstrated that subclinical vitamin K-deficiency is common in the healthy adult population and may be associated with low bone mass ${ }^{31-33}$, increased fracture rate in postmenopausal osteoporosis ${ }^{34}$, and increased vascular calcification ${ }^{35}$. These phenomena may be related to the synthesis of incompletely carboxylated Gla-proteins such as osteocalcin in bones ${ }^{36}$, and matrix Gla-protein (MGP) in the arterial vessel wall ${ }^{37}$. Therefore, nutrients capable of shifting the balance between hepatic and extra-hepatic vitamin $\mathrm{K}$ uptake may have a dual effect. On one hand they might induce a mildly anticoagulant effect by decreasing the hepatic vitamin $\mathrm{K}$ status, thus lowering the arterial thrombosis tendency. On the other hand they might improve vascular MGP carboxylation and thus contribute to the prevention of arterial calcification. 


\title{
NOVEL EFFECTS OF DIETS ENRICHED WITH CORN OIL OR AN OLIVE OIL / SUNFLOWER OIL MIXTURE ON VITAMIN K METABOLISM AND VITAMIN K-DEPENDENT PROTEINS IN YOUNG MEN
}

\begin{abstract}
Little is known of how the fat components of diets influence the absorption, and metabolism of vitamin $K$ and the possible consequences to the synthesis of vitamin $K$ dependent (VKD) proteins in different target organs. We have evaluated the effects of two diets on circulating phylloquinone $\left(K_{1}\right)$ and triacylglycerols $(T A G)$. One diet was enriched with corn oil (CO) (also rich in $\gamma$-tocopherol) and the other with an olive/sunflower (O/SO) mixture (rich in $\alpha$-tocopherol). Effects on $\gamma$-carboxylation were assessed from coagulation assays and sensitive assays for undercarboxylated prothrombin (ucFII) and osteocalcin (ucOC). Total plasma matrix Gla-protein (MGP) was also measured. After an initial adjustment diet, 26 healthy young men were fed, in a crossover design, the O/SO or CO diet for 2 weeks. Mean intakes of $K_{1}$ during consumption of adjustment, O/SO, and CO diets were $225 \mu \mathrm{g} /$ day, $291 \mu \mathrm{g} /$ day, and $291 \mu \mathrm{g} /$ day, respectively. Mean fasting levels of TAG and $K_{1}$ were both significantly reduced by the CO diet, but not by the O/SO diet. Neither diet reduced FII activity but ucFII became detectable in 9 subjects, 8 of whom showed this abnormality with both diets. The $\mathrm{CO}$ diet induced a rise in ucOC $(P<0.05)$ which was negatively correlated to ucFII $(r=-0.71, P<0.03)$ suggesting differences between subjects in the relative bioavailability of vitamin $K$ between liver and bone. The CO but not O/SO diet induced a decrease of total circulating MGP. We conclude that both oils, notably CO, affected vitamin $K$ absorption and/or metabolism which may increase the requirements for $\gamma$-carboxylation.
\end{abstract} The mechanism is unclear but may result from interactions of vitamin $K$ with PUFA and/or other lipid components such as vitamin E.

\section{Introduction}

The nutritional need for vitamin $\mathrm{K}$ is most commonly associated with the four vitamin K-dependent (VKD) coagulation factors (II, VII, IX and X) that are all synthesized in the liver ${ }^{38}$. Other VKD proteins are synthesized in extra-hepatic tissues. They include the bone protein OC, and MGP whose mRNA is expressed by various tissues and cell types. There is good evidence that OC plays a regulatory role in bone turnover ${ }^{39}$ and that MGP is essential 
to prevent calcification of arteries ${ }^{40}$. All these proteins require vitamin $\mathrm{K}$ for a posttranslational modification in which selective glutamate residues are transformed to $\gamma$ carboxyglutamate (Gla) residues. The necessity of Gla residues for functional activity is known for the VKD coagulation proteins ${ }^{38,41}$ and is probable for others. When the supply of vitamin $\mathrm{K}$ is insufficient or when there is a metabolic blockade (e.g. by oral anticoagulants), undercarboxylated species of Gla-proteins are released into the circulation and provide a measure of the vitamin $\mathrm{K}$ status at their site of synthesis ${ }^{42}$.

The major dietary and circulating form of vitamin $\mathrm{K}$ is phylloquinone (vitamin $\left.\mathrm{K}_{1}\right)^{38}$. After intestinal absorption, phylloquinone, like other fat-soluble vitamins is carried via the chylomicron pathway. However, a major difference from other fat-soluble vitamins is that triacylglycerol-rich (TAG-rich) lipoproteins continue to be the major carriers of phylloquinone in both the postprandial ${ }^{18}$ and fasting ${ }^{17}$ states. This association with TAGrich lipoproteins is reflected in a positive correlation of plasma phylloquinone and triacylglycerol concentrations ${ }^{14-16}$. This suggests that dietary and other factors that influence the metabolism of TAG-rich lipoproteins may also affect the transport, tissue distribution and metabolism of vitamin K possibly affecting $\gamma$-carboxylation of the target Gla proteins. Indeed it was recently suggested that decreases in FII and FVII in rats produced by diets enriched with n-3 PUFA may have resulted from a lipid-lowering effect which affected the lipoprotein transport and delivery of vitamin $\mathrm{K}$ to the liver ${ }^{12}$.

As far as we are aware there have been no human studies that have directly examined whether dietary manipulation of the fat components of diets can influence the intestinal absorption and/or metabolism of vitamin $\mathrm{K}$ and thereby the $\gamma$-carboxylation of VKD proteins. The present study was facilitated by our access to a dietary cross-over study in healthy young men that had initially been designed to compare the effects of $\gamma$-tocopherol-rich corn oil (CO) and $\alpha$-tocopherol-rich olive/sunflower $(\mathrm{O} / \mathrm{SO})$ oil on DNA damage in healthy young men ${ }^{43}$. This study was also of interest to us because high dietary intakes of vitamin $\mathrm{E}$ have been associated with an inhibitory effect on vitamin $\mathrm{K}$ action ${ }^{44}$. Apart from measurements of plasma phylloquinone, vitamin $\mathrm{K}$ status was assessed from functional assays of VKD coagulation proteins, sensitive assays for undercarboxylated prothrombin 45 and undercarboxylated osteocalcin ${ }^{46}$ and a new assay for total MGP ${ }^{47}$.

\section{Materials and Methods}

\section{Subjects and Study Design}

Twenty-six healthy men (aged 19-31 years) were recruited from the population of Vienna. None were taking medications or vitamin supplements for at least 2 weeks before 
entering the study. During an randomly assigned initial 2-week period all subjects consumed the same adjustment diet followed by diets enriched with either an olive/sunflower oil mixture (O/SO diet) or corn oil ( $\mathrm{CO}$ diet) in a cross-over design of 2 weeks per diet. Weighed dietary records were kept for each participant for the entire study period to calculate nutrient intakes. Venous blood samples were collected in trisodium citrate (after an overnight fast) at 2-weekly intervals coinciding with the end of each dietary regime. Plasma samples were stored in aliquots at $-80^{\circ} \mathrm{C}$ until analysis. The study protocol was approved by the Medical Ethics Committee of the University of Vienna and all subjects gave their informed consent in writing.

\section{Dietary Oils and Experimental Diets}

The sources of the oils used for the diets were: corn oil, CPC-Bestfoods (Heilbronn, Germany); olive oil, Linea Natura (Milan, Italy); sunflower oil, Nestle (Karlsruhe, Germany). Their SAFA/MUFA/PUFA compositions were: olive oil 14:77:9, sunflower oil 12:24:64 and corn oil 13:33:54. Their vitamin E contents per 100g oil were: olive oil $20 \mathrm{mg} \alpha$-tocopherol and $1.7 \mathrm{mg} \gamma$-tocopherol, sunflower oil $85.3 \mathrm{mg} \alpha$-tocopherol and $8.8 \mathrm{mg} \gamma$-tocopherol, corn oil $24.6 \mathrm{mg} \alpha$-tocopherol and $126.2 \mathrm{mg} \gamma$-tocopherol ${ }^{43}$. The $\mathrm{K}_{1}$ contents of olive, sunflower and corn oil were $54.8,5.7$, and $2.7 \mu \mathrm{g} / 100 \mathrm{~g}$, respectively.

All food was prepared at the Institute of Nutritional Sciences of the University of Vienna as three daily meals and offered to the subjects in the presence of one of the investigators. On weekdays all subjects ate their mid-day meal in the Institute. Breakfast and evening meals were pre-packed and given to the subjects on a daily basis. Weekend meals were also prepared beforehand and given to the subjects on Fridays. Typical foodstuffs for breakfasts comprised rye and wheat bread, muesli, buttermilk and occasionally yogurt and fruit. Lunches comprised soup, fish or meat with vegetables and usually a fresh salad. Common food items for evening meals were bread, yogurt, fruit and cheese.

The composition of the diets is shown in Table 1. The adjustment diet provided the daily intakes of $35 \mathrm{~g}$ olive oil, $4.4 \mathrm{~g}$ sunflower oil and $13.8 \mathrm{~g}$ of butter. The $\mathrm{O} / \mathrm{SO}$ and CO test diets were identical apart from their different fat contents. The O/SO diet provided the daily intakes of $68 \mathrm{~g}$ olive oil and $12 \mathrm{~g}$ sunflower oil (SAFA/MUFA/PUFA $=28 / 49 / 23$ ) and the $\mathrm{CO}$ diet the equivalent intake of $80 \mathrm{~g}$ corn oil (SAFA/MUFA/PUFA $=29 / 33 / 38$ ). The $80 \mathrm{~g}$ total daily intakes of dietary oils represented $73 \%$ of the total daily fat intake. Both $\mathrm{O} / \mathrm{SO}$ and $\mathrm{CO}$ diets provided similar intakes of $\alpha$-tocopherol but the $\mathrm{CO}$ diet provided a high intake of $\gamma$-tocopherol (100 mg/day) compared to the $\mathrm{O} / \mathrm{SO}$ diet (2.4 mg/day) (Table 1). Dietary intakes of phylloquinone $\left(\mathrm{K}_{1}\right)$ were calculated from the weighed dietary records of the participants and the $\mathrm{K}_{1}$ content of foods taken from newly available data bases from The Netherlands and the U.K ${ }^{48-50}$. Based solely on the $\mathrm{K}_{1}$ values for their component oils the $\mathrm{O} / \mathrm{SO}$ and CO diets 
provided daily intakes of $15.4 \mu \mathrm{g}$ and $2.8 \mu \mathrm{g} \mathrm{K}_{1}$ respectively. However, this difference was negligible compared to the intakes of $K_{1}$ from other food components, especially green leafy vegetables. With the cross-over design the average daily intakes of vitamin $\mathrm{K}$ were closely similar for both groups, but there was considerable day to day variation (mean: $291 \mu \mathrm{g}$, S.D. \pm 213 ) which was due to the variability of consumption of green vegetables. The average daily intakes of $K_{1}$ calculated for each phase of the study were $225 \mu \mathrm{g}$ (adjustment phase), $238 \mu \mathrm{g}$ (cross-over phase I) and $343 \mu \mathrm{g}$ (cross-over phase II).

Table 1. Composition of the diets

\begin{tabular}{lccc}
\hline Diet content & Adjustment diet & Olive/sunflower oil diet & Corn oil diet \\
\hline Mean energy (MJ) & & & \\
Carbohydrate (energy\%) & 11.6 & 11.6 & 11.6 \\
Protein (energy\%) & $50-55$ & $50-55$ & $50-55$ \\
Fat (energy\%) & 15 & 15 & 15 \\
SAFA (energy\%) & $30-35$ & $30-35$ & $30-35$ \\
MUFA (energy\%) & $11-13$ & $8-10$ & $9-10$ \\
PUFA (energy\%) & $13-15$ & $15-17$ & $10-12$ \\
$\alpha$-Tocopherol (mg/day) & $6-7$ & $7-8$ & $11-13$ \\
$\gamma$-Tocopherol (mg/day) & 12 & 24 & 20 \\
Phylloquinone $(\mu \mathrm{g} /$ day) & - & 2.4 & 100 \\
\hline
\end{tabular}

Table shows the range of daily consumption of macronutrients and the mean daily consumption of tocopherol and phylloquinone (vitamin $\mathrm{K}_{1}$ ) micronutrients

\section{Various Assays}

All biochemical analyses were performed in duplicate and mean values are given throughout this paper. Prothrombin times (PT) were determined by automated assay using Thromborel S (Behringwerke, Marburg, Germany) as thromboplastin reagent. Factor II (FII) concentrations were assessed assay using Thromborel $\mathrm{S}$ and human clotting factor IIdeficient plasma from Behringwerke. Species of undercarboxylated FII (ucFII) were measured using a conformation-specific monoclonal antibody in an ELISA-based assay ${ }^{45}$. Results are expressed as Arbitrary Units per L (AU/L) because in states of vitamin K deficiency circulating ucFII may comprise multiple forms of partially carboxylated FII and neither their relative abundance in plasma nor their relative affinity for the antibody is known. Using electrophoretic techniques $1 \mathrm{AU}$ is equivalent to $1 \mu \mathrm{g}$ of purified ucFII ${ }^{45}$. The detection limit was $150 \mathrm{AU} / \mathrm{L}$ plasma.

Total immunoreactive OC was measured using the two-site N-mid hOsteocalcin ELISA (Osteometer A/S, Copenhagen, Denmark). Undercarboxylated osteocalcin (ucOC) 76| 
was determined with the Glu-OC kit from Takara Shuzo (Tokyo, Japan). MGP was determined with an ELISA-based assay recently developed at the Maastricht Biochemistry Department ${ }^{47}$. Serum MGP concentrations were calculated with the aid of a reference curve from pooled normal serum, and expressed as arbitrary units per liter (AU/L).

Plasma $K_{1}$ concentrations were measured by high performance liquid chromatography (HPLC) and fluorescence detection after on-line, post column electrochemical reduction of the effluent which converted the quinone forms of vitamin $\mathrm{K}$ compounds to their fluorescent quinol forms ${ }^{22}$. Plasma TAG concentrations were determined by an automated enzymatic procedure using commercial reagents (Boehringer Mannheim, Germany) and a Beckmann Synchron CX 7-2 autoanalyser (Fullerton, CA).

\section{Data analysis}

Blood samples taken at the end of the adjustment phase, cross-over phase I and crossover phase II and were analysed as repeated measurements in the cross-over design to determine whether there were any significant trends. The analysis was used to examine statistical differences between both the oil-regimens and the adjustment phase or between both oil-regimens themselves. The statistical significance of differences between the oilregimens and the adjustment phase were examined using the SPSS 9.0 Students paired t-tests (2-tailed). Differences between the regimens in either cross-over phase I or cross-over phase II were examined with the Wilcoxon matched pairs test. Differences were considered to be statistically significant at $\mathrm{P}<0.05$.

\section{Results}

The results of coagulation assays together with plasma concentrations of TAG, $\mathrm{K}_{1}$ and VKD proteins at the end of each dietary period are shown in Table 2. Compared to the adjustment phase diet, plasma levels of both TAG and $\mathrm{K}_{1}$ were significantly lowered by the $\mathrm{CO} \operatorname{diet}\left(\mathrm{P}<0.01\right.$ for TAG, $\mathrm{P}<0.05$ for $\left.\mathrm{K}_{1}\right)$ but not by the $\mathrm{O} / \mathrm{SO}$ diet. The effect of both diets on hepatic synthesis of VKD procoagulants was assessed by three different assays with varying sensitivities: the PT (an overall coagulation assay which is insensitive to large decreases in the Gla-content of VKD coagulation factors ${ }^{12}$ ), the FII assay (specific for functional Gla forms of prothombin), and an in-house ELISA to detect low concentrations of ucFII. No diet-induced change in hepatic VKD coagulation proteins was detected by either the PT or FII assay. After the adjustment diet, ucFII was below the limit of detection in all subjects but elevated levels were found in 8 subjects (also defined as ucFII positive) after the $\mathrm{O} / \mathrm{SO}$ diet, and in 9 subjects after the $\mathrm{CO}$ diet (Figure 1). Eight of these had an elevated ucFII after both diets which first presented at the end of the first dietary cross-over phase (phase I) 
with the $\mathrm{O} / \mathrm{SO}$ diet and which continued to remain elevated during phase II while taking the $\mathrm{CO}$ diet (subject group B in Table 2). One subject showed an elevated ucFII at the end of cross-over phase I while taking the $\mathrm{CO}$ diet which then dropped below the detectable limit after phase II with the OSO diet. In the remaining 17 subjects ucFII remained undetectable throughout the study. In the ucFII positive subjects, there was no significant difference in the magnitude of ucFII after $\mathrm{O} / \mathrm{SO}$ or $\mathrm{CO}$ diets (Table 2) although in 6/8 subjects who had an elevated ucFII after phase I (O/SO diet), the levels had increased slightly by the end of phase II (CO diet) (Figure 1). There was no correlation between ucFII and plasma $\mathrm{K}_{1}$ concentrations: for the $\mathrm{O} / \mathrm{SO}$ diet the mean $\mathrm{K}_{1}$ concentrations in subjects with undetectable or detectable ucFII were $0.53 \mathrm{nmol} / \mathrm{L}(\mathrm{n}=18)$ and $0.63 \mathrm{nmol} / \mathrm{L}(\mathrm{n}=8)$ respectively. Similarly, for the $\mathrm{CO}$ diet, the mean plasma $\mathrm{K}_{1}$ concentrations were $0.39 \mathrm{nmol} / \mathrm{L}$ in ucFII negative subjects $(\mathrm{n}=17)$ and $0.48 \mathrm{nmol} / \mathrm{L}$ in ucFII positive subjects $(\mathrm{n}=9)$.

Table 2. Effects of OSO and CO tests diets on vitamin $\mathrm{K}$-dependent proteins, vitamin $\mathrm{K}$ and triglycerides

\begin{tabular}{|c|c|c|c|c|c|c|c|c|c|}
\hline \multirow[t]{2}{*}{ Measurement } & \multicolumn{3}{|c|}{ Adjustment diet } & \multicolumn{3}{|c|}{ OSO test diet } & \multicolumn{3}{|c|}{ CO test diet } \\
\hline & all subjects & group $A$ & group B & all subjects & group $A$ & group B & all subjects & group $A$ & group B \\
\hline Prothrombin time (s) & $14.4 \pm 0.8$ & $14.3 \pm 1.0$ & $14.4 \pm 0.7$ & $14.2 \pm 0.9$ & $14.0 \pm 1.0$ & $14.5 \pm 0.9$ & $14.5 \pm 0.8$ & $14.8 \pm 0.9$ & $14.1 \pm 0.4$ \\
\hline Factor II (\% normal) & $88.7 \pm 7.5$ & $88.7 \pm 7.6$ & $88.8 \pm 7.7$ & $92.1 \pm 9.7$ & $89.6 \pm 10.0$ & $94.6 \pm 9.0^{* *}$ & $90.9 \pm 11.8$ & $89.2 \pm 13.5$ & $92.7 \pm 10.1^{*}$ \\
\hline ucF $\|(A U / L)$ & $<150$ & $<150$ & 150 & $220 \pm 120^{* *}$ & $<150$ & $280 \pm 150^{\star *}$ & $240 \pm 160^{* *}$ & $180 \pm 90$ & $310 \pm 180$ \\
\hline ucF II (prevalence) & $0 / 26$ & $0 / 13$ & $0 / 13$ & '8/26 & $0 / 13$ & $8 / 13$ & $9 / 26$ & $1 / 13$ & $9 / 13$ \\
\hline Total osteocalcin $(\mu \mathrm{g} / \mathrm{L})$ & $22.3 \pm 12.9$ & $23.5 \pm 13.7$ & $21.2 \pm 12.5$ & $19.1 \pm 9.1$ & $18.6 \pm 8.7^{*}$ & $19.5 \pm 9.9$ & $18.6 \pm 10.5^{*}$ & $16.4 \pm 8.4^{* \star \ddagger}$ & $20.8 \pm 12.3$ \\
\hline $\mathrm{ucOC}(\mu \mathrm{g} / \mathrm{L})$ & $5.9 \pm 2.4$ & $6.0 \pm 2.4$ & $5.8 \pm 2.5$ & $6.3 \pm 2.4$ & $6.8 \pm 2.8$ & $5.9 \pm 1.9$ & $6.3 \pm 2.3^{*}$ & $6.3 \pm 2.3$ & $6.3 \pm 2.3$ \\
\hline Matrix Gla-protein (U/L) & $93 \pm 8$ & $92 \pm 9$ & $94 \pm 9$ & $98 \pm 10$ & $94 \pm 11$ & $101 \pm 9$ & $86 \pm 11^{\text {**㧊 }}$ & $88 \pm 12$ & 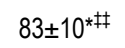 \\
\hline Vitamin $\mathrm{K}_{1}(\mathrm{nmol} / \mathrm{L})$ & $0.59 \pm 0.37$ & $0.64 \pm 0.35$ & $0.54 \pm 0.40$ & $0.56 \pm 0.29$ & $0.51 \pm 0.18$ & $0.61 \pm 0.37$ & $0.42 \pm 0.23^{\star \ddagger}$ & $0.43 \pm 0.19$ & $0.41 \pm 0.27^{\ddagger}$ \\
\hline Triglycerides (mmol/L) & $0.85 \pm 0.46$ & $0.91 \pm 0.44$ & $0.79 \pm 0.49$ & $0.79 \pm 0.44$ & $0.72 \pm 0.33$ & $0.86 \pm 0.53$ & $0.64 \pm 0.34^{\star * \ddagger}$ & $0.57 \pm 0.30^{* * \ddagger}$ & $0.71 \pm 0.38$ \\
\hline
\end{tabular}

The results (mean $\pm \mathrm{SD}$ ) are shown for measurements made at the end of each 2-week dietary phase after the subjects had received the adjustment, the olive/sunflower oil (OSO) and corn oil (CO) diets respectively. Values for each diet are shown for all subjects after completion of the cross-over study and under groups $\mathrm{A}$ and $\mathrm{B}$ according to the sequence in which the 2 randomized groups of 13 subjects received the $\mathrm{OSO}$ and $\mathrm{CO}$ test diets after the adjustment diet. Subjects in group A received the CO diet in phase I and the OSO diet in phase II while subjects in group B received the OSO diet in phase I and the $\mathrm{CO}$ diet in phase II of the cross-over design. * denotes significant differences between adjustment diet and either $\mathrm{OSO}$ or $\mathrm{CO}$ diets with *: $\mathrm{P}<0.05$, and $* *: \mathrm{P}<0.01$. $\ddagger$ denotes significant differences between $\mathrm{OSO}$ and $\mathrm{CO}$ diets with $\ddagger$ : $\mathrm{P}<0.05$, and $\$$ : $\mathrm{P}<0.01$. 


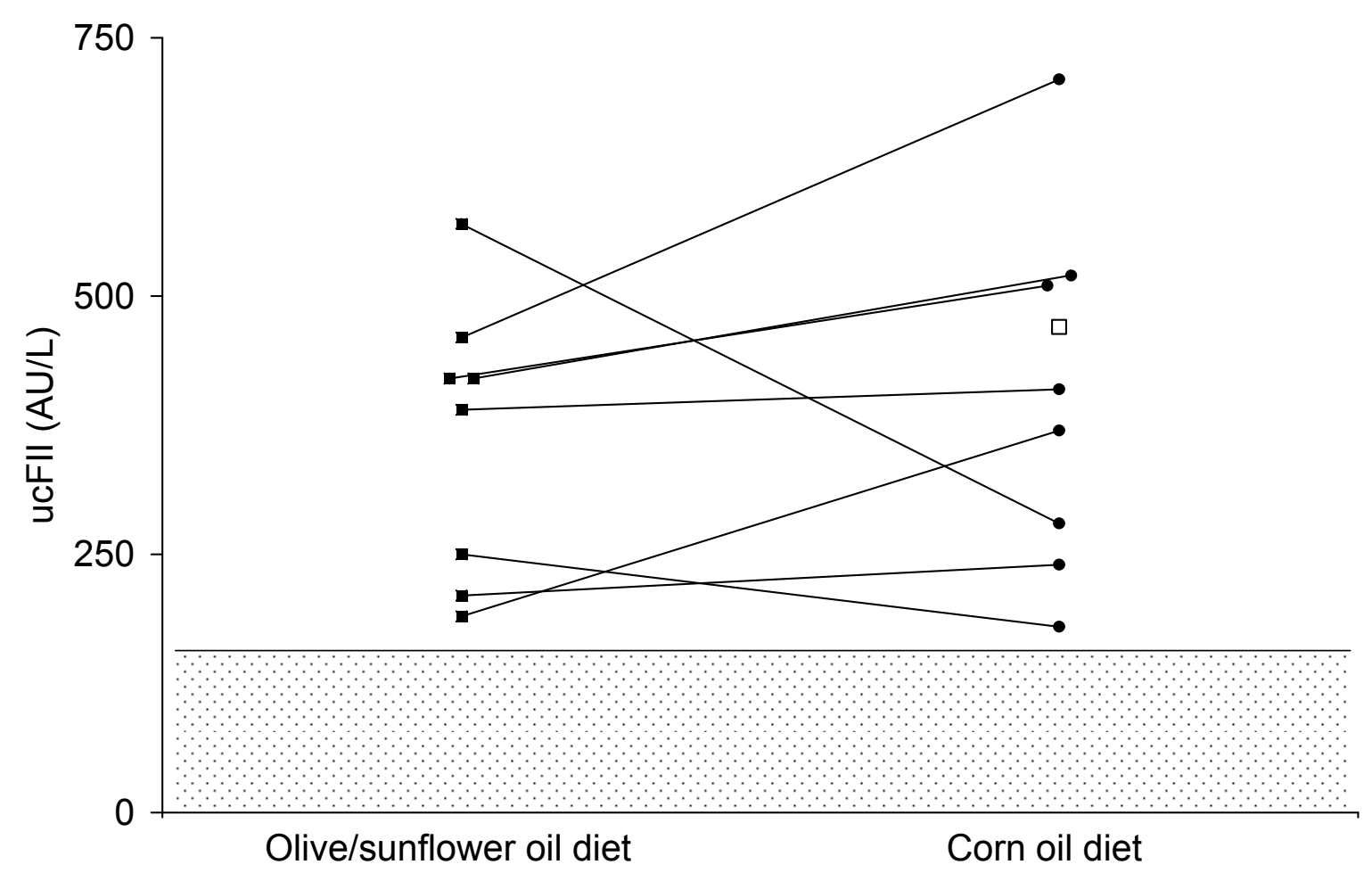

Figure 1.

Diet induced increase of undercarboxylated factor II (ucFII). Explanation of symbols: $\mathbf{a}=$ positive responders after the $\mathrm{O} / \mathrm{SO}$ diet; $\bullet=$ positive responders (paired samples) after the $\mathrm{CO}$ diet (connecting lines indicate same subjects); $\square=$ subject only positive in the CO diet. The shaded area shows the lower detection limit (150 AU/L).

The effect of both diets on the synthesis of extra-hepatic VKD proteins was assessed for OC and MGP. Neither diet affected circulating concentrations of total immunoreactive OC. However, differences were seen with a monoclonal-based assay specific for ucOC. Both $\mathrm{CO}$ and $\mathrm{O} / \mathrm{SO}$ diets induced an increase in plasma ucOC but this only became statistically significant for the CO diet. Suggestive for a differential carboxylation of FII in the liver and $\mathrm{OC}$ in bone was the observation that for both $\mathrm{O} / \mathrm{SO}$ and $\mathrm{CO}$ diets, the mean ucOC concentrations in ucFII positive subjects were $20 \%$ lower than in ucFII negative subjects (ucOC $5.4 \mu \mathrm{g} / \mathrm{L}$ vs $6.8 \mu \mathrm{g} / \mathrm{L}$ in positive and negative subjects respectively). This relatively small difference did not attain statistical significance, however. A test of the degree of correlation between ucOC and ucFII concentrations was only possible in about a third of the subjects with detectable ucFII, and as shown in Figure 2 for the CO diet there was a negative correlation between ucOC and ucFII $(\mathrm{r}=-0.71, \mathrm{P}=0.03)$. In the $\mathrm{O} / \mathrm{SO}$ group this correlation was also negative $(r=-0.35)$ but not statistically significant. 


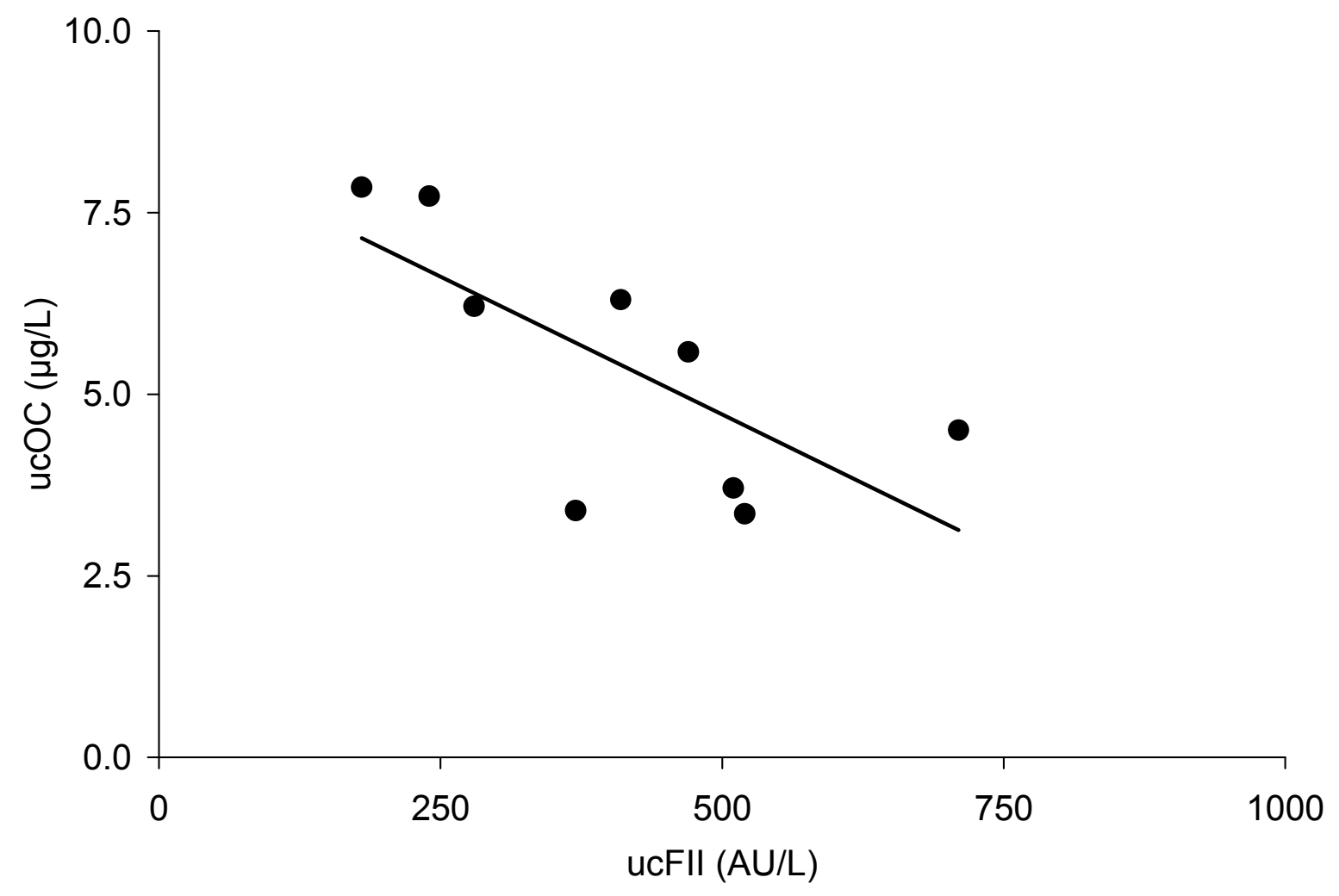

Figure 2.

Inverse correlation between ucFII and ucOC during the $\mathrm{CO}$ diet. The Pearson correlation coefficient (r) was -0.71 and level of significance $(\mathrm{P})$ was 0.03 .

We also measured the circulating levels of MGP, which were significantly lower after the $\mathrm{CO}$ diet than after either the adjustment or $\mathrm{O} / \mathrm{SO}$ diets (Figure 3). These measurements represent total MGP, assays discriminating between MGP and ucMGP are presently not available.

Since previous studies have reported that circulating VKD coagulation factors may be positively related to plasma lipids, we examined the relationship between plasma TAG and the VKD proteins. FII was positively correlated with TAG during all diets (pooled data: $\mathrm{R}=0.385 ; \mathrm{P}<0.01)$ and also separately within each dietary phase with the strongest correlation for the $\mathrm{CO}$ diet $(\mathrm{R}=0.536 ; \mathrm{P}<0.01)$. The extra-hepatic $\mathrm{VKD}$ proteins $\mathrm{OC}$ and MGP did not correlate with TAG. 


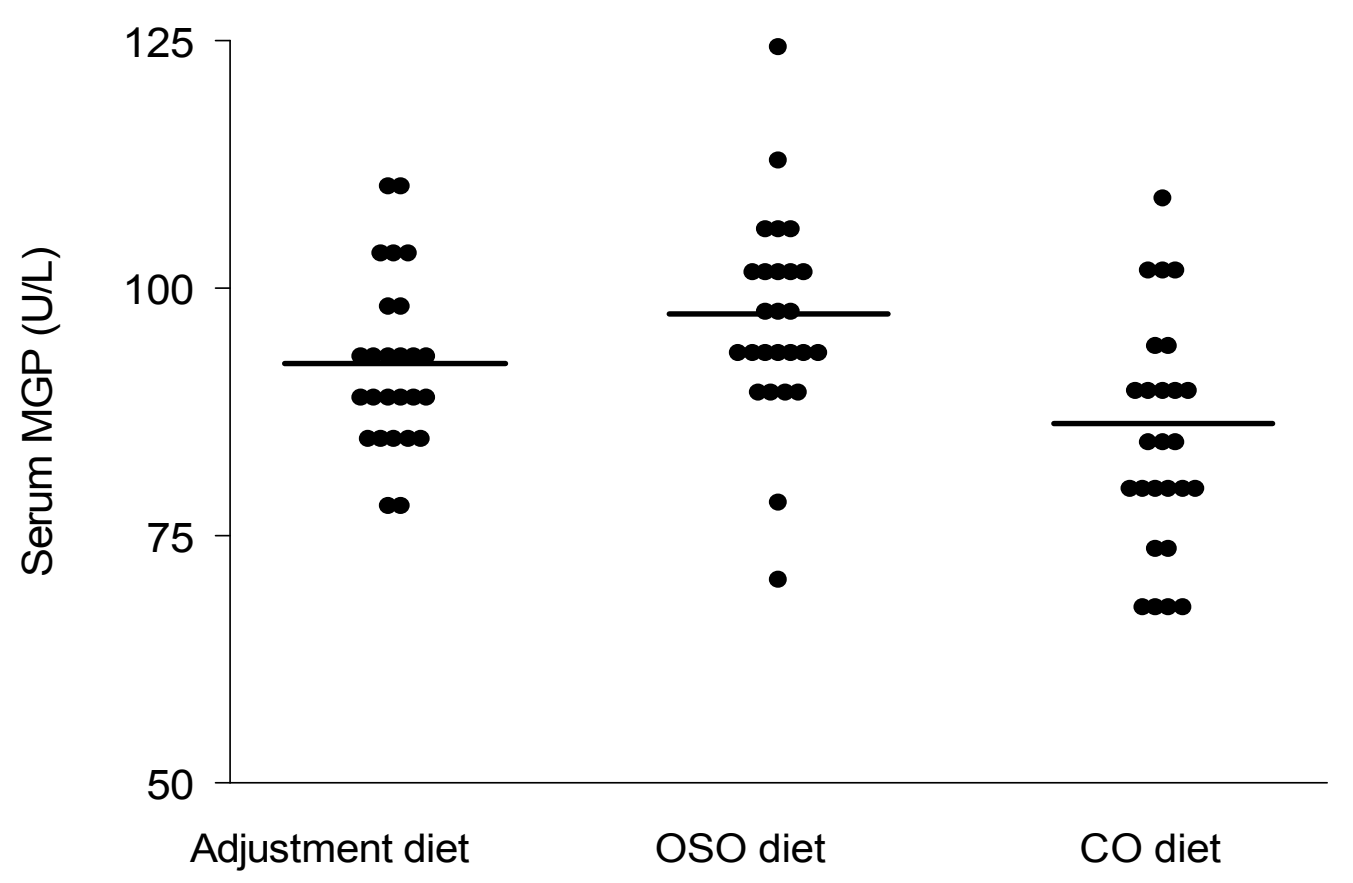

Figure 3.

Serum MGP concentrations during the three different dietary regimes. The mean value during the CO diet was significantly lower than the values during the adjustment phase and the OSO diet.

\section{Discussion}

The present study provides evidence that altering the lipid component of the diet has the potential to reduce plasma levels of $\mathrm{K}_{1}$ and/or impair the $\gamma$-carboxylation of representative hepatic (FII) and extra-hepatic (OC) Gla-proteins. It was noteworthy that the PUFA-rich CO diet induced a significant reduction in plasma $\mathrm{K}_{1}$ and $\mathrm{TAG}$ compared to both adjustment and $\mathrm{O} / \mathrm{SO}$ diets. This is consistent with the carriage of $\mathrm{K}_{1}$ by TRL ${ }^{18}$ and with the well-established capacity of diets rich in PUFA to reduce post-absorptive concentrations of plasma TAG ${ }^{8}$, probably by reducing the post-prandial accumulation of TRL ${ }^{29}$. The accompanying evidence of slight increases in undercarboxylation of FII and osteocalcin by the $\mathrm{CO}$ diet imply a lowered vitamin $\mathrm{K}$ status that may, however, be unrelated to the lowering of plasma TAG and $\mathrm{K}_{1}$. Possible explanations include a reduced intestinal absorption of vitamin $\mathrm{K}$, a reduced extra cellular or intracellular delivery of vitamin $\mathrm{K}$ to target proteins, an increased turnover rate of the vitamin, or an inhibitory effect on VKD $\gamma$-carboxylation.

The possibility that the $\mathrm{CO}$ diet reduced the intestinal absorption of vitamin $\mathrm{K}$ is supported by in vivo studies in rats which showed that the PUFA linoleic acid (18:2) caused a 
marked decrease in the intestinal absorption rate of vitamin $\mathrm{K}_{1}{ }^{51}$. This inhibition was not seen with the MUFA oleic acid (18:1). The same authors briefly commented that linoleic acid also inhibited the absorption of vitamin A. Other in vivo studies have shown that feeding diets with increasing linoleic acid contents to rats depressed the intestinal lymphatic absorption of vitamin $\mathrm{E}^{52}$. Taken together, these studies in rats suggest a general inhibitory effect of PUFAs on the absorption of fat soluble vitamins which share a similar pathway of absorption and lymphatic transport.

Previous studies in healthy adults have indicated that the levels of VKD FVII are more influenced by the total fat content of the diet rather than the SAFA/MUFA/PUFA composition ${ }^{53}$. In our study we also found no effects of the $\mathrm{O} / \mathrm{SO}$ or $\mathrm{CO}$ diets on the PT or FII concentrations but we did find a significant correlation of FII levels with plasma TAG. This is in agreement with previous studies showing associations of one or more VKD coagulation factors with TAG in patients with hyperlipidemia ${ }^{54,55}$ and in healthy young men ${ }^{30}$. The reason for this association of VKD proteins with lipids is still unclear, but the recent finding of the in vivo binding of all VKD coagulation proteins to TRL ${ }^{56}$ provides one explanation. Our data support the view that circulating levels of VKD coagulation proteins are linked to lipid metabolism in normal physiology ${ }^{30}$ with the possibility that part of this interaction with lipids may mediated via an effect on vitamin $\mathrm{K}$ metabolism ${ }^{12}$.

To assess possible effects of the diets on the $\gamma$-carboxylation of FII, we used a sensitive immunoassay specific to ucFII. Hitherto, plasma ucFII concentrations in freeliving, healthy adults with this assay have always been below the detection limit. The same was true in the present study for all 26 subjects after the adjustment phase but both test diets induced detectable ucFII. That this was a genuine effect of the diets is supported by the fact that the analyses of ucFII were blind and carried out in random order. It should be emphasised that the absolute increases in ucFII were relatively low and that the presence of such low concentrations (200-700 AU/L) did not affect the PT or FII assay. In patients on stable anticoagulant therapy ucFII values with this assay range from 6,900-99,500 AU/L (mean 40,000 AU/L) (M.J. Shearer, unpublished results). It seems unlikely, therefore, that this small increment in ucFII, and presumably also in ucFVII, ucIX and ucX, would lead to a hypocoagulable state. On the other hand, evidence that minor reductions in VKD coagulation factors may result in a clinically significant decreased coagulability comes from studies of low dose warfarin regimes. Thus, daily doses of $1 \mathrm{mg}$ warfarin reduced the incidence of deep vein thrombosis after surgery with no appreciable prolongation of the $\mathrm{PT}{ }^{57}$, and prevented thrombosis in central venous catheters with no changes in overall coagulation assays or decreases in specific VKD factors ${ }^{58}$. This suggests that a hypocoagulable state can be induced by relatively minor perturbations of the carboxylation status of VKD coagulation proteins. 
In contrast to the hepatic Gla-proteins, there is evidence that the bone protein $\mathrm{OC}$ is not fully carboxylated and is readily responsive to changes in dietary intakes of vitamin $\mathrm{K}^{59}$. Compared to the adjustment diet, ucOC was significantly reduced only by the $\mathrm{CO}$ diet, but with the concomitant fall in total OC this effect was significant for both diets when ucOC was expressed as a percent of total OC. Total circulating OC is also a marker of osteoblastic activity, reflecting the rate of bone formation, but as this reduction of total OC was unexpected, further studies would be needed to address such a relationship. Unlike FII, there was no correlation of either $\mathrm{OC}$ or ucOC with TAG levels and there are no reports in the literature indicating such a relationship.

A direct inhibition of the VKD $\gamma$-glutamyl carboxylase or other enzymes of the vitamin K-epoxide cycle by non-TAG components also cannot be excluded. Compared to the adjustment diet, both the $\mathrm{O} / \mathrm{SO}$ and $\mathrm{CO}$ diets provided about double the intake of $\alpha$ tocopherol while the $\mathrm{CO}$ diet provided a high intake of $\gamma$-tocopherol. The high $\gamma$-tocopherol content of corn oil has already been forwarded as an explanation of the reduced frequency of sister chromatid exchange seen in the same subjects after the $\mathrm{CO}$ diet compared with the $\mathrm{O} / \mathrm{SO}$ diet ${ }^{43}$. Corn oil is also a rich source of ubiquinone-9. Vitamin $\mathrm{E}$ and ubiquinone compounds are structurally related to vitamin $\mathrm{K}$, and have been reported to inhibit VKD carboxylase in vitro ${ }^{26,27}$.

The literature contains several reports that vitamin E compounds may interfere with vitamin $\mathrm{K}$ action in animals or humans but the mechanism remains unclear ${ }^{60-63}$. An early study showed that the daily oral administration of large (100 $\mathrm{mg})$ doses of $\alpha$ tocopherolquinone to pregnant mice caused bleeding in the reproductive system which was reversible with vitamin $\mathrm{K}^{60}$ and a similar vitamin K-reversible coagulopathy was observed in chicks with large doses of vitamin $\mathrm{E}^{62}$. Helson et al. ${ }^{63}$ showed in patients with neuroblastoma that large doses of vitamin E caused a bleeding diathesis and that this was a systemic effect on vitamin $\mathrm{K}$ metabolism rather than an effect on absorption. More recently, Alexander \& Suttie ${ }^{64}$ have provided further evidence for cellular and whole animal interactions of vitamin E with vitamin K. Firstly, cultured H-35 cells showed significant decrease in FII production in the presence of both $\alpha$-tocopherol and $\alpha$-tocopherolquinone. Secondly, rats fed a vitamin $\mathrm{K}$ deficient diet and increasing amounts of $\alpha$-tocopherol in combination with a constant amount of phylloquinone showed a dose-dependent reduction in plasma FII and concomitant reductions in both plasma and liver phylloquinone. The effects on vitamin $\mathrm{K}$ and VKD proteins observed in our study were minor in comparison but they raise the possibility of an interaction with the increased dietary intakes of vitamin $\mathrm{E}$.

The strong inverse relationship between ucFII and ucOC seen in those subjects who had detectable ucFII after the CO diet is suggestive of some inter-subject variability in the relative bioavailability of vitamin $\mathrm{K}$ between the liver and bone. This could be mediated by 
difference(s) in lipoprotein metabolism that causes a differential organ/tissue uptake of TRL. One candidate is apolipoprotein $\mathrm{E}$ whose common variants are known to influence postprandial TG metabolism and to mediate the uptake of TRL remnant particles ${ }^{65}$. From this and other studies, Kohlmeier et al. ${ }^{17}$ generated the hypothesis that the liver and bone are competing organs for vitamin $\mathrm{K}$, a hypothesis that may explain the inverse correlation of ucFII and ucOC.

Measurements of total plasma MGP with a recently available assay showed that the $\mathrm{CO}$ diet but not the $\mathrm{O} / \mathrm{SO}$ diet caused a decrease in circulating MGP compared to the adjustment diet. This fall in MGP after the CO diet mirrored that in total OC but the significance of this finding is unclear since little is yet known of the determinants of plasma MGP. There is strong interest in this VKD protein because recent studies show that vascular MGP synthesis is upregulated at sites of atherosclerotic calcification in the vessel wall ${ }^{66}$ and that circulating MGP is increased during some stages of atherosclerosis ${ }^{47}$. 


\section{REFERENCES}

1. Hornstra G, Kester AD. Effect of the dietary fat type on arterial thrombosis tendency: systematic studies with a rat model. Atherosclerosis. 1997;131:25-33.

2. Gurr MI. Dietary lipids and coronary heart disease: old evidence, new perspective. Prog Lipid Res. 1992;31:195-243.

3. Hornstra G, Vendelmans-Starrenburg A. Induction of experimental arterial occlusive thrombi in rats. Atherosclerosis. 1973;17:369-82.

4. Hornstra G, Lussenburg RN. Relationship between the type of dietary fatty acid and arterial thrombosis tendency in rats. Atherosclerosis. 1975;22:499-516.

5. Mennen LI, Schouten EG, Grobbee DE, Kluft C. Coagulation factor VII, dietary fat and blood lipids: a review. Thromb Haemost. 1996;76:492-9.

6. Kohlmeier M, Riesen W, Schlierf G. Metabolic changes in healthy men using fat-modified diets. I. Disposition of serum cholesterol. Ann Nutr Metab. 1988;32:1-9.

7. Wardlaw GM, Snook JT. Effect of diets high in butter, corn oil, or high-oleic acid sunflower oil on serum lipids and apolipoproteins in men. Am J Clin Nutr. 1990;51:815-21.

8. Weintraub MS, Zechner R, Brown A, Eisenberg S, Breslow JL. Dietary polyunsaturated fats of the W-6 and W-3 series reduce postprandial lipoprotein levels. Chronic and acute effects of fat saturation on postprandial lipoprotein metabolism. J Clin Invest. 1988;82:1884-93.

9. Dupont J, White PJ, Carpenter MP, Schaefer EJ, Meydani SN, Elson CE, Woods M, Gorbach SL. Food uses and health effects of corn oil. J Am Coll Nutr. 1990;9:438-70.

10. Goto Y, Tamachi H, Moriguchi EH. Eicosapentaenoic acid and atherosclerosis. Prostaglandins Leukot Essent Fatty Acids. 1993;48:337-42.

11. Chin JP. Marine oils and cardiovascular reactivity. Prostaglandins Leukot Essent Fatty Acids. 1994;50:211-22.

12. Nieuwenhuys CM, Beguin S, Offermans RF, Emeis JJ, Hornstra G, Heemskerk JW. Hypocoagulant and lipid-lowering effects of dietary n-3 polyunsaturated fatty acids with unchanged platelet activation in rats. Arterioscler Thromb Vasc Biol. 1998;18:1480-9.

13. Shahar E, Folsom AR, Wu KK, Dennis BH, Shimakawa T, Conlan MG, Davis CE, Williams OD. Associations of fish intake and dietary n-3 polyunsaturated fatty acids with a hypocoagulable profile. The Atherosclerosis Risk in Communities (ARIC) Study. Arterioscler Thromb. 1993;13:1205-12.

14. Sadowski JA, Hood SJ, Dallal GE, Garry PJ. Phylloquinone in plasma from elderly and young adults: factors influencing its concentration. Am J Clin Nutr. 1989;50:100-8.

15. Saupe J, Shearer MJ, Kohlmeier M. Phylloquinone transport and its influence on gammacarboxyglutamate residues of osteocalcin in patients on maintenance hemodialysis. Am J Clin Nutr. 1993;58:204-8.

16. Kohlmeier M, Saupe J, Drossel HJ, Shearer MJ. Variation of phylloquinone (vitamin K1) concentrations in hemodialysis patients. Thromb Haemost. 1995;74:1252-4.

17. Kohlmeier M, Salomon A, Saupe J, Shearer MJ. Transport of vitamin K to bone in humans. $J$ Nutr. 1996;126:1192s-6s.

18. Lamon-Fava S, Sadowski JA, Davidson KW, O'Brien ME, McNamara JR, Schaefer EJ. Plasma lipoproteins as carriers of phylloquinone (vitamin $\mathrm{K}_{1}$ ) in humans. Am J Clin Nutr. 1998;67:1226-1231.

19. Shearer MJ, Barkhan P, Webster GR. Absorption and excretion of an oral dose of tritiated vitamin K1 in man. Br J Haematol. 1970;18:297-308.

20. Groenen-van Dooren MM, Soute BA, Jie KS, Thijssen HH, Vermeer C. The relative effects of phylloquinone and menaquinone-4 on the blood coagulation factor synthesis in vitamin K- 
deficient rats. Biochem Pharmacol. 1993;46:433-437.

21. Roncaglioni MC, di Minno G, Pangrazzi J, Reyers I, Mussoni L, de Gaetano G, Donati MB. Plasmatic and vascular factors of the hemostatic system in rats receiving an estrogenprogestogen combination. Contraception. 1980;22:249-57.

22. Gijsbers BL, Jie KS, Vermeer C. Effect of food composition on vitamin K absorption in human volunteers. Br J Nutr. 1996;76:223-9.

23. Thijssen HH, Drittij-Reijnders MJ. Vitamin $\mathrm{K}$ metabolism and vitamin $\mathrm{K}_{1}$ status in human liver samples: a search for inter-individual differences in warfarin sensitivity. $\mathrm{Br} J$ Haematol. 1993;84:681-685.

24. Reyers I, Hennissen A, Donati MB, Hornstra G, de Gaetano G. Aspirin and the prevention of experimental arterial thrombosis: difficulty in establishing unequivocal effectiveness. Thromb Haemost. 1985;54:619-21.

25. Kohlmeier M, Drossel HJ, Sinha P, Kottgen E. Rapid and simple method for the identification of apolipoprotein E isomorphic phenotypes from whole serum. Electrophoresis. 1992;13:258-61.

26. Ronden JE, Soute BA, Thijssen HH, Saupe J, Vermeer C. Natural prenylquinones inhibit the enzymes of the vitamin K cycle in vitro. Biochim Biophys Acta. 1996;1298:87-94.

27. Uotila L. Inhibition of vitamin $\mathrm{K}$ dependent carboxylase by vitamin $\mathrm{E}$ and its derivatives. Current Advances in Vitamin K Research (ed: Suttie JW). 1988;Elsevier, New York:59-64.

28. Havel RJ, Kane JP. Introduction: structure and metabolism of plasma lipoproteins. The metabolic and molecular basis of inherited disease (ed. Scriver, C.R.). 1995;7th ed. New York: McGraw-Hill:1841-1851.

29. Williams CM. Postprandial lipid metabolism: effects of dietary fatty acids. Proc Nutr Soc. 1997;56:679-92.

30. Hoffman CJ, Lawson WE, Miller RH, Hultin MB. Correlation of vitamin K-dependent clotting factors with cholesterol and triglycerides in healthy young adults. Arterioscler Thromb. 1994;14:1737-40.

31. Szulc P, Arlot M, Chapuy MC, Duboeuf F, Meunier PJ, Delmas PD. Serum undercarboxylated osteocalcin correlates with hip bone mineral density in elderly women. $J$ Bone Miner Res. 1994;9:1591-5.

32. Knapen MH, Nieuwenhuijzen Kruseman AC, Wouters RS, Vermeer C. Correlation of serum osteocalcin fractions with bone mineral density in women during the first 10 years after menopause. Calcif Tissue Int. 1998;63:375-9.

33. Väänänen HK, Luukinen $H$, Käkönen S-M, Pettersson K, Koski K, Laippala P, Lövgren T, Kivelä S-L. Strong prediction of fractures among the elderly by the ratio of carboxylated and total serum osteocalcin. Calcif Tissue Int. 1999;64:S79.

34. Szulc P, Chapuy MC, Meunier PJ, Delmas PD. Serum undercarboxylated osteocalcin is a marker of the risk of hip fracture: a three year follow-up study. Bone. 1996;18:487-8.

35. Jie KS, Bots ML, Vermeer C, Witteman JC, Grobbee DE. Vitamin K intake and osteocalcin levels in women with and without aortic atherosclerosis: a population-based study. Atherosclerosis. 1995;116:117-23.

36. Cairns JR, Williamson MK, Price PA. Direct identification of gamma-carboxyglutamic acid in the sequencing of vitamin K-dependent proteins. Anal Biochem. 1991;199:93-7.

37. Price PA, Faus SA, Williamson MK. Warfarin causes rapid calcification of the elastic lamellae in rat arteries and heart valves. Arterioscler Thromb Vasc Biol. 1998;18:1400-7.

38. Shearer MJ. Vitamin K. Lancet. 1995;345:229-34.

39. Shearer MJ. The roles of vitamins D and K in bone health and osteoporosis prevention. Proc Nutr Soc. 1997;56:915-37.

40. Luo G, Ducy P, McKee MD, Pinero GJ, Loyer E, Behringer RR, Karsenty G. Spontaneous 
calcification of arteries and cartilage in mice lacking matrix GLA protein. Nature. 1997;385:7881.

41. Vermeer C. Gamma-carboxyglutamate-containing proteins and the vitamin K-dependent carboxylase. Biochem J. 1990;266:625-36.

42. Vermeer C, Hamulyák K. Pathophysiology of vitamin K-deficiency and oral anticoagulants. Thromb Haemostas. 1991;66:153-159.

43. Elmadfa I, Park E. Impact of diets with corn oil or olive/sunflower oils on DNA damage in healthy young men. Eur J Nutr. 1999;38:286-92.

44. Olson RE. The function and metabolism of vitamin K. Annu Rev Nutr. 1984;4:281-337.

45. Belle M, Brebant R, Guinet R, Leclercq M. Production of a new monoclonal antibody specific to human des-gamma- carboxyprothrombin in the presence of calcium ions. Application to the development of a sensitive ELISA-test. J Immunoassay. 1995;16:213-29.

46. Gundberg CM, Nieman SD, Abrams S, Rosen H. Vitamin K status and bone health: an analysis of methods for determination of undercarboxylated osteocalcin. J Clin Endocrinol Metab. 1998;83:3258-66.

47. Braam LA, Dissel P, Gijsbers BL, Spronk HM, Hamulyak K, Soute BA, Debie W, Vermeer C. Assay for Human Matrix Gla Protein in Serum : Potential Applications in the Cardiovascular Field. Arterioscler Thromb Vasc Biol. 2000;20:1257-1261.

48. Bolton-Smith C, Price RJ, Fenton ST, Harrington DJ, Shearer MJ. Compilation of a provisional UK database for the phylloquinone (vitamin $\mathrm{K}_{1}$ ) content of foods. Br J Nutr. 2000;83:389-399.

49. Ferland G, Sadowski JA. Vitamin $\mathrm{K}_{1}$ (phylloquinone) content of edible oils: effects of heating and light exposure. J Agricult Food Chem. 1992;40:1869-1873.

50. Schurgers LJ, Vermeer C. Determination of Phylloquinone and Menaquinones in Food. effect of food matrix on circulating vitamin K concentrations. Haemostasis. 2000;30:298-307.

51. Hollander D, Rim E, Muralidhara KS. Vitamin $\mathrm{K}_{1}$ intestinal absorption in vivo: influence of luminal contents on transport. Am J Physiol. 1977;232:E69-74.

52. Gallo-Torres HE, Weber F, Wiss O. The effect of different dietary lipids on the lymphatic appearance of vitamin E. Int J Vitam Nutr Res. 1971;41:504-15.

53. Marckmann P, Sandstrom B, Jespersen J. Effects of total fat content and fatty acid composition in diet on factor VII coagulant activity and blood lipids. Atherosclerosis. 1990;80:227-33.

54. Burns P, Hoffman CJ, Katz JP, Miller RH, Lawson WE, Hultin MB. Vitamin K-dependent clotting factors are elevated in young adults who have close relatives with ischemic heart disease. J Lab Clin Med. 1993;122:720-7.

55. Constantino M, Merskey C, Kudzma DJ, Zucker MB. Increased activity of vitamin K-dependent clotting factors in human hyperlipoproteinaemia - association with cholesterol and triglyceride levels. Thromb Haemost. 1977;38:465-74.

56. Xu N, Dahlback B, Ohlin AK, Nilsson A. Association of vitamin K-dependent coagulation proteins and $\mathrm{C} 4 \mathrm{~b}$ binding protein with triglyceride-rich lipoproteins of human plasma. Arterioscler Thromb Vasc Biol. 1998;18:33-9.

57. Poller L, McKernan A, Thomson JM, Elstein M, Hirsch PJ, Jones JB. Fixed minidose warfarin: a new approach to prophylaxis against venous thrombosis after major surgery. $\mathrm{Br}$ Med J (Clin Res Ed). 1987;295:1309-12.

58. Bern MM, Lokich JJ, Wallach SR, Bothe A, Benotti PN, Arkin CF, Greco FA, Huberman M, Moore C. Very low doses of warfarin can prevent thrombosis in central venous catheters. A randomized prospective trial. Ann Intern Med. 1990;112:423-8.

59. Sokoll LJ, Booth SL, O'Brien ME, Davidson KW, Tsaioun KI, Sadowski JA. Changes in serum osteocalcin, plasma phylloquinone, and urinary gamma- carboxyglutamic acid in response to altered intakes of dietary phylloquinone in human subjects. Am J Clin Nutr. 1997;65:779-84. 
60. Woolley DW. Some biological effects produced by a-tocopherol quinone. J Biol Chem. 1945;159:59-66.

61. Corrigan JJ, Jr., Marcus FI. Coagulopathy associated with vitamin E ingestion. Jama. 1974;230:1300-1.

62. March BE, Wong E, Seier L, Sim J, Biely J. Hypervitaminosis E in the chick. J Nutr. 1973;103:371-7.

63. Helson $\mathrm{L}$. The effect of intravenous vitamin $\mathrm{E}$ and menadiol sodium diphosphate on vitamin $\mathrm{K}$ dependent clotting factors. Thromb Res. 1984;35:11-8.

64. Alexander GD, Suttie JW. The effect of vitamin E on vitamin K activity. Faseb (abstract). 1999:430.1.

65. Mahley RW. Apolipoprotein E: cholesterol transport protein with expanding role in cell biology. Science. 1988;240:622-30.

66. Proudfoot D, Skepper JN, Shanahan CM, Weissberg PL. Calcification of human vascular cells in vitro is correlated with high levels of matrix Gla protein and low levels of osteopontin expression. Arterioscler Thromb Vasc Biol. 1998;18:379-88. 




\section{4 \\ VITAMIN K METABOLISM IN SUBJECTS WITH LOW VITAMIN K-STATUS}





\title{
4.1
}

\section{LOW VITAMIN K-STATUS IN PATIENTS WITH EITHER CONGENITAL DEFICIENCY OR LOW ABSORPTION OF VITAMIN K}

\begin{abstract}
In this chapter we describe studies in two different groups of people who have a low vitamin $K$ status or resistance to its effect, arising from either acquired or hereditary causes. Firstly we report on a hereditary combined deficiency of all vitamin K-dependent coagulation factors. Secondly we investigated low vitamin K-status due to Crohn's disease. Although the etiology of both cases is totally different, they both result in a state in which intestinal absorption is too low to meet the tissue requirement for vitamin $K$.

Patients with an autosomal recessive deficiency of all vitamin $K$ dependent coagulation factors may experience severe or even fatal perinatal intra-cerebral hemorrhage. In the family investigated here, the deficiency of the coagulation factors could be corrected by oral vitamin $K$ substitution. A defect in the $\gamma$-glutamyl carboxylase gene was excluded by sequencing of the gene. Furthermore, the use of coumarins was excluded. The finding of very high amounts of vitamin $K$-epoxide suggests a defect in the vitamin K2,3epoxide-reductase (VKOR) - complex, which explains why a high vitamin $K$ status is needed for normal synthesis of all vitamin K-dependent proteins.

Patients with impaired absorption of fat-soluble vitamins, such as found in Crohn's disease, also have a low vitamin K status. Serum vitamin K concentrations were significantly lower in patients with Crohn's disease than in healthy age-and sex-matched subjects. The tissue vitamin $K$ status was measured using the carboxylation degree of osteocalcin, one of the vitamin $K$-dependent proteins most sensitive to vitamin $K$ status. It was found that in Crohn's disease the bone tissue is sub-clinically vitamin K deficient. Moreover, these patients had a lower bone mineral density compared to controls.

It is concluded that in certain types of patients increased vitamin $K$ intake may result in a significant increase of Gla-protein carboxylation, and thus in improved functionality of these proteins. This was demonstrated in the case of a defective VKOR-complex. More intervention studies are required to demonstrate whether vitamin K-supplements may similarly lead to improved bone health in chronic diseases characterized by impaired intestinal absorption such as Crohn's desease.
\end{abstract}




\section{Introduction}

Vitamin $\mathrm{K}$ is a fat-soluble vitamin and serves as a cofactor for the endoplasmic enzyme $\gamma$-glutamyl-carboxylase. It provides the energy to drive the $\gamma$-glutamate-carboxylation reaction and catalyses the incorporation of an extra carboxyl group in the protein bound glutamate ${ }^{1,2}$. This new, unusual amino acid is called $\boldsymbol{\gamma}$-carboxy glutamate (Gla) and renders vitamin K-dependent proteins their functionality. Vitamin K-dependent proteins play a critical role in three physiological processes: blood coagulation (prothrombin, and factors VII, IX, X and protein S, C, and Z), bone metabolism (osteocalcin, matrix Gla-protein (MGP), and protein S) and vascular biology (MGP, growth arrest specific gene-6 protein (gas-6) and protein S).

Bleeding problems due to vitamin K-deficiency are extremely rare in the healthy adult population. Only in newborns a low vitamin K status is common because of poor transfer of maternal vitamin $\mathrm{K}$ to the fetus ${ }^{3,4}$. It is therefore, that newborns receive i.m. or oral vitamin $\mathrm{K}$ to prevent them from vitamin K-deficiency bleeding (VKDB). In some cases, however, also higher intake of vitamin $\mathrm{K}$ in the adult population is required to ensure full carboxylation of vitamin K-dependent proteins.

Vitamin $\mathrm{K}$ deficiency may also be caused by malabsorption of fat soluble vitamins, especially in patients with ileal involvement or cystic fibrosis ${ }^{5,6}$. Low serum concentrations of vitamin $\mathrm{K}$ have been reported in patients with osteoporotic fractures ${ }^{7}$. Undercarboxylated OC (ucOC) has been shown to be the protein most sensitive to vitamin K-deficiency. Higher concentrations of ucOC were demonstrated to be related to advanced age, low BMD, and the risk of hip fracture ${ }^{7-9}$.

Besides low intake and poor vitamin $\mathrm{K}$ absorption, there are also several other explanations for under-carboxylation of Gla-proteins. First, the recycling of vitamin K may be impaired by a blockade of the enzyme KO-reductase as a result of coumarin ingestion, which leads to exhaustion of the available vitamin $\mathrm{K}$ stores. Under normal conditions one molecule of vitamin K may catalyze the synthesis of up to 500 Gla-residues; however, in case of coumarin intoxication one molecule of vitamin $\mathrm{K}$ can only induce the formation of one Gla-residue. Second, malfunction of the precursor protein caused by mutation(s) in the propeptide region can result in poor recognition by carboxylase or impairment of propeptide cleavage from the mature vitamin K-dependent protein. Third, a mutation in the $\gamma$-glutamyl carboxylase gene or the vitamin K2,3-epoxide-reductase (VKOR)-complex can be the cause of increased vitamin K-requirement.

A hereditary deficiency of all vitamin $\mathrm{K}$ dependent proteins is likely to result from functional deficiency of either the $\gamma$-glutamyl carboxylase or the VKOR-complex. So far, the molecular defect has been described in two families, in whom a missense mutation in the gene coding for the $\gamma$-glutamyl carboxylase enzyme has been identified ${ }^{10,11}$. In a third family 
with additional signs of skeletal abnormalities evidence for a likely involvement of the VKOR-complex has been reported ${ }^{12}$. In case of vitamin $\mathrm{K}$ deficiency osteocalcin is the first vitamin K-dependent protein circulating in its undercarboxylated form. It is generally accepted, therefore, that this protein is most sensitive to vitamin K-status. Even in apparently healthy subjects, undercarboxylated osteocalcin is present in substantial amounts, whereas undercarboxylated species of clotting factors are absent.

In one part of this chapter we report two new families with recessively inherited combined deficiency of the vitamin $\mathrm{K}$ dependent coagulation proteins. Molecular analysis of the $\gamma$-glutamyl carboxylase gene and determination of vitamin K-epoxide (KO) levels indicated that a dysfunction of a protein related to the VKOR-complex is likely being causative for the disease. The second part of this study was to investigate serum and bone vitamin K status in patients with longstanding Crohn's disease (CD) and to elucidate the relation between vitamin $\mathrm{K}$ status and bone mineral density (BMD) in these patients.

\section{Results}

\section{Congenital deficiency of vitamin $K$ dependent coagulation factors}

Congenital deficiency of vitamin $\mathrm{K}$ has in most cases a chromosome defect as the underlying cause. In our study family A was from Lebanese origin and consanguinity of the parents was revealed. In family B, from German origin, consanguinity could not be determined but could not be ruled out either. In both families some offsprings had severe intracerebral hemorrhage and cephal haematoma. Two children of family A died due to severe bleeding. All affected individuals from family A and B showed a mild deficiency of all vitamin K-dependent coagulation factors (Table 1). In all other members, who where expected to be heterozygous carriers of the diseased allele, normal levels of the vitamin Kdependent coagulation factors were found.

Table 1A: Vitamin K dependent factor levels in affected (bold) and non-affected members of families A and B. Family structure are shown in figures $1 \mathrm{~A}$ and $1 \mathrm{~B}$.

\begin{tabular}{|c|c|c|c|c|c|c|c|c|c|c|c|c|c|c|c|}
\hline & & A1 & A2 & A3 & A4 & A5 & A6 & A7 & A8 & A9 & A10 & B1 & B2 & B3 & B4 \\
\hline \multicolumn{16}{|c|}{ (normal range) } \\
\hline II:C & $(70-130 \mathrm{U} / \mathrm{dl})$ & 114 & 127 & 63 & 103 & 40 & 59 & 88 & 42 & 105 & $79^{*}$ & 88 & 93 & 45 & 44 \\
\hline VII:C & $(70-130 \mathrm{U} / \mathrm{dl})$ & 97 & 102 & 47 & 76 & 20 & 55 & 98 & 45 & 79 & $62^{*}$ & 81 & 144 & 29 & 42 \\
\hline IX:C & $(70-130 \mathrm{U} / \mathrm{dl})$ & 125 & 120 & 66 & 142 & 52 & 99 & 91 & 40 & 111 & $51^{*}$ & 116 & 137 & 55 & 51 \\
\hline$X: C$ & $(70-130 \mathrm{U} / \mathrm{dl})$ & 140 & 135 & 40 & 123 & 24 & 49 & 97 & 32 & 116 & $56^{*}$ & 111 & 140 & 33 & 30 \\
\hline$P C: C$ & $(70-130 \mathrm{U} / \mathrm{dl})$ & 109 & n.d. & 56 & 112 & 61 & 80 & 101 & 43 & n.d. & n.d. & 91 & 113 & 60 & 55 \\
\hline
\end{tabular}


Table 1B. Vitamin $\mathrm{K}$ dependent factor levels in affected individuals 1 day after oral substitution of $5 \mathrm{mg}$ (A5, A6, A8) and $1 \mathrm{mg}$ (B3) Vitamin K, respectively.

\begin{tabular}{llccc|c}
\hline (normal range) & A5 & A6 & A8 & B3 \\
\hline II:C & $(70-130 \mathrm{U} / \mathrm{dl})$ & 86 & 110 & 96 & 104 \\
VII:C & $(70-130 \mathrm{U} / \mathrm{dl})$ & 77 & 107 & 101 & 90 \\
IX:C & $(70-130 \mathrm{U} / \mathrm{dl})$ & 135 & 140 & 110 & 87 \\
X:C & $(70-130 \mathrm{U} / \mathrm{dl})$ & 91 & 138 & 99 & 85 \\
PC:C & $(70-130 \mathrm{U} / \mathrm{dl})$ & n.d. & n.d. & n.d. & 66 \\
\hline
\end{tabular}

The molecular analysis of all 15 exons of the $\gamma$-glutamyl carboxylase gene showed no mutation in the affected probands. Since a genetic defect in the non-coding region of the $\gamma$ glutamyl carboxylase gene could not be excluded, haplotypes of the $\gamma$-glutamyl carboxylase gene were constructed to ascertain whether the phenotype in the families is segregating with one allele of the $\gamma$-glutamyl carboxylase gene. However, there was no single haplotype segregating with the normal or the disease phenotype, thus arguing against the gene locus of the $\gamma$-glutamyl carboxylase being causative for the disorder in both families.

Table 2. Serum concentrations of Vitamin K (VK) and Vitamin K epoxide (VKO) before and $5 \mathrm{~h}$ after oral substitution of a $10 \mathrm{mg}$ vitamin $\mathrm{K}$ dragee. Affected individuals are indicated with bold letters. The detection limit of $\mathrm{VKO}$ is $0.05 \mathrm{ng} / \mathrm{ml}$.

\begin{tabular}{l|cc|ccc}
\hline & \multicolumn{2}{|c|}{$\begin{array}{c}\text { basal serum concentrations } \\
\text { (ng/ml) }\end{array}$} & \multicolumn{3}{|c}{ serum concentrations (ng/ml) 5 h after } \\
& VK & VKO & \multicolumn{2}{c}{ VKal substitution of 10 mg vitamin K } \\
& 0.4 & $<0.05$ & 201.8 & VKO & VK / VKO \\
\hline A4 & 0.4 & $<0.05$ & 84.6 & 19.5 & $>1000$ \\
A5 & 0.6 & $<0.05$ & 219.6 & 52.6 & 4.3 \\
A6 & 0.4 & $<0.05$ & 262.5 & $<0.05$ & $>1000$ \\
A7 & n.d. & n.d. & 147 & 59.7 & 2.5 \\
A8 & n.d. & n.d. & 607.3 & $<0.05$ & $>1000$ \\
A9 & 0.5 & $<0.05$ & 112.5 & $<0.05$ & $>1000$ \\
B1 & 0.5 & $<0.05$ & 310.3 & 2.6 & 119.3 \\
B2 & 0.7 & $<0.05$ & 490.4 & 66.2 & 7.4 \\
B3 & 0.4 & $<0.05$ & 410.7 & 38.6 & 10.6 \\
B4 & & & & &
\end{tabular}

The finding of a normal $\gamma$-glutamyl carboxylase gene in both families points to a defect in a protein of the VKOR-complex. To prove this hypothesis, affected and normal subjects of both families were supplemented with $10 \mathrm{mg}$ phylloquinone. Blood was taken 
before and $5 \mathrm{~h}$ after oral drug intake at the expected maximum of plasma vitamin $\mathrm{K}$ levels. The results are shown in Table 2. While vitamin K-epoxide levels are normally undetectable in serum, all tested individuals of both families with the diseased phenotype showed highly increased vitamin $\mathrm{KO}$ levels ranging from $19.5 \mathrm{ng} / \mathrm{mL}$ to $59 \mathrm{ng} / \mathrm{mL}$ in family A and from 38.6 to $66.2 \mathrm{ng} / \mathrm{mL}$ in family B. Vitamin $\mathrm{KO}$ could not be detected in the non-affected individuals of family A and B with the exception of one individual in family B who exhibited a very low vitamin $\mathrm{KO}$ level (ratio $\mathrm{K} / \mathrm{KO}$ of 119.3). These findings indicate that a defect of the VKOR-complex is likely to be causative for the apparent vitamin $\mathrm{K}$ deficiency and the undercarboxylation of all vitamin $\mathrm{K}$ dependent proteins in both families.

\section{Low vitamin K-status in patients with longstanding Crohn's disease (CD)}

In the second case of apparent vitamin K deficiency, a malabsorption of all fat-soluble vitamins is the underlying cause. Patients with $\mathrm{CD}$ exhibit a malabsorption of fat-soluble vitamins. None of the patients had a history of bleeding problems. Because vitamin $\mathrm{K}$ can affect bone metabolism via osteocalcin, we also measured in this population all kind of markers involved in bone metabolism. Mean BMD, expressed as absolute values in $\mathrm{g} / \mathrm{cm} 2$, of the femoral neck, lumbar spine, and total body were 0.89 (013), $1.10(0.16)$, and $1.11(0.09)$, respectively. Mean T-scores were -0.61 (1.29), -0.98 (1.16), and -0.66 (1.13), respectively. Mean z-scores were -0.49 (1.07), -0.45 (1.25), and -0.28 (1.10), respectively.

Total OC was measured using the Osteometer test kit (Biotech, Herlev, Denmark). Since carboxylated OC and undercarboxylated OC differ substantially in their affinity for insoluble calcium salts, these fractions can be quantified by measuring serum OC before and after extraction with a standard amount of hydroxyapatite. The fraction which does not bind to hydroxyapatite consists of undercarboxylated "free" osteocalcin (OCfree). To measure the OCfree fraction, $45 \mathrm{mg}$ of hydroxyapatite were added to $300 \mu \mathrm{l}$ of serum. The fraction of carboxylated OC (OCbound) is calculated from the difference between the total immunoreactive OC (OCtotal) and OCfree. OCbound expressed as a percentage of total OC is known as the hydroxyapatite binding capacity (HBC) of osteocalcin.

Serum vitamin $\mathrm{K}$ concentrations in patients with $\mathrm{CD}$ were significantly lower than a reference population of 384 healthy subjects $(p<0.001)$. Patients with $C D$ had higher serum OCfree $(p<0.05)$ and lower hydroxyapatite bindings capacity $(\mathrm{HBC})$ values $(\mathrm{P}<0.001)$ compared with values obtained from the age and sex matched control group of 34 healthy subject randomly selected from the community registry (Figures 1 and 2). Although the mean OCfree was generally lower and mean serum vitamin $\mathrm{K}$ was higher in patients with normal BMD than in patients with a $\mathrm{T}$ score $<-1$ this difference was not statistically significant. In patients, a negative correlation was found between lumbar spine BMD and OCfree $(\mathrm{r}=$ $-0.381, \mathrm{p}<0.05)$ and between $\mathrm{z}$ score and OCfree $(\mathrm{r}=-0.381, \mathrm{p}<0.01)$ (Figures 3 and 4$)$. 


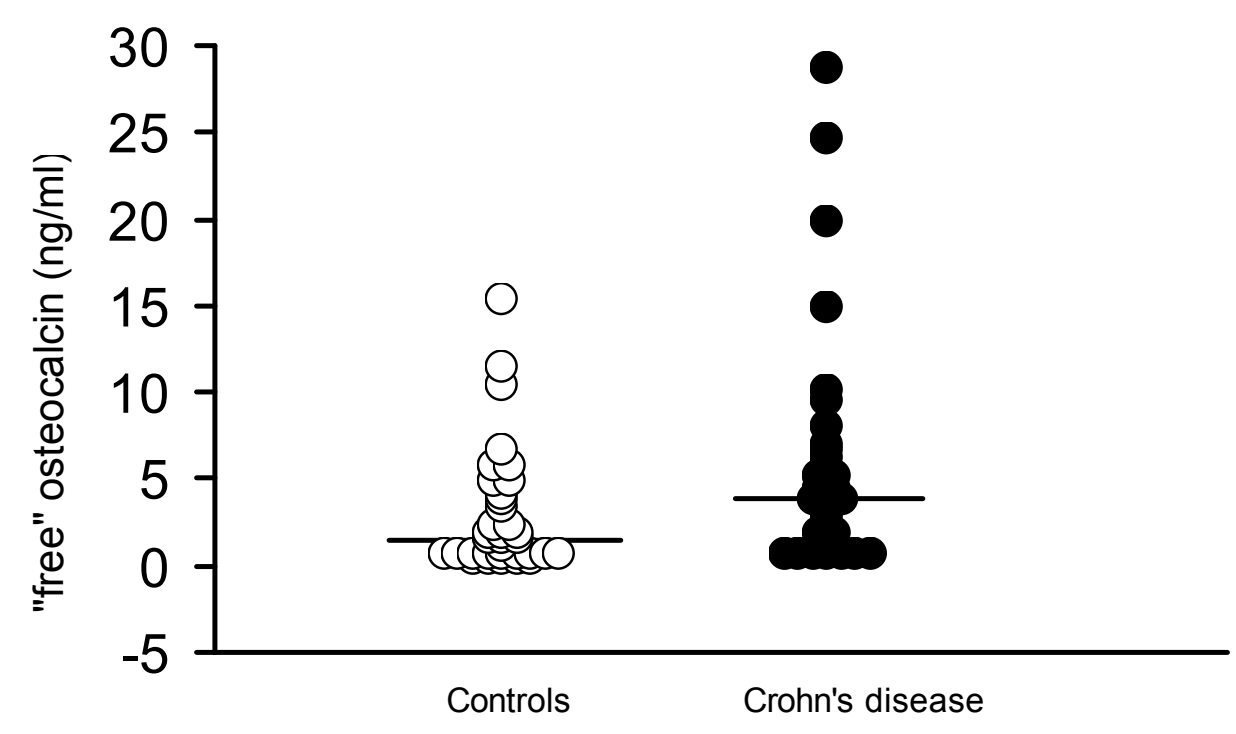

Figure 1.

Serum concentrations of "free" (undercarboxylated) osteocalcin in patients with longstanding Crohn's disease $(n=32)$ compared with age and sex matched healthy controls $(n=34)$. Lines indicate median values. Medain for patients with Crohn's disese is $3.98 \mathrm{ng} / \mathrm{mL}$; median for healthy controls is $1.51 \mathrm{ng} / \mathrm{mL}$.

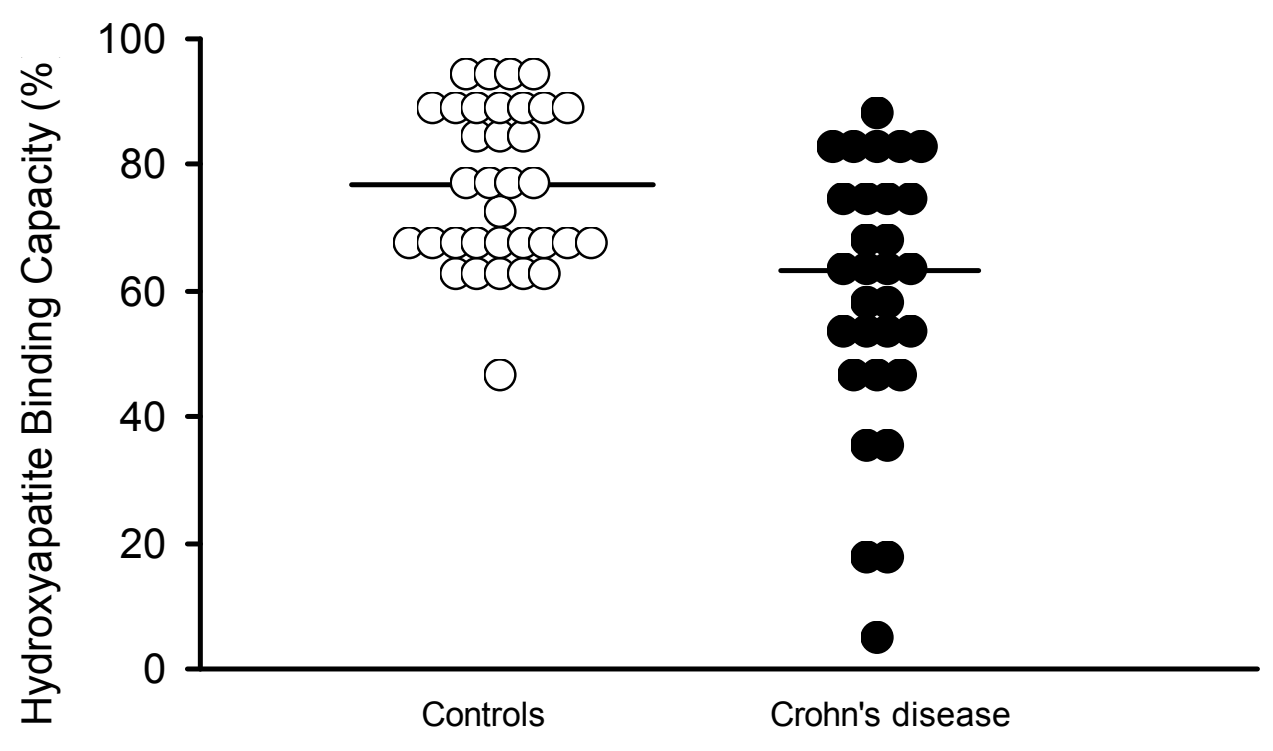

Figure 2 .

Hydroxyapatite binding capacity in patients with longstanding Crohn's disease $(n=32)$ compared with age and sex matched healthy controls $(n=34)$. Lines indicate median values. Median for patients with Crohn's disease is $61.7 \%$; median for healthy controls is $76.8 \%$. 
Mean serum level of vitamin D in patients was 28.4 (10.5) nmol/L; 11 patients (34\%) were vitamin $\mathrm{D}$ deficient (serum 25-hydroxy vitamin $\mathrm{D}<25 \mathrm{nmol} / \mathrm{L}$ ). A significant correlation was found between serum concentrations of vitamin $\mathrm{D}$ and $\mathrm{K}(\mathrm{r}=0.681, \mathrm{p}<0.01)$. No correlation was was found between serum concentrations of vitamin D and vitamin $\mathrm{K}$ status of bone (either HBC (\%) or OCfree). Mean serum triglyceride concentration was 1.5 (1.1) $\mathrm{mmol} / \mathrm{L}$. A positive correlation was found between serum concentrations of vitamin D and triglycerides $(\mathrm{r}=0.707, \mathrm{p}<0.01)$ and vitamin $\mathrm{K}$ and triglycerides $(\mathrm{r}=0.789, \mathrm{p}<0.01)$, respectively. In the patient group, the variables sex, age, body mass index, serum vitamin $\mathrm{K}$, OCfree, and vitamin D were included in a multiple linear regression. No correlations were found between serum vitamin $\mathrm{K}$ levels and BMD or $\mathrm{T}$ and $\mathrm{z}$ scores at any measurement site. We found that OCfree correlated significantly with BMD of the lumbar spine $(p=0.05)$ and with the lumbar spine $z$ score $(p=0.035)$. The correlation between OCfree and the $T$ score of the lumbar spine did not reach significance $(\mathrm{p}=0.091)$. No correlations were found between $\mathrm{BMD}, \mathrm{T}$ and $\mathrm{z}$ scores of the femoral neck and total body, and Ocfree. No correlations were found between serum vitamin $\mathrm{D}$ levels and $\mathrm{BMD}$, or $\mathrm{T}$ and $\mathrm{z}$ scores at any measurement site.

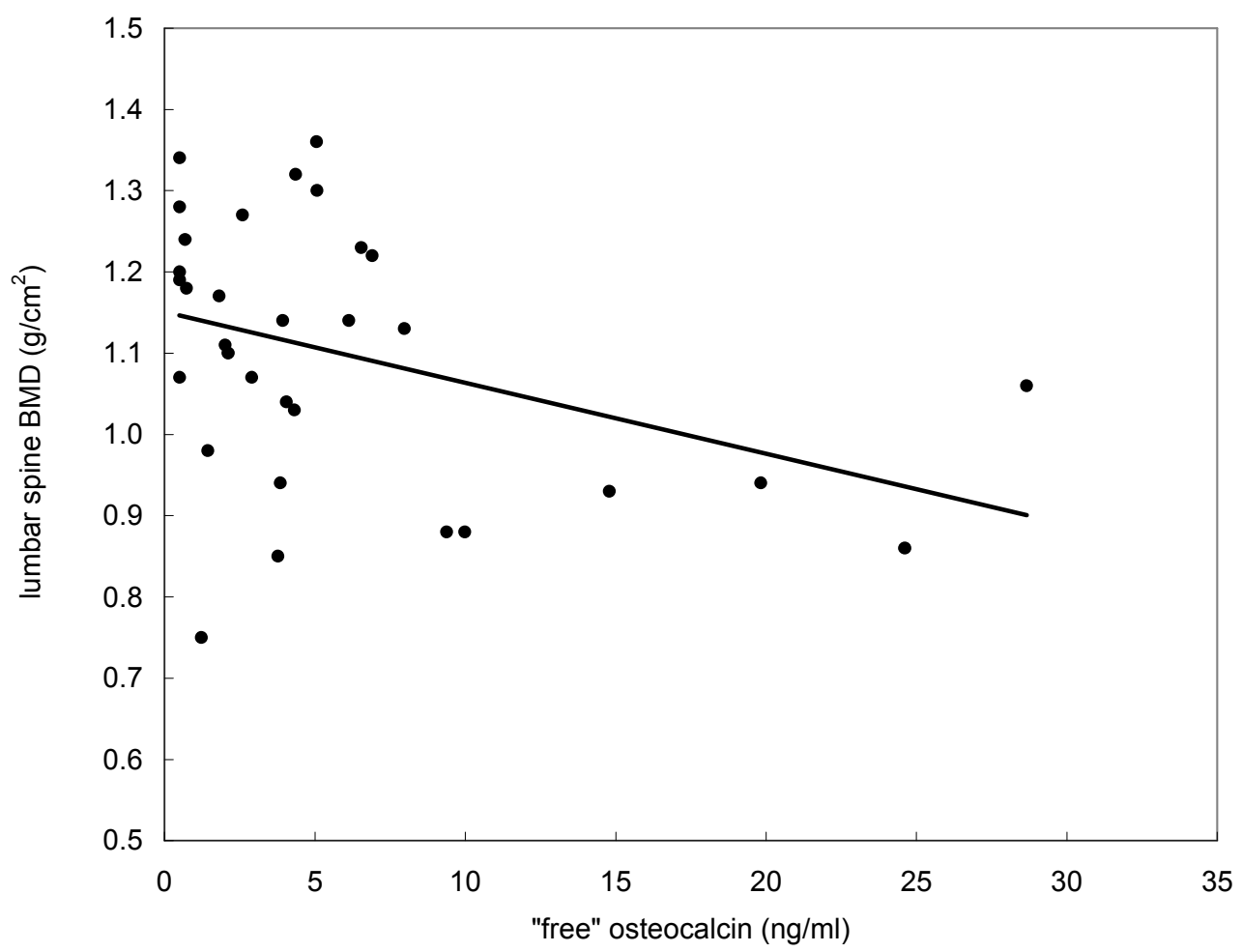

Figure 3.

Correlation between "free" (undercarboxylated) osteocalcin and bone mineral density (BMD) of the lumbar spine in patients with longstanding Crohn's disease $(n=32)$ Correlation coefficient (Pearson's) $\mathrm{r}=-0.375 ; \mathrm{p}<0.05$. 


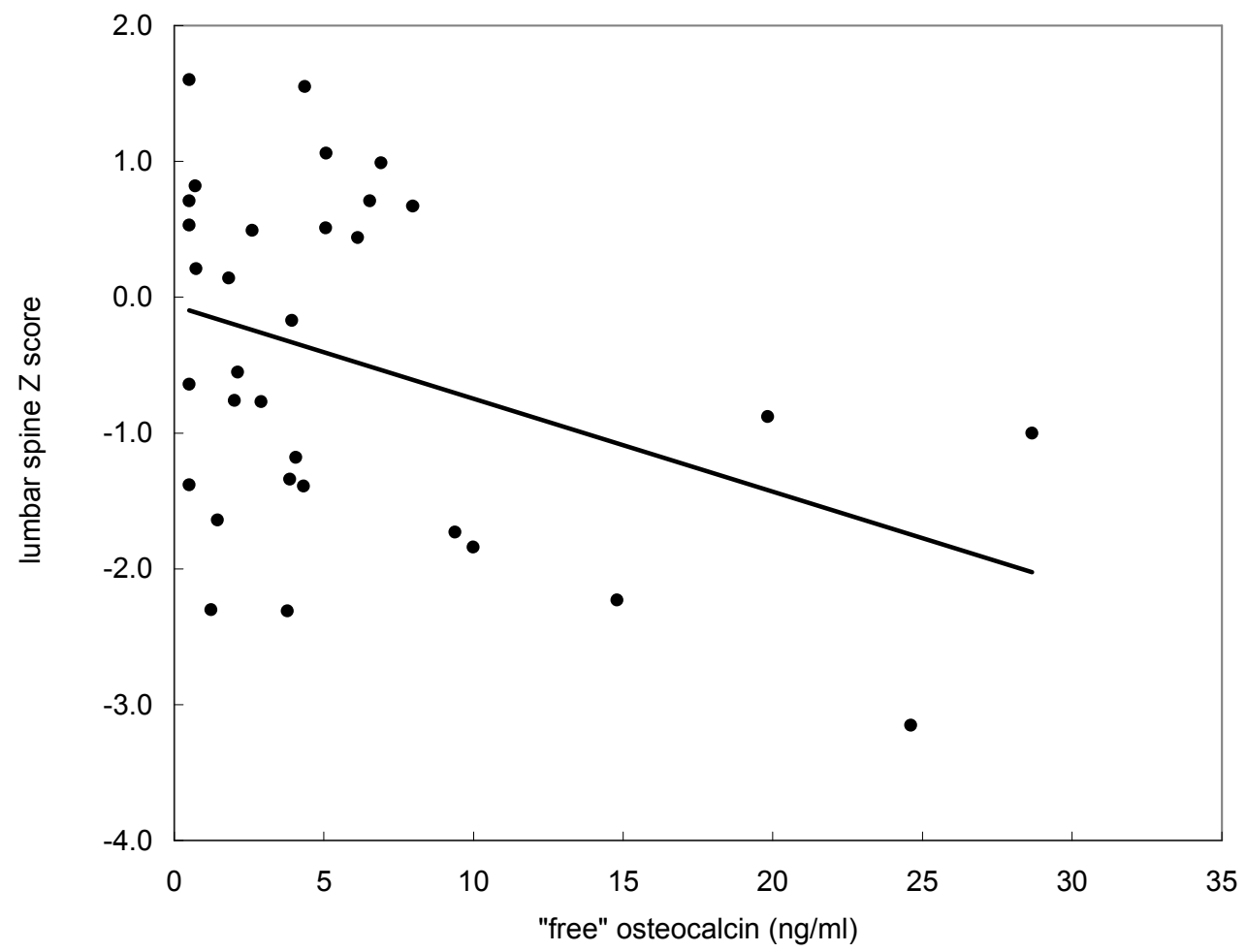

Figure 4.

Correlation between "free" (undercarboxylated) osteocalcin and bone mineral density z score of the lumbar spine in patients with longstanding Crohn's disease $(n=32)$. Correlation coefficient (Pearson's) $\mathrm{r}=-0.381 ; \mathrm{p}<0.01$.

\section{Discussion}

\section{Congenital deficiency of vitamin $K$ dependent coagulation factors}

Vitamin K-deficiency and treatment with coumarin derivatives are the common acquired causes for a decrease in the vitamin K-dependent coagulation factors. Inherited combined deficiency of these coagulation factors is unlikely because it would require at least four simultaneous mutations. The underlying cause is more likely to be a defect of one of the enzymes responsible for normal carboxylation of the vitamin K-dependent proteins. In our study a defect of one of these enzymes, the VKOR-complex, was the most probable cause of the bleeding problems. Bleeding problems are most severe in childhood when vitamin $\mathrm{K}$ levels are low. The combination of a low vitamin $\mathrm{K}$ status and a defect in the recycling of vitamin $\mathrm{K}$ makes that newborns are at high risk for spontanuous bleeding, for instance resulting in haemarthrosis or mucocutaneous bleeding. So far only twelve kindreds with a combined deficiency of all vitamin K-dependent coagulation factors have been reported in 
the literature. Such rare disorders with suggested autosomal recessive inheritance occur predominantly in families with consanguineous marriage. The degree of deficiency of vitamin K-dependent coagulation proteins varies considerably from very severe forms with activity levels less than 5\% to mild with activity levels ranging form $20-60 \%$. Only in three of the previously published families some details of the pathophysiological mechanism were discussed ${ }^{10-12}$. Pauli et al. found increased plasma levels of vitamin K-epoxide in the affected proband that point to a defect in the VKOR-complex. Brenner et al. and Spronk et al. showed that a missense mutation within the $\gamma$-glutamyl carboxylase gene was causative for the diseased phenotype. In our study, molecular analysis of the $\gamma$-glutamyl carboxylase gene and the increased vitamin K-epoxide levels in the affected probands in both families, suggests a defect in the VKOR-complex causing the mild deficiency of all vitamin K-dependent coagulation factors. Thus, the families reported herein represent the second and third families with a suggested defect in the VKOR-complex. Purification and isolation of the VKOR enzyme has been attempted by several groups without success for many years. It now seems that the VKOR represents a multi-enzyme complex and that purification procedures destroy the protein integrity of this complex and subsequently the VKOR enzyme activity. According to a hypothetical model, the VKOR-complex consists at least of the transmembraneous microsomal epoxide-hydrolase and a further protein originating from the glutathion-Stransferase super family ${ }^{13,14}$.

In line with this, we expected in the two families reported herein also a molecular defect in one of these proteins. The genetic disorder in both of our families became clinically apparent by severe or even fatal perinatal intra cerebral bleeding. Severe bleeding at birth is known to be associated with acquired conditions of combined deficiency of vitamin $\mathrm{K}$ dependent coagulation factors, but may be amplified by genetic mutations. The clinical symptoms may be masked if vitamin $\mathrm{K}$ substitution leads to a temporary normalization of coagulation factors. Mild reduction of vitamin $\mathrm{K}$ dependent coagulation factors, as it was present in heterozygous members of our families, may also complicate diagnosis. So far, in three of the families with a moderate to severe deficiency of coagulation factors $12,15,16$ skeletal abnormalities were associated with the combined decrease of vitamin $\mathrm{K}$ dependent proteins (Table 4). These skeletal abnormalities comprised irregular ossification, nasal hypoplasia, distal digital hypoplasia and mild conductive hearing loss, thus resembling the phenotype of warfarin embryopathy. In contrast, none of the four families with a milder form of the disease showed skeletal abnormalities. Although the warfarin embryopathy phenotype may result from a primary pharmacological effect of coumarin derivates, the report of Pauli et al. provided evidence that the disease is secondary to the pharmacological effect of warfarin, e. g. inhibition of the VKOR-complex. 


\section{Low vitamin K-status in patients with longstanding Crohn's disease}

All three bone Gla-proteins are synthesized by the osteoblasts (the bone forming cells), but only osteocalcin is a unique product of bone tissue. After its synthesis it is secreted by the osteoblasts and a major part is directly bound to the hydroxyapatite matrix of the bone ${ }^{17}$. About $25 \%$ of the de novo synthesized osteocalcin, however, is set free in the circulation where it can be detected with commercially available test kits ${ }^{18,19}$. So the serum concentration of osteocalcin forms a reflection of the osteoblast activity, which makes it an important and widely used marker for bone formation. Its precise function is not known, but transgenic osteocalcin-deficient animals have shown that it is a negative regulator of bone formation ${ }^{20}$, and that it has a function in the orderly alignment of hydroxyapatite crystals in bone ${ }^{21}$. In patients with $\mathrm{CD}$, cystic fibrosis, and ileopathy, bile and fat malabsorption causes steatorrhoea and malabsorption of fat soluble vitamins. In these patients, the majority had raised PIVKA-II levels in their plasma, indicating a vitamin $\mathrm{K}$ deficiency in the liver ${ }^{6}$. However, none of the patients had bleeding problems, which is consistent with only a subclinical vitamin $\mathrm{K}$ deficiency.

Serum vitamin K concentrations are influenced by plasma triglyceride concentrations and reflect recent dietary intake in healthy subjects. ${ }^{22,23}$ While there are several publications on the role of vitamin $\mathrm{D}$ in metabolic bone disease in $\mathrm{CD},{ }^{24-29}$ only few data are available with regard to vitamin $\mathrm{K}$ status in $\mathrm{CD}$. In a study in which uncarboxylated prothrombin was used as a marker, vitamin $\mathrm{K}$ deficiency was identified in $46 \%$ of $\mathrm{CD}$ patients with ileal involvement but not in patients with Crohn's colitis ${ }^{30}$. It has also been reported that OCfree, as used in the present study, is a much more sensitive marker for vitamin $\mathrm{K}$ status than prothrombin ${ }^{31}$. The fact that vitamin $\mathrm{K}$ serves as a cofactor for carboxylation of bone Gla proteins and is of potential importance for bone formation is reflected by a significant independent and inverse correlation between OCfree and BMD of the lumbar spine (BMD and $\mathrm{z}$ score). The trabecular bone of the spine is metabolically more active than the cortical bone of the hip and may thus be more susceptible to vitamin $\mathrm{K}$ deficiency. This may explain the lack of correlation between OCfree and BMD of the femoral neck and total body. Bone mineral loss in $\mathrm{CD}$ is a multi-factorial process and vitamin $\mathrm{K}$ deficiency is only one factor in this process. In the present study there are indications that in patients with longstanding $C D$, vitamin $\mathrm{K}$ deficiency of bone has a greater influence on BMD than serum 25-hydroxy vitamin D levels. The body vitamin D stores are reflected by serum concentrations of $25-$ hydroxy vitamin D. In accordance with our expectations, significant correlations between serum vitamin $\mathrm{D}$ and $\mathrm{K}$ concentrations and triglycerides were found. In the present study, however, patients who were vitamin D deficient did not have significantly decreased BMD. Published data are equivocal in this respect: a significant correlation between vitamin $\mathrm{D}$ and BMD of the forearm was found in one of three large studies on vitamin D deficiency and 
BMD in patients with $C{ }^{26-28}$. Vitamin $\mathrm{D}$ deficiency may cause secondary hyperparathyroidism which predominantly affects cortical bone. The questions remaining are whether bone that is vitamin $\mathrm{K}$ deficient is rendered sensitive to other pathogenetic factors of osteoporosis, such as corticosteroids, and whether vitamin $\mathrm{K}$ supplementation can improve bone mineralisation in $\mathrm{CD}$ patients, as has been demonstrated in other conditions. In prednisolone treated rats, vitamin $\mathrm{K}$ supplementation inhibited bone loss ${ }^{32}$. Treatment with vitamin $\mathrm{K}$ (menatetrenone) has been reported to increase BMD in disused bones in vitamin $\mathrm{K}$ and $\mathrm{D}$ deficient hemiplegic patients ${ }^{33}$. In a study in cystic fibrosis patients, a significantly elevated level of OCfree was found in patients who were not supplemented with vitamin $\mathrm{K}$ (phylloquinone) versus supplemented patients ${ }^{34}$. The questions addressed above require further study. It has recently been demonstrated that vitamin $\mathrm{K}$ treatment effectively prevents the occurrence of new vertebral fractures in patients with osteoporosis ${ }^{35}$.

\section{Potential implications of long-term low vitamin K-status}

Both the fetal warfarin syndrome and mutations in one of the enzymes of the vitamin $\mathrm{K}$ cycle may lead to bone pathology characterized by excessive calcification in the rapidly growing parts of bone and strong impairment of bone growth. Similar defects may be induced by warfarin treatment of young animals. These phenomena are caused by undercarboxylation of the bone Gla-proteins osteocalcin and MGP, both of which are known to be involved in the regulation of calcium phosphate precipitation in growing bone and cartilage. Both proteins are strong inhibitors of calcium precipitation, and their function is based on the presence of the Gla-residues. Remarkably, the effects are most pronounced in young, rapidly growing bone. In CD and other malabsorption diseases, vitamin K-deficiency leading to bleeding is rarely seen. The question remains whether long-term poor vitamin K-status may affect the quantity and/or quality of adult bone, even after growth has been completed. Several observational studies supporting this possibility have been published. During recent years there have been two population-based studies in which the relationship between dietary vitamin $\mathrm{K}$ intakes and hip fractures or bone mineral density were investigated. The first study was among participants in the Nurses Health Study ${ }^{36}$, using a food frequency questionnaire to assess dietary vitamin $\mathrm{K}$ intake at baseline, and recording hip fractures during the 10-year follow-up of this cohort. The results suggest an increased fracture risk for subjects with low vitamin $\mathrm{K}$ intake. A comparable study was carried out among both men and women of the Framingham Heart Study, and again an association was found between low vitamin K intakes and hip fracture risk ${ }^{37}$. The underlying mechanism in both cases is a low vitamin $\mathrm{K}$ intake resulting in increased undercarboxylated osteocalcin levels. Thus far, no biochemical mechanism has been established yet. Serum ucOC is a biochemical marker for poor vitamin $\mathrm{K}$ status of bone, and during the last decade a number of studies have shown that increased 
serum ucOC is associated with low bone mass ${ }^{38}$ and increased fracture rate ${ }^{8,9}$. Moreover, in a recent meta-analysis Caraballo et al. concluded that oral anticoagulant treatment is a risk factor for low bone mass and osteoporosis development at later age ${ }^{39}$. An intriguing question is whether a similar mechanism underlies the fetal warfarin syndrome and vitamin $\mathrm{K}$ deficiency related osteoporosis. After maturation, bone is not a static tissue, but it is renewed in a constant process known as bone turnover. In this process, cells called osteoclasts resorb bone and produce cavities known as the osteoclastic pits, which are filled up again by bone forming cells (osteoblasts). We would like to put forward the hypothesis that the new bone formation in the osteoclastic bone pits resembles the rapid growth of bone in fetuses and young children. Hence it seems probable that within these pits vitamin K-deficiency induces excessive calcium phosphate precipitation resulting in preliminary termination of the bone renewal and incomplete refilling of the osteoclastic bone pits. In this way it may be understood that vitamin $\mathrm{K}$ deficiency is the underlying mechanism in both warfarin- and vitamin K-deficiency-induced bone malformations in foetuses and young individuals as well as low bone mass and osteoporotic fractures in CD and other malabsorption diseases. 


\title{
EFFECT OF DIETARY VITAMIN K ON STABILITY OF ORAL ANTICOAGULANT THERAPY: DOSE RESPONSE RELATIONSHIPS IN HEALTHY SUBJECTS
}

\begin{abstract}
This study was performed in young healthy volunteers to measure the effect of dietary vitamin $K$ on the stability of oral anticoagulant $(O A C)$ treatment. In the first instance we have assessed the effect of daily gradied doses of vitamin $K_{1}$ given in pure tablet form. We than carried out a second study to asses the effect of a single meal containing a very high content of vitamin $K_{1}$ or menaquinones. We have investigated dose-response relationships of vitamin $K_{1}$ given as a vitamin $K$ supplement and of vitamin $K$-rich foods containing either vitamin $K_{1}\left(K_{1}\right.$; spinach, broccoli), menaquinone-7 (MK-7; natto) or menaquinone-9 (MK-9; curd cheese). The effect on coagulation was monitored 4 times (INR) or twice weekly (FIIc, FVIIc, PIVKA-II (ucFII)). The effect of vitamin K intake on extra-hepatic metabolism was recorded by measuring carboxylated and undercarboxylated osteocalcin (cOC and ucOC, respectively). In addition, we determined the plasma $K_{1}, M K-7$ and MK-9 levels after intake. Daily supplementation with vitamin $K_{1}$ resulted in decreases of INR from baseline of $11.5 \%, 23.4 \%, 25.6$ and $31.5 \%$ for 100 , 200, 300 and $500 \mu \mathrm{g} K_{1}$ respectively. Parallel changes were seen for FIIc, FVIIc and PIVKA-II, the latter showing the fastest response. Plasma peak $K_{l}(4 h)$ and fasting 24-h post $K_{l}$ levels both increased linearly with vitamin K-intake. Single meals of $400 \mathrm{~g}$ spinach (1500 $\left.\mu \mathrm{g} K_{1}\right)$ or broccoli (625 $\left.\mu \mathrm{g} K_{l}\right)$ induced a similar, but short-lived (24h), decline in INR (14\%) and increase in FIIc and FVIIc. In contrast, a single meal of $100 \mathrm{~g}$ natto (1000 $\mu \mathrm{g}$ MK-7) induced a decrease in INR of $24 \%$ that lasted for up to $4 d$ that was accompanied by complete normalisation of FVIIc. Plasma levels of $M K-7$ peaked at $5 \mathrm{~h}$ but unlike $K_{1}$ remained at a high level for $4 \mathrm{~d}$. Curd cheese had no effect on OAC therapy, probably because of the low amount of MK-9 present in a single meal. In conclusion: (1) The effects of taking vitamin $K_{1}$ supplements on the stability of OAC therapy measured by the INR became statistically significant at doses of $>150 \mu \mathrm{g} / \mathrm{d}$. The interference became clinically relevant at intakes above $150 \mu \mathrm{g} / \mathrm{d}$. (2) A high intake of $K_{1}$ from a single meal of green vegetables is not likely do destabilize OAC therapy. However, the relative bioavailability compared to pure $K_{1}$ preparations may vary; the estimated uptake from spinach and broccoli was about $10 \%$ and 35\%, respectively. (3) A single meal containing a naturally high content of MK-7 had a greater and more sustained effect in reducing OAC response which is probably related to its much longer retention as reflected by the prolonged plasma half-life. This finding suggests that common foods containing long chain MKs may have a greater effect in destabilizing OAC therapy than previously suspected.
\end{abstract}




\section{Introduction}

Oral anticoagulants (OAC, also known as vitamin $\mathrm{K}$ antagonists) are used in subjects at risk for thrombo-embolic events. Their mode of action is based on the inhibition of the enzyme vitamin $\mathrm{K}$ epoxide reductase, an enzyme of the vitamin $\mathrm{K}$ cycle. Thus, OAC block the re-use of vitamin $\mathrm{K}$ and in this way they induce a relative vitamin $\mathrm{K}$-deficiency in liver as well as in other tissues ${ }^{40}$.

Vitamin $\mathrm{K}$ acts as a cofactor in the posttranslational carboxylation by which a number of specified glutamate residues in proteins are converted into gamma-carboxyglutamate (Gla). Gla-residues are found in a number of blood coagulation factors as well as in some bone proteins including osteocalcin and matrix Gla-protein ${ }^{1,2}$ and are essential for their biological activity. Both vitamin K-deficiency and ingestion of OAC result in the synthesis of undercarboxylated Gla-proteins (also known as PIVKA's), which may be quantified in the circulation with assays based on conformation-specific antibodies ${ }^{41,42}$.

There are many factors that may lead to instability of OAC therapy. They include age, alcohol consumption, a number of drugs ${ }^{43-46}$, as well as the irregular consumption of vitamin K-rich foods or vitamin K-containing food supplements ${ }^{47-50}$. There are little data to which extent dietary vitamin $\mathrm{K}$ intake influence the daily dose of OAC treatment. Imbalance may lead to either an increased thrombotic tendency (high vitamin $\mathrm{K}$ intake) or to the risk of bleeding (overdose of $\mathrm{OAC}$ ), and frequent control is required. The stability of OAC therapy is monitored by measuring the International Normalized Ratio (INR), which was used in the present study as the gold standard for assessment of the level of anticoagulation. Other tests we used to monitor OAC therapy include quantification of the plasma levels of the coagulation factors II, VII, and undercarboxylated factor II (ucFII) as a measure of hepatic vitamin $\mathrm{K}$ status, and carboxylated bone Gla-protein (osteocalcin, OC) and undercarboxylated osteocalcin (ucOC) as a measure for the vitamin $\mathrm{K}$ status in bone.

The experiments reported represent the first systematic study of the dose-response relationships of vitamin K-containing supplements and vitamin K-rich foods on the stability of anticoagulation and on the carboxylation of a number of hepatic and extra-hepatic Glaproteins in healthy subjects. In our experiments we have chosen for an anticoagulant with a short half-life time (acenocoumarol, $\mathrm{t}^{1 / 2}=10 \mathrm{~h}$ ) and aimed at a relatively low INR value because it may be expected that under these conditions the effects of the various vitamin $\mathrm{K}$ sources will be maximal ${ }^{51,52}$. Since prothrombin is uniquely synthesized in the liver and osteocalcin in bone, we have compared circulating undercarboxylated forms of both proteins (ucFII and ucOC) to compare the efficacy of vitamin $\mathrm{K}$ uptake by these tissues. 


\section{Materials and Methods}

\section{Subjects and Study Design}

Twelve healthy volunteers were recruited from the population of Maastricht. To limit inter-individual fluctuations volunteers where selected in a narrow age-range. All volunteers were screened for medical health by a physician before entering the study. None of the participants had taken medication for at least 3 months prior to the study or taken a vitamin K-preparation for the last two weeks, and none of them had a family history of a coagulation disorder. The participants were asked to refrain from the consumption of food known to be rich in vitamin $\mathrm{K}$ (spinach, kale, broccoli, Brussels sprouts) during the entire study. After entering the study, the volunteers were anticoagulated by daily doses of acenocoumarol. The target INR level was 2.0, during the 4 weeks adjustment phase the actual INR values were checked daily (except weekends) during the first two weeks and four times weekly (Monday, Tuesday, Wednesday, and Friday) during the next two weeks. After the first two weeks of OAC treatment, all participants reached stable anticoagulation with an INR value around 2.0 (mean $\pm \mathrm{SD} ; 2.02 \pm 0.40$ ). At start of the supplementation phase, the mean INR value was $2.04 \pm 0.31$, and the participants received a daily dose (tablet) of $50 \mu \mathrm{g} \mathrm{K}_{1}$ for 7 days. In the following weeks, the daily dose of vitamin $\mathrm{K}_{1}$ was increased with $50 \mu \mathrm{g}$ increments each week until $300 \mu \mathrm{g} /$ day in week 6 and to $500 \mu \mathrm{g}$ /day in week 7 . The regular control of the INR value which is the appropriate parameter for this study was monitored 4 times per week, whereas the other coagulation factors FIIc, FVIIc, and ucFII were investigated 2 times per week. The volunteers received every Monday morning acenocoumarol tablets sufficient for one week of treatment; empty boxes were inspected for compliance control. The subjects took their acenocoumarol tablets between 5 and $6 \mathrm{pm}$, and before their evening meal (Figure 1). Together with a standardized breakfast, the vitamin $\mathrm{K}$ supplement was taken every morning between 8 and 9 am at the University's premises.

\begin{tabular}{|c|c|c|c|c|c|c|c|c|c|c|c|c|c|c|c|c|c|}
\hline $\mathrm{A}$ & \multicolumn{4}{|c|}{ Adjustment phase } & \multicolumn{7}{|c|}{ Phase I: pharmacological K1 } & \multicolumn{2}{|c|}{ Wash-out } & \multicolumn{4}{|c|}{ Phase II: vit $\mathrm{K}$ in food } \\
\hline B & 1 & 2 & 3 & 4 & 5 & 6 & 7 & 8 & 9 & 10 & 11 & 12 & 13 & 14 & 15 & 16 & 17 \\
\hline $\mathrm{C}$ & 0 & 0 & 0 & 0 & 50 & 100 & 150 & 200 & 250 & 300 & 500 & 0 & 0 & 1500 & 700 & 103 & 1000 \\
\hline
\end{tabular}

Figure 1.

A] Protocol scheme; B] Weeks in trial; C] Vitamin K intake above the regular diet in the subsequent weeks ( $\mu \mathrm{g} / \mathrm{day}$ ). In each week the INR was measured four times (Monday, Tuesday, Wednesday, and Friday). The FIIc, FVIIc, ucFII, ucOC, cOC, vitamin K, and TAG was measured twice weekly (Monday and Tuesday). 
Blood samples were taken by venipuncture at the times indicated and collected in trisodium citrate (Greiner Bio-one, Germany). For all coagulation assays blood collection took place after an overnight fast. On Mondays (after the start of each new vitamin K regimen) also at $\mathrm{t}=4 \mathrm{~h}$ a blood sample was taken. During the weekends the volunteers had to take their vitamin $\mathrm{K}$ supplement at home. After a 2-week washout period, the effect of different, single vitamin K-rich meals on INR value was assessed with subsequent 6-day washouts between meals. The meals were all prepared and consumed at the University of Maastricht. Plasma vitamin $\mathrm{K}$ levels were measured at 0 and $4 \mathrm{~h}$ postprandially. Plasma samples were stored in aliquots at $-80{ }^{\circ} \mathrm{C}$ until serial analysis. The study protocol was approved by the Medical Ethics Committee of the University of Maastricht and all subjects gave a written informed consent.

\section{Materials}

Reference compounds (for analysis) used were phylloquinone (vitamin $\mathrm{K}_{1}$ ), from Sigma (St. Louis, MO), as well as a series of $\mathrm{K}_{2}$ vitamins (menaquinones, MK-4 through MK-10) and 2,3,-dihydrophylloquinone which were kindly provided by Hoffmann- La Roche (Basel, Switzerland). The supplements of vitamin $\mathrm{K}_{1}$ were provided in tablets of 100 $\mu \mathrm{g} /$ tablet (Roche Vitamins Ltd). Each tablet was scored for easy breaking into two equal parts for the intake of a $50 \mu \mathrm{g}$ dose. For the nutrition experiment we used deep-frozen ready-to-use cooked spinach from Iglo Ola (Utrecht, Netherlands). Fresh broccoli and curd cheese (Mona $\left.{ }^{\circledR}\right)$ were bought in a local supermarket; natto was bought as a ready-to-use product at a local oriental store. To facilitate absorption of the fat-soluble vitamin $\mathrm{K}, 30 \mathrm{~g}$ of corn oil (CPC-Bestfoods, Heilbronn, Germany) was added to each meal. The vitamin K content of the corn oil was negligible ( $\mathrm{K}_{1}: 2.7 \mu \mathrm{g} / 100 \mathrm{~g}$; $\mathrm{K}_{2}$ : not detectable). Silica Sep-pak cartridges were purchased from Millipore (Milford, MA, USA). All other chemicals used were of the highest analytical grade.

\section{Various biochemical assays}

All biochemical analyses were performed in duplicate and mean values are given throughout this paper. Prothrombin times (PT) were determined with an automated analyser (STA, Diagnostica Stago, Asnière, France) using Thromborel S (Behringwerke, Marburg, Germany) as a thromboplastin reagent. The data were expressed as International Normalized Ratio (INR) values. The INR was calculated by using the formula INR = patients PT/mean normal PT) ${ }^{\mathrm{ISI}}$. In this formula ISI is the international sensitivity index that compares each thromboplastin's sensitivity to an international reference thromboplastin of $1.00^{53}$. Factor II (FIIc) and factor VII (FVIIc) procoagulant activities were measured in a coagulometer, ACL 300 Research (Instrumentation Laboratory, Milan, Italy) using Thromborel S and human 
coagulation factor II and VII-deficient plasma (Behringwerke AG, Marburg, Germany). Species of undercarboxylated FII (ucFII) were measured using a conformation-specific monoclonal antibody in an ELISA-based assay ${ }^{41}$. Results are expressed as Arbitrary Units per $\mathrm{L}(\mathrm{AU} / \mathrm{L})$ because in cases of vitamin $\mathrm{K}$ deficiency circulating ucFII may comprise multiple forms of partially carboxylated FII and neither their relative abundance in plasma nor their relative affinity for the antibody is known. Using electrophoretic techniques $1 \mathrm{AU}$ is equivalent to $1 \mu \mathrm{g}$ of purified ucFII ${ }^{41}$. The lower detection limit was $150 \mathrm{AU} / \mathrm{L}$ plasma. Undercarboxylated osteocalcin (ucOC) and carboxylated osteocalcin (cOC) were determined with the Glu-OC and Gla-OC kits from Takara Shuzo (Tokyo, Japan), respectively. Plasma vitamin $\mathrm{K}_{1}$ concentrations were measured by high performance liquid chromatography (HPLC) and fluorescence detection after on-line, post column electrochemical reduction of the effluent which converted the quinone forms of vitamin $\mathrm{K}$ compounds to their fluorescent quinol forms ${ }^{54}$. Plasma triglyceride concentrations were determined by an automated enzymatic procedure using commercial reagents (Boehringer Mannheim, Germany) and a Beckmann Synchron CX 7-2 auto-analyzer (Fullerton, CA).

\section{Dietary vitamin K assessment}

During the third week of the adjustment phase, the volunteers had to record their food intake during 7 consecutive days using a dietary diary. In this way the daily vitamin $\mathrm{K}$ intake was calculated. The weighed dietary record was repeated in the supplementation phase (200 $\mu \mathrm{g}$ supplementation phase). Using previously published databases ${ }^{54-56}$, the daily vitamin $\mathrm{K}$ ( $\mu \mathrm{g} /$ day) intake was calculated.

\section{Data analysis}

For all biochemical markers, fasting blood samples from four days per week were analysed for significant trends as repeated measurements and as means per week. For each marker the differences between supplementation phase and baseline were analyzed using the SPSS 10.0 Wilcoxon matched pairs test. Differences were considered to be statistically significant at $\mathrm{P}<0.05$. Additionally, the postprandial increase of plasma vitamin $\mathrm{K}$ was measured by comparing the early (fasting) sample and a sample taken $4 \mathrm{~h}$ later on Mondays. 


\section{Results}

\section{The adjustment phase}

The baseline characteristics of the participants are given in Table 1. There was a substantial difference in body mass index between men and women, which may be the reason why men required slightly more acenocoumarol than women to reach the target INR value. All had FIIc and FVIIc in the normal range, whereas the ucFII was below the detection level. As it is usual in healthy adults, part of the circulating OC circulated in the undercarboxylated form (mean 28\%). Vitamin $\mathrm{K}_{1}$ was within the normal range (400-2000 pmol/L), $\mathrm{K}_{2}$ vitamins were undetectable $(<0.50 \mathrm{pmol} / \mathrm{L})$ and triacylglycerol concentrations were normal.

Table 1: Characteristics of the subjects.

\begin{tabular}{lccc}
\hline & All & Male & Female \\
\hline $\mathrm{n}=$ & 12 & 6 & 6 \\
Age $(\mathrm{yrs})$ & $27.8 \pm 1.8$ & $28.3 \pm 1.51$ & $27.3 \pm 2.07$ \\
weight $(\mathrm{Kg})$ & $75.5 \pm 14.8$ & $85.8 \pm 9.4$ & $65.2 \pm 11.8$ \\
BMI (Kg/M2) & $24.2 \pm 2.6$ & $25.0 \pm 2.8$ & $23.4 \pm 2.4$ \\
OAC intake $(\mathrm{mg})$ & $3.1 \pm 0.7$ & $3.3 \pm 0.7$ & $2.8 \pm 0.7$ \\
baseline values & & & \\
INR & $1.02 \pm 0.07$ & $1.04 \pm 0.06$ & $1.01 \pm 0.08$ \\
FIlc $(\%)$ & $103 \pm 11$ & $103 \pm 7$ & $103 \pm 15$ \\
FVIIc $(\%)$ & $109 \pm 22$ & $108 \pm 23$ & $110 \pm 23$ \\
ucFII $(\mathrm{AU} / \mathrm{L})$ & $<150$ & $<150$ & $<150$ \\
ucOC $(\mathrm{ng} / \mathrm{mL})$ & $3.4 \pm 1.7$ & $3.9 \pm 1.6$ & $3.0 \pm 1.9$ \\
cOC $(\mathrm{ng} / \mathrm{mL})$ & $9.4 \pm 3.4$ & $10.7 \pm 3.7$ & $8.2 \pm 2.8$ \\
Vitamin K1 $(\mathrm{nmol} / \mathrm{L})$ & $1.27 \pm 0.4$ & $1.36 \pm 0.5$ & $1.18 \pm 0.5$ \\
Vitamin K2 $(\mathrm{nmol} / \mathrm{L})$ & $\mathrm{n} . \mathrm{d}$. & $\mathrm{n} . \mathrm{d}$. & $\mathrm{n} . \mathrm{d}$. \\
Triacylglycerol $(\mathrm{mmol} / \mathrm{L})$ & $1.02 \pm 0.48$ & $1.18 \pm 0.59$ & $0.87 \pm 0.33$ \\
\hline
\end{tabular}

Twelve healthy subjects were enrolled in the study and all received their individual dose of OAC. The target INR value of 2.0 was reached after about 2 weeks of treatment. During the subsequent two weeks the INR remained stable (mean value: $2.04 \pm 0.31$ ). The recorded food intake data were used to calculate the daily vitamin $\mathrm{K}$ intake. No significant differences in vitamin $\mathrm{K}$ intake were found between the two weeks analyzed (week 3 and 8 , respectively; see also Figure 1), and also not between the volunteers within one week. Hence refraining from food known to be rich in vitamin $\mathrm{K}_{1}$ resulted in a satisfactorily constant dietary vitamin $\mathrm{K}$ intake.

\section{Effects of vitamin K supplements}

In Table 2 we have summarized the effects of increasing vitamin $\mathrm{K}$ intake on the variables measured. The baselinedata representing the effect of no extra supplementation are those of week 4 (last week of the adjustment phase), and the Monday morning value was 
taken as the last value of the preceding week. Consequently, the data for each treatment regimen are those obtained on Tuesday, Wednesday, Friday, and the subsequent Monday morning. INR values decreased dose-dependently as the dose of vitamin $\mathrm{K}$ increased, but the difference from baseline (adjustment phase) became only statistically significant at doses 150 $\mu \mathrm{g} / \mathrm{day}$ in women and $200 \mu \mathrm{g} / \mathrm{day}$ in men. If calculated for each subject individually, the fastest responder showed a significant response at $150 \mu \mathrm{g} /$ day. In parallel with the decreasing INR, FIIc and FVIIc increased at increasing vitamin $\mathrm{K}$ intake, and the increase was statistically significant at $150 \mu \mathrm{g}$ /day for FIIc and at $200 \mu \mathrm{g}$ /day for FVIIc. An inverse correlation was found between the INR and FIIc $\left(r^{2}=-0.891, p<0.001\right)$ and between the INR and FVIIc $\left(r^{2}=-0.823, p<0.001\right)$. As was expected, ucFII concentrations were high after the adjustment phase, and declined at increasing vitamin $\mathrm{K}$ intake. The decline was significant at $100 \mu \mathrm{g}$ /day of vitamin $\mathrm{K}$. The vitamin $\mathrm{K}$ status of bone tissue was deduced by comparing the circulating bone proteins $\mathrm{cOC}$ and ucOC. As can be seen in Table 2, the concentration of ucOC was only measurably decreased at very high vitamin $\mathrm{K}$ intakes (300 $\mu \mathrm{g} / \mathrm{day})$.

Table 2. Effects of a pharmacological vitamin $\mathrm{K}_{1}$ preparation on $\mathrm{OAC}$ treatment (mean values of $n=12 \pm S D$ ).

\begin{tabular}{|c|c|c|c|c|c|c|}
\hline Supplementation & INR & Fllc & FVIIC & Pivka-II & UcOC & $\mathrm{cOC}$ \\
\hline 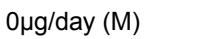 & $1.96 \pm 0.34$ & $46.3 \pm 9.0$ & $52.7 \pm 23.5$ & $24432 \pm 6421$ & $31.5 \pm 8.1$ & $2.2 \pm 0.9$ \\
\hline Oug/day (T) & $2.08 \pm 0.38$ & $45.7 \pm 10.8$ & $47.8 \pm 23.0$ & $23631 \pm 8993$ & $33.1 \pm 9.2$ & $2.1 \pm 0.8$ \\
\hline Oug/day (W) & $2.02 \pm 0.41$ & & & & & \\
\hline Oug/day (F) & $2.04 \pm 0.50$ & & & & & \\
\hline 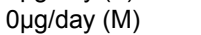 & $1.93 \pm 0.26$ & $45.7 \pm 7.1$ & $49.4 \pm 16.6$ & $26912 \pm 10440$ & $29.9 \pm 8.8$ & $2.1 \pm 0.5$ \\
\hline $50 \mu \mathrm{g} /$ day (M) & $1.93 \pm 0.26$ & $45.7 \pm 7.1$ & $49.4 \pm 16.6$ & $26912 \pm 10440$ & $29.9 \pm 8.8$ & $2.1 \pm 0.5$ \\
\hline $50 \mu \mathrm{g} / \mathrm{day}(\mathrm{T})$ & $1.95 \pm 0.36$ & $51.8 \pm 10.6$ & $58.6 \pm 36.1$ & $27344 \pm 14062$ & $32.4 \pm 8.8$ & $2.1 \pm 0.8$ \\
\hline $50 \mu \mathrm{g} /$ day $(\mathrm{W})$ & $1.81 \pm 0.29$ & & & & & \\
\hline $50 \mu \mathrm{g} /$ day $(\mathrm{F})$ & $1.73 \pm 0.27$ & & & & & \\
\hline $50 \mu \mathrm{g} /$ day (M) & $1.85 \pm 0.31$ & $50.0 \pm 8.4$ & $50.3 \pm 23.6$ & $22469 \pm 17974$ & $30.6 \pm 9.9$ & $2.0 \pm 0.9$ \\
\hline $100 \mu \mathrm{g} /$ day $(\mathrm{M})$ & $1.85 \pm 0.31$ & $50.0 \pm 8.4$ & $50.3 \pm 23.6$ & $22469 \pm 17974$ & $30.6 \pm 9.9$ & $2.0 \pm 0.9$ \\
\hline $100 \mu \mathrm{g} / \mathrm{day}(\mathrm{T})$ & $1.86 \pm 0.30$ & $52.8 \pm 7.0$ & $54.7 \pm 20.1$ & $19184 \pm 9289$ & $33.4 \pm 9.1$ & $2.0 \pm 1.1$ \\
\hline $100 \mu \mathrm{g} / \mathrm{day}(\mathrm{W})$ & $1.78 \pm 0.29$ & & & & & \\
\hline $100 \mu \mathrm{g} /$ day $(\mathrm{F})$ & $1.67 \pm 0.22$ & & & & & \\
\hline $100 \mu \mathrm{g} /$ day $(\mathrm{M})$ & $1.75 \pm 0.26$ & $48.3 \pm 17.2$ & $44.3 \pm 17.2$ & $20535 \pm 11847$ & $33.0 \pm 8.2$ & $2.4 \pm 1.6$ \\
\hline $150 \mu \mathrm{g} /$ day $(\mathrm{M})$ & $1.75 \pm 0.26$ & $48.3 \pm 17.2$ & $44.3 \pm 17.2$ & $20535 \pm 11847$ & $33.0 \pm 8.2$ & $2.4 \pm 1.6$ \\
\hline $150 \mu \mathrm{g} /$ day $(\mathrm{T})$ & $1.75 \pm 0.24$ & $55.1 \pm 8.7$ & $62.8 \pm 25.3$ & $19291 \pm 8252$ & $32.6 \pm 7.8$ & $2.7 \pm 1.2$ \\
\hline $150 \mu \mathrm{g} / \mathrm{day}(\mathrm{W})$ & $1.59 \pm 0.26$ & & & & & \\
\hline $150 \mu \mathrm{g} /$ day $(\mathrm{F})$ & $1.56 \pm 0.27$ & & & & & \\
\hline $150 \mu \mathrm{g} /$ day $(\mathrm{M})$ & $1.58 \pm 0.20$ & $55.0 \pm 8.0$ & $66.4 \pm 43.5$ & $15140 \pm 8271$ & $31.0 \pm 9.2$ & $2.4 \pm 1.1$ \\
\hline $200 \mu \mathrm{g} /$ day $(\mathrm{M})$ & $1.58 \pm 0.20$ & $55.0 \pm 8.0$ & $66.4 \pm 43.5$ & $15140 \pm 8271$ & $31.0 \pm 9.2$ & $2.4 \pm 1.1$ \\
\hline $200 \mu \mathrm{g} / \mathrm{day}(\mathrm{T})$ & $1.57 \pm 0.23$ & $56.7 \pm 8.8$ & $69.3 \pm 26.7$ & $15457 \pm 9630$ & $32.3 \pm 6.2$ & $2.9 \pm 1.1$ \\
\hline $200 \mu \mathrm{g} /$ day $(\mathrm{W})$ & $1.54 \pm 0.16$ & & & & & \\
\hline $200 \mu \mathrm{g} /$ day $(\mathrm{F})$ & $1.50 \pm 0.21$ & & & & & \\
\hline $200 \mu \mathrm{g} /$ day (M) & $1.53 \pm 0.18$ & $59.3 \pm 7.5$ & $61.9 \pm 19.4$ & $16352 \pm 9884$ & $32.7 \pm 8.2$ & $3.1 \pm 1.4$ \\
\hline $250 \mu \mathrm{g} /$ day $(\mathrm{M})$ & $1.53 \pm 0.18$ & $59.3 \pm 7.5$ & $61.9 \pm 19.4$ & $16352 \pm 9884$ & $32.7 \pm 8.2$ & $3.1 \pm 1.4$ \\
\hline $250 \mu \mathrm{g} /$ day $(\mathrm{T})$ & $1.55 \pm 0.24$ & $61.1 \pm 5.2$ & $69.4 \pm 19.2$ & $12183 \pm 5962$ & $29.8 \pm 8.5$ & $3.0 \pm 1.0$ \\
\hline $250 \mu \mathrm{g} / \mathrm{day}(\mathrm{W})$ & $1.50 \pm 0.15$ & & & & & \\
\hline $250 \mu \mathrm{g} /$ day $(\mathrm{F})$ & $1.53 \pm 0.16$ & & & & & \\
\hline $250 \mu \mathrm{g} /$ day $(\mathrm{M})$ & $1.47 \pm 0.24$ & $61.9 \pm 6.7$ & $75.8 \pm 39.1$ & $14301 \pm 8221$ & $27.9 \pm 9.9$ & $2.9 \pm 1.6$ \\
\hline $300 \mu \mathrm{g} /$ day $(\mathrm{M})$ & $1.47 \pm 0.24$ & $61.9 \pm 6.7$ & $75.8 \pm 39.1$ & $14301 \pm 8221$ & $27.9 \pm 9.9$ & $2.9 \pm 1.6$ \\
\hline $300 \mu \mathrm{g} / \mathrm{day}(\mathrm{T})$ & $1.47 \pm 0.15$ & $57.9 \pm 5.6$ & $61.3 \pm 29.9$ & $10480 \pm 6531$ & $20.8 \pm 8.1$ & $3.6 \pm 1.6$ \\
\hline $300 \mu \mathrm{g} / \mathrm{day}(\mathrm{W})$ & $1.51 \pm 0.13$ & & & & & \\
\hline $300 \mu \mathrm{g} /$ day $(F)$ & $1.57 \pm 0.11$ & & & & & \\
\hline $300 \mu \mathrm{g} /$ day $(\mathrm{M})$ & $1.42 \pm 0.17$ & $64.5 \pm 9.5$ & $75.4 \pm 30.1$ & $9454 \pm 10374$ & $19.2 \pm 4.3$ & $4.3 \pm 1.2$ \\
\hline $500 \mu \mathrm{g} /$ day $(\mathrm{M})$ & $1.42 \pm 0.17$ & $64.5 \pm 9.5$ & $75.4 \pm 30.1$ & $9454 \pm 10374$ & $19.2 \pm 4.3$ & $4.3 \pm 1.2$ \\
\hline $500 \mu \mathrm{g} / \mathrm{day}(\mathrm{T})$ & $1.39 \pm 0.13$ & $64.0 \pm 6.9$ & $60.3 \pm 12.0$ & $6111 \pm 4020$ & $18.5 \pm 5.4$ & $4.4 \pm 1.2$ \\
\hline $500 \mu \mathrm{g} / \mathrm{day}(\mathrm{W})$ & $1.41 \pm 0.14$ & & & & & \\
\hline $500 \mu \mathrm{g} /$ day $(F)$ & $1.37 \pm 0.12$ & & & & & \\
\hline
\end{tabular}


Circulating vitamin $\mathrm{K}$ concentrations were measured at $\mathrm{t}=0$, 4, and $24 \mathrm{~h}$ after intake of each new vitamin $\mathrm{K}$ regimen. The $4 \mathrm{~h}$ points represent the peak of the absorption curves, and show a linear dose-response relation (figure 2). At $24 \mathrm{~h}$ after intake the values had almost completely returned to the baseline level, which is consistent with the rapid plasma clearance of vitamin $\mathrm{K}$.

\section{Effects of vitamin K from food}

Vitamin K-rich meals were prepared and administered on Monday morning. In this way the effect of a single meal was studied. The meals differed with respect to their vitamin $\mathrm{K}$ content as well as the type of vitamin $\mathrm{K}$ present (see table 3). Although spinach contains more vitamin $\mathrm{K}_{1}$ than broccoli, the circulating (absorbed) vitamin $\mathrm{K}_{1}$ after the spinach meal was lower than after the broccoli meal; in addition the effects of broccoli on the INR and the individual coagulation factors were larger than that of spinach. This observation is consistent with the much better absorption of vitamin $\mathrm{K}_{1}$ from broccoli than from spinach. The effect of $\mathrm{K}_{1}$ from both spinach and broccoli on the INR lasted only for 24 hours and 48 hours after food intake the INR values had returned to their baseline values. No significant effects of a spinach or broccoli meal were observed on ucOC and cOC. Curd cheese (rich in MK-9) had a less pronounced effect and did not result in significant effects on any of the markers assayed. The circulating MK-9 concentration at $4 \mathrm{~h}$ after intake was $3.23 \mathrm{nmol} / \mathrm{L}$ and returned to baseline at $24 \mathrm{~h}$. Natto is known to be a rich source of vitamin $\mathrm{K}_{2}$ (mainly MK-7). At $4 \mathrm{~h}$ after intake, circulating MK-7 concentrations were high (13.25 nmol/L), and remained elevated until $144 \mathrm{~h}$ after intake. The long plasma half-life time was reflected in a significant decrease in INR over the whole week. Consistently, FIIc and FVIIc were increased significantly until four days postprandially. Despite the effect on the coagulation system, the consumption of natto did not affect the Gla-content of circulating osteocalcin which reflects the extra-hepatic metabolism. 
Table 3. Effects of a food items rich in vitamin $\mathrm{K}$ on the OAC treatment. Mean values $\alpha \mathrm{SD}$ of $\mathrm{n}=12$ volunteers.

* In the natto supplementation week we added an additional measurement on Thursday because the effect of natto on vitamin $\mathrm{K}$ dependent proteins was so pronounced and lasted for the whole week.

\begin{tabular}{|c|c|c|c|c|c|c|}
\hline Supplementation & INR & Fllc & FVIIc & Pivka-II & UcOC & $\mathrm{cOC}$ \\
\hline Wash-out (M) & $2.02 \pm 0.40$ & $47.3 \pm 8.0$ & $52.7 \pm 23.5$ & $26200 \pm 15000$ & $20.2 \pm 7.5$ & $3.7 \pm 1.4$ \\
\hline Wash-out (T) & $2.05 \pm 0.29$ & & & & & \\
\hline Washout (W) & $1.97 \pm 0.26$ & & & & & \\
\hline Wash-out (F) & $2.19 \pm 0.44$ & & & & & \\
\hline Washout (M) & $2.11 \pm 0.34$ & $49.9 \pm 8.2$ & $47.3 \pm 11.3$ & $27371 \pm 20906$ & $19.0 \pm 7.1$ & $3.8 \pm 1.3$ \\
\hline Spinach (M) & $2.11 \pm 0.34$ & $49.9 \pm 8.2$ & $47.3 \pm 11.3$ & $27371 \pm 20906$ & $19.0 \pm 7.1$ & $3.8 \pm 1.3$ \\
\hline Spinach $(\mathrm{T})$ & $1.70 \pm 0.16$ & $56.5 \pm 6.3$ & $71.1 \pm 22.6$ & $25000 \pm 12782$ & $18.0 \pm 7.9$ & $4.3 \pm 1.4$ \\
\hline Spinach (W) & $1.91 \pm 0.38$ & & & & & \\
\hline Spinach (F) & $1.86 \pm 0.34$ & & & & & \\
\hline Spinach (M) & $2.03 \pm 0.27$ & $47.7 \pm 10.1$ & $57.0 \pm 18.9$ & $22092 \pm 16227$ & $20.2 \pm 7.6$ & $4.3 \pm 1.1$ \\
\hline Broccoli (M) & $2.03 \pm 0.27$ & $47.7 \pm 10.1$ & $57.0 \pm 18.9$ & $22092 \pm 16227$ & $20.2 \pm 7.6$ & $4.3 \pm 1.1$ \\
\hline Broccoli $(\mathrm{T})$ & $1.62 \pm 0.20$ & $61.6 \pm 9.8$ & $76.5 \pm 23.1$ & $21000 \pm 13000$ & $17.4 \pm 7.4$ & $4.2 \pm 1.4$ \\
\hline Broccoli (W) & $1.87 \pm .28$ & & & & & \\
\hline Broccoli $(F)$ & $1.89 \pm 0.28$ & & & & & \\
\hline Broccoli (M) & $1.98 \pm 0.31$ & $52.0 \pm 7.0$ & $47.0 \pm 15.8$ & $26873 \pm 15736$ & $18.4 \pm 5.7$ & $4.3 \pm 1.1$ \\
\hline Curd cheese (M) & $1.98 \pm 0.31$ & $52.0 \pm 7.0$ & $47.0 \pm 15.8$ & $26873 \pm 15736$ & $18.4 \pm 5.7$ & $4.3 \pm 1.1$ \\
\hline Curd cheese $(T)$ & $1.84 \pm 0.23$ & $53.0 \pm 9.4$ & $54.4 \pm 20.6$ & $25000 \pm 9221$ & $22.4 \pm 7.6$ & $3.7 \pm 1.4$ \\
\hline Curd cheese (W) & $1.81 \pm 0.31$ & & & & & \\
\hline Curd cheese (F) & $1.88 \pm 0.28$ & & & & & \\
\hline Curd cheese (M) & $2.01 \pm 0.57$ & $50.5 \pm 11.3$ & $51.3 \pm 23.3$ & $21019 \pm 21354$ & $23.1 \pm 7.7$ & $3.6 \pm 1.2$ \\
\hline Natto (M) & $2.11 \pm 0.34$ & $49.9 \pm 8.2$ & $47.3 \pm 11.3$ & $27371 \pm 20906$ & $19.0 \pm 7.1$ & $3.8 \pm 1.3$ \\
\hline Natto $(T)$ & $1.50 \pm 0.21$ & $55.2 \pm 9.0$ & $87.9 \pm 30.2$ & $24820 \pm 16671$ & $26.0 \pm 8.5$ & $3.7 \pm 1.1$ \\
\hline Natto (W) & $1.49 \pm 0.26$ & $56.2 \pm 9.4$ & $81.2 \pm 27.8$ & $22970 \pm 12460$ & $22.8 \pm 7.4$ & $4.3 \pm 1.7$ \\
\hline Natto $(T h)^{*}$ & $1.42 \pm 0.13$ & $54.6 \pm 8.4$ & $73.7 \pm 19.3$ & $11446 \pm 7085$ & $21.3 \pm 6.7$ & $4.3 \pm 2.2$ \\
\hline Natto (F) & $1.44 \pm 0.21$ & $58.0 \pm 8.6$ & $78.1 \pm 28.2$ & $25378 \pm 16557$ & $21.5 \pm 8.0$ & $3.8 \pm 1.7$ \\
\hline Natto (M) & $1.75 \pm 0.38$ & $52.3 \pm 10.6$ & $54.0 \pm 27.6$ & $24903 \pm 17988$ & $22.9 \pm 8.4$ & $3.8 \pm 1.9$ \\
\hline
\end{tabular}




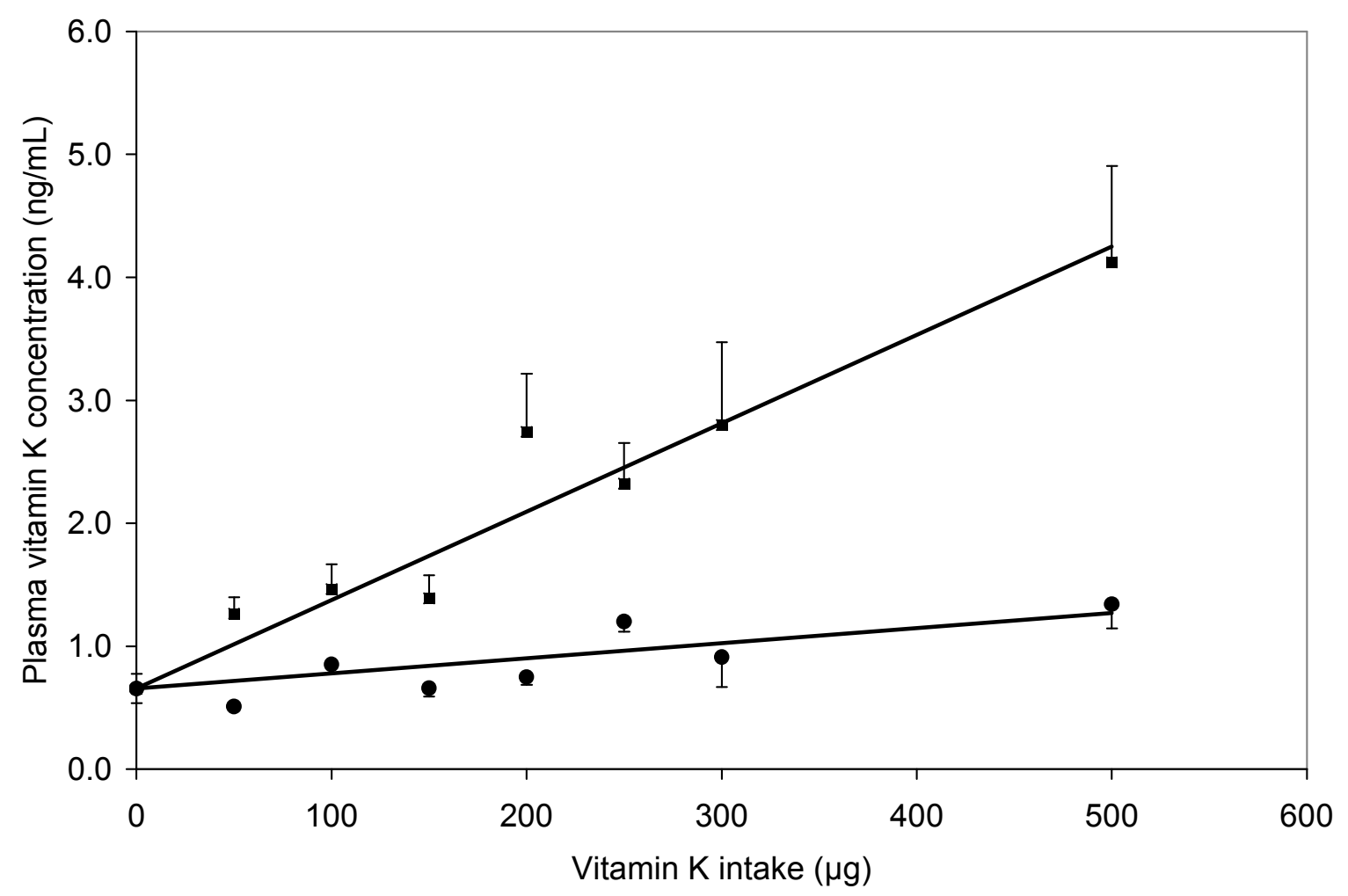

Figure 2.

Plasma vitamin $\mathrm{K}$ as a function of vitamin $\mathrm{K}$ intake: analysis at $4 \mathrm{~h}(\boldsymbol{\square})$ and at $24 \mathrm{~h}$, day $7(\bullet)$ of treatment with indicated dose.

\section{Discussion}

Fluctuations in OAC therapy are often attributed to variations in the dietary vitamin $\mathrm{K}$ intake. Vitamin $\mathrm{K}_{1}$ is of plant origin and forms $80-90 \%$ of the total vitamin $\mathrm{K}$ content of the western diet. Most of it occurs in green vegetables, and one serving of spinach or kale may contain as much as $2 \mathrm{mg}$ of $\mathrm{K}_{1}$. In these vegetables, vitamin $\mathrm{K}$ is tightly bound to the thylakoid membrane of the chloroplasts, so that intestinal absorption is relatively poor ${ }^{54,57,58}$. Hence pronounced disturbances of OAC therapy by fluctuations in vegetable consumption are uncommon. As far as we are aware, no data are available on the interaction of OAC therapy and menaquinones ( $\mathrm{K}_{2}$-vitamins) intake. These are usually present in the unbound matrix of food suggesting that their absorption is generally much better than that of $\mathrm{K}_{1}$ from plants. On the otherhand, as evidence has grown on the beneficial effects of vitamin $\mathrm{K}$ on bone health, there is an increasing trend to add vitamin $\mathrm{K}$ to food supplements and multivitamin preparations. Most of these products contain synthetic vitamin $\mathrm{K}_{1}$ and, notably if this is consumed in combination with a little bit of fat, its absorption is almost complete 
57,58. Here we carried out a systematic analysis of the effect of a $\mathrm{K}_{1}$ supplement as well as various food items known to be rich in either $\mathrm{K}_{1}$ or $\mathrm{K}_{2}$ on the level of anticoagulation established by measuring their effect on the INR.

The INR is relatively insensitive for small fluctuations of the individual plasma coagulation factors, but it is used world wide to control the desired degree of anticoagulation. A clinically relevant disturbance was defined as the value which would require adjustment of the OAC dose ( $15 \%$ of the target INR value), which is close to the value for statistical significance $(2 \mathrm{xD})$. Overall, our group analysis suggested that pure vitamin $\mathrm{K}$ supplements only affected the INR value at a daily dose of 150-200 $\mu \mathrm{g}$ /day. Measurement of the procoagulant activities of FIIc and FVIIc was slightly more sensitive, and at $150 \mu \mathrm{g} /$ day significant effects were found. Although small variations in its plasma concentration are not clinically relevant, ucFII was the most sensitive coagulation parameter in our protocol. However, even for this marker a decrease was only found at intakes $=100 \mu \mathrm{g} / \mathrm{day}$. Interindividual differences with respect to the sensitivity of the administered vitamin $\mathrm{K}$ were substantial, with the lowest effective dose for effect ranging between $100 \mu \mathrm{g} /$ day (in one individual) and $500 \mu \mathrm{g} /$ day (two subjects). From these data we conclude that vitamin $\mathrm{K}$ supplements in a daily dose of $<100 \mu \mathrm{g}$ /day are not interfering with OAC treatment, even at irregular use during $\mathrm{OAC}$ treatment. Both hematologists and patients should be aware, however, that some of these preparations (available as over-the-counter products) contain as much as $500 \mu \mathrm{g} \mathrm{K}_{1}$, and that such products may strongly affect OAC treatment.

Although the concept of the assay for ucOC is comparable to that for ucFII, an effect on ucOC was only observed at a high vitamin $\mathrm{K}$ intake (300 $\mu \mathrm{g}$ /day). This is consistent with previous work that has suggested that the vitamin $\mathrm{K}$ requirement of extra-hepatic tissues such as bone is substantially higher than that of liver, and that at low tissue vitamin K-status the liver has a high efficacy of vitamin $\mathrm{K}$ absorption from the blood stream.

When analysing the data of the effect of a single dose of different vitamin $\mathrm{K}$ rich foods, these comparisons were made with the first day. It is obvious that after the consumption of vitamin $\mathrm{K}$ rich vegetables, the circulating vitamin $\mathrm{K}$ concentrations are far lower than after intake of a comparable amount of $\mathrm{K}$ from supplements. This is consistent with previous publications ${ }^{54,57,58}$, and suggests a poor absorption from vegetables, notably from spinach. Additionally, vitamin $\mathrm{K}_{1}$ rapidly disappears from the circulation, and also from liver: even at high intakes the plasma concentrations had returned to nearly baseline and the effects on coagulation factors (having half-life times of 8 (FVIIc) and 56 (FIIc) h) were only apparent at $24 \mathrm{~h}$ postprandially. It cannot be excluded that vitamin $\mathrm{K}$ from food containing vitamin $\mathrm{K}$ rich vegetable oils (not tested in our study) has a much higher impact on the INR values, because of the likelihood of a better absorption. Those forms of $\mathrm{K}_{2}$ with long sidechaions have long plasma half-life times. However, the number food items rich in $\mathrm{K}_{2}$ are 
restricted. In the western diet the highest menaquinone concentrations (notably MK-9 and MK-10) are found in cheese and curd cheese. However, the concentrations are well below those of $K_{1}$ in vegetables and a large, single dose had no effect on the INR value. Because of their long biological half-life time the higher menaquinones may accumulate when eaten regularly, but the extent to which this may influence OAC therapy cannot be deduced from our data. Natto is an Asian product which is very rich in MK-7, and which is probably unknown among western hematologists. A single portion of natto had a profound effect on the INR, which was detectable even after several days. Also MK-7 itself remained in the circulation for at least 4 days, so regular consumption of natto may lead to significant accumulation of MK-7 and may substantially interfere with OAC treatment.

In conclusion, we have demonstrated in this study that food supplements providing $<$ $150 \mu \mathrm{g} /$ day of vitamin $\mathrm{K}_{1}$ do not significantly interfere with oral anticoagulant therapy. Furthermore, irregular consumption of green vegetables in normal amounts will only contribute marginally to fluctuations of the INR value. However, foods rich in menaquinones may form a source of fluctuations. Only a limited number of the more common foods in the western diet have been analyzed for their vitamin $\mathrm{K}_{2}$ content. This paper demonstrates the importance of a more systematic analysis of also more uncommon and exotic foods, which may form an unsuspected source of variable INR values or apparent warfarin resistance. 


\section{REFERENCES}

1. Vermeer C. Gamma-carboxyglutamate-containing proteins and the vitamin K-dependent carboxylase. Biochem J. 1990;266:625-36.

2. Furie B, Bouchard BA, Furie BC. Vitamin K-dependent biosynthesis of gammacarboxyglutamic acid. Blood. 1999;93:1798-808.

3. von Kries R, Greer FR, Suttie JW. Assessment of vitamin K status of the newborn infant. $J$ Pediatr Gastroenterol Nutr. 1993;16:231-8.

4. Shearer MJ. Assay of coumarin antagonists of vitamin K in blood by high-performance liquid chromatography. Methods Enzymol. 1986;123:223-34.

5. Sokol RJ, Reardon MC, Accurso FJ, Stall C, Narkewicz M, Abman SH, Hammond KB. Fatsoluble-vitamin status during the first year of life in infants with cystic fibrosis identified by screening of newborns. Am J Clin Nutr. 1989;50:1064-71.

6. Rashid M, Durie P, Andrew M, Kalnins D, Shin J, Corey M, Tullis E, Pencharz PB. Prevalence of vitamin K deficiency in cystic fibrosis. Am J Clin Nutr. 1999;70:378-82.

7. Binkley NC, Suttie JW. Vitamin K nutrition and osteoporosis. J Nutr. 1995;125:1812-21.

8. Szulc P, Chapuy MC, Meunier PJ, Delmas PD. Serum undercarboxylated osteocalcin is a marker of the risk of hip fracture in elderly women. J Clin Invest. 1993;91:1769-74.

9. Väänänen HK, Luukinen H, Käkönen S-M, Pettersson K, Koski K, Laippala P, Lövgren T, Kivelä S-L. Strong prediction of fractures among the elderly by the ratio of carboxylated and total serum osteocalcin. Calcif Tissue Int. 1999;64:S79.

10. Brenner B, Sanchez-Vega B, Wu SM, Lanir N, Stafford DW, Solera J. A missense mutation in gamma-glutamyl carboxylase gene causes combined deficiency of all vitamin K-dependent blood coagulation factors. Blood. 1998;92:4554-9.

11. Spronk HM, Farah RA, Buchanan GR, Vermeer C, Soute BA. Novel mutation in the gammaglutamyl carboxylase gene resulting in congenital combined deficiency of all vitamin Kdependent blood coagulation factors. Blood. 2000;96:3650-3652.

12. Pauli RM, Lian JB, Mosher DF, Suttie JW. Association of congenital deficiency of multiple vitamin K-dependent coagulation factors and the phenotype of the warfarin embryopathy: clues to the mechanism of teratogenicity of coumarin derivatives. Am J Hum Genet. 1987;41:566-83.

13. Cain D, Hutson SM, Wallin R. Assembly of the warfarin-sensitive vitamin K 2,3-epoxide reductase enzyme complex in the endoplasmic reticulum membrane. $J$ Biol Chem. 1997;272:29068-75.

14. Guenthner TM, Cai D, Wallin R. Co-purification of microsomal epoxide hydrolase with the warfarin-sensitive vitamin K1 oxide reductase of the vitamin K cycle. Biochem-Pharmacol. 1998;55:169-75.

15. Leonard CO. Vitamin K responsive bleeding disorder. A genocopy of the warfarin embryopathy. Proceedings of the Greenwood Genetic Center. 1988;7:165-166.

16. Boneh A, Bar-Ziv J. Hereditary deficiency of vitamin K-dependent coagulation factors with skeletal abnormalities. Am J Med Genet. 1996;65:241-3.

17. Hauschka PV, Lian JB, Cole DE, Gundberg CM. Osteocalcin and matrix Gla protein: vitamin Kdependent proteins in bone. Physiol Rev. 1989;69:990-1047.

18. Knapen $\mathrm{MH}$, Eisenwiener HG, Vermeer C. Osteocalcin detection in aging serum and whole blood: stability of different osteocalcin fractions. Clin Chim Acta. 1996;256:151-64.

19. Power MJ, Fottrell PF. Osteocalcin: diagnostic methods and clinical applications. Crit Rev Clin Lab Sci. 1991;28:287-335.

20. Ducy P, Desbois C, Boyce B, Pinero G, Story B, Dunstan C, Smith E, Bonadio J, Goldstein S, Gundberg C, Bradley A, Karsenty G. Increased bone formation in osteocalcin-deficient mice. 
Nature. 1996;382:448-52.

21. Schinke T, McKee MD, Karsenty G. Extracellular matrix calcification: where is the action? [news; comment]. Nat Genet. 1999;21:150-1.

22. Vermeer C, Jie KS, Knapen MH. Role of vitamin K in bone metabolism. Annu Rev Nutr. 1995; 15:1-22.

23. Ferland G, Sadowski JA, ME OB. Dietary induced subclinical vitamin K deficiency in normal human subjects. J Clin Invest. 1993;91:1761-8.

24. Abitbol V, Roux C, Chaussade S, Guillemant S, Kolta S, Dougados M, Couturier D, Amor B. Metabolic bone assessment in patients with inflammatory bowel disease. Gastroenterology. 1995; 108:417-22.

25. Driscoll RH, Jr., Meredith SC, Sitrin M, Rosenberg IH. Vitamin D deficiency and bone disease in patients with Crohn's disease. Gastroenterology. 1982;83:1252-8.

26. Andreassen H, Rix M, Brot C, Eskildsen P. Regulators of calcium homeostasis and bone mineral density in patients with Crohn's disease. Scand J Gastroenterol. 1998;33:1087-93.

27. Hessov I, Mosekilde L, Melsen F, Fasth S, Hulten L, Lund B, Sorensen OH. Osteopenia with normal vitamin D metabolites after small-bowel resection for Crohn's disease. Scand $J$ Gastroenterol. 1984;19:691-6.

28. Silvennoinen J. Relationships between vitamin D, parathyroid hormone and bone mineral density in inflammatory bowel disease. J Intern Med. 1996;239:131-7.

29. Vogelsang H, Ferenci P, Woloszczuk W, Resch H, Herold C, Frotz S, Gangl A. Bone disease in vitamin D-deficient patients with Crohn's disease. Dig Dis Sci. 1989;34:1094-9.

30. Krasinski SD, Russell RM, Furie BC, Kruger SF, Jacques PF, Furie B. The prevalence of vitamin K deficiency in chronic gastrointestinal disorders. Am J Clin Nutr. 1985;41:639-43.

31. Rucker RB. Improved functional endpoints for use in vitamin $\mathrm{K}$ assessment: important implications for bone disease. Am J Clin Nutr. 1997;65:883-4.

32. Hara K, Akiyama Y, Ohkawa I, Tajima T. Effects of menatetrenone on prednisolone-induced bone loss in rats. Bone. 1993;14:813-8.

33. Sato Y, Honda Y, Kuno H, Oizumi K. Menatetrenone ameliorates osteopenia in disuse-affected limbs of vitamin D- and K-deficient stroke patients. Bone. 1998;23:291-6.

34. Beker LT, Ahrens RA, Fink RJ, O'Brien ME, Davidson KW, Sokoll LJ, Sadowski JA. Effect of vitamin $\mathrm{K} 1$ supplementation on vitamin $\mathrm{K}$ status in cystic fibrosis patients. $J$ Pediatr Gastroenterol Nutr. 1997;24:512-7.

35. Shiraki M, Shiraki Y, Aoki C, Miura M. Vitamin K2 (menatetrenone) effectively prevents fractures and sustains lumbar bone mineral density in osteoporosis. $J$ Bone Miner Res. 2000;15:515-21.

36. Feskanich D, Weber P, Willett WC, Rockett H, Booth SL, Colditz GA. Vitamin K intake and hip fractures in women: a prospective study. Am J Clin Nutr. 1999;69:74-9.

37. Booth SL, Tucker KL, Chen H, Hannan MT, Gagnon DR, Cupples LA, Wilson PW, Ordovas J, Schaefer EJ, Dawson-Hughes B, Kiel DP. Dietary vitamin K intakes are associated with hip fracture but not with bone mineral density in elderly men and women. Am J Clin Nutr. 2000;71:1201-8.

38. Szulc P, Arlot M, Chapuy MC, Duboeuf F, Meunier PJ, Delmas PD. Serum undercarboxylated osteocalcin correlates with hip bone mineral density in elderly women. $J$ Bone Miner Res. 1994;9:1591-5.

39. Caraballo PJ, Heit JA, Atkinson EJ, Silverstein MD, O'Fallon WM, Castro MR, Melton LJ, 3rd. Long-term use of oral anticoagulants and the risk of fracture. Arch Intern Med. 1999;159:1750-6.

40. Vermeer C, Hamulyak K. Pathophysiology of vitamin K-deficiency and oral anticoagulants. Thromb Haemost. 1991;66:153-9. 
41. Belle M, Brebant R, Guinet R, Leclercq M. Production of a new monoclonal antibody specific to human des-gamma- carboxyprothrombin in the presence of calcium ions. Application to the development of a sensitive ELISA-test. J Immunoassay. 1995;16:213-29.

42. Vergnaud P, Garnero P, Meunier PJ, Breart G, Kamihagi K, Delmas PD. Undercarboxylated osteocalcin measured with a specific immunoassay predicts hip fracture in elderly women: the EPIDOS Study. J Clin Endocrinol Metab. 1997;82:719-24.

43. Kumar S, Haigh JR, Rhodes LE, Peaker S, Davies JA, Roberts BE, Feely MP. Poor compliance is a major factor in unstable outpatient control of anticoagulant therapy. Thromb Haemost. 1989;62:729-732.

44. James AH, Britt RP, Raskino CL, Thompson SG. Factors affecting the maintenance dose of warfarin. J Clin Pathol. 1992;45:704-706.

45. Harris JE. Interaction of dietary factors with oral anticoagulants: review and applications. $J \mathrm{Am}$ Diet Assoc. 1995;95:580-584.

46. Beyth RJ, Landefeld CS. Anticoagulants in older patients. A safety perspective [published erratum appears in Drugs Aging 1995 Apr;6(4):343]. Drugs Aging. 1995;6:45-54.

47. Kempin SJ. Warfarin resistance caused by broccoli [letter]. N Engl J Med. 1983;308:1229-1230.

48. Karlson B, Leijd B, Hellstrom K. On the influence of vitamin K-rich vegetables and wine on the effectiveness of warfarin treatment. Acta Med Scand. 1986;220:347-350.

49. Kalra PA, Cooklin M, Wood G, O'Shea GM, Holmes AM. Dietary modification as cause of anticoagulation instability [letter]. Lancet. 1988;2:803.

50. Pedersen FM, Hamberg O, Hess K, Ovesen L. The effect of dietary vitamin K on warfarininduced anticoagulation. J Intern Med. 1991;229:517-520.

51. Fekkes N, de Jonge H, Veltkamp JJ, Bieger R, Loeliger EA. Comparative study of the clinical effect of acenocoumarol (Sintrom) and phenprocoumon (Marcoumar) in myocardial infarction and angina pectoris. Acta Med Scand. 1971;190:535-40.

52. Breed WP, van Hooff JP, Haanen C. A comparative study concerning the stability of the anticoagulant effect of acenocoumarol and phenprocoumon. Acta Med Scand. 1969;186:283-8.

53. Hirsch J, Dalen J. Oral anticoagulants. Mechanism of action, clinical effectiveness and optimal therapeutic range. Chest. 1992;104:312s-326s.

54. Schurgers LJ, Vermeer C. Determination of Phylloquinone and Menaquinones in Food. effect of food matrix on circulating vitamin K concentrations. Haemostasis. 2000;30:298-307.

55. Bolton-Smith C, Price RJ, Fenton ST, Harrington DJ, Shearer MJ. Compilation of a provisional UK database for the phylloquinone (vitamin $\mathrm{K}_{1}$ ) content of foods. Br J Nutr. 2000;83:389-399.

56. Booth SL, Sadowski JA, Weihrauch JL, Ferland G. Vitamin $\mathrm{K}_{1}$ (phylloquinone) content of foods: a provisional table. J Food Comp Anal. 1993;6:109-120.

57. Garber AK, Binkley NC, Krueger DC, Suttie JW. Comparison of phylloquinone bioavailability from food sources or a supplement in human subjects. J Nutr. 1999;129:1201-3.

58. Gijsbers BL, Jie KS, Vermeer C. Effect of food composition on vitamin K absorption in human volunteers. Br J Nutr. 1996;76:223-9. 

ROLE OF K-VITAMINS AND VITAMIN K-DEPENDENT PROTEINS IN VASCULAR CALCIFICATION 



\title{
ROLE OF VITAMIN K AND VITAMIN K-DEPENDENT PROTEINS IN VASCULAR CALCIFICATION
}

\begin{abstract}
To provide a rational basis for recommended daily allowances (RDA) of dietary phylloquinone (vitamin $K_{1}$ ) and menaquinone (vitamin $K_{2}$ ) intake that adequately supply extra-hepatic (notably vascular) tissue requirements. Vitamin $K$ has a key function in the synthesis of at least two proteins involved in calcium and bone metabolism, namely osteocalcin and matrix Gla-protein (MGP). MGP was shown to be a strong inhibitor of vascular calcification. Present RDA values for vitamin $K$ are based on the hepatic phylloquinone requirement for coagulation factor synthesis. Accumulating data suggest that extra-hepatic tissues such as bone and vessel wall require higher dietary intakes and have a preference for menaquinone rather than for phylloquinone. Tissue-specific vitamin $K$ consumption under controlled intake was determined in warfarin-treated rats using the vitamin $K$-quinone/epoxide ratio as a measure for vitamin $K$ consumption. Immunohistochemical analysis of human vascular material was performed using a monoclonal antibody against MGP. The same antibody was used for quantification of MGP levels in serum. At least some extra-hepatic tissues including the arterial vessel wall have a high preference for accumulating and using menaquinone rather than phylloquinone. Both intima and media sclerosis are associated with high tissue concentrations of MGP, with the most prominent accumulation at the interface between vascular tissue and calcified material. This was consistent with increased concentrations of circulating MGP in subjects with atherosclerosis and diabetes mellitus. This is the first report demonstrating the association between MGP and vascular calcification. The hypothesis is put forward that undercarboxylation of MGP is a risk factor for vascular calcification and that the present RDA values are too low to ensure full carboxylation of MGP.
\end{abstract}




\section{Structure and function of vitamin $K$}

The only unequivocal biochemical role for vitamin $\mathrm{K}$ in mammals is that it acts as a cofactor in a unique posttranslational modification during protein biosynthesis ${ }^{1}$. In this reaction, specific glutamate residues in the poly-peptide chain are converted into $\gamma$ carboxyglutamate (Gla) by an enzyme known as $\gamma$-glutamate carboxylase (Figure 1). Via specific staining ${ }^{2}$ or HPLC detection techniques ${ }^{3}$ these so-called Gla-proteins can be identified as unique products of vitamin $\mathrm{K}$ action.<smiles>CNC(CCC(=O)O)C(C)=O</smiles>

Glu<smiles>CNC(CC(C(C)=O)C(=O)O)C(=O)O</smiles>

Gla

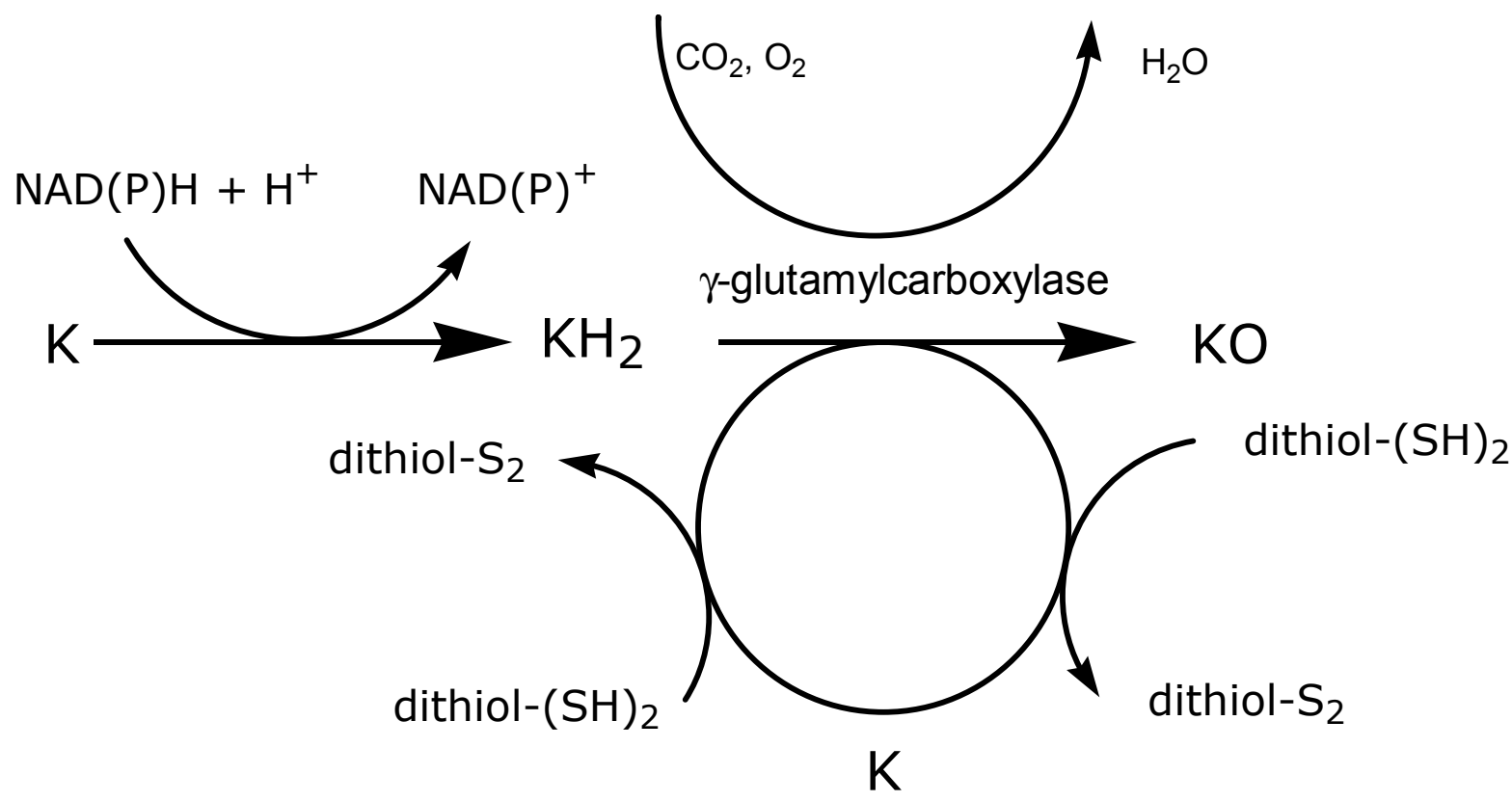

Figure 1.

The posttranslational carboxylation of glutamate residues. In this reaction, which takes place in the endoplasmic reticulum, vitamin $\mathrm{K}$ hydroquinone $\left(\mathrm{KH}_{2}\right)$ serves as a coenzyme. The vitamin $\mathrm{K}$ epoxide $(\mathrm{KO})$ formed is reconverted to $\mathrm{KH}_{2}$ by the enzyme $\mathrm{KO}$-reductase, thus enabling the recycling of vitamin $\mathrm{K}$. 
The vitamin K-dependent step is a carboxylation reaction that selectively takes place at a number of well-defined glutamate residues in only a small number of proteins ${ }^{1,4}$. Vitamin $\mathrm{K}$ is transported in its most stable form, i.e. as a quinone, but before being active as a coenzyme vitamin $\mathrm{K}$ quinone must be reduced into its hydroquinone form $\left(\mathrm{KH}_{2}\right)$. Oxidation of $\mathrm{KH}_{2}$ provides the energy for the abstraction of a proton from the $\gamma$-carbon in the glutamate residue to generate a carbanion that undergoes carboxylation resulting in a Gla-residue and vitamin $\mathrm{K}$ 2,3-epoxide (KO). The latter can be re-converted into $\mathrm{K}$ and $\mathrm{KH}_{2}$ by the action of an enzyme called KO-reductase, and in this way vitamin $\mathrm{K}$ is recycled several thousand fold before it is metabolized into more polar, inactive products. This explains why the requirement of vitamin $\mathrm{K}$ is much lower than that of most other vitamins.

The common part of the structure of all K-vitamins is 2-methyl-1,4-naphthoquinone, also known as menadione. Natural K-vitamers are menadione-derivatives differing from each other in a polyisoprenoid side chain attached to the 3-position of the ring structure. Phylloquinone, also known as vitamin $\mathrm{K}_{1}$, is produced by green plants, where it is tightly associated with the thylakoid membranes of the chloroplasts. It is a single compound containing 4 isoprenoid residues (one of which is unsaturated) in its aliphatic side chain. Menaquinones, also known by their group name vitamin $\mathrm{K}_{2}$, contain side chains of varying length; they are designated as MK-n where $n$ stands for the number of isoprenoid residues, all of which are unsaturated. Long chain menaquinones (MK-7 through MK-10) are exclusively synthesized by bacteria, but some mammalian tissues (notably testis, pancreas and arterial vessel wall) possess the remarkable ability to convert phylloquinone into MK-4 ${ }^{5}$. The fact that even at very high phylloquinone intake the accumulated vitamin $\mathrm{K}$ in these tissues is almost exclusively in the form of MK-4 suggests that menaquinones are more important for these tissues than is phylloquinone ${ }^{6}$. Also the bacterial flora in the intestinal tract produces large amounts of menaquinones, but since at the site of synthesis (the colon) absorption seems to be unlikely, the question of whether and to which extent the intestinal flora contributes to the human vitamin $\mathrm{K}$ status is still unclear ${ }^{7,8}$. From these data it appears that both phylloquinone and menaquinones are present in the circulation, and that the ratio in which these K-vitamers are taken up is tissue dependent. We have addressed, therefore, the question of whether experimental animals (rats) exhibit a tissue-specific use of either phylloquinone or menaquinones. In these experiments, in which we have used MK-4 as a representative of the group of menaquinones, reduction of $\mathrm{KO}$ was blocked by warfarin, so that the contribution of each $\mathrm{K}$-vitamer to Gla-formation could be assessed from the $\mathrm{K} / \mathrm{KO}$ ratio. This technique was previously reported for liver by Reedstrom and Suttie ${ }^{9}$. In a group of 5 rats, $\mathrm{K} / \mathrm{KO}$ ratios (mean $\pm \mathrm{SEM}$ ) for hepatic phylloquinone $(0.25 \pm 0.05)$ were much lower than for MK-4 (1.91 \pm 0.59$)$, suggesting a preferential use of phylloquinone by the liver. In arterial vessel wall, on the other hand, substantial MK-4 epoxide formation was 
observed with 10 fold lower $\mathrm{K} / \mathrm{KO}$ ratios for MK-4 $(0.39 \pm 0.16)$ than for phylloquinone $(3.78 \pm 1.15)$. These data point in the direction of a tissue specific utilization of K1 and $\mathrm{K} 2$.

\section{Functions of Gla-proteins}

Gamma-glutamate carboxylase has been found in a wide variety of mammalian tissues, but it seems that - besides those mentioned below - the corresponding Gla-proteins are produced in relatively low quantities. Incompletely characterized Gla-proteins have been reported to occur in spermatozoa, urine, and extracts of calcified atherosclerotic plaques ${ }^{1,10}$. Those characterized to the level of aminoacid sequence have regulatory functions in either of three important physiological processes: blood coagulation ${ }^{11}$, bone metabolism ${ }^{12,13}$, and vascular biology ${ }^{14}$. Here we will restrict ourselves to the latter group. In the arterial vessel wall the functions of Gla-proteins are probably associated with: local inhibition of thrombosis (protein $\mathrm{S}^{15}$ ), inhibition of mineralization (MGP ${ }^{16}$ ), and stimulation of normal cell growth and prevention of apoptosis in growth arrested cells (Gas6 ${ }^{17,18}$ ). Circulating protein $\mathrm{S}$ is known to inhibit blood coagulation and thrombus formation by acting as a cofactor for activated protein $\mathrm{C}$; there are no arguments indicating that the function of vascular protein $\mathrm{S}$ is different. The function of growth arrest specific gene 6 protein (Gas6) has been investigated only in cell culture systems thus far, in which it was shown that Gas6 prevents starvation-induced death of fibroblasts and smooth muscle cells, and also may act as a growth-potentiating factor which acts synergistically with other known growth factors in these cells. These data suggest that in humans Gas6 plays a role in preventing the degeneration of the atherosclerotic vessel wall. Gla-residues were shown to be essential for Gas6 functions in cell culture ${ }^{17}$.

MGP is a $10-\mathrm{kD}$ secretory protein containing 5 Gla-residues. It was discovered as a component in demineralized bone extracts ${ }^{19}$ but it is now known that it is also expressed in a wide variety of soft tissues such as cartilage, heart, lung, kidney, and arterial vessel wall 16,20,21. Cultured cells in which MGP synthesis has been detected include osteoblasts, chondrocytes, vascular smooth muscle cells, pneumocytes, kidney cells, and fibroblasts ${ }^{21-23}$. Although several soft tissues express more MGP mRNA than does bone, significant levels of the protein itself have only been found in bone and cartilage ${ }^{19,20}$. Massive cartilage and vascular calcification in transgenic MGP-deficient mice demonstrated that MGP is a strong inhibitor of soft tissue calcification ${ }^{24}$. Excessive aorta mineralization was also observed in rats after 4-6 weeks of treatment with vitamin K-antagonists, showing that the Gla-residues are essential for the function of $\mathrm{MGP}^{25}$. 


\section{Pathophysiology of vitamin K-deficiency and oral anticoagulants}

The discovery that Gla-proteins are synthesized in widely varying amounts of various tissues, has led to the concept of tissue-specific vitamin K-requirement. Only in extreme cases low dietary vitamin $\mathrm{K}$ intake leads to the hepatic synthesis of undercarboxylated clotting factors ${ }^{26}$. Apparently, the liver is capable of extracting vitamin $\mathrm{K}$ from the circulation in a highly efficient way. Since accumulating evidence suggests that the present RDA value ( $1 \mu \mathrm{g} /$ day per $\mathrm{kg}$ body weight) is too low to allow adequate carboxylation of all extra-hepatic Gla-proteins, it is at least questionable, therefore, that recommended dietary allowances for vitamin $\mathrm{K}$ are exclusively based on blood coagulation data (i.e.: the hepatic synthesis of blood clotting factors). Moreover, this value is exclusively based on vitamin $\mathrm{K}_{1}$ intake. It has been shown, however, that extra-hepatic tissues preferentially accumulate and use menaquinones; hence it is not very meaningful to apply RDA values defined on the basis of hepatic vitamin $\mathrm{K}_{1}$ requirement.

In the light of the arguments summarized above it is not surprising that in a large majority of the investigated healthy human adults, extra-hepatic Gla-proteins such as osteocalcin and MGP were found in a partly carboxylated form ${ }^{19,27}$. The question whether the occurrence of undercarboxylated osteocalcin and MGP are associated with certain diseases has not been answered unequivocally at this time. Low serum levels of vitamin $\mathrm{K}$ were found in subjects with postmenopausal osteoporosis and femur neck fractures ${ }^{28,29}$, and in a population-based study low dietary vitamin $\mathrm{K}_{1}$ intake was found to be associated with low bone mass ${ }^{30}$. Moreover, independent studies have demonstrated that circulating undercarboxylated osteocalcin is inversely correlated with bone mass ${ }^{31}$, and directly correlated with fracture risk ${ }^{32,33}$, whereas increased intake of vitamin $\mathrm{K}$ resulted in improved osteocalcin carboxylation ${ }^{34,35}$. A number of Japanese studies have also shown a significant higher bone mass and decreased fracture risk after long term supplementation with vitamin $\mathrm{K}_{2}$, but these studies require confirmation in other populations and geographic areas ${ }^{36,37}$.

Oral anticoagulants such as warfarin are vitamin K-antagonists, and have more pronounced effects than vitamin $\mathrm{K}$ deficiency, notably at young age. This was discovered in women who were anticoagulated during the first trimester of pregnancy, and who gave birth to babies with serious bone defects in $30 \%$ of the cases (the 'fetal warfarin syndrome' ${ }^{38}$ ). Similar bone defects could be provoked by subjecting young animals to a regimen of vitamin $\mathrm{K}+$ warfarin $^{39}$. Only after the discovery of the major importance of MGP for the prevention of arterial calcification ${ }^{24}$, also the effects of warfarin treatment on the vessel wall were investigated ${ }^{25}$. It appeared that the rat arterial vessel wall, notably the tunica media, already contained substantial calcifications after 2-3 weeks of warfarin treatment. At later age, both in experimental animals and in humans, the effects of oral anticoagulant treatment seem to be less severe, but it should be emphasized that in many cases this therapy is continued for 
several years, sometimes lifelong. Accumulating literature data demonstrate that in adults the long-term use of oral anticoagulants is associated with decreased bone mass. No data have been published about effects of warfarin on the human vascular system, but it may be expected that oral anticoagulant treatment forms a risk factor for arterial calcification, notably for calcium deposition around the elastin fibers of the tunica media.

\section{Development of a monoclonal antibody against MGP}

Recently, we have reported the production of a monoclonal antibody raised against a synthetic peptide homologous to the amino acid sequence 3-15 in human MGP ${ }^{40}$. Selection of the clones was performed by specific recognition of recombinant MGP which had been expressed in E.coli as a chimeric protein linked to murine dihydrofolate reductase. On Western blots prepared after polyacrylamide gel electrophoresis under reducing conditions the antibody specifically recognized full length synthetic MGP (84 amino acid residues), as well as a single protein band in a homogenate prepared from human cartilage (kind gift from Dr. R. Wallin). The apparent molecular weights of synthetic and native MGP were $10 \mathrm{kD}$. The antibody will be designated as $m \mathrm{Ab}^{3-15}$ and is used in a number of studies described below.

\section{Association of arterial MGP with vascular sclerosis}

MGP was visualized by immuno-histochemical techniques in healthy and atherosclerotic coronary arteries. Figure $2 \mathrm{~A}$ shows the typical low but distinct constitutive MGP expression as is generally seen in the smooth muscle cells of healthy and early atherosclerotic arteries. Accumulation of MGP was found at sites of intima sclerosis, starting at type II but was increasingly present at types III, IV (AHA classification, Figure 2B). The highest concentrations of MGP were found at the interface of tissue and precipitated calcium salts in type $\mathrm{Vb}$ atherosclerotic lesions (Figures $2 C$ and $D$ ). Although other explanations are possible, these data suggest that as a response to intima sclerosis de novo MGP synthesis is induced, possibly as a defence mechanism against the intrusion of calcium salt crystals. In another series of experiments we have analysed coronary arteries from patients with severe diabetes. As is shown in Figure 2E, calcium precipitates were mainly found in the tunica media, and also in this case MGP was mainly associated with the sites of calcification (Figure $2 F$ ). This is noteworthy because the aetiology of media calcification might be different from that of calcium deposition in the intima and in the atherosclerotic plaque. Plaque formation is generally thought to be the result of an inflammatory process, associated with apoptosis, accretion of lipids and macrophage infiltration. Media sclerosis, also known 


\section{Figure 2.}

Immunohistochemical localization of MGP-related antigen in intimal (A-D) and medial (E-H) sclerosis. First antibody was $\mathrm{mAb}^{3-15}$, second antibody was biotin-conjugated swine anti-mouse total IgG and staining was performed with avidine-conjugated alkaline phosphatase. A: early atherosclerosis of a coronary artery with intima (In) and media (M), the arrowheads indicate the internal elastic lamina. B: similar staining of atherosclerosis type IV with accumulation of MGP in the lipid core of the plaque. C: Von Kossa staining of calcium (black) of type $\mathrm{Vb}$ atherosclerosis with calcification. D: same site showing strong accumulation of MGP-related antigen, typically found at the boundaries between arterial tissue and calcified material (arrow). E: Von Kossa staining of calcium in Mönckeberg sclerosis. Most of the heavily calcified tissue has been lost from the section. F: staining for MGP at the same site. G: Von Kossa staining of calcium of a peripheral artery in early Mönckeberg sclerosis. Arrows indicate parts of the elastica with little calcification. H: staining for MGP-related antigen of the same site, with most prominent MGP accumulation in areas of low calcification.

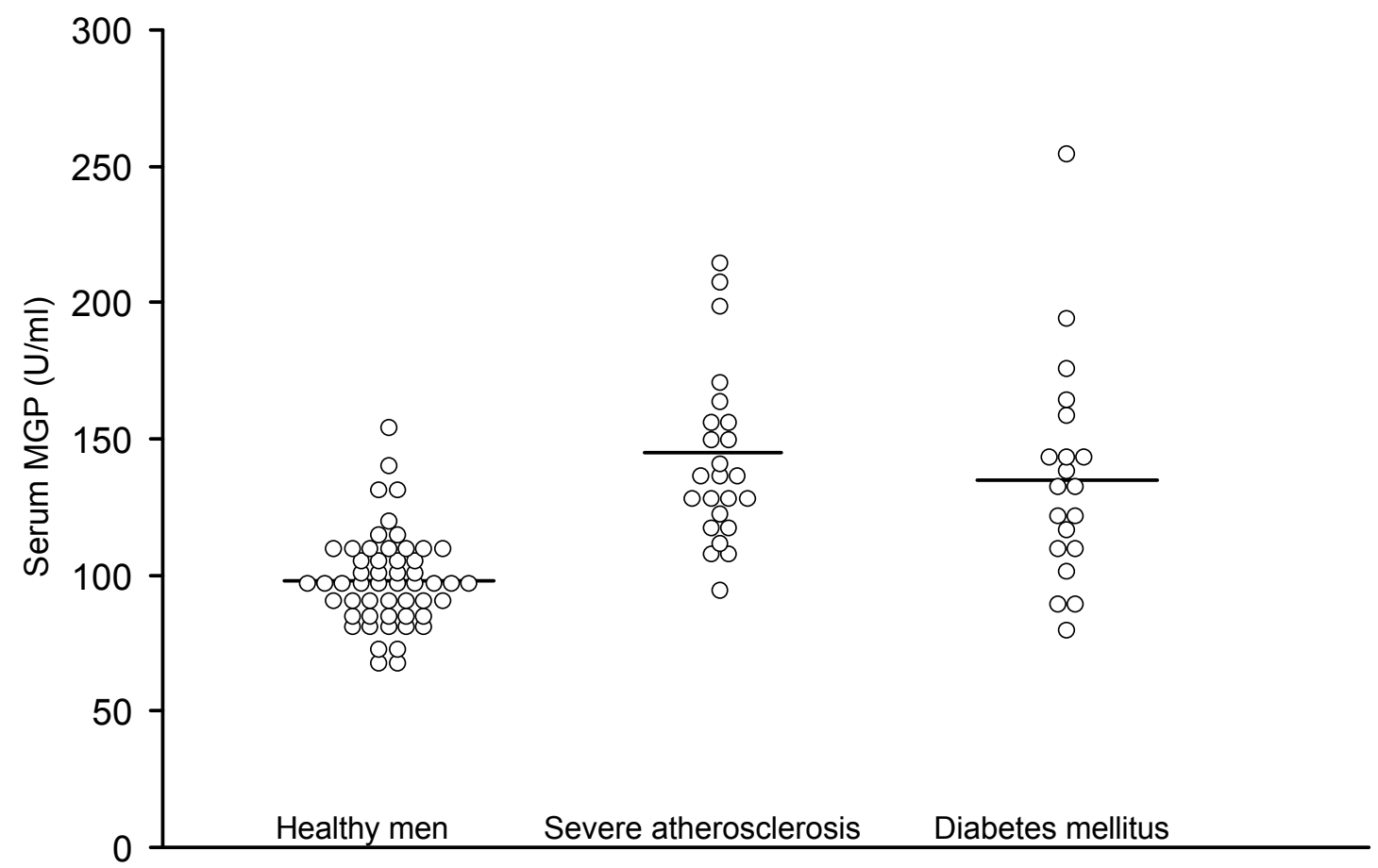

\section{Figure 3.}

Serum MGP in patients and matched controls (mean \pm SE; $99.3 \pm 2.32$ ). All subjects were 55-65 years of age. Serum MGP is expressed as arbitrary units per ml. Mean values \pm SE for severe atherosclerosis $145.8 \pm 6.6$ and type 1 diabetes mellitus $134.5 \pm 8.6$. Both groups were significantly different from the controls $(\mathrm{p}<0.05)$. 


\section{Discussion}

Data presented in this paper demonstrate that vascular degeneration is associated with increased expression of MGP, starting well before visible calcification, but most prominently present at the boundaries between precipitated calcium salts and adjacent tissue. Since the generally accepted function of MGP is the prevention of calcification, our data lead to an apparent contradiction: in calcifying tissue there is a strong increase of MGP expression, but calcification is not prevented. These observations can be explained as follows. First, most body fluids are supersaturated with calcium and phosphate, and precipitation of calcium salts is actively prevented by a complex mechanism of crystallization inhibition ${ }^{14}$. MGP forms part of this mechanism, but apparently pathological conditions leading to calcium deposition may be stronger than the calcification inhibitory activity of MGP is, even at increased MGP expression. This assumption is supported by the fact that at sites of most intense MGP staining calcification seemed to be less pronounced (cf. Figures $2 C$ and $D$, and $2 G$ and $H$ ). Second, we wish to put forward the hypothesis that in a substantial part of the adult population the arterial vitamin K supply is marginal, so that at increased MGP synthesis (as a response to tissue calcification) the vitamin $\mathrm{K}$ status of the arterial vessel wall is inadequate to support full MGP carboxylation. This means that mainly undercarboxylated, nonfunctional MGP is produced which is incapable of retarding the calcification process. Unfortunately, this hypothesis cannot be confirmed before conformation-specific antibodies become available allowing the separate visualization of carboxylated and undercarboxylated MGP.

The hypothesis of vascular vitamin K-deficiency in subjects with normal haemostasis implies the concept of tissue-defined vitamin $\mathrm{K}$ requirement: whereas the hepatic vitamin $\mathrm{K}$ supply is sufficient to support full carboxylation of the blood coagulation factors, other tissues may produce Gla-proteins in an undercarboxylated form. Several independent studies have demonstrated that undercarboxylation of the bone Gla-protein osteocalcin is common in healthy adults, and it has been suggested that undercarboxylated osteocalcin is a sensitive marker for the vitamin $\mathrm{K}$ status of extra-hepatic tissues including the vessel wall ${ }^{41}$. It is not hard to envision that in cases in which the vascular vitamin $\mathrm{K}$ status is insufficient to support normal MGP carboxylation, up-regulation of MGP expression will only result in more undercarboxylated (non-functional) MGP. Hence the remaining questions are: how much vitamin $\mathrm{K}$ is required for an optimal vascular function, and is there a specific role for menaquinones. Human nutrition data have demonstrated that $\mathrm{K}_{2}$ vitamins are preferentially found in the LDL fraction of serum lipoproteins (L.J. Schurgers et al., unpublished data). This suggests a specific transport to and uptake of menaquinones by extra-hepatic tissues. Specific uptake of MK-4 rather than $\mathrm{K}_{1}$ was also found in experimental animals, with $\mathrm{K}_{1} / \mathrm{MK}-4$ ratios differing 2-3 orders of magnitude for liver and aorta ${ }^{6}$. Finally, our data on 
menaquinone content of common foods were recently added to the Rotterdam Study data base, and showed a strong and increasing protection against cardiovascular disease from the lowest to the highest quartile of menaquinone (and not phylloquinone) intake. (J.M. Geleijnse et al., unpublished data). Taken together these data strongly suggest that for the vessel wall menaquinones are more important than is phylloquinone.

Since no RDA value for dietary menaquinone intake has been defined in any country in the world a starting point for recommendations could be the Rotterdam Study. Mean values of quartiles for vitamin $K_{2}$ (all menaquinones) intake were: 10, 23, 33, and $45 \mu \mathrm{g}$ /day 42. Therefore, we recommend that menaquinone intake should be increased to $45 \mu \mathrm{g} / \mathrm{day}$, which is comparable to the amount present in $60 \mathrm{~g}$ of cheese or curd cheese or 4 grams of natto. If a similar definition would be applied for vitamin $K_{1}$ the RDA value would increase from 60 to $375 \mu \mathrm{g} / \mathrm{day}$, which is comparable to $100-200$ grams of green vegetables per day. In fact it is remarkable that only $25 \%$ of the Dutch population meets this recommendation at this time. 


\section{REFERENCES}

1. Vermeer C. Gamma-carboxyglutamate-containing proteins and the vitamin K-dependent carboxylase. Biochem J. 1990;266:625-36.

2. Jie KS, Gijsbers BL, Vermeer C. A specific colorimetric staining method for gammacarboxyglutamic acid-containing proteins in polyacrylamide gels. Anal Biochem. 1995;224:1635.

3. Kuwada M, Katayama K. An improved method for the determination of gammacarboxyglutamic acid in proteins, bone, and urine. Anal Biochem. 1983;131:173-9.

4. Furie B, Furie BC. Molecular basis of vitamin K-dependent gamma-carboxylation. Blood. 1990;75:1753-1762.

5. Ronden JE, Drittij-Reijnders MJ, Vermeer C, Thijssen HH. Intestinal flora is not an intermediate in the phylloquinone- menaquinone-4 conversion in the rat. Biochim Biophys Acta. 1998;1379:69-75.

6. Ronden JE, Thijssen HH, Vermeer C. Tissue distribution of K-vitamers under different nutritional regimens in the rat. Biochim Biophys Acta. 1998;1379:16-22.

7. Conly JM, Stein K, Worobetz L, Rutledge-Harding S. The contribution of vitamin K2 (menaquinones) produced by the intestinal microflora to human nutritional requirements for vitamin K. Am J Gastroenterol. 1994;89:915-923.

8. Shearer MJ. Vitamin K metabolism and nutriture. Blood Rev. 1992;6:92-104.

9. Reedstrom CK, Suttie JW. Comparative distribution, metabolism, and utilization of phylloquinone and menaquinone-9 in rat liver. Proc Soc Exp Biol Med. 1995;209:403-9.

10. Gijsbers BL, van Haarlem LJ, Soute BA, Ebberink RH, Vermeer C. Characterization of a Glacontaining protein from calcified human atherosclerotic plaques. Arteriosclerosis. 1990;10:9915.

11. Davie EW. Biochemical and molecular aspects of the coagulation cascade. Thromb Haemost. 1995;74:1-6.

12. Hauschka PV, Lian JB, Cole DE, Gundberg CM. Osteocalcin and matrix Gla protein: vitamin Kdependent proteins in bone. Physiol-Rev. 1989;69:990-1047.

13. Vermeer C, Jie KS, Knapen MH. Role of vitamin $\mathrm{K}$ in bone metabolism. Annu Rev Nutr. 1995; 15:1-22.

14. Shanahan CM, Proudfoot D, Farzaneh-Far A, Weissberg PL. The role of Gla proteins in vascular calcification. Crit Rev Eukaryot Gene Expr. 1998;8:357-75.

15. Fair DS, Marlar RA, Levin EG. Human endothelial cells synthesize protein S. Blood. 1986;67:1168-71.

16. Fraser JD, Price PA. Lung, heart, and kidney express high levels of mRNA for the vitamin Kdependent matrix Gla protein. Implications for the possible functions of matrix Gla protein and for the tissue distribution of the gamma-carboxylase. J Biol Chem. 1988;263:11033-6.

17. Nakano T, Kawamoto K, Kishino J, Nomura K, Higashino K, Arita H. Requirement of gammacarboxyglutamic acid residues for the biological activity of Gas6: contribution of endogenous Gas6 to the proliferation of vascular smooth muscle cells. Biochem J. 1997;323:387-92.

18. Nakano T, Kawamoto K, Higashino K, Arita H. Prevention of growth arrest-induced cell death of vascular smooth muscle cells by a product of growth arrest-specific gene, gas6. FEBS Lett. 1996;387:78-80.

19. Price PA, Williamson MK. Primary structure of bovine matrix Gla protein, a new vitamin Kdependent bone protein. J Biol Chem. 1985;260:14971-5.

20. Hale JE, Fraser JD, Price PA. The identification of matrix Gla protein in cartilage. J Biol Chem. 1988;263:5820-4. 
21. Shanahan CM, Weissberg PL, Metcalfe JC. Isolation of gene markers of differentiated and proliferating vascular smooth muscle cells. Circ Res. 1993;73:193-204.

22. Rannels SR, Cancela ML, Wolpert EB, Price PA. Matrix Gla protein mRNA expression in cultured type II pneumocytes. Am J Physiol. 1993;265:L270-8.

23. Price PA, Rice JS, Williamson MK. Conserved phosphorylation of serines in the Ser-X$\mathrm{Glu} / \mathrm{Ser}(\mathrm{P})$ sequences of the vitamin K-dependent matrix Gla protein from shark, lamb, rat, cow, and human. Protein Sci. 1994;3:822-30.

24. Luo G, Ducy P, McKee MD, Pinero GJ, Loyer E, Behringer RR, Karsenty G. Spontaneous calcification of arteries and cartilage in mice lacking matrix GLA protein. Nature. 1997;385:7881.

25. Price PA, Faus SA, Williamson MK. Warfarin-induced artery calcification is accelerated by growth and vitamin D. Arterioscler Thromb Vasc Biol. 2000;20:317-27.

26. Suttie JW, Mummah Schendel LL, Shah DV, Lyle BJ, Greger JL. Vitamin K deficiency from dietary vitamin K restriction in humans. Am J Clin Nutr. 1988;47:475-80.

27. Cairns JR, Williamson MK, Price PA. Direct identification of gamma-carboxyglutamic acid in the sequencing of vitamin K-dependent proteins. Anal Biochem. 1991;199:93-7.

28. Hart JP, Shearer MJ, Klenerman L, Catterall A, Reeve J, Sambrook PN, Dodds RA, Bitensky L, Chayen J. Electrochemical detection of depressed circulating levels of vitamin $\mathrm{K} 1$ in osteoporosis. J Clin Endocrinol Metab. 1985;60:1268-9.

29. Hodges SJ, Akesson K, Vergnaud P, Obrant K, Delmas PD. Circulating levels of vitamins K1 and K2 decreased in elderly women with hip fracture. J Bone Miner Res. 1993;8:1241-5.

30. Feskanich D, Weber P, Willett WC, Rockett H, Booth SL, Colditz GA. Vitamin K intake and hip fractures in women: a prospective study. Am J Clin Nutr. 1999;69:74-9.

31. Knapen MH, Nieuwenhuijzen Kruseman AC, Wouters RS, Vermeer C. Correlation of serum osteocalcin fractions with bone mineral density in women during the first 10 years after menopause. Calcif Tissue Int. 1998;63:375-9.

32. Szulc P, Chapuy MC, Meunier PJ, Delmas PD. Serum undercarboxylated osteocalcin is a marker of the risk of hip fracture in elderly women. J Clin Invest. 1993;91:1769-74.

33. Väänänen HK, Luukinen H, Käkönen S-M, Pettersson K, Koski K, Laippala P, Lövgren T, Kivelä S-L. Strong prediction of fractures among the elderly by the ratio of carboxylated and total serum osteocalcin. Calcif Tissue Int. 1999;64:S79.

34. Knapen MH, Hamulyak K, Vermeer C. The effect of vitamin K supplementation on circulating osteocalcin (bone Gla protein) and urinary calcium excretion. Ann Intern Med. 1989;111:1001-5.

35. Planatalech LC, Chapuy MC, Guillaumont M, Chapuy P, Leclercq M, Delmas PD. Impaired carboxylation of serum osteocalcin in elderly women: effect of vitamin $\mathrm{K}_{1}$ treatment. In: Christiansen, C., Overgaard, K. (eds) Osteoporosis 1990. Osteopress. 1990.

36. Sato Y, Honda Y, Kuno H, Oizumi K. Menatetrenone ameliorates osteopenia in disuse-affected limbs of vitamin D- and K-deficient stroke patients. Bone. 1998;23:291-6.

37. Shiraki M, Shiraki Y, Aoki C, Miura M. Vitamin K2 (menatetrenone) effectively prevents fractures and sustains lumbar bone mineral density in osteoporosis. $J$ Bone Miner Res. 2000;15:515-21.

38. Pettifor JM, Benson R. Congenital malformations associated with the administration of oral anticoagulants during pregnancy. J Pediatr. 1975;86:459-62.

39. Price PA, Williamson MK, Haba T, Dell RB, Jee WS. Excessive mineralization with growth plate closure in rats on chronic warfarin treatment. Proc Natl Acad Sci U S A. 1982;79:7734-8.

40. Braam LA, Dissel P, Gijsbers BL, Spronk HM, Hamulyak K, Soute BA, Debie W, Vermeer C. Assay for Human Matrix Gla Protein in Serum : Potential Applications in the Cardiovascular Field. Arterioscler Thromb Vasc Biol. 2000;20:1257-1261. 
41. Sokoll LJ, Sadowski JA. Comparison of biochemical indexes for assessing vitamin K nutritional status in a healthy adult population. Am J Clin Nutr. 1996;63:566-73.

42. Schurgers LJ, Geleijnse JM, Grobbee DE, Pols HAP, Hofman A, Witteman JCM, C. Vermeer C. Nutritional intake of vitamins K-1 (phylloquinone) and K-2 (menaquinone) in The Netherlands. J Nutr Environm Med. 1999;9:115-122. 


6

GENERAL DISCUSSION / SAMENVATTING 



\section{1}

\section{GENERAL DISCUSSION}

\section{Summary and General Discussion}

Until now only in the USA ${ }^{1}$ and in the UK ${ }^{2}$ a limited number of data bases have been published on the vitamin $\mathrm{K}_{1}$ content of foods. Except an analysis of Japanese foods, little information is available on $\mathrm{K}_{2}$ vitamins ${ }^{34}$. Because the vitamin $\mathrm{K}_{1}$ content of vegetables may depend on factors such as sunlight exposure, soil composition, and climate and the $\mathrm{K}_{2}$ content of animal products may depend on food fortification and housing, it is important that accurate data bases are produced in different countries. In this thesis we present the first combined data base on vitamin $\mathrm{K}_{1}+\mathrm{K}_{2}$ contents of common foods in the western society. The foods that were analysed are those typically obtained in shops and supermarkets in the Netherlands, and only one exotic product (natto) was included for comparison. Natto is available in the so-called oriental shops found in most Dutch cities. The availability of the vitamin $\mathrm{K}$ data base enabled our group to initiate population-based studies in which a clear inverse correlation could be demonstrated between vitamin $\mathrm{K}_{2}$ intake and arterial calcification ${ }^{5} . \mathrm{K}_{2}$, however, forms less than $20 \%$ of the total vitamin $\mathrm{K}$ intake in the Dutch population. The fact that no such correlation was found for $\mathrm{K}_{1}$ suggested different metabolic pathways for both types of vitamin $\mathrm{K}$, a hypothesis which formed the basis of the nutrition studies in experimental animals and humans described in this thesis.

It appeared that the food matrix is of crucial importance for the efficacy of vitamin Kuptake from the diet: whereas oil-solubilized forms of vitamin $\mathrm{K}$ (such as $\mathrm{K}_{1}$ in plant oils and $\mathrm{K}_{2}$ in dairy produce) are absorbed relatively well, the $\mathrm{K}_{1}$ present in green leafy vegetables (about $80 \%$ of our total dietary vitamin $\mathrm{K}$ intake) is tightly bound to the mitochondrial membranes, and is solubilized there from with great difficulty by bile salts. The concomitant intake of fat had a positive effect on vitamin $\mathrm{K}_{1}$ absorption from vegetables, probably because the fat stimulated bile secretion. Remarkably, there was also a more than two-fold difference between uptake from spinach and broccoli. From these data we conclude that the calculation of vitamin $\mathrm{K}$ intake from food frequency questionnaires and food composition tables will merely provide a rough estimate of the amounts of vitamin $\mathrm{K}$ that will reach the circulation. 
Accounting for less than $20 \%$ of the total vitamin $\mathrm{K}$ intake, vitamin $\mathrm{K}_{2}$ is less abundant in our daily food than $\mathrm{K}_{1}$. However, because $\mathrm{K}_{2}$ mainly occurs in the matrix of cheese, eggs and meat, the efficacy of uptake will be higher than that of $K_{1}$, which may lead to underestimation of its importance and contribution to the human vitamin $\mathrm{K}$ status. Among the different $\mathrm{K}_{2}$ vitamins there are probably substantial differences in the rate with which they are metabolized. It is well known that MK-4 has a relatively short half-life time both in tissues and in the circulation. Animal studies have demonstrated that MK-9 may remain in the circulation much longer ${ }^{6}$, but the extent to which these long-chain menaquinones are absorbed in the gastro-intestinal tract remains questionable ${ }^{77}$. From our studies it appeared that MK-7 (from natto) was taken up efficiently in human volunteers, and that it had a much longer plasma and tissue half-life time than either vitamin $\mathrm{K}_{1}$ or MK-4. This was shown by direct analysis in plasma and by its effect on the INR in anticoagulated subjects. Thus, the length of the side chain of menaquinones may be important with regards to the extent to which these vitamers are absorbed, with probably a cut-off between MK-7 (well absorbed) on one hand and higher menaquinones such as MK-8 or MK-9 (poorly absorbed) on the other hand.

From our studies it became also clear that following absorption, the aliphatic side chain in vitamin $\mathrm{K}$ also plays a prominent role in its plasma transport to the various target tissues. During the first postprandial hours, the increasing plasma vitamin K concentrations are primarily the result of transport via triglyceride-rich lipoproteins (TGRLP), which are rapidly cleared by the liver. MK-4 is the first vitamer to disappear from this fraction and it is not quite clear whether this is because of a more widespread uptake (in liver as well as in various extra-hepatic tissues), or the result of a more rapid hepatic metabolism. The longchain menaquinones, on the other hand, were detectable in the circulation for several days, and during the later postprandial stages they were mainly present in the LDL fraction. Since LDL forms a major transport system for fat soluble substances from the liver to extra-hepatic tissues, the liver may have a key function in selecting and re-packing menaquinones in LDL particles, whereas most of $\mathrm{K}_{1}$ is utilized by the liver itself. When hypothesizing on the metabolic pathways of K-vitamins, it should be kept in mind that long chain menaquinones form the largest fraction of the total vitamin $\mathrm{K}$ store in the human liver ${ }^{89}$. It is questionable, however, whether these menaquinones are also utilized by the liver. Rather, it seems that the liver serves as a store tissue for long-chain menaquinones, and re-distributes them into LDL for transport and utilization in extra-hepatic tissues. This would explain the reported protective effect of $\mathrm{K}_{2}$ (and not of $\mathrm{K}_{1}$ ) against arterial calcification, myocardial infarction and cardiac death ${ }^{5}$, and also gives an explanation for recent data from Spronk et al., who demonstrated that $\mathrm{K}_{2}$ (and not $\mathrm{K}_{1}$ ) effectively inhibits warfarin-induced arterial calcification. Finally, also the type of dietary fat (mono- or poly-unsaturated) present in the vitamin K- 
containing test meal was shown to influence the vitamin $\mathrm{K}$ status of liver and bone (Chapter 3).

In chapter 4 we describe two widely different diseases both leading to a substantially increased vitamin $\mathrm{K}$ requirement. The first case is a family with a non-functional vitamin $\mathrm{K}$ epoxide-reductase, resulting in a blockade of the vitamin K-cycle. Theoretically, a full blockade will lead to a $500-1,000$ fold increase of the vitamin K requirement. Since for the majority of the healthy adult population the nutritional vitamin $\mathrm{K}$ intake is marginal, it is not surprising that such high requirements are not met by the daily diet, and affected members of the family showed impaired blood coagulation. These subjects will require vitamin $\mathrm{K}$ supplements life-long to maintain normal haemostasis. The second example of poor vitamin $\mathrm{K}$ status investigated was a group of patients with Crohn's disease. This disease is associated with malabsorption of fats and fat-soluble vitamins and the substantial undercarboxylation of the bone Gla-protein osteocalcin indicates that their bone vitamin $\mathrm{K}$ status (and probably that of other extra-hepatic tissues as well) is sub-optimal. It has been demonstrated by several groups that in postmenopausal women, increased levels of circulating undercarboxylated osteocalcin are associated with low bone mass and with an increased risk for hip fractures 10111213. Although a similar association remains to be demonstrated in patients with Crohn's disease, our data suggest that vitamin K-supplementation may contribute to improving bone mass in this group. Assuming that undercarboxylated osteocalcin is a marker for extrahepatic vitamin $\mathrm{K}$ status, we propose that most apparently healthy subjects are subclinical vitamin K-deficient. The observations described above have lead to a recent 1.5 fold increase of the recommendations for vitamin $\mathrm{K}$ intake by the US Food and Nutrition Board ${ }^{14}$.

In the last part of this thesis we have addressed the question of whether the recommended daily allowance for vitamin $\mathrm{K}$ intake should be increased further, and whether this may lead to unwanted side-effects, notably interference with oral anticoagulant therapy. It was shown that interference by diet is unlikely, and that even at extreme intakes such as a meal of $400 \mathrm{~g}$ of spinach, the effect on the INR-value is minimal. Our data show that varying intakes of green vegetables up to $250 \mathrm{~g}$ per day will not interfere with oral anticoagulant treatment. Only natto leads to a long-lasting disturbance, which is consistent with both the efficient absorption of vitamin K (mainly MK-7) there from, and with the long half-life time of this vitamer. Natto, however, is not a common food in the western society. Food supplements are characterized by a far more complete uptake of vitamin $\mathrm{K}$, and at relatively low doses $(150 \mu \mathrm{g} /$ day) a significant effect on (low) INR values was observed. This observation, however, was noticed in healthy volunteers set to a low target INR value, using a coumarin-derivative with a short half-life time, all factors contributing to an "easy" disturbance of INR by vitamin K interference. Furthermore, the critical dose of vitamin K for a significant disturbance of the on INR value had a high variation; $150 \mu \mathrm{g} \mathrm{K} / \mathrm{d}$ (1 volunteer), $200 \mu \mathrm{g} \mathrm{K} / \mathrm{d}(2), 250 \mu \mathrm{g} \mathrm{K} \mathrm{K}_{1} / \mathrm{d}(1), 300 \mu \mathrm{g} \mathrm{K} \mathrm{K}_{1} / \mathrm{d}(1)$, and $>300 \mu \mathrm{g} / \mathrm{day} \mathrm{K}_{1} / \mathrm{d}$ (5). Therefore, 
these results cannot be extrapolated to patients, who are often set on higher INR target value and using coumarins with long half-life times (e.g. warfarin $\left(\mathrm{t}^{1} / 2=50 \mathrm{~h}\right)$ or phenprocoumon $\left.\left(\mathrm{t}^{1} / 2=100 \mathrm{~h}\right)\right)$.

Using a monoclonal antibody made in our group, we have analysed the occurrence of the vitamin K-dependent protein MGP in the arterial vessel wall during various stages of atherosclerosis and Mönckeberg's sclerosis. Substantial accumulation of MGP was observed in tissue prone to calcification (elastin fibres) as well as in areas surrounding calcium precipitates. This is not compatible with the known calcification inhibitory function of MGP.

The fact that MGP must be in its carboxylated (= active) form to inhibit calcification was shown in rats by Price et al. ${ }^{15}$ and in hypertrophic chondrocytes by Yagami et al. ${ }^{16}$. In both experiments the action of vitamin $\mathrm{K}$ was counteracted by warfarin and calcification was triggered. In the hypertrophic chondrocytes the calcification was reversed by over expression MGP in the presence of vitamin $K_{1}$.

Our hypothesis is that in non-calcified arteries the vitamin $\mathrm{K}$ concentration is low and hardly sufficient for complete carboxylation of MGP. The accumulated MGP around calcifications may be the result of strongly increased expression, possibly triggered by the precipitated calcium salts ${ }^{17}$, resulting in a parallelly increased vitamin K-requirement. Since it is unlikely that the vascular vitamin $\mathrm{K}$ stores are sufficient to meet the increased requirement, most of the MGP will be produced in an undercarboxylated (read: inactive) form. This would explain the fact that vascular calcium precipitates are generally surrounded by MGP deposits. The basis for this hypothesis is the assumption that the extra-hepatic vitamin $\mathrm{K}$ status is marginal in the majority of the healthy population. There are several arguments from the literature that support this view. First, both extra-hepatic Gla-proteins in which the Gla-content has been assessed by amino acid analysis (osteocalcin and MGP) were shown to occur as a mixture of carboxylated and undercarboxylated species ${ }^{1819}$, which is suggestive for a sub-optimal extra-hepatic vitamin $\mathrm{K}$ status. Second, the present recommendations for vitamin $\mathrm{K}$ intake are not met by large parts of the population ${ }^{20}$. Third, undercarboxylated osteocalcin correlates inversely with bone mass, and vitamin $\mathrm{K}_{2}$ intake is inversely associated with cardiovascular disease. Finally, the first clinical trials with vitamin $\mathrm{K}$-supplements have demonstrated a beneficial effect on the rate of postmenopausal bone loss ${ }^{2122}$ (Braam et al, Submitted unpublished observations). Since the dosages used in these studies vary from $45 \mathrm{mg} /$ day to $0.2 \mathrm{mg}$ /day, the optimal dose for supplementation is not yet quite clear. As yet several studies suggest, however, that the present recommendations for vitamin $\mathrm{K}$ intake are too low to meet the extrahepatic requirements. Therefore, we propose that until more adequate data are available, the recommendations for dietary vitamin $\mathrm{K}$ intake are the medians for the upper quartile of intake in the Rotterdam Study cohort, as they were assessed on the basis of our food composition table. Furthermore, we propose that separate 
recommendations are made for $\mathrm{K}_{1}$ and $\mathrm{K}_{2}$, since these vitamers may have different target tissues. In case these recommendations are not met, supplementation or food fortification may be an option. For vitamin K no Tolerable Upper Intake Level (UL) has been established because no adverse effects have been reported. Therefore, only patients receiving oral anticoagulant treatment should be aware of the interaction between high doses of vitamin $\mathrm{K}$ and its antagonists. 


\section{REFERENCES}

1. Booth SL, Sadowski JA, Weihrauch JL, Ferland G. Vitamin $\mathrm{K}_{1}$ (phylloquinone) content of foods: a provisional table. J Food Comp Anal. 1993;6:109-120.

2. Bolton-Smith C, Price RJ, Fenton ST, Harrington DJ, Shearer MJ. Compilation of a provisional UK database for the phylloquinone (vitamin $\mathrm{K}_{1}$ ) content of foods. Br J Nutr. 2000;83:389-399.

3. Hirauchi K, Sakano T, Notsumoto S, Nagaoka T, Morimoto A, Fujimoto K, Masuda S, Suzuki $\mathrm{Y}$. Measurement of $\mathrm{K}$ vitamins in animal tissues by high-performance liquid chromatography with fluorimetric detection. J Chromatogr. 1989;497:131-7.

4. Hirauchi K, Sakano T, Notsumoto S, Nagaoka T, Morimoto A, Fujimoto K, Masuda S, Suzuki Y. Measurement of K-vitamins in food by high-performance liquid chromatography with fluorimetric detection. Vitamins. 1989;63:147-151.

5. Geleijnse JM, Vermeer C, Schurgers LJ, Grobbee DE, Pols HAP, Witteman JCM. Inverse association of dietary vitamin K-2 intake with cardiac events and aortic atherosclerosis: The Rotterdam study. Thrombosis and Heamostasis. 2001;Supplement ISTH XVIII:P473.

6. Groenen van Dooren MM, Ronden JE, Soute BA, Vermeer C. Bioavailability of phylloquinone and menaquinones after oral and colorectal administration in vitamin K-deficient rats. Biochem Pharmacol. 1995;50:797-801.

7. Craciun AM, Groenen-van Dooren MM, Thijssen HH, Vermeer C. Induction of prothrombin synthesis by $\mathrm{K}$-vitamins compared in vitamin $\mathrm{K}$ - deficient and in brodifacoum-treated rats. Biochim Biophys Acta. 1998;1380:75-81.

8. Shearer MJ. The roles of vitamins D and $\mathrm{K}$ in bone health and osteoporosis prevention. Proc Nutr Soc. 1997;56:915-37.

9. Thijssen HH, Drittij Reijnders MJ. Vitamin $\mathrm{K}$ status in human tissues: tissue-specific accumulation of phylloquinone and menaquinone-4. Br J Nutr. 1996;75:121-7.

10. Szulc P, Arlot M, Chapuy MC, Duboeuf F, Meunier PJ, Delmas PD. Serum undercarboxylated osteocalcin correlates with hip bone mineral density in elderly women. $J$ Bone Miner Res. 1994;9:1591-5.

11. Knapen MH, Nieuwenhuijzen Kruseman AC, Wouters RS, Vermeer C. Correlation of serum osteocalcin fractions with bone mineral density in women during the first 10 years after menopause. Calcif Tissue Int. 1998;63:375-9.

12. Szulc P, Chapuy MC, Meunier PJ, Delmas PD. Serum undercarboxylated osteocalcin is a marker of the risk of hip fracture in elderly women. J Clin Invest. 1993;91:1769-74.

13. Väänänen HK, Luukinen $H$, Käkönen S-M, Pettersson K, Koski K, Laippala P, Lövgren T, Kivelä S-L. Strong prediction of fractures among the elderly by the ratio of carboxylated and total serum osteocalcin. Calcif Tissue Int. 1999;64:S79.

14. Vitamin K. In: Dietary reference intakes for vitamin A, vitamin K, arsenic, boron, chromium, copper, iodine, iron, manganese, molybdenum, nickel, silicon, vanadium, and zinc. National Academic Press. 2001; Institute of Medicine, Washington DC.

15. Price PA, Faus SA, Williamson MK. Warfarin causes rapid calcification of the elastic lamellae in rat arteries and heart valves. Arterioscler Thromb Vasc Biol. 1998;18:1400-7.

16. Yagami K, Suh JY, Enomoto-Iwamoto M, Koyama E, Abrams WR, Shapiro IM, Pacifici M, Iwamoto M. Matrix GLA protein is a developmental regulator of chondrocyte mineralization and, when constitutively expressed, blocks endochondral and intramembranous ossification in the limb. J Cell Biol. 1999;147:1097-108.

17. Shanahan CM, Cary NR, Metcalfe JC, Weissberg PL. High expression of genes for calcification-regulating proteins in human atherosclerotic plaques. J Clin Invest. 1994;93:23932402. 
18. Price PA, Otsuka AA, Poser JW, Kristaponis J, Raman N. Characterization of a gammacarboxyglutamic acid-containing protein from bone. Proc Natl Acad Sci USA. 1976;73:1447-51.

19. Price PA, Williamson MK. Primary structure of bovine matrix Gla protein, a new vitamin Kdependent bone protein. J Biol Chem. 1985;260:14971-5.

20. Booth SL, Pennington JA, Sadowski JA. Food sources and dietary intakes of vitamin K-1 (phylloquinone) in the American diet: data from the FDA Total Diet Study. J Am Diet Assoc. 1996;96:149-54.

21. Orimo H, Shiraki M, Tomita A, Morii H, Fujita T, Ohata M. Effects of menatetrenone on the bone and calcium metabolism in osteoporosis: A double-blind placebo-controlled study. Journal of Bone and Mineral Metabolism. 1998;16:106-112.

22. Bolton-Smith C, Mole PA, McMurdo MET, Paterson CR, Shearer MJ. Two-Year intervention with phylloquinone (vitamin K1), vitamin D and calcium effect on bone mineral content of older women. Ann Nutr Metab. 2001;45 (suppl 1):46. 



\section{2}

\section{SAMENVATTING}

Behalve bij de bloedstolling, is vitamine $\mathrm{K}$ betrokken bij de anmaak van eiwitten in bot en in de arteriële vaatwand. Hoewel we de preciese functie van de vitamine Kafhankelijke eiwitten in deze weefsels nog niet kennen, wordt steeds duidelijker dat ze bijdragen aan de bescherming tegen osteoporotisch botverlies en tegen arteriële verkalking. Deze processen spelen in onze (vergrijzende) samenleving een steeds belangrijker rol. Harten vaatziekten vormen nog steeds de voornaamste doodsoorzaak in de westerse samenleving. Osteoporose is het gevolg van langdurig botverlies, dat met name vaak bij ouderen wordt gezien, en dat kan leiden tot inzakkende wervels en heupfracturen. Met name heupfracturen dragen substantieel bij aan de morbiditeit en mortaliteit van ouderen aangezien $25 \%$ van de patiënten binnen één jaar na de fractuur ten gevolge van complicaties overlijdt, terwijl van de resterende groep de helft nooit meer zonder hulpmiddelen zal kunnen lopen. Dit proefschrift beschrijft de hoeveelheid vitamine $\mathrm{K}$ in diverse voedingsmiddelen, de mate waarin deze in de darm worden opgenomen, het plasma transport van diverse K-vitamines, en de opname in de weefsels. Wij hebben ons de vraag gesteld hoeveel vitamine $\mathrm{K}$ nodig is per dag om optimaal in de behoefte van bot en vaatwand te voorzien, en tevens of deze inname ongewenste bijwerkingen kan hebben. Tevens werd onderzocht hoe het vitamine K-afhankelijke eiwit MGP zich ophoopt in de gezonde en in de verkalkende vaatwand.

Vitamine $\mathrm{K}$ is een essentiële cofactor in de aanmaak van het ongewone aminozuur $\gamma$ carboxyglutaminezuur (afgekort: Gla) dat op specifieke plaatsen in een beperkt aantal eiwitten voorkomt. In alle tot nog toe bekende zogenaamde "vitamine K-afhankelijke" of Gla eiwitten zorgen deze Gla-residuen voor de functionaliteit (activiteit) van het eiwit. Deze Gla residuen zijn calcium bindende groepen, die ervoor zorgen dat de eiwitten kunnen binden aan negatieve fosfolipide membranen (bloedstollingsfactoren FII, FVII, FIX, en FX) of aan een calcium houdende matrix (osteocalcine en MGP). Indien de vitamine $\mathrm{K}$ status ontoereikend is zullen de Gla-eiwitten in een niet actieve, ondergecarboxyleerde vorm worden gesynthetiseerd. Deze eiwitten bevatten dan geen Gla maar glutaminezuur (Glu) residuen. Hoofdstuk 1 geeft een literatuuroverzicht van onze huidige kennis op het gebied van vitamine K.

Vitamine $\mathrm{K}$ is een vet-oplosbaar vitamine dat via de voeding wordt opgenomen. In de natuur worden twee vormen van vitamine $\mathrm{K}$ gevonden: vitamine $\mathrm{K}_{1}$ (fyllochinon) en vitamine $\mathrm{K}_{2}$ (menachinonen). De laatste groep is een verzamelnaam voor een reeks $\mathrm{K}$-vitamines die verschillen wat betreft de lengte van de alifatische zijketen. $\mathrm{K}_{1}$ en $\mathrm{K}_{2}$ hebben een identieke aromatische groep (2-methyl-naftochinon), maar verschillen wat betreft de mate van 
verzadiging van de zijketen. Voor de menachinonen geldt hoe langer de zijketen, hoe meer vet-oplosbaar het vitamine is. Mondiaal gezien heeft het onderzoek zich tot nog toe voornamelijk gericht op vitamine $\mathrm{K}_{1}$. Alleen in Japan bestaat ook veel aandacht voor $\mathrm{K}_{2}$. In hoofdstuk 2 wordt beschreven welke (voornamelijk Nederlandse) voedingsmiddelen rijk zijn aan vitamines $\mathrm{K}_{1}$ en $\mathrm{K}_{2}$. Deze database maakt het mogelijk om populatie-gericht onderzoek te verrichten in welke de rol van vitamine $\mathrm{K}$ wordt onderzocht m.b.t. vasculaire aandoeningen. Vitamine $\mathrm{K}_{1}$ komt met name voor in groene bladgroenten en zorgt voor ongeveer $85 \%$ van de vitamine $\mathrm{K}$ inname in het Nederlandse dieet. De overige $15 \%$ is vitamine $\mathrm{K}_{2}$, dat vooral aanwezig is in gefermenteerde voedingsproducten zoals kaas, kwark, en zuurkool, maar ook in lever en vleesproducten. Echter, bij de inschatting van de bijdrage van individuele voedingsmiddelen aan de vitamine $\mathrm{K}$-status telt niet alleen de concentratie vitamine $\mathrm{K}$ in de diverse producten, maar ook de mate waarin het vitamine daaruit wordt vrijgemaakt en geabsorbeerd in de dunne darm. De zgn. biologische beschikbaarheid van vitamine $\mathrm{K}$ is o.a. afhankelijk van het soort vitamine $\mathrm{K}\left(\mathrm{K}_{1}\right.$ of $\left.\mathrm{K}_{2}\right)$, de matrix in welke het zit verpakt, en de hoeveelheid vet die tijdens de maaltijd wordt genuttigd. Uit onderzoek beschreven in hoofdstuk 2.1 bleek dat de opname van de verschillende soorten vitamines $\mathrm{K}$ sterk kan verschillen, en dat de voedingsmatirx een belangrijke factor is in de biologische beschikbaarheid. Vitamine $\mathrm{K}_{1}$, dat aan de chloroplast membraan van groene bladgroenten zit, wordt daaruit slechts voor een zeer beperkt deel opgelost en geabsorbeerd. Vitamine $\mathrm{K}_{2}$, daarentegen, zit meestal in de vetfractie van het voedsel, waaruit het gemakkelijk wordt vrijgemaakt. In hoofdstuk 2.2, waarin de opname van hoge orale doses vitamine $\mathrm{K}$ wordt gemeten, blijkt dat MK-4 (een vorm van vitamine $\mathrm{K}_{2}$ ) veel beter wordt opgenomen dan $\mathrm{K}_{1}$ en dat dit laatste maar voor $10 \%$ wordt opgenomen uit de voeding! Uit deze experimenten kan worden geconcludeerd dat de inname van vitamine $\mathrm{K}$ via de voeding slechts een grove indicatie geeft van wat er werkelijk door het lichaam wordt opgenomen en daadwerkelijk de bloedstroom bereikt. Naast de biologische beschikbaarheid is er ook het transport van vitamine $\mathrm{K}$ in de bloedstroom naar de verschillende weefsels toe dat bepaald hoeveel van vitamine $\mathrm{K}$ de doelorganen bereikt. Omdat vitamine $\mathrm{K}$ een vet-oplosbaar vitamine is wordt het in de bloedstroom getransporteerd door lipoproteïne deeltjes. Het onderzoek beschreven in hoofdstuk 2.3 maakt duidelijk dat de zijketen uitermate belangrijk is voor het transport naar de doel-organen. $\mathrm{Na}$ absorptie van een mengsel zuivere stof $\mathrm{K}_{1}, \mathrm{MK}-4$ ( $\mathrm{K}_{2}$-vitamine met een korte zijketen) en MK-9 ( $\mathrm{K}_{2}$-vitamine met een lange zijketen), zien we de drie K-vitamines in de eerste uren na absorptie voornamelijk terug in de triglyceride-rijke lipoproteine (TRL) fractie. MK-4 dat het minst vetoplosbaar is, verdwijnt als eerst uit deze fractie en het is niet duidelijk of dit door weefsel absorptie komt of door een snelle metabolisatie in de lever. Vitamine $\mathrm{K}_{1}$, dat qua lipofiliciteit tussen MK-4 en MK-9 zit, wordt zolang het in plasma aantoonbaar is voornamelijk in de TRP fractie teruggevonden, en verschijnt maar nauwelijks 
in de LDL en HDL fractie. Dit duidt erop dat vitamine $\mathrm{K}_{1}$ als belangrijkste doelorgaan de lever heeft. MK-4 echter is 2 uur na inname reeds gelijkelijk verdeeld over de TRL fractie en de LDL en HDL fractie. Het verschil in verdeling over de verschillende lipoproteine fracties duidt erop dat de diverse K-vitamines verschillende doel-organen hebben. $\mathrm{K}_{2}$ met een lange zijketen vertoonde een heel ander patroon in het bloed: het verscheen later in de bloedstroom dan de andere twee K-vitamines, en het bleef veel langer aantoonbaar, tot meer dan vier dagen na inname. Lipoproteine fractionering toonde aan dat het voornamelijk in de LDL fractie aanwezig was. Deze fractie is verantwoordelijk voor het transport van vetoplosbare stoffen (bv. cholesterol) van de lever naar de perifere weefsels. Echter, in de literatuur is aangetoond dat de $\mathrm{K}_{2}$-vitamines $90 \%$ van de totale vitamine $\mathrm{K}$-voorraad in de lever vertegenwoordigen. De vraag is of deze $\mathrm{K}_{2}$ vitamines ook in de lever gebruikt worden of dat ze er tijdelijk worden opgeslagen voor de herverdeling in de LDL fractie. Deze laatst genoemde hypothese past in het beeld dat vooral vitamine $\mathrm{K}_{2}$ (en in veel mindere mate $\mathrm{K}_{1}$ ) een beschermende werking heeft tegen arteriële verkalking en daaruit voorvloeiende hart- en vaatziekten. Verder is dit ook in lijn met gevonden resultaten uit onze groep (Spronk et al.) waarin aangetoond werd dat vitamine $\mathrm{K}_{2}$ (en niet $\mathrm{K}_{1}$ ) de warfarine geïnduceerde arteriële verkalking voorkwam.

In hoofdstuk 3 werd de invloed van het dieet (lees: vet) op de absorptie en het metabolisme van vitamine K onderzocht. Dat gelijktijdige vet-inname een belangrijke factor is bij de absorptie van vet-oplosbare vitamines was reeds bekend. Ook is bekend dat sommige oliën een verlagend effect hebben op de serum cholesterol en triglyderide spiegels. Daarmee daalt ook het trombose-risico. Het onderliggende mechanisme is nog niet precies bekend, maar één van de hypotheses is dat het verlaagde trombose-risico te verklaren is door de simultane milde reductie van de vitamine $\mathrm{K}$ afhankelijke bloedstollingsfactoren, welke deels geassocieerd zijn met de triglyceriden. In hoofdstuk 3 is gekeken naar de relatie tussen de inname van vet en parameters voor de bloedstolling. Hoofdstuk 3.1 beschrijft het effect van verschillende oliën op de arteriële trombose-neiging in ratten gemeten met een aorta-loop model. Uit dit onderzoek bleek dat oliën met veel niet-verzadigde vetzuren de triglyceriden en het cholesterol in bloed verlaagden, maar ook het serum vitamine K. Verder had voornamelijk maïsolie (rijk in n-6 vetzuren) een gunstig effect op de arteriële stollingsneiging. In hoofdstuk 3.2 werd het effect van verschillende oliën op het vitamine Kmetabolisme gemeten in de (gezonde) mens onderzocht. Naast de reguliere metingen van de bloedstolling (INR, FIIc en FVIIc) werd ook de ondergecarboxyleerde fractie van FII (ucFII) gemeten. Dit is een veel gevoeligere marker voor de vitamine K status in de lever. Naast de vitamine $\mathrm{K}$ afhankelijk eiwitten gesynthetiseerd in de lever werd ook het vitamine $\mathrm{K}$ afhankelijke eiwit osteocalcine gemeten. Dit eiwit wordt uitsluitend gemaakt in bot, en de ondergecarboxyleerde fractie van dit eiwit geeft een weerspiegeling van de vitamine $\mathrm{K}$ status 
van bot. Uit het onderzoek beschreven in dit hoofdstuk blijkt dat olie niet alleen een invloed op de absorptie heeft maar ook op het metabolisme van vitamine $\mathrm{K}$.

$\mathrm{n}$ hoofdstuk 4.1 worden twee totaal verschillende ziektes beschreven die beide een verhoogde vitamine $\mathrm{K}$ inname nodig hebben. De eerste ziekte is een genetisch defect in één van de enzymen verantwoordelijk voor het recyclen van vitamine $\mathrm{K}$. Theoretisch leidt dit tot een 500 - 1000 keer verhoogde vitamine K behoefte. Gezien het feit dat een groot deel van de gezonde populatie maar een marginale vitamine K-inname heeft is het niet vreemd dat deze patiënten symptomen (bijvoorbeeld verhoogde bloedingsneiging) van een sterke vitamine Kdeficiëntie vertoonden. Om het risico op spontane bloedingen te verminderen is levenslange vitamine $\mathrm{K}$ supplementatie nodig. Het tweede voorbeeld van een lage vitamine K-status is in patiënten met de ziekte van Crohn. Deze ziekte wordt gekenmerkt door een slechte absorptie van vet en vetoplosbare vitamines. Wij vonden dat in deze patiënten een aanzienlijk deel van het serum osteocalcine voorkomt in een ondergecarboxyleerde vorm, hetgeen duidt op een slechte vitamine $\mathrm{K}$ status van het bot. In post-menopauzale vrouwen is dit circulerend ondergecarboxyleerd osteocalcine geassocieerd met een lage botmassa en met een verhoogd risico op heup-fracturen. Alhoewel een dergelijke associatie nog moet worden aangetoond in Crohn patiënten, suggereren onze data dat extra vitamine $\mathrm{K}$ supplementatie in deze groep de bot status zou kunnen verbeteren. Ervan uitgaand dat ondergecarboxyleerd osteocalcine een marker is voor de extra-hepatische vitamine $\mathrm{K}$ status, kunnen we veronderstellen dat de vitamine K-inname van een groot deel van de ogenschijnlijk gezonde populatie niet optimaal is. Deze observaties hebben er toe geleidt dat de US Food and Nutrition Board recent de aanbevelingen voor de dagelijkse vitamine K-behoefte met 50\% heeft verhoogd. Onze groep heeft actief bijgedragen aan de besprekingen welke tot deze nieuwe aanbevelingen hebben geleid.

In hoofdstuk 4.2 hebben we ons zelf de vraag gesteld of de aanbevolen dagelijkse hoeveelheid vitamine $\mathrm{K}$ verder verhoogd moet worden en of er dan ongewenste bijwerkingen kunnen optreden, met name voor mensen die behandeld worden met orale antistollingsmiddelen (de zgn. bloedverdunners). De mogelijke invloed van voeding op de INR, een meting die de mate van antistolling bepaald, was tot voor kort omstreden. Ons onderzoek toont aan dat een eenmalige inname van een voeding rijk in vitamine $\mathrm{K}_{1}$ (spinazie of broccoli) de INR wél significant beïnvloed, maar slechts kortstondig en niet klinisch relevant. Echter een maaltijd rijk aan $\mathrm{K}_{2}$ (natto; MK-7) zorgt voor een veel sterkere daling van de INR, en deze is wel degelijk klinisch relevant. In het laatste geval bleef de verlaging van de INR zelfs een hele week duidelijk meetbaar. Dit is in overeenstemming met de goede absorptie van $\mathrm{K}_{2}$ en de lange half-waarde tijd in het bloed. Natto komt echter niet frequent voor in het westerse dieet. Vitamine $\mathrm{K}_{1}$ supplementen worden gekarakteriseerd door een veel betere opname dan vitamine $K_{1}$ uit voeding. Dit is terug te vinden in de response op de INR: 
relatief lage doseringen vitamine $\mathrm{K}_{1}$ hebben al een significant effect op de INR. Gegeven deze dosis-response van vitamine $\mathrm{K}$ op de antistolling kan worden geconcludeerd dat vitamine $\mathrm{K}$ supplementen tot maximaal $100 \mu \mathrm{g} / \mathrm{dag}$ veilig zijn voor mensen op antistolling. Voor mensen die niet op antistolling staan zijn ook van zeer hoge doseringen (bijvoorbeeld $45 \mathrm{mg} / \mathrm{dag}$ ) geen nadelige bijwerkingen bekend.

In het laatste onderdeel van dit proefschrift, hoofdstuk 5, hebben we gekeken naar een vitamine $\mathrm{K}$ afhankelijk eiwit dat o.a. gemaakt wordt in de vaatwand. Onze groep heeft een zeer belangrijk "gereedschap" gemaakt voor de detectie van matrix Gla-eiwit (MGP), een monoclonaal antilichaam. Met behulp van dit antilichaam hebben we in de arteriële vaatwand de MGP aanmaak in verschillende stadia van atherosclerose en Mönckeberg's sclerose bekeken. Er werd een substantiële accumulatie van MGP gevonden op plaatsen die gemakkelijk verkalken (elastine vezels) en rond plaatsen waar al calciumzouten geprecipiteerd waren. Dit komt echter niet overeen met de bekende remmende functie die MGP uitoefent. Het feit dat MGP in de gecarboxyleerde (= actieve) vorm moet voorkomen om calcificatie te remmen is aangetoond door Price et al. in ratten en door Yagami et al. in hypertrofe kraakbeen culturen. In beide experimenten werd de werking van (vitamine $\mathrm{K}$ afhankelijk) MGP volledig geblokkeerd door warfarine toediening, resulterend in buitensporige verkalking van weefsel, resp. celculturen. In de hypertrofe kraakbeen culturen kon de calcificatie worden opgeheven door overexpressie van MGP in de aanwezigheid van vitamine $\mathrm{K}$.

Onze hypothese is dat niet verkalkte arteriën marginaal zijn w.b. de hoeveelheid aanwezige vitamine $\mathrm{K}$, en maar net voldoende vitamine $\mathrm{K}$ aangevoerd krijgen voor een adequate carboxylering van o.a. MGP. De accumulatie van MGP rond verkalking is waarschijnlijk het resultaat van de locaal sterk verhoogde MGP expressie, mogelijk geïnduceerd door de aanwezigheid van de calciumzout precipitaten. De verhoogde synthese van het vitamine K-afhankelijke MGP zal zonder twijfel resulteren in een verhoogde vitamine $\mathrm{K}$ behoefte. Omdat het echter zeer onaannemelijk is dat zich in de vaatwand voldoende vitamine $\mathrm{K}$ bevindt om bij deze verhoogde aanmaak alle MGP te carboxyeren tot de actieve vorm, zal het meeste MGP in een ondergecarboxyleerde (niet actieve) vorm geproduceerd worden. Dit zou kunnen verklaren waarom vasculaire calcium precipitaten vaak omgeven worden door MGP deposities. De basis voor deze hypothese is de aanname dat de extra-hepatische vitamine $\mathrm{K}$ status marginaal is in de meerderheid van de gezonde populatie. Hiervoor zijn meerdere argumenten aan te dragen. In de eerste plaats lieten Glaanalyses van beide extra-hepatische Gla-eiwitten (osteocalcine en MGP) die tot op heden in hun natieve vorm gezuiverd zijn, een mengsel zien van gecarboxyleerde en ondergecarboxyleerde vormen; dit is zeer suggestief is voor een sub-optimale vitamine $\mathrm{K}$ status van de weefsels waarin deze eiwitten gemaakt zijn. In de tweede plaats wordt de 
huidige dagelijkse aanbeveling voor vitamine $\mathrm{K}$ inname niet gehaald door een groot deel van de bevolking; daarbij steekt Nederland nog erg gunstig af t.o.v. bijvoorbeeld Engeland en de USA. In de derde plaats correleren ondergecarboxyleerde vormen van osteocalcine negatief met de bot massa en het fractuur risico, terwijl hoge vitamine $\mathrm{K}$ inname beschermend werkt tegen hart- en vaatziekten. Tenslotte laten de eerste (pas recent gepubliceerde) klinische trials met vitamine $\mathrm{K}$ supplementen een gunstig effect op de mate van bot verlies in postmenopauzale vrouwen zien. De vitamine $\mathrm{K}$ hoeveelheden gegeven in deze studies variëren echter van $0.2 \mathrm{mg} / \mathrm{dag}$ tot $45 \mathrm{mg} / \mathrm{dag}$, en de minimale dosis nodig voor een optimaal effect is nog steeds niet bekend. Daarom menen wij dat, totdat er meer adequate data beschikbaar zijn, de aanbevelingen voor vitamine $\mathrm{K}$ inname in opwaartse richting bijgeesteld dienen te worden tot die in het hoogste kwartiel van de Rotterdamse ouderen (ERGO-populatie). Verder stellen wij voor dat er onafhankelijke aanbevelingen moeten komen voor $\mathrm{K}_{1}$ en $\mathrm{K}_{2}$, omdat deze vitamines andere metabole routes volgen. In het geval dat de aanbevelingen voor vitamine $\mathrm{K}$ niet worden gehaald via de voeding, kunnen vitamine $\mathrm{K}$ supplementen een optie vormen. In dat geval zou (vanwege de betere absorptie) een dosering van $100 \mu \mathrm{g} / \mathrm{dag}$ voldoende zijn en geen risico inhouden op beïnvloeding van het niveau van antistolling in patiënten die behandeld worden met bloedverdunnende medicijnen. 




\section{DANKWOORD}

Eindelijk ben ik beland bij het laatste stuk van dit proefschrift; het dankwoord! Dit is ook het enige stuk dat ik helemaal alleen heb uitgevoerd, de rest van dit proefschrift kwam tot stand met medewerking van heel veel mensen.

Allereerst wil ik mijn promotor Prof. Dr. J. Rosing bedanken; beste Jan, bedankt voor de mogelijkheid om bij jou te promoveren. Je was op de achtergrond aanwezig, maar had wel altijd tijd voor me. Ik wil je bedanken voor het be-discussieren van mijn artikelen, en natuurlijk voor het kritisch doornemen van dit proefschrift.

Dr. C. Vermeer, Kees. Jou ben ik wel de meeste dank verschuldigd! Ergens begin 1995 kwam ik als stagiair bij jou binnen. Na dat je me had "gedwongen" te trouwen ben ik als analist bij je aan de slag gegaan, om in de zomer van 1998 als promovendus mijn carriere bij jou te vervolgen. Jij was degene die mij alle vrijheid gaf en altijd in mij geloofde. Je liet me zelfs je presentaties overnemen als je zelf geen tijd kon (of wilde) vrijmaken. Ook onze reizen samen waren een genot. Je zwarte humor en vrolijke manier van vertellen maakten dat het reizen een stuk prettiger verliep. Eigenlijk hoef ik dit stuk niet in de verleden tijd te schrijven want ook de tegenwoordige tijd blijven we bij samenwerken. Je pas opgerichte bedrijf Vita $K$ geeft aan dat je naast wetenschapper ook manager en zakenman bent. Van stagiair, analist, promovendus, nu op naar post-doc binnen je groep. Ik weet zeker dat we ook in deze nieuwe fase plezierig zullen samenwerken.

Dr. B. Soute, beste Berry. Toen ik begon binnen de vitamine K groep was je nog regelmatig achter de lab-tafel te vinden, maar inmiddels heb je dat verruild voor je bureau. Je bent behalve een wandelende bibliotheek (niet alleen op biochemische- en computer-gebied) ook het luisterende oor van de groep. Het congres bezoek in Toulouse samen zal ik nooit meer vergeten. Ook de trip naar Vermont was meer dan een wetenschappelijke meeting, en jij was het die altijd zei dat de belangrijkste discussies aan de bar werden gevoerd. Alleen denk ik dat we samen beter maar niet meer in een kano kunnen gaan zitten (of was het Martins schuld?). Ook de gastvrijheid bij jou en Anneke thuis; de vele etentjes (en BBQ-tjes), de wijntjes, en de wintersport samen maakten je meer dan alleen een collega.

Dear Dr. Shearer, Martin, I would like to use this opportunity to thank you for helping me with writing parts of this thesis. It was a privilege for me to work with one of the "godfathers" in the field of vitamin K-research. I loved the discussions (especially in the bar, or not?) when we met on scientific meetings or when I was over in London. Besides an excellent scientist (with a real scientific view) you are a perfect host. I hope we can continue our collaboration, and work and publish together in the field of vitamin $\mathrm{K}$ in the near future. 
Also many thanks for accepting the position in the corona. Furthermore I would like to thank Dom, Julia, Neha, Yatin, and Adrian for hospitality, discussions and beer.

Henri, we hebben beide ongeveer de zelfde achtergrond: Limburgers die via de Mavo naar het promoveren zijn geklommen (waarschijnlijk de kortste omweg). Jij hebt echter nog een tussenstation genomen in de vorm van de universiteit. Alhoewel je zelf soms denkt dat dit niets extra's brengt, weet ik zeker dat het in je verdere carriere zeker geen windeieren leggen. Je bent iemand met een goed stel hersens, niet alleen op het gebied van wetenschap. Ook computer-software hoort tot jou expertise; of het nu word, excel, chromeleon, mp3's, een homepage maken of een proefschrift lay-outen. Bedankt voor al je hulp en tijd. Je bent oprecht en eerlijk, iets wat in Limburg vaak op weerstand stuit. Blijf echter zoals je bent!

Beste Lavienja, Fienneke. De epidemiologe en statistische strateeg van onze groep. Ondanks dat je weinig op hebt met de echte biochemie heb jij laten zien dat dat niet nodig is om goed te intergreren in onze groep en ook nog eens een toegevoegde waarde te zijn. Het omzetten van massa's getallen in kleine tabellen en dan ook nog eens de juiste statistiek er op toepassen. Je bent een gweldige meid, en samen met je vriend Cyriel (met zijn geweldig gevoel voor humor) een perfect koppel. Dat was te merken aan onze talloze gezamelijke etentjes, bezoekjes, en op stap gaan. Succes met het afronden van je proefschrift (jij ook Cyriel) en gelukkig blijven we collega's.

Beste Marjo. In mijn eerste dagen bij de groep van Kees was jij mijn stage begeleidster. Je ging echter snel met zwangerschapsverlof en jou full-time baan veranderde in een part-time aanstelling. Toch ging je door met het verzorgen van grote klinische trials en werd er op het werk weinig hinder ondervonden van je part-time aanstelling. Bedankt voor de gezellige uurtjes op de kamer. Je hebt zelf nu ook besloten om te promoveren en ik wens je alle succes toe.

Kirsten, jij bent de benjamin van de groep. Niet alleen de jongste maar ook als laatste bij onze groep gekomen. In deze korte tijd heb ik je leren kennen als een spontane, vlotte meid. Doordat ik het laatste jaar veel tijd achter mijn PC heb gezeten hebben we nog niet echt veel samen op het lab gestaan, maar daar komt verandering in! Ik hoop dat we in de nabije toekomst veel zullen samenwerken.

Pauline Versteeg wil ik bedanken voor de gezellige uurtjes op de kamer, het bemoederen, en de goede gesprekken.

Ik wil de mensen bedanken met wie ik heb samengewerkt maar die inmiddels zijn vertrokken. Paul, samen hebben we veel tijd doorgebracht, op het lab en in de trein. Ik mis de goede gesprekken die we hadden. Roger, met jou samen op een kamer, met het zelfde gevoel voor humor werkte aanstekelijk. Ook de reisjes die je organiseerde waren altijd perfect. Birgit, Nicole, Monique, Alexandra, en Jacintha bedankt voor de plezierige samenwerking. 
De "proef"- personen uit hoofdstuk 4.2 wil ik hier graag bij naam noemen. Bedankt voor het perfect laten verlopen van deze proef! 72 keer bloedgeven in drie maanden is niet niets, en dan ook nog eens natto moeten eten.... Het feit dat we nog regelmatig samen borrelen laat zien dat het een hechte groep was. Cyriel, Fien, Henri, Joyce, Natasja, Nicole, Paul, Ron, Sven, Wendy, en Wieke bedankt!

Henk Thijssen wil ik bedanken voor de vele nuttige discussies op het gebied van vitamine $\mathrm{K}$, lipoproteines, carboxyleren, en coumarines. Ik sta altijd versteld van de hoeveelheid literatuur die jij je eigen bent.

Verder bedank ik: Alle (oud) medewerkers van biochemie. Mariet en Trees voor de secretatiele ondersteuning, de gastvrijheid en gezelligheid. De jongens van de centrale glas en sterillidatieafdeling voor het verwerken van al onze "troep".

Erik Schoon, wil ik bedanken voor de prettige samenwerking van de resultaten beschreven in hoofdstuk 4.1. De combinatie van fundamentele wetenschap en de kliniek werkte uitstekend. Ik hoop dat we ook in de toekomst nog veel zullen samenwerken.

De mensen van de afdeling patologie, (met name het "kalk-clubje"; Mat, Jack, en Cherida) wil ik bedanken voor het introduceren in de "coupe-wereld", hun medewerking, gastvrijheid, en gezelligheid.

De leden van de beoordelingscommissie, Prof. Dr. De Mey, Prof. Dr. Daemen, Prof. Dr. Hillen, Prof. Dr. Jahnen-Dechent, en Prof. Dr. Ir. Saris wil ik bedanken voor het beoordelen van dit proefschrift.

De paranimphen Simone Hamacher en Tjeu Heykant bedank ik voor de bereidheid deze taak op zich te nemen. Ralph Hendrikx wil ik bedanken voor het helpen bij het ontwerpen van de cover (en ons huis!), waar heel wat engelengeduld nodig voor is.

Ook buiten de universiteit ben ik een antal mensen veel dank verschuldigd. Teneerste mijn ouders, die in belangrijke mate mij hebben gemaakt tot wat ik nu ben. Ook bedank ik hen voor het altijd klaar staan zonder er overigens ooit iets voor terug te vragen (zeker nu met het bouwen van ons huis).

Tjeu en Yvon wil ik bedanken voor de vriendschap, vele discussies, en het altijd klaar staan. Zo zie je maar, vriendschap kent geen (leef) tijd!

Tenslotte wil ik Romy bedanken. Samen zitten we in een drukke periode. Promoveren, een huis zelf bouwen en twee kinderen opvoeden. Toch gaat het ons samen van een leie dakje. Romy, bedankt voor je steun, liefde, tijd en zorgzaamheid. Juul en Sam, omdat jullie zulke geweldige kinderen zijn. 



\section{CURriculum Vitae}

De auteur van dit proefschrift werd op 17 februari 1970 geboren te Geilenkirchen, Duitsland. Na een kortstondig verblijf in Hillensberg (D) verhuisde hij naar Doenrade (NL). $\mathrm{Na}$ de lagere school met goed gevolg te hebben afgerond werd de Nic Beckers MAVO te Sittard als eerste hindernis genomen. Daarna volgde de HAVO (Serviam lyceum) te Sittard waarna er werd gestart met het Hoger Laboratorium Onderwijs, eveneens te Sittard. De afstudeerperiode werd gevolgd aan de toenmalige Rijksuniversiteit Limburg, vakgroep Biochemie, bij Dr. C. Vermeer. Hier werd na een periode van drie jaar als analist, besloten tot een promotie onderzoek getart in augustus 1998. Dit promotie-onderzoek werd verricht binnen de onderzoeksschool hart en vaatziekten (CARIM) aan de Universiteit Maastricht, hetgeen heeft geleidt tot dit proefschrift. Voor een deel van zijn onderzoek kreeg de auteur in 2001 de "Young Investigators Award" (XVIIIth Congress ISTH, Paris). Ook was hij een van de genodigde panelleden voor " the workshop on vitamine A and K; US Food and Nutrition Board" in 1999 waar besloten werd tot verhoging van de RDA waarden voor vitamine K. Sinds 1 april 2001 is hij in vaste dienst binnen VitaK, alwaar hij als post-doc vanaf 1 mei 2002 (Nederlandse Hartstichting) zijn onderzoek op het gebied van hart en vaatziekten zal voortzetten. 



\section{LIST OF PUBLICATIONS}

Vermeer, C., Knapen, M.H.J., Schurgers, L.J. Vitamin K and metabolic bone disease. J. Clin. Pathol. 1998; 51, 424-426.

Vermeer, C., Gijsbers, B.L.M.G., Schurgers, L.J., Soute, B.A.M. Role of vitamin K in vascular mineralization and in reduction of arterial thrombosis. In: Vitamin K and aging. (Ed.: H. Orimo) Intermedd Inc., Tokyo, 1998, pp 33-45.

Schurgers, L.J., Geleijnse, J.M., Grobbee, D.E., Pols, H.A.P., Hofman, A., Witteman, J.C.M., Vermeer, C. Nutritional intake of vitamins K-1 (phylloquinone) and K-2 (menaquinone) in The Netherlands. J. Nutr. Environm. Med. 1999; 9, 115-122.

Koivu-Tikkanen, T.J., Schurgers, L.J., Thijssen, H.H.W., Vermeer, C. Intestinal, hepatic, and circulating vitamin $\mathrm{K}$ at low and high intake of vitamin $\mathrm{K}$ in rats. Br. J. Nutr. 2000; 83, $185-190$

Vermeer, C., Schurgers, L.J. A Comprehensive Review on Vitamin K and Vitamin K Antagonists. Hematol Oncol Clin North Am. 2000 Apr;14(2):339-353.

Oldenburg, J., Brederlow, B. von, Fregin, A., Rost, S., Wolz, W., Eberl, W., Eber, S., Lenz, E., Schwaab, R., Brackmann, H.H., Effenberger, W., Harbrecht, U., Schurgers, L.J., Vermeer, C., Muller, C.R. Congenital deficiency of vitamin K dependent coagulation factors in two families is caused by a defect of the vitamin K-epoxide-reductase comples. Thromb. Haemostas. 2000; 84, 937-941

Schurgers, L.J., and Vermeer, C. Determination of phylloquinone and menaquinones in food. Effect of food matrix on circulating vitamin K concentrations. Haemostasis, 2000; 30 (6): 298-307

Schoon, E.J., Müller, M.A.C., Vermeer, C., Schurgers, L.J., Stockbrügger, R.W., Brummer, R.-J. Low serum and bone vitamin K status in patients with longstanding Crohn's disease: another pathogenic factor of osteoporosis in Crohn's disease? Gut. 2001;48:473-477

Schurgers, L.J., Dissel, P.E.P., Spronk, H.M.H., Soute, B.A.M., Dhore, C.R., Cleutjens, J.P.M., Vermeer, C. Role of vitamin K and vitamin K-dependent proteins in vascular calcification. Z Kardiologie, 2001, Suppl. 3, III/57-63

Schoon, E.J., Geerling, B.J., van Dooren, I.M.A., Schurgers, L.J., Vermeer, C., Stockbrügger, R.W., Brummer, R-J. Suppressed bone formation, but normal bone resorption in long-standing Crohn's disease in remission. Element. Pharmacol. Therapeut 2001; 15 (6), 783-792

Schurgers L.J., Vermeer, C. Corn oil-induced decrease of arterial thrombosis tendency may be related to altered plasma vitamin K transport. J Lipid Res 2001; 42 (7): 1120-1124 
Spronk, H.M.H., Soute, B.A.M., Schurgers, L.J., Cleutjens, J.P.M., Thijssen, H.H.W., De Mey, J.G.R., and Vermeer, C. Matrix Gla protein accumulates at the border of regions of calcification and normal tissue in the media of the arterial vessel wall. Biochem Biophys Res Commun (Nov) 30;289 (2):485-490

Celie, P.H.N., Stempvoort, G., Fribourg, C., Schurgers, L.J., Lenting, P.J., Mertens, K. The connecting segment between both epidermal growth factor-like domains in blood coagulation factor IX contributes to stimulation by factor VIIIa and its isolated A2 domain. J Biol Chem. In Press

Schurgers, L.J., Vermeer, C. Differential lipoprotein transport pathways of $\mathrm{K}$ vitamins in healthy adults. $B B A$ 2002; 1570: 27-32

Schurgers, L.J., M.J. Shearer, B.A.M. Soute, I. Elmadfa, J. Harvey, K.H. Wagner, R. Tomasch, C. Vermeer. Effects of diets rich in mono- or polyunsaturated fatty acids on vitamin K metabolism and vitamin K-dependent proteins in young men. J Lipid Res 2002 in Press

Vermeer, C. and Schurgers, L.J.. Detection of Matrix Gla-protein (MGP) in vascular tissue and in serum: new tools to investigate arterial calcification. Z Kardiologie 2002 accepted

Geleijnse, J.M., Vermeer, C., Grobbee, D.E., Pols, H.A.P., Schurgers, L.J., Knapen, M.H.J., van der Meer, I.M., Hofman, A., Witteman, J.C.M. Dietary intake of vitamin K-2 reduces the risk of cardiac events and aortic atherosclerosis: The Rotterdam Study. Submitted

Schurgers, L.J., Gijsbers, B.L.M.G., Konings, E.J.M, Saris, W.H.M., Vermeer, C. Method for calculating the intestinal absorption of K-vitamins from their serum profiles: Validation in healthy ileostomy volunteers. Submitted.

Spronk, H.M.H., Soute, B.A.M., Schurgers, L.J., Thijssen, H.H.W., De Mey, J.G.R., and Vermeer, C. Tissue-specific utilization of menaquinone-4 results in prevention of arterial calcification in warfarin treated rats. Submitted.

Schurgers, L.J., Shearer, M.J., Hamulyak, K., Stoecklin, E., Vermeer, C. Effect of dietary vitamin K on stability of oral anticoagulant therapy: Dose response relationships in healthy subjects. Submitted

Schurgers L.J., Soute, B.A.M., Cleutjens J.P.M, Daemen, M.J.A.P., Vermeer, C. Potential involvement of vitamin K-dependent matrix Gla-protein (MGP) in ectopic calcification. In preparation. 


\section{Abstracts}

Soute, B.A.M., Hamulyák, K., Gijsbers, B.L.M.G., Schurgers, L.J., Vermeer, C. Dietary phylloquinone and menaquinones: potential effects on oral anticoagulant treatment. Thromb. Haemostas. 78 Suppl (1997) p 705.

Schurgers, L.J., Ronden, J.E., Elmadfa, I., Vermeer, C. Modulation of vitamin K-status and arterial thrombosis tendency by nutritional intake of corn oil. Helsinki, 1998. Abstr of the Lipidforum Seminar on Minor Lipid Components.

Schurgers, L.J., Soute, B.A.M., Elmadfa, I., Vermeer, C. The beneficial properties of corn oil for vascular health may be related to its effect on the arterial vessel wall. Washington DC, Thrombos. Haemostas. Suppl. (1999), 729.

Schurgers, L.J. B.L.M.G. Gijsbers, H.H.W. Thijssen, C. Vermeer. Absorption, plasma concentration and lipoprotein association of K-vitamins in healthy men. Fat-soluble vitamin congress. Toulouse, France, March 9-11, 2000.

Schurgers, L.J., Vermeer, C. Potential Involvement of Vitamin K-dependent Matrix GlaProtein (MGP) in Ectopic Calcification. XIVth Aachen Colloquim on biomaterials. March 2001

Schurgers, L.J., Soute, B.A.M., Cleutjens, J.P.M., Daemen M.J.A.P., Vermeer, C. Potential involvement of vitamin K-dependent matrix Gla-protein (MGP) in ectopic calcification. Thromb. Haemostas. Suppl (2001) p 473.

Schurgers L.J., Shearer, M.J., Hamulyák, K., Vermeer, C. Effect of dietary vitamin K on stability of oral anticoagulant therapy: Dose response relationships in healthy subjects. Thromb. Haemostas. Suppl (2001) p 769.

Geleijnse J.M., Vermeer C., Schurgers L.J., Grobbee D.E., Pols H.A.P., Witteman J.C.M. Inverse Association of Dietary vitamin $\mathrm{K}-2$ intake with cardiac events and aortic atherosclerosis: The Rotterdam Study. Thromb. Haemostas. Suppl (2001) p 2789 .

Schurgers,L.J. and C. Vermeer. Oral anticoagulants: Friend or foe in cardiovascular disease. The XVIth ISH meeting Cairo 2002. 


